\title{
Sensing and signalling in the upper gastrointestinal tract
}

Citation for published version (APA):

Alleleyn, A. M. E. (2021). Sensing and signalling in the upper gastrointestinal tract. [Doctoral Thesis, Maastricht University]. Maastricht University. https://doi.org/10.26481/dis.20211013aa

Document status and date:

Published: 01/01/2021

DOI:

10.26481/dis.20211013aa

Document Version:

Publisher's PDF, also known as Version of record

\section{Please check the document version of this publication:}

- A submitted manuscript is the version of the article upon submission and before peer-review. There can be important differences between the submitted version and the official published version of record.

People interested in the research are advised to contact the author for the final version of the publication, or visit the DOI to the publisher's website.

- The final author version and the galley proof are versions of the publication after peer review.

- The final published version features the final layout of the paper including the volume, issue and page numbers.

Link to publication

\footnotetext{
General rights rights.

- You may freely distribute the URL identifying the publication in the public portal. please follow below link for the End User Agreement:

www.umlib.nl/taverne-license

Take down policy

If you believe that this document breaches copyright please contact us at:

repository@maastrichtuniversity.nl

providing details and we will investigate your claim.
}

Copyright and moral rights for the publications made accessible in the public portal are retained by the authors and/or other copyright owners and it is a condition of accessing publications that users recognise and abide by the legal requirements associated with these

- Users may download and print one copy of any publication from the public portal for the purpose of private study or research.

- You may not further distribute the material or use it for any profit-making activity or commercial gain

If the publication is distributed under the terms of Article $25 \mathrm{fa}$ of the Dutch Copyright Act, indicated by the "Taverne" license above, 
Sensing and signalling in the upper gastrointestinal tract 
Copyright (C), Annick Alleleyn, Maastricht, 2021.

All rights reserved. No part of this book may be reproduced or transmitted in any form or by any means, without prior permission in writing by the author, or when appropriate, by the publishers of the publications.

ISBN: 978-94-6416-801-3

Cover: Evelien Jagtman

Layout: Tiny Wouters

Printed by: Ridderprint

The studies presented in this thesis were performed within the framework of NUTRIM School of Nutrition and Translational Research in Metabolism (Maastricht University).

Printing of this thesis was financially supported by Maastricht University. 


\title{
Sensing and signalling in the
}

\section{upper gastrointestinal tract}

\author{
PROEFSCHRIFT \\ ter verkrijging van de graad van doctor aan de Universiteit Maastricht, \\ op gezag van de Rector Magnificus, Prof. dr. Rianne M. Letschert, \\ volgens het besluit van het College van Decanen, \\ in het openbaar te verdedigen op \\ woensdag 13 oktober 2021 om 13.00 uur
}

door

Annick Maria Elisabeth Alleleyn 


\section{Promotor}

Prof. dr. A.A.M. Masclee

\section{Copromotor}

Dr. D. Keszthelyi

\section{Beoordelingscommissie}

Prof. dr. N.D. Bouvy (voorzitter)

Prof. dr. J. Tack, KU Leuven, België

Prof. dr. B.M.J. Witteman, Wageningen University

Dr. T. Adam

Dr. K. Lenaerts 


\section{Table of contents}

Chapter 1 General introduction and outline of the thesis 7

Chapter 2 Gastrointestinal nutrient infusion site and eating behavior: $\quad 19$ evidence for a proximal to distal gradient within the small intestine

Chapter 3 The effect of an encapsulated nutrient mixture on food intake and satiety: A double-blind randomized cross-over proof of concept study

Chapter 4 Encapsulation of lipids as emulsion-alginate beads 59 reduces food intake: a randomized placebo-controlled cross-over human trial in overweight adults

Chapter 5 The effect of lidocaine infusion on ad libitum food intake 79 and satiety in healthy male volunteers: results of a double-blind randomized cross over study

Chapter 6 Intraintestinal delivery of tastants using a naso-duodenalileal catheter does not influence food intake or satiety

Chapter $7 \quad$ Evidence for the role of impaired mucosal integrity in 111 the generation of esophageal pain using capsaicin in humans

Chapter 8 Relative intercellular space area in gastroesophageal reflux disease: a new standardized method for the evaluation of the intercellular space diameter

Chapter 9 General discussion

$\begin{array}{lll}\text { Addendum Summary } & 167\end{array}$

Nederlandse samenvatting $\quad 173$

$\begin{array}{ll}\text { Impact } & 179\end{array}$

Dankwoord 183

List of publications $\quad 189$

$\begin{array}{ll}\text { Curriculum vitae } & 191\end{array}$ 


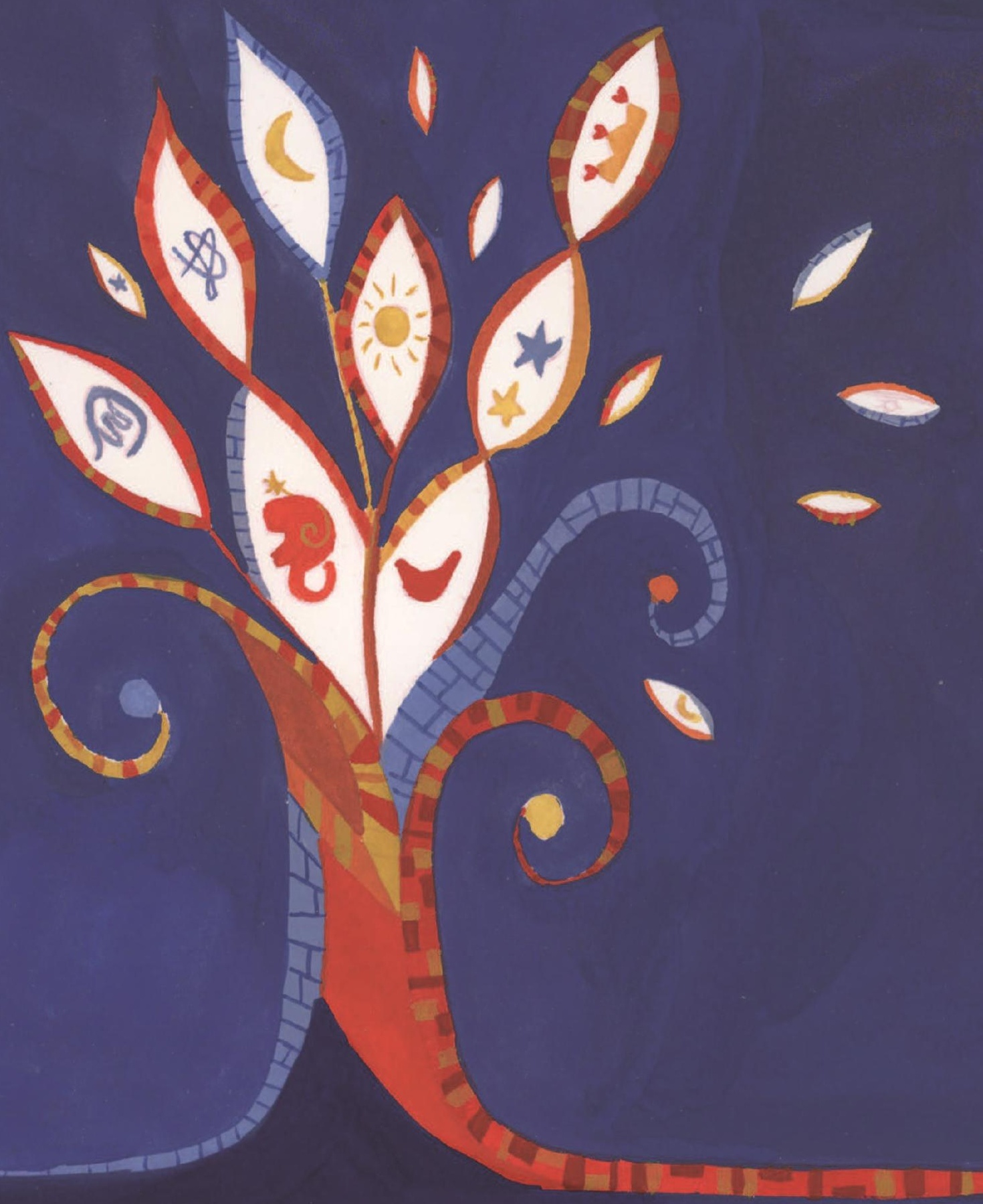




\section{CHAPTER 1}

General introduction and outline of the thesis 



\section{General introduction}

\section{"Sensing and signalling in upper gastrointestinal tract"}

The gastrointestinal (GI) tract has a variety of functions related to digestion and absorption of nutrients and to the epithelial barrier. In this respect, the Gl tract is also a sensory organ that responds to a large variety of signals originating from the $\mathrm{Gl}$ lumen. The upper Gl tract is the first part of this organ, thereby exposed to exogenous and endogenous potential noxious substances. On the one hand, the Gl tract regulates the processes of detection, digestion and absorption of nutrients. On the other hand, the Gl tract protects the body from potentially noxious or toxic materials entering the systemic compartment via an effective intestinal epithelial barrier. Sensing of substances via mucosal receptors and an extensive intestinal neuronal network is crucial for homeostasis.

In this thesis, we primarily focus on the upper Gl tract and its ability to sense the chemical content of the gut lumen in order to orchestrate responses relevant to preserve Gl physiology. We specifically focus on 1) the role of the upper Gl tract in detection, digestion and absorption of nutrients and food components in controlling satiety and food intake and 2) the role of Transient Receptor Potential Vanilloid 1 (TRPV1) and its involvement in the protection of the mucosal integrity in the upper Gl tract.

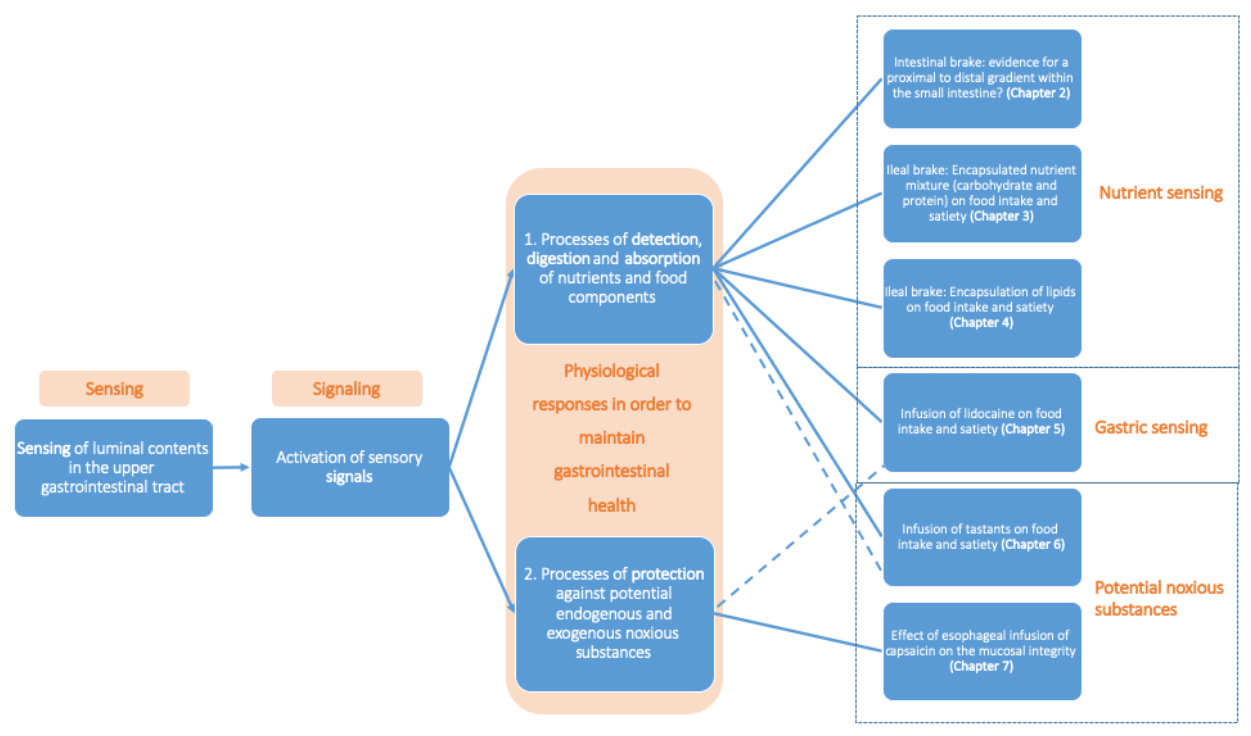




\section{Role of the upper gastrointestinal tract in controlling food intake and satiety}

The upper Gl mucosa senses many exogenous substances such as nutrients, chemicals, tastants and potentially noxious substances. Gut luminal chemosensing is a crucial element in the regulation of food intake and energy balance. Several physiological functions are affected by luminal substances: motility and transport, secretion, digestion and absorption. ${ }^{1-5}$ It has been shown that intraluminal nutrients are sensed by specific receptors located in the luminal membrane of cells in the Gl mucosa. ${ }^{6.7}$ This sensing is primarily regulated by enteroendocrine cells (EECs), located in the intestinal epithelium. EECs represent the first level of integration of signals derived from the Gl lumen. Via an enteric network of neurons these signals communicate with various regions in the central nervous to maintain $\mathrm{Gl}$ and systemic health. ${ }^{8}$ These cells, as part of the enteroendocrine system, interact with and react to dietary components and nutrients. Several studies have shown that activation of these receptors results in the release of gut peptide from ECC cells. ${ }^{8}$ These peptides can exert their effect by 1) acting locally on the specific receptors (paracrine route) or 2) on receptors on the vagal cholinergic afferent nerve endings (neuroendocrine route), which on their turn signal the nucleus of the solitary tract and CNS regions or 3) release into the systemic circulation excreting effects at distant sites (endocrine route).

EECs play a key role in Gl chemosensing and contain a wide variety of receptors, which are expressed on the luminal side of the Gl mucosa cells. The majority of these receptors are G-protein coupled receptors (GPCRs). One of the receptor families expressed by EECs include the taste receptors. There are two major groups of taste detecting GPCRs expressed in the Gl tract; the taste receptor type 1 (TAS1R) sensing umami and sweet, and the taste receptor type 2 (TAS2R) detecting the bitter taste. ${ }^{9,10}$ Various studies have shown that these taste receptors can be found throughout the entire Gl tract. ${ }^{11-14}$ Recently, much scientific attention has been paid to the effects of bitter substances on the Gl tract related to food intake and satiety. It was observed that infusion into the stomach of bitter substances resulted in inhibition of gastric motility. ${ }^{15,16}$ The bitter taste is evolutionary linked to (presence of) toxic substances, and this adverse reaction is assumed to be inborn. ${ }^{17}$ With regards to inhibition of food intake, it was recently observed that infusion of a combination of tastants (sweet, bitter and umami) into the duodenum resulted in a significant decrease in food intake, accompanied by a reduction in hunger and an increase in satiety feelings. ${ }^{18}$ The 
presence and activity of these taste receptors in the Gl tract points to relevance of sensing luminal substances thereby maintaining intestinal and systemic homeostasis.

\section{Gastrointestinal signals affecting satiety and satiation}

The upper Gl tract plays a major role in the regulation of satiety and food intake. Both the stomach and the small intestine are important in this regard but underlying mechanisms differ from each other. Important functions of the stomach include the storage of an ingested meal, the so-called adaptive relaxation of the proximal stomach, the mixing and grinding of nutrients with gastric contents in order to start the process of digestion with degradation of nutrients that consequently allow a stepwise controlled transport to the duodenum. ${ }^{19}$ The satiating effect that arises after ingestion of a meal mainly results from pressure and volume changes of the stomach wall, also known as mechanical stimulation. After ingestion of a meal, stretch and tension mechanoreceptors are triggered and vagal and splanchnic nerve endings in the stomach wall are activated. These (mechano)receptors relay their information to various brain regions and result in satiation and meal termination. ${ }^{20}$ Several studies in humans have repeatedly shown that gastric distension by an inflated balloon resulted in decreased hunger scores. Such strong inhibitory signals, when repeatedly or chronically administered have the potential to result in weight loss. ${ }^{21-23}$ Based on these results, influencing gastric signals arising after meal ingestion, may be a potential target to modulate feelings of satiety/satiation and food intake.

Gastric contents are transported further into the small intestine and this results in the activation of a negative feedback mechanism that reduces food intake and induces satiety. Signals arising from the small intestine are more nutrient induced (chemical) compared to gastric signalling (mechanical). Welch et al. were the first to perform an in vivo human study, in which lipid was infused directly into the duodenum. These authors observed a decrease in food intake and a delay in gastric emptying. ${ }^{24}$ After this study, several other human studies were performed, in which macronutrients (carbohydrates, proteins and lipids) were infused into various parts of the small intestine. Repeatedly, a decrease in food intake and increase in satiety was observed $^{25-29}$, although the magnitude of the effect is dependent on the type of stimulus, intestinal site of delivery and the gut area exposed to macronutrients. This mechanism is called the "intestinal brake" and all parts of the small intestine (duodenum, jejunum and ileum) are able to activate this feedback mechanism. 


\section{Responses of the upper gastrointestinal tract and the role of TRPV1 in protecting against potential noxious substances}

The physiological role of the Gl tract is to digest and absorb nutrients, but also to select and eliminate potential harmful substances. These tasks require an adequate and detailed analysis of the luminal contents of the Gl tract in order to activate the appropriate effector mechanisms. ${ }^{30}$ The Gl tract is innervated by intrinsic sensory neurons of the enteric nervous system. These neurons and the related receptors are able to sense chemicals and changes in chemical composition in the gut lumen as well as being able to initiate protective responses. ${ }^{31}$ These sensory neurons contain a wide variety of receptors. There is growing evidence for involvement of the TRPV1 receptor, an important nociceptive receptor in the regulation Gl mucosal defense. ${ }^{32}$ The TRPV1 receptor can be activated by capsaicin, noxious heat $\left(>42^{\circ} \mathrm{C}\right.$ ), protons $(\mathrm{pH}<6)$, lipogenase products and is expressed by $50-70 \%$ of all sensory neurons. ${ }^{33}$ TRPV1 expression has also been observed in non-nervous tissue such as gastric epithelial cells. ${ }^{34}$ Activation of the TRPV1 receptor results in the release of the proinflammatory sensory neuropeptides substance $P$ and calcitonin gene related peptide (CGRP) leading to neurogenic inflammation and local vasodilation. ${ }^{35}$ These findings demonstrate that TRPV1 receptors are a potential factor in several Gl symptoms and disorders but are also is a potential target for therapies in Gl diseases with subsequently altered GI mucosal barrier.

\section{Aim and outline of the thesis}

The Gl tract has the ability to sense luminal contents with subsequent activation of several pathways that are involved in maintaining $\mathrm{Gl}$ and systemic homeostasis. The Gl tract continuously communicates via the gut-brain axis with the brain and vice versa. Identification of the clinically important intestinal nutrient sensors and their signalling pathways may help to provide potential new drug targets for the treatment of obesity, anorexia, pain and several other Gl disorders. In the first part of this thesis, we aimed to explore interventions that influence satiety and food intake regulation after the presence of nutrients, tastants or a local anesthetic in the Gl tract. In the second part, we focused on tastants and on the TRPV1-mediated pathway and its involvement in the maintenance of the Gl mucosal barrier protection 
Several studies have shown that infusion of nutrients in the small intestine results in the activation of the intestinal "brakes", a negative feedback mechanism on the functions of the more proximal parts of the Gl tract and on food intake and satiety. It has been well established that infusion of all three macronutrients (protein, lipid, and carbohydrates) into all parts of the small intestine (duodenum, jejunum and ileum) can activate this intestinal brake. Chapter $\mathbf{2}$ provides an overview of the current evidence of intestinal brake activation with special attention for the existence of a proximal to distal gradient in the magnitude of the effects on food intake and satiety.

Studies investigating the intestinal brake were performed by intubation with an intestinal catheter in order to infuse the nutrients into the desired part of the small intestine. However, this invasive procedure is not feasible in daily practice and therefore not an option in weight management strategies. In chapter 3, we describe the results of a proof-of-concept study in which we investigated the effects of an orally ingested encapsulated nutrient mixture containing proteins and carbohydrates, targeting the distal small intestine, on food intake and satiety. In chapter 4, we describe the results of a proof-of-concept study on ingestion of encapsulated lipid as emulsion-alginate beads, in order to achieve distal delivery of the degradation products of lipids, on food intake and satiety.

Distension of the stomach and consequently activating the mechanoreceptors in the gastric mucosa results in meal termination. In chapter 5, we investigate whether postprandial gastric signalling can be impaired by infusion of the local anesthetic lidocaine and if there is evidence for an effect on food intake and satiety.

It was already observed that intraduodenal infusion of a mixture of tastants in humans significantly decreased food intake. Currently, there is no evidence from human studies for taste receptor activation in the more distal small intestine. Thus, it is not known whether the before mentioned proximal to distal gradient in the magnitude of intestinal brake activation, as explored in chapter $\mathbf{2}$, is also operational and active for taste receptor activation. In chapter $\mathbf{6}$, we describe the effect of intra-duodenal and/or intra-ileal activation of taste receptors on food intake and satiety.

There is growing evidence for the potential protective properties of the TRPV1 receptor on the sensory afferent neurons in the mucosa of the Gl tract. In chapter 7. we investigate the effect of capsaicin infusion into the esophagus on the mucosal integrity, as reflected by baseline impedance, and the possible involvement of the TRPV1 receptor pathway in this effect. In chapter $\mathbf{8}$, we investigate an alternative 
method for the evaluation of intercellular space area and compared it with the classic method. Chapter 9 serves as a summary of the key findings of the studies presented in this thesis and discusses our new findings in relation to previous described studies with regard to the sensing and signalling function of the upper Gl tract. 


\section{References}

1.

Lin HC, Zhao XT, Wang L. Intestinal transit is more potently inhibited by fat in the distal (ileal brake) than in the proximal (jejunal brake) gut. Dig Dis Sci. 1997:42(1):19-25.

2. Read NW, McFarlane A, Kinsman RI, Bates TE, Blackhall NW, Farrar GB, et al. Effect of infusion of nutrient solutions into the ileum on gastrointestinal transit and plasma levels of neurotensin and enteroglucagon. Gastroenterology. 1984;86(2):274-80.

3. Keller J, Holst JJ, Layer P. Inhibition of human pancreatic and biliary output but not intestinal motility by physiological intraileal lipid loads. Am J Physiol Gastrointest Liver Physiol. 2006;290(4):G704-9.

4. Layer P, Holst JJ, Grandt D, Goebell H. Ileal release of glucagon-like peptide-1 (GLP-1). Association with inhibition of gastric acid secretion in humans. Dig Dis Sci. 1995:40(5):1074-82.

5. Layer P. Peschel S, Schlesinger T, Goebell H. Human pancreatic secretion and intestinal motility: effects of ileal nutrient perfusion. Am J Physiol. 1990;258(2 Pt 1):G196-201.

6. Choi S, Lee M, Shiu AL, Yo SJ, Aponte GW. Identification of a protein hydrolysate responsive G proteincoupled receptor in enterocytes. Am J Physiol Gastrointest Liver Physiol. 2007:292(1):G98-G112.

7. Hirasawa A, Tsumaya K, Awaji T, Katsuma S, Adachi T, Yamada M, et al. Free fatty acids regulate gut incretin glucagon-like peptide-1 secretion through GPR120. Nat Med. 2005:11(1):90-4.

8. Sternini C, Anselmi L, Rozengurt E. Enteroendocrine cells: a site of 'taste' in gastrointestinal chemosensing. Curr Opin Endocrinol Diabetes Obes. 2008;15(1):73-8.

9. Dyer J, Salmon KS, Zibrik L, Shirazi-Beechey SP. Expression of sweet taste receptors of the T1R family in the intestinal tract and enteroendocrine cells. Biochem Soc Trans. 2005:33(Pt 1):302-5.

10. Wu SV, Rozengurt N, Yang M, Young SH, Sinnett-Smith J, Rozengurt E. Expression of bitter taste receptors of the T2R family in the gastrointestinal tract and enteroendocrine STC-1 cells. Proc Natl Acad Sci U S A. 2002:99(4):2392-7.

11. Bezencon C, le Coutre J, Damak S. Taste-signaling proteins are coexpressed in solitary intestinal epithelial cells. Chem Senses. 2007:32(1):41-9.

12. Gu F, Liu X, Liang J, Chen J, Chen F, Li F. Bitter taste receptor mTas2r105 is expressed in small intestinal villus and crypts. Biochem Biophys Res Commun. 2015:463(4):934-41

13. Jang HJ, Kokrashvili Z, Theodorakis MJ, Carlson OD, Kim BJ, Zhou J, et al. Gut-expressed gustducin and taste receptors regulate secretion of glucagon-like peptide-1. Proc Natl Acad Sci U S A. 2007:104(38): 15069-74.

14. Young RL, Sutherland K, Pezos N, Brierley SM, Horowitz M, Rayner CK, et al. Expression of taste molecules in the upper gastrointestinal tract in humans with and without type 2 diabetes. Gut. 2009; 58(3):337-46.

15. Deloose E, Corsetti M, Van Oudenhove L, Depoortere I, Tack J. Intragastric infusion of the bitter tastant quinine suppresses hormone release and antral motility during the fasting state in healthy female volunteers. Neurogastroenterol Motil. 2018;30(1)

16. Deloose E, Janssen P, Corsetti M, Biesiekierski J, Masuy I, Rotondo A, et al. Intragastric infusion of denatonium benzoate attenuates interdigestive gastric motility and hunger scores in healthy female volunteers. Am J Clin Nutr. 2017:105(3):580-8.

17. Steiner JE, Glaser D, Hawilo ME, Berridge KC. Comparative expression of hedonic impact: affective reactions to taste by human infants and other primates. Neurosci Biobehav Rev. 2001;25(1):53-74.

18. van Avesaat M, Troost FJ, Ripken D, Peters J, Hendriks HF, Masclee AA. Intraduodenal infusion of a combination of tastants decreases food intake in humans. Am J Clin Nutr. 2015:102(4):729-35.

19. Janssen P, Vanden Berghe P, Verschueren S, Lehmann A, Depoortere I, Tack J. Review article: the role of gastric motility in the control of food intake. Aliment Pharmacol Ther. 2011;33(8):880-94.

20. Phillips RJ, Powley TL. Tension and stretch receptors in gastrointestinal smooth muscle: re-evaluating vagal mechanoreceptor electrophysiology. Brain Res Brain Res Rev. 2000:34(1-2):1-26.

21. Nieben OG, Harboe $\mathrm{H}$. Intragastric balloon as an artificial bezoar for treatment of obesity. Lancet. 1982;1(8265):198-9.

22. Powley TL, Phillips RJ. Gastric satiation is volumetric, intestinal satiation is nutritive. Physiol Behav. 2004;82(1):69-74. 
23. Rigaud D, Trostler N, Rozen R, Vallot T, Apfelbaum M. Gastric distension, hunger and energy intake after balloon implantation in severe obesity. Int J Obes Relat Metab Disord. 1995;19(7):489-95.

24. Welch I, Saunders K, Read NW. Effect of ileal and intravenous infusions of fat emulsions on feeding and satiety in human volunteers. Gastroenterology. 1985;89(6):1293-7.

25. Welch IM, Sepple CP, Read NW. Comparisons of the effects on satiety and eating behaviour of infusion of lipid into the different regions of the small intestine. Gut. 1988;29(3):306-11.

26. van Avesaat M, Troost FJ, Ripken D. Hendriks HF, Masclee AA. Ileal brake activation: macronutrientspecific effects on eating behavior? Int J Obes (Lond). 2015:39(2):235-43.

27. Geraedts MC, Troost FJ, Munsters MJ, Stegen JH, de Ridder RJ, Conchillo JM, et al. Intraduodenal administration of intact pea protein effectively reduces food intake in both lean and obese male subjects. PLoS One. 2011;6(9):e24878.

28. Chapman IM. Goble EA, Wittert GA, Horowitz M. Effects of small-intestinal fat and carbohydrate infusions on appetite and food intake in obese and nonobese men. Am J Clin Nutr. 1999;69(1):6-12.

29. Chaikomin R, Wu KL, Doran S, Meyer JH, Jones KL, Feinle-Bisset C, et al. Effects of mid-jejunal compared to duodenal glucose infusion on peptide hormone release and appetite in healthy men. Regul Pept. 2008;150(1-3):38-42.

30. Holzer P. Efferent-like roles of afferent neurons in the gut: Blood flow regulation and tissue protection. Auton Neurosci. 2006:125(1-2):70-5.

31. Lai NY, Mills K, Chiu IM. Sensory neuron regulation of gastrointestinal inflammation and bacterial host defence. J Intern Med. 2017:282(1):5-23.

32. Holzer P. Neural emergency system in the stomach. Gastroenterology. 1998;114(4):823-39.

33. Ludy MJ, Moore GE, Mattes RD. The effects of capsaicin and capsiate on energy balance: critical review and meta-analyses of studies in humans. Chem Senses. 2012;37(2):103-21.

34. Ericson A, Nur EM, Petersson F, Kechagias S. The effects of capsaicin on gastrin secretion in isolated human antral glands: before and after ingestion of red chilli. Dig Dis Sci. 2009:54(3):491-8.

35. Szallasi A, Cortright DN, Blum CA, Eid SR. The vanilloid receptor TRPV1: 10 years from channel cloning to antagonist proof-of-concept. Nat Rev Drug Discov. 2007:6(5):357-72. 



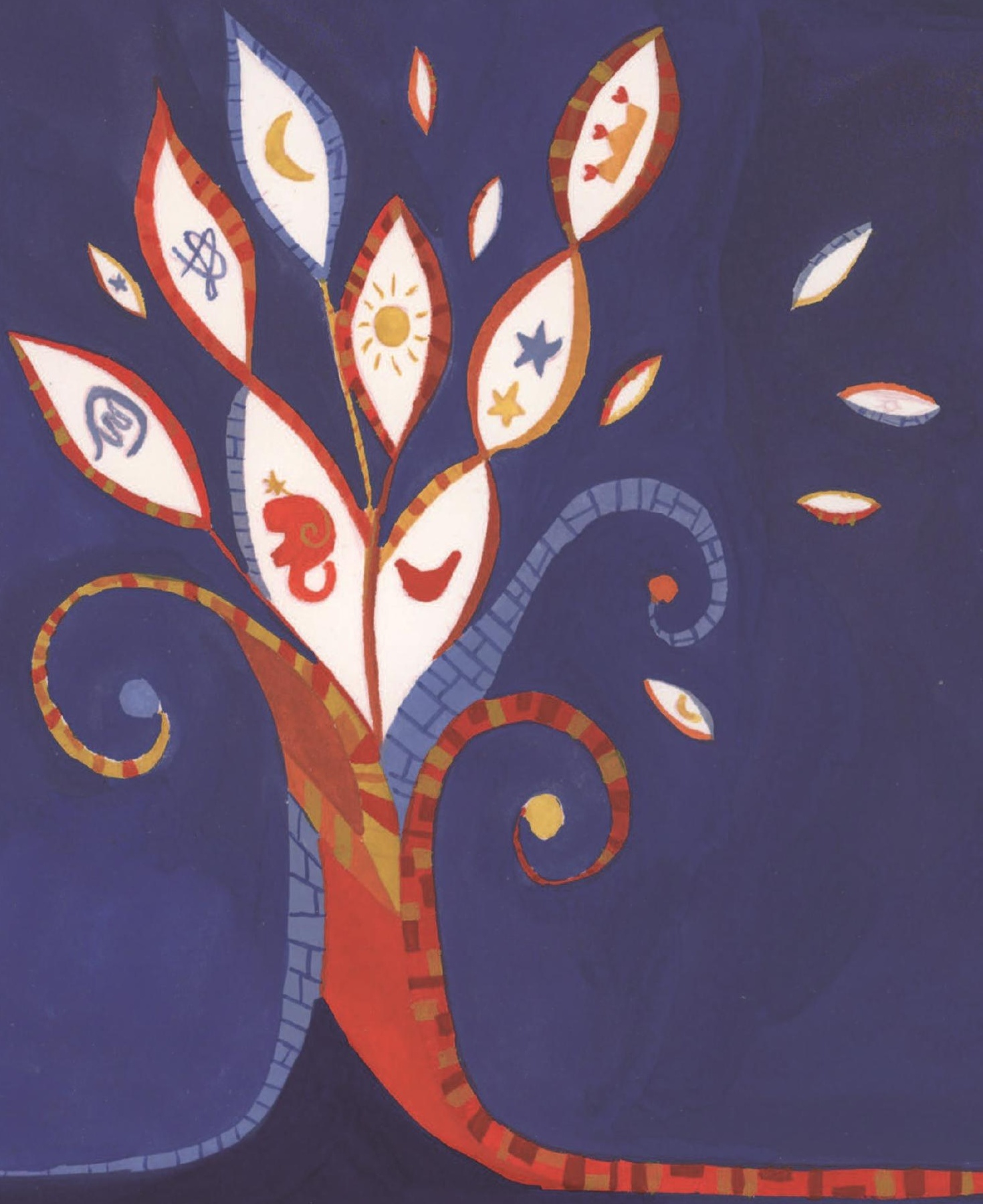




\section{CHAPTER}

Gastrointestinal nutrient infusion site and eating behavior: Evidence for a proximal to distal gradient within the small intestine? 


\section{Abstract}

The rapidly increasing prevalence of overweight and obesity demands new strategies focusing on prevention and treatment of this significant health care problem. In the search for newand effective therapeutic modalities for overweight subjects, the gastrointestinal (Gl) tract is increasingly considered as an attractive target for medical and food-based strategies. The entry of nutrients into the small intestine activates socalled intestinal "brakes", negative feedback mechanisms that influence not only functions of more proximal parts of the Gl tract but also satiety and food intake. Recent evidence suggests that all three macronutrients (protein, fat, and carbohydrates) are able to activate the intestinal brake, although to a different extent and by different mechanisms of action. This review provides a detailed overview of the current evidence for intestinal brake activation of the three macronutrients and their effects on Gl function, satiety, and food intake. In addition, these effects appear to depend on region and length of infusion in the small intestine. A recommendation for a therapeutic approach is provided based on the observed differences between intestinal brake activation. 


\section{Introduction}

Obesity is considered to be a global health problem with a rapidly rising prevalence that has more than doubled over the past 30 years. ${ }^{1}$ Obesity and its associated comorbidities result in a rapidly expanding impact on health care utilization and costs. $^{2}$ Weight loss strategies, apart from bariatric surgery, have poor success rates and an unfavorable long-term outcome. Bariatric surgery is known to be a highly effective strategy in the treatment of obesity, but it is still seen as a drastic measure and only indicated in a small group of morbidly obese subjects. For example Rouxen-Y gastric bypass (RYGB), a combined procedure with a restrictive and a malabsorptive component, results in increased exposure of the distal small intestine to nutrients. The response of the gastrointestinal (Gl) tract to this increased exposure of nutrients appears to play a major role in the success of bariatric surgery. In order to find new, effective, and less invasive approaches for overweight subjects, investigators are now focusing more on the Gl tract as a target for medical and foodbased weight loss strategies.

After ingestion of nutrients and their digestive products, several processes are activated that initiate digestion and absorption and also affect satiety and food intake. First, postprandial distension of the stomach results in the release of satiety signals; mechanoreceptors of the stomach interact with the brain by vagal and spinal sensory nerves. Thereafter, emptying of nutrients into the small intestine results in chemical interaction of the ingested nutrients with various luminal receptors in the gut wall. Part of this interaction is the activation of the so-called "intestinal brakes", negative feedback mechanisms that influence not only motility 3.4 and secretion ${ }^{5-7}$ of more proximal parts of the Gl tract but also satiety and food intake.

Welch, et al. were the first to perform a human in vivo study in which a fat emulsion was directly infused into the ileum to assess the effect of this infusion on eating behavior. They observed a reduction in food intake and a delay in gastric emptying rate compared with the placebo. ${ }^{8}$ Up to now, several others have demonstrated the inhibitory effects of ileal fat infusion on food intake, but this brake mechanism appears not to be restricted to the ileum. The existence of an intestinal brake effect on food intake is also present in the more proximal parts of the small intestine (the duodenum and jejunum). In a direct comparison between fat infusion into the duodenum and into the ileum ( $0.9 \mathrm{kcal} / \mathrm{min}$ ), a more potent effect on appetite and fullness was observed when the same amount of fat was infused into the ileum. ${ }^{9}$ This observation points to the existence of a proximal to distal gradient in the negative feedback of the small intestine on eating behavior. 
Thus far, the "intestinal brake" has mainly been explored with ileal fat infusion as the brake substrate; however, delivery of carbohydrates $(\mathrm{CHO})$ and protein in other parts of the small intestine also has the ability to induce an intestinal brake and to suppress food intake and feelings of hunger. The potency of the intestinal brake is suggested not only to be dependent on the site of intestinal delivery, but also on the length of the region that is exposed as well as the duration and type of macronutrient infusion. This review will focus on the effects of intestinal brake activation on Gl function, satiety, and food intake. The literature regarding the intestinal brake has been reviewed before. ${ }^{10,11}$ Our aim is to give special attention to the existence of a possible proximal to distal gradient in the magnitude of the intestinal brake effect. In addition, effects of the various macronutrients will be compared.

\section{Site-dependent effects on GI function}

\subsection{Motility}

The theory of intestinal brake activation originates from the hypothesis that steatorrhea was associated with small bowel hypomotility; malabsorbed fat that reached the ileum and colon is associated with inhibition of duodenal and jejunal motility. ${ }^{12}$ The presence of nutrients in the small intestine is essential for subsequent absorption and digestion, and this control is accomplished via adaptation of $\mathrm{Gl}$ transport, including gastric emptying and intestinal transit.

\subsection{Small intestinal transit time}

Delayed small intestinal transit time is best described in the context of the ileal brake. Spiller, et al. infused $10 \mathrm{~g}$ fat (90 kcal in $30 \mathrm{~min}$ ) in the ileum and observed a delay in transit time with an inhibition of jejunal pressure waves. ${ }^{13}$ This is in line with a study conducted by the same research group a few years later in which they compared free fatty acid infusion into the ileum vs. jejunum. Taken together, these observations indicate that infusion of fat into the ileum exerts an inhibitory effect on jejunal motility. However, when fat was infused directly into the jejunum, transit time was accelerated and the jejunal flow was increased. ${ }^{14}$ These results suggest that important differences exist between jejunal and ileal activation and their effects on small intestinal transit time and motility. 


\subsection{Gastric emptying rate}

A delay in gastric emptying, in the absence of mechanical obstruction, is thought to result from changes in gastric motor functions: via an increase in phasic and tonic pyloric pressure waves $^{15}$ or via suppression of antral pressure waves ${ }^{15}$ and a reduction in fundic tone. ${ }^{16}$ Cook, et al. observed an increase in the frequency and amplitude of the isolated pyloric pressure waves (IPPW) after infusion of fat into the duodenum. ${ }^{17}$ The delivery of nutrients into the duodenum delays gastric emptying and increases phasic and tonic pressure in regions located near the pylorus. Lin, et al. infused oleate (fat) in the small intestine of dogs with a proximal jejunal fistula $(\approx 60 \mathrm{~cm}$ from the pylorus) or with a distal midgut fistula $(\approx 150 \mathrm{~cm}$ from the pylorus). They observed an inhibition of gastric emptying in a dose-related fashion. Herewith, the existence of a similar "brake" mechanism in the duodenum and jejunum was shown. ${ }^{18}$ Lin, et al. also demonstrated a full inhibitory response on gastric emptying when oleate was infused over a total length of $150 \mathrm{~cm}$ in the small intestine. This result suggests that increasing the exposure of nutrients to regions of the small intestine strengthens the inhibitory response on gastric emptying.

Only a few studies explored the inhibitory effect of nutrient infusion in different regions of the small intestine on Gl motility. For instance, gastric emptying of a liquid meal was significantly more delayed after ileal fat infusion compared to infusion of the same amount of fat in the duodenum. ${ }^{19}$ Infusion of a mixture of glucose and rice starch into the ileum induced changes in upper Gl function and delayed gastric emptying. ${ }^{20}$ With respect to protein, the effects on gastric emptying are not uniform. In dogs, amino acid infusion of $0.3,0.6$, or $0.9 \mathrm{~kJ} / \mathrm{min}$ generated a dose-dependent delay in gastric emptying. ${ }^{21}$ Welch, et al. infused a protein hydrolysate (8\%) into the human ileum and found no inhibitory effect on gastric emptying. ${ }^{22}$

Taken together, the findings from these studies indicate that nutrients in the small intestine regulate the gastric emptying process ${ }^{15}$ and the extent of this nutrientmediated feedback is not only dependent on the region exposed to nutrients, but also on the length of the small intestine exposed to nutrients ${ }^{18}$ and type of macronutrients infused.

\section{Site-dependent effects on food intake and satiety: duodenal brake}

Most of the studies evaluating the effects of intestinal nutrient infusion on food intake and satiety have been conducted by duodenal delivery (Table 2.1). This is probably due to the fact that positioning an intestinal catheter in the duodenum is easier and more convenient than positioning the catheter in the jejunum or ileum. Alternatively, 
to isolate the observed small intestinal effects from oral and particularly intragastric effects, it is best to infuse the nutrients as proximal as possible in the gut, that is, directly after passing the pylorus, avoiding the effects of gastric emptying. The existence of a duodenal brake for $\mathrm{CHO}$ originates from the idea that increased interactions of glucose with glucose-sensing receptors will also increase the satiating effects of $\mathrm{CHO}^{23}$ This idea was based on two principles; (1) glucose in the small intestine was shown to stimulate vagal activity; and (2) infusion of glucose elevated plasma insulin in cats. ${ }^{24}$ From then on, several studies more systematically evaluated the effects of $\mathrm{CHO}$ infusion into the duodenum on satiety and food intake. Lavin, et al. observed a significant reduction in energy intake (17\%), suppression of hunger, and increase in satiety when glucose was infused into the duodenum compared to intravenous infusion of glucose in a placebo-controlled study, while blood glucose concentrations did not differ between the two interventions. ${ }^{23}$ Two years later, the same researchers observed comparable results after intraduodenal infusion of glucose $(3.2 \mathrm{kcal} / \mathrm{min}$ ): a significant reduction in energy intake of $26 \%$ compared to control. ${ }^{25}$ When comparing the studies that infused $\mathrm{CHO}$ into the duodenum, Macintosh, et al. found a significant effect on food intake, with a threshold of $\geq 2.86$ $\mathrm{kcal} / \mathrm{min}^{26}$ Furthermore, an inhibitory effect on the desire to eat was already observed at a caloric load of $2.0 \mathrm{kcal} / \mathrm{min}^{27}$ Taken together, these observations indicate that activation of the duodenal brake by $\mathrm{CHO}$ leads to an increased perception of fullness, suppression of hunger, an increase in satiety, and a reduction in energy intake (Table 2.1), unaffected by fluctuations in blood glucose concentrations. Changes in blood glucose concentrations have a significant impact on the gastric emptying rate in healthy adults and thereby interfere with the observed effects on food intake and satiety. There is evidence that hypoglycemia accelerates gastric emptying and consequently hastens the absorption of $\mathrm{CHO}$ from the Gl tract. Hyperglycemia potentiates a delay in gastric emptying. 


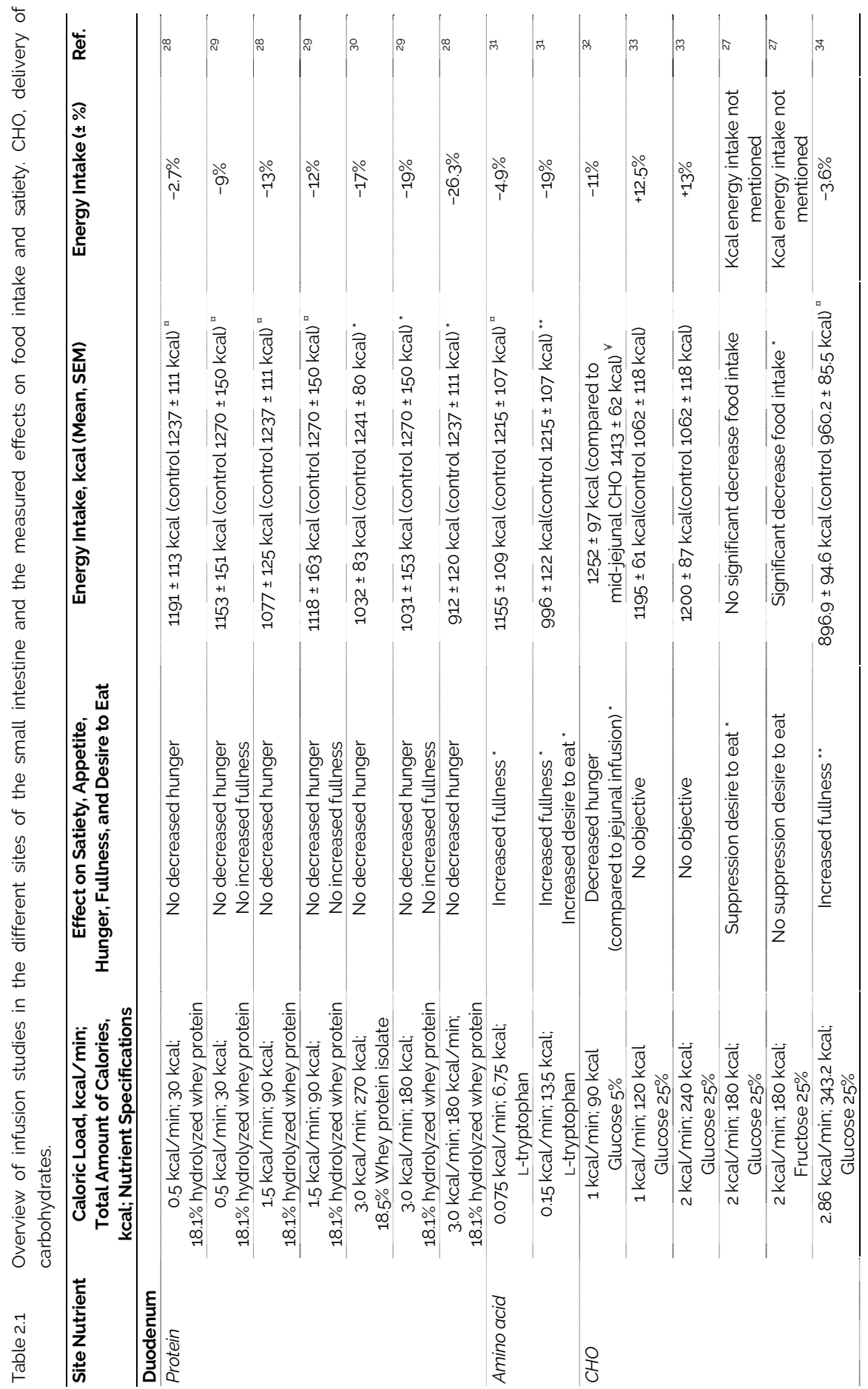




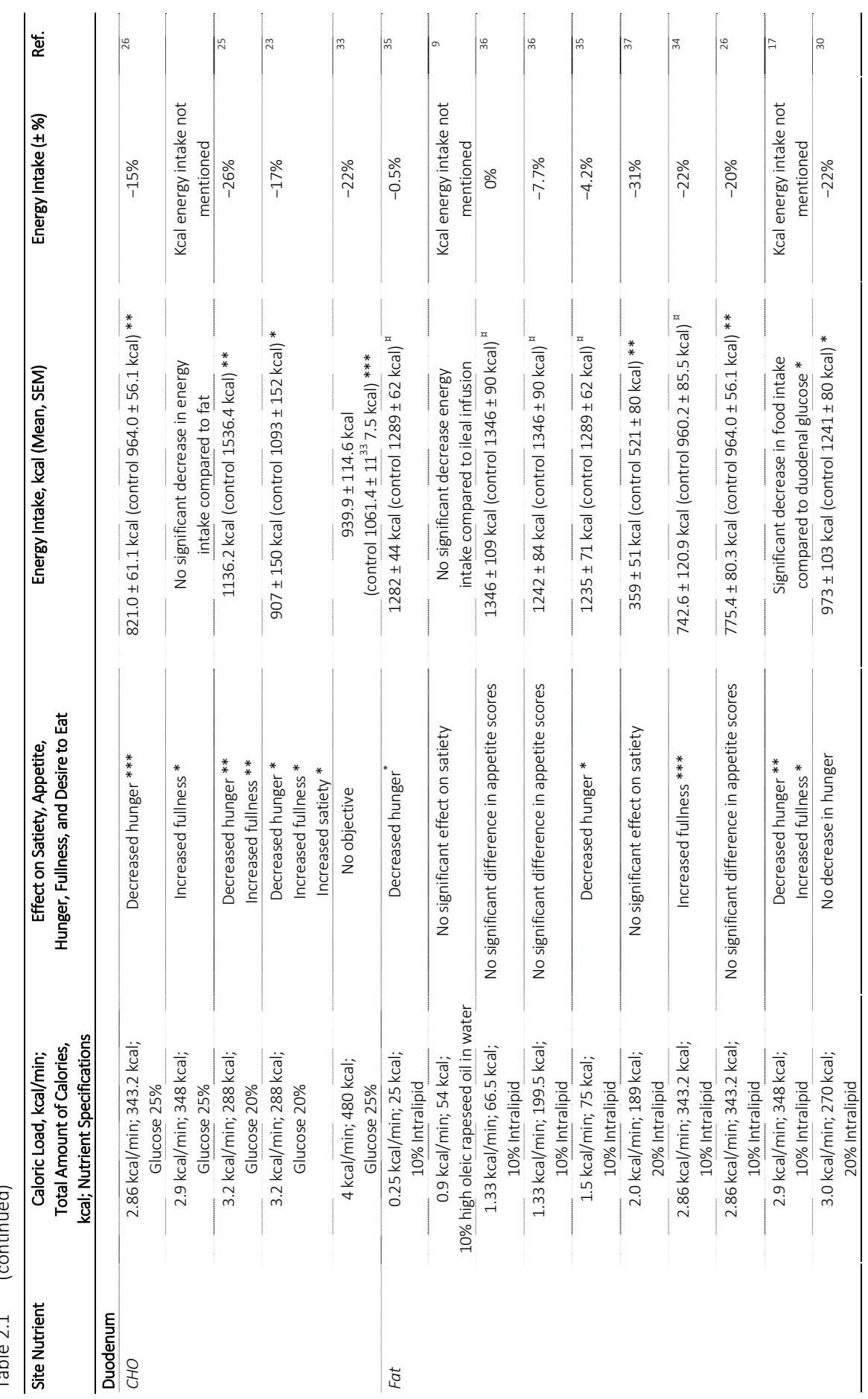




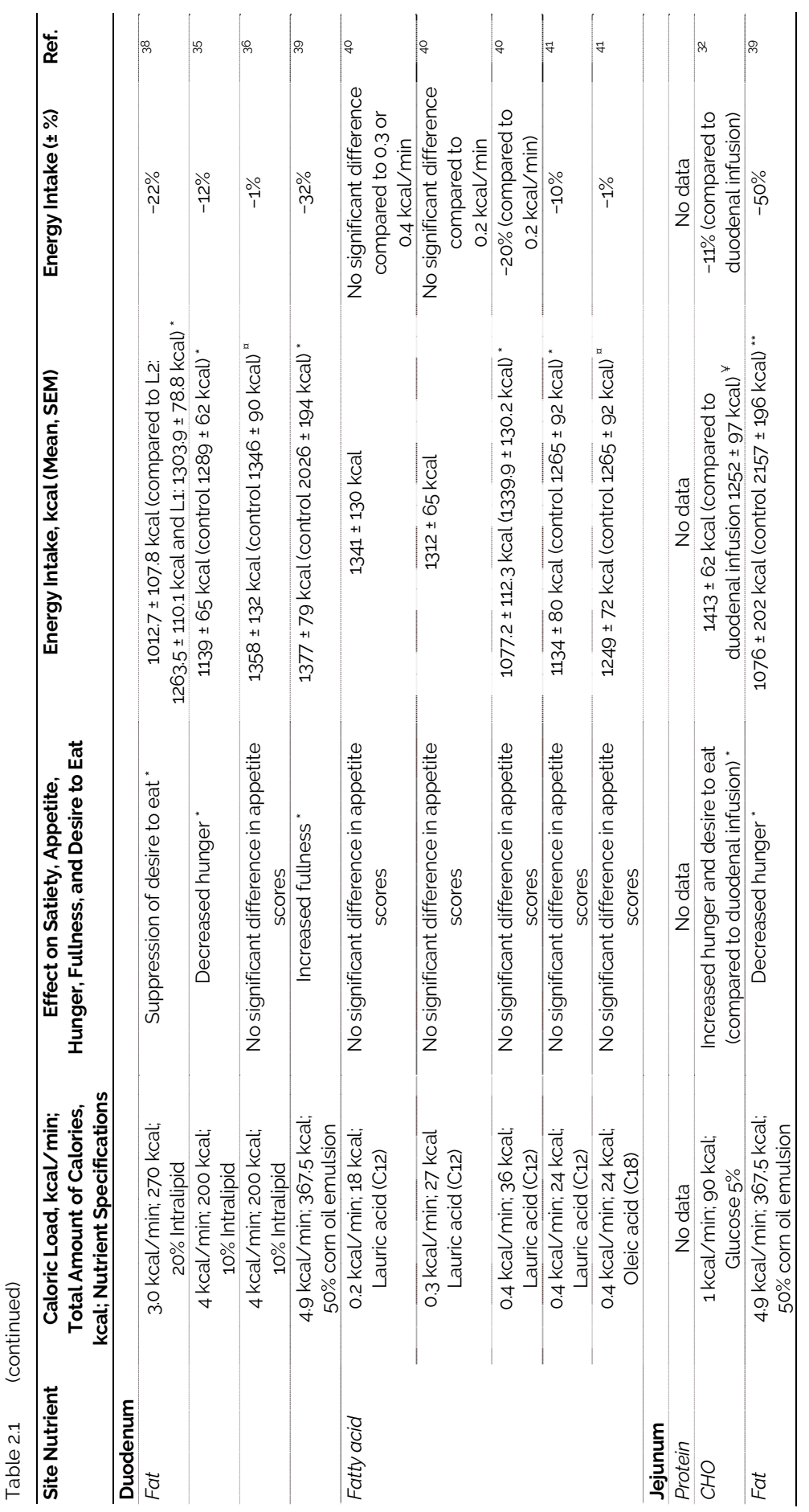




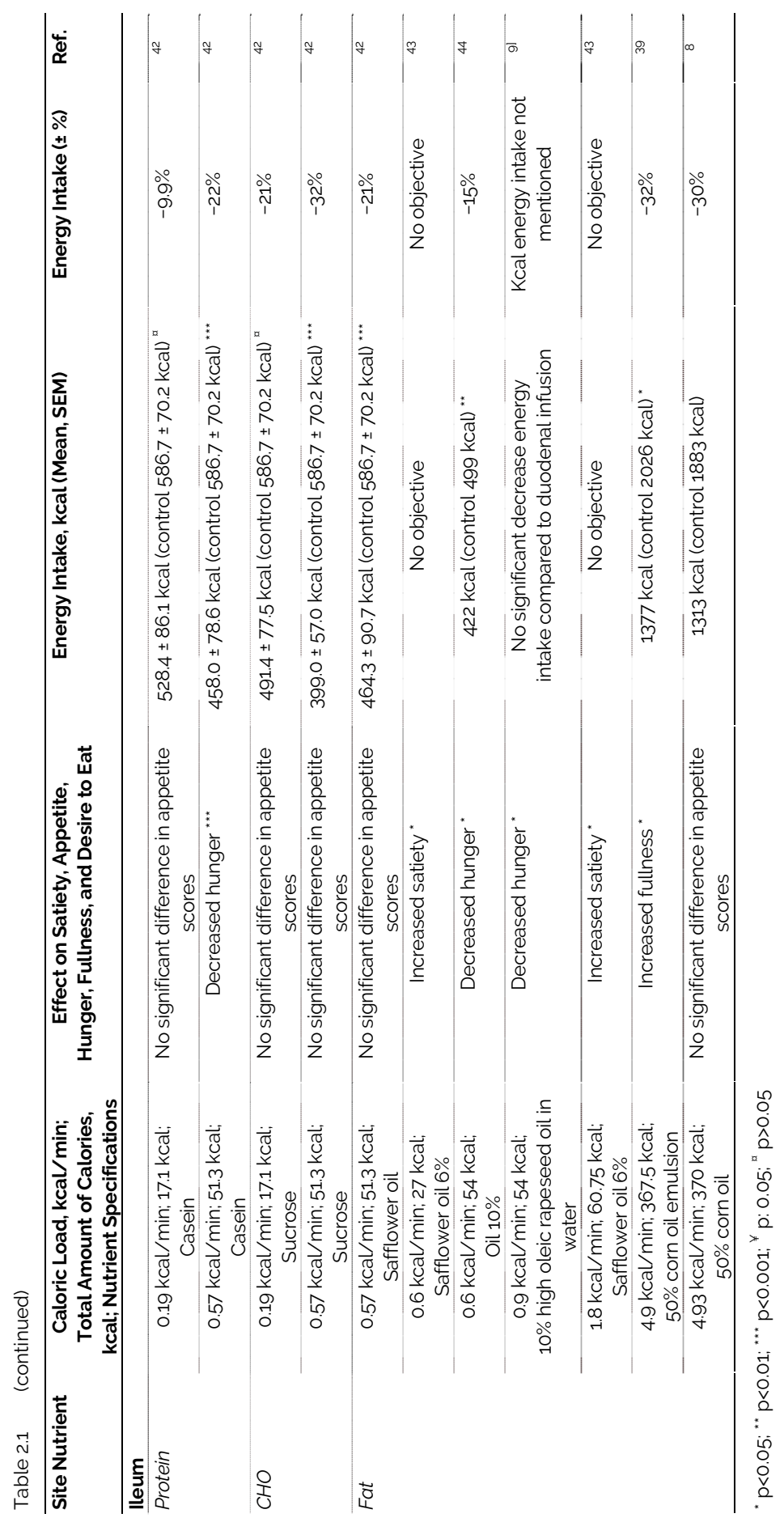


Protein is considered to be the most anorectic of the three macronutrients. ${ }^{45.46}$ Consequently, several investigators have studied the effects of intraduodenal protein infusion on food intake and satiety. Furthermore, it has been established that intraduodenal infusion of pea protein results in a greater decrease in energy intake when compared with oral ingestion of the same amount of pea protein. ${ }^{28,47}$ Ryan, et al. conducted a study to evaluate the effect of intraduodenal whey protein infusion on satiety and energy intake. Assuming that intraduodenal fat and $\mathrm{CHO}$ suppress appetite and energy intake in a dose-dependent manner, this group aimed to study whether a dose-dependent effect of duodenal protein delivery exists on appetite. Caloric infusion rates of $0.5,1.5$, and $3.0 \mathrm{kcal} / \mathrm{min}$ of protein showed that the effects of intraduodenal protein are indeed dose dependent and resulted in suppression of food intake (Table 2.1). However, this effect was only found to be significant vs. placebo after an infusion of $3 \mathrm{kcal} / \mathrm{min}$ (26.3\% reduction in food intake). ${ }^{28}$

Remarkably, no significant decrease in hunger or appetite scores during and after protein infusion was observed (Table 2.1). Intraduodenal nutrients can potently suppress food intake, while little to no effect is seen on appetite perceptions. In addition, Steinert, et al. observed a more potent appetite-suppressing effect after intragastric infusion of glucose than with intraduodenal infusion. These results indicate that the stomach has an important contribution in inducing satiety mechanisms and that this is possibly mediated by mechanical factors, such as gastric distension. ${ }^{48}$ This effect may be macronutrient dependent, related to the influence of the macronutrient on the gastric emptying rate. Another explanation for the lack of effect on satiety and hunger scores may be related to the differences in appetitesuppressive effects within different sources of protein. ${ }^{49}$ In addition, the absence of the satiating effects of intraduodenal protein may have been caused by differences in study design-differences in feeding status before the start of infusion, duration of fasting, and total time of infusion.

Comparing intraduodenal fat and glucose, fat is shown to be a more potent inhibitor of food intake compared to isocaloric $\mathrm{CHO}$ infusion (Table 2.2). ${ }^{17,26,50}$ Protein and fat both activate the duodenal brake in a dose-dependent fashion, probably due to interaction with a larger number of receptors within the small intestine. ${ }^{29,35}$ A specific threshold in caloric load is necessary for macronutrients to activate the duodenal brake. For protein, a caloric load of $3 \mathrm{kcal} / \mathrm{min}$ significantly reduced energy intake (26.3\% reduction). ${ }^{28} \mathrm{CHO}$ reduced energy intake by $17 \%$ when a caloric load of $3.2 \mathrm{kcal} / \mathrm{min}$ was infused. ${ }^{25}$ Remarkably, infusion of fat at a caloric load of $2.0 \mathrm{kcal} / \mathrm{min}$ already inhibits energy intake at 31\% compared to the control (Table 2.1). ${ }^{37}$ 
Table 2.2 Summary of the effects of the different macronutrients in the different sites in the small intestine on energy intake.

\begin{tabular}{|c|c|c|c|}
\hline Heading & $\begin{array}{c}\text { Average Decrease Energy Intake in \%; } \\
\text { Average Caloric Infusion Rate in } \mathrm{kcal} / \mathrm{min}\end{array}$ & Energy Intake & Reference \\
\hline \multicolumn{4}{|c|}{ Duodenum } \\
\hline Protein & $20.8 \% ; 3.0 \mathrm{kcal} / \mathrm{min}$ & $\downarrow$ & $28-30$ \\
\hline $\mathrm{CHO}$ & $20 \% ; 2.85 \mathrm{kcal} / \mathrm{min}$ & $\downarrow$ & $23,25,26,32,33$ \\
\hline Fat & $21.5 \% ; 3.69 \mathrm{kcal} / \mathrm{min}$ & $\downarrow$ & $26.30,35.37,39$ \\
\hline \multicolumn{4}{|l|}{ Jejunum } \\
\hline Protein & * & * & \\
\hline $\mathrm{CHO}$ & $11 \% ; 1 \mathrm{kcal} / \mathrm{min}$ & $\downarrow \downarrow^{\circ}$ & 32 \\
\hline Fat & $50 \% ; 4.9 \mathrm{kcal} / \mathrm{min}$ & $\downarrow \downarrow$ & 39 \\
\hline \multicolumn{4}{|l|}{ Ileum } \\
\hline Protein & $22 \% ; 0.57 \mathrm{kcal} / \mathrm{min}$ & $\downarrow \downarrow \downarrow$ & 42 \\
\hline $\mathrm{CHO}$ & $32 \% ; 0.57 \mathrm{kcal} / \mathrm{min}$ & $\downarrow \downarrow \downarrow$ & 42 \\
\hline Fat & $21.7 \% ; 2.02 \mathrm{kcal} / \mathrm{min}$ & $\downarrow \downarrow$ & $39.42,44$ \\
\hline
\end{tabular}

* No data; ${ }^{\circ}$ Directly compared jejunal infusion and duodenal infusion (1413 $\pm 62 \mathrm{kcal}$ vs. $1252 \pm 97 \mathrm{kcal}$ ); $\downarrow:<10 \%$ decrease energy intake at a caloric infusion rate of $1 \mathrm{kcal} / \mathrm{min} ; \downarrow \downarrow:>10 \%$ and $<20 \%$ decrease energy intake at a caloric infusion rate of $1 \mathrm{kcal} / \mathrm{min} ; \downarrow \downarrow \downarrow$ : >20\% decrease energy intake at a caloric infusion rate of 1 $\mathrm{kcal} / \mathrm{min}$.

Combining fat with protein or glucose shows no effect on food intake and satiety. ${ }^{30,38}$ The absence of these additive effects can be caused by the assumption that not a specific caloric load, but a specific concentration threshold of fatty acids, monosaccharides, or free amino acids is required to be present in the lumen of the small intestine in order to activate a negative feedback mechanism. For example, infusion of the amino acid l-tryptophan at a caloric load of $0.15 \mathrm{kcal} / \mathrm{min}$ shows a significant effect on satiety and food intake (Table 2.1 ) (19\% reduction). ${ }^{31}$ In addition, when a fatty acid (lauric acid, C12) is directly infused into the duodenum with a caloric load of $0.4 \mathrm{kcal} / \mathrm{min}$, a significant effect on food intake was observed (reduction of 20\%) while no effects on satiety scores were seen (Table 2.1). ${ }^{40}$ These results suggest that increasing the release of degradation products of fat, protein, and $\mathrm{CHO}$ strengthens the effects on the inhibition of food intake. However, it should be noted that this effect is also dependent on the type of fatty acid or amino acid infused. It is hypothesized that, when a combination of macronutrients is infused at the same caloric load as a single macronutrient, the critical threshold of activating the duodenal brake is not reached by the reduced presence of degradation products of fat, glucose, and protein.

The abovementioned results suggest that all three macronutrients activate the duodenal brake, though to a different extent. The three different macronutrients exert an effect on food intake and satiety by mediating different mechanisms of action. The data reported here support the assumption that fat requires the lowest amount of 
calories infused per minute to trigger a significant reduction in food intake. Furthermore, combining fat with glucose or protein showed no additive effects. Infusion of nutrients at a higher rate than the normal gastric emptying rate ( $\approx 2-3 \mathrm{kcal} / \mathrm{min})$ or in supraphysiological concentrations could activate the more distal regions of the small intestine, and thereby have a more potent effect on food intake and satiety. In addition, when directly infusing degradation products of fat, protein, or $\mathrm{CHO}$, supraphysiological concentrations are reached within a short period. Thereby, the physiological concentration of these degradation products in the distal regions of the small intestine is varying and not completely known. Consequently, is it difficult to distinguish between specific effects contributing to the duodenal brake and the more distal parts of the small intestine.

\section{Site-dependent effects on food intake and satiety: Jejunal brake}

Several studies have shown that infusion of nutrients into the jejunum modulates intestinal transit time. At present, only few studies have explored the effects of jejunal nutrient infusion on food intake, appetite, and feelings of satiety. Welch, et al. infused a fat emulsion with a caloric delivery rate of $4.9 \mathrm{kcal} / \mathrm{min}$ in the ileum and jejunum in humans and found early satiety and a reduction in food intake at both sites (Table 2.1.) ${ }^{39}$ However, the reduction in food intake was larger after jejunal infusion $(50 \%$ compared to the control). It is worth noting that the infusion rate of $4.9 \mathrm{kcal} / \mathrm{min}$ can be seen as supraphysiological and exceeds the rate of nutrients entering the small intestine in the postprandial state ${ }^{51}$; therefore, fat could have spilled into the more distal small intestine, thereby activating the more distal ileal brake.

To the best of our knowledge, no studies have been published in which the effects of jejunal protein infusion on food intake and satiety have been investigated. Regarding $\mathrm{CHO}$, one study compared the effects of jejunal and duodenal infusion on food intake and satiety. A significant decrease in satiety and food intake (11\%) in favor of jejunal infusion was shown compared to duodenal infusion. These results suggest that jejunal infusion of nutrients has an effect on food intake, but expanding the area exposed to nutrients increases the impact on food intake. Comparable effects are observed after Roux-and-Y Gastric Bypass, in which nutrients bypass the duodenum and a large part of the jejunum. Hereby, a supraphysiological amount of non-digested nutrients is delivered to the distal small intestine and contributes to a more chronic and sustained activation of the jejunal and ileal brake. Compared to the duodenum and ileum, reports on effects of jejunal perfusion with nutrients on food intake and 
satiety are scarce (Table 2.1). As stated before, positioning of a catheter or tube in the more distal regions of the small intestine is invasive and time consuming.

\section{Site-dependent effects on food intake and satiety: Ileal brake}

Several studies have shown that infusion of fat into the ileum induces a brake effect on satiety and food intake ${ }^{8.39}$, delays gastric emptying, and reduces the secretion of gastric acid $^{7}$ and pancreatic enzymes. ${ }^{5}$ Welch, et al. were the first to demonstrate the effects of nutrient-driven satiety in the ileum. These investigators infused an emulsion of $50 \%$ corn oil and $3 \%$ albumen into the ileum of healthy volunteers and measured the effect on food intake and satiety. Subjects had a significant reduction in energy intake $(30 \%)$ during ileal infusion of fat, with a caloric load of $4.93 \mathrm{kcal} / \mathrm{min}$ compared with the control (Table 2.1). ${ }^{8}$ This caloric infusion rate is considered supraphysiological and it should be taken into account that some of the fat will have spilled over into the colon. The colon is capable of secreting Peptide YY (PYY) and Glucagon-like peptide-1 $(G L P-1)^{52,53}$ and may also have a role in regulating appetite and food intake.

The ileal brake concept has traditionally been studied by directly infusing nutrients into the ileum, but information on this negative feedback mechanism on food intake and satiety is provided by studying surgical interventions in which the distal small intestine is exposed to an increased amount of nutrients. One such example is "ileal transposition". In animal experiments, transposing 10 or $20 \mathrm{~cm}$ of lower ileum to mid duodenum or a jejuno-ileal bypass showed a sustained post-operative reduction in food intake and change in body weight. ${ }^{54}$ In addition, ileal transposition in Zucker obese rats, by transposing a $10 \mathrm{~cm}$ segment of the terminal ileum to the upper jejunum, caused long-term reduction in body weight and a persistent decrease in preference for dietary fat. ${ }^{55}$ In humans, the jejuno-ileal bypass (JIB) by Payne and De Wind was the first surgical treatment for morbid obesity. ${ }^{56,57}$ The weight loss observed after this procedure has at first been contributed to chronic malabsorption of nutrients. However, the loss in body weight was larger than could be accounted for via caloric loss in the stool. Näslund, et al. found significantly higher serum concentrations of distal gut hormones PYY and GLP-1 after JIB compared to pre-surgical levels, providing a possible explanation for the excess weight loss via neuro-hormonal feedback. ${ }^{41}$ However, due to the high rate of complications after JIB, this surgical procedure is currently no longer performed in bariatric practice..$^{8}$

It has been well established that a high amount of fat activates the ileal brake. However, more recent studies indicate that much smaller amounts of fat can also 
activate the ileal brake. Maljaars, et al. tested this hypothesis by conducting several studies on the satiating effects of small amounts of fat, and these authors investigated whether this effect is dose dependent. Healthy volunteers were intubated with a naso-ileal catheter and were randomized to the ileal infusion of $3 \mathrm{~g}$ or $9 \mathrm{~g}$ fat over a 45-min period, resulting in an infusion rate of $0.6 \mathrm{kcal} / \mathrm{min}$ and $1.8 \mathrm{kcal} / \mathrm{min}$. The control group received a fat-containing breakfast of $3 \mathrm{~g}$ with an ileal placebo infusion. Both the low and high ileal fat infusion resulted in a reduction in appetite and an increase in satiety, without any evidence for dose dependency ${ }^{43}$, in contrast to the dose-dependent effect of intraduodenal fat administration. ${ }^{35}$ A possible explanation for the absence of this dose-dependent effect could be related to the variety of lipolytic capacity of the different regions of the small intestine. It is known that the lipolytic capacity in the ileum is much smaller compared with the duodenum ${ }^{59}$, and therefore it is possible that a high dose of fat could not be fully hydrolyzed to fatty acids and monoglycerides before entering the colon. Currently, digestion of triacylglycerol is considered a necessary step for fat to establish its satiety-increasing properties. ${ }^{60}$

Studies in humans evaluating the effects of all three macronutrients and their potency in inducing an ileal brake are limited. Van Avesaat, et al. tested the macronutrientspecific effects in the ileum on eating behavior. In this single-blind randomized placebo controlled study, they compared the effects of six different interventions: saline, fat emulsion (51.7 kcal), low-dose protein $(17.2 \mathrm{kcal})$, high-dose protein (51.7 kcal), low-dose $\mathrm{CHO}$ (17.2 kcal), and high-dose $\mathrm{CHO}$ (51.7 kcal) for $90 \mathrm{~min}$ (Table 2.1). The low doses of macronutrients were infused at a rate of $0.19 \mathrm{kcal} / \mathrm{min}$ and the high doses at a rate of $0.57 \mathrm{kcal} / \mathrm{min}$. Notably, these caloric infusion rates do not exceed the physiological gastric emptying rate, which is known to vary between 1 and $4 \mathrm{kcal} / \mathrm{min}$ in healthy adults. These authors were the first to observe a suppression of food intake after $\mathrm{CHO}$ and protein infusion into the human ileum to the same extent as an equicaloric amount of fat (infusion rate $0.57 \mathrm{kcal} / \mathrm{min}$ ). No effects were observed after infusion of $0.19 \mathrm{kcal} / \mathrm{min}$ of $\mathrm{CHO}$ or protein. Protein was the only macronutrient to influence satiety scores. ${ }^{42}$ This effect is not unexpected; protein is considered to be the most anorectic macronutrient. However, no significant differences in food intake between protein, $\mathrm{CHO}$, and fat were observed at a caloric infusion rate of $0.57 \mathrm{kcal} / \mathrm{min}^{42}$ Therefore, it is still unclear whether differences between these macronutrients in terms of their ileal brake inhibitory effect on food intake exist. These results suggest that equicaloric amounts of protein and $\mathrm{CHO}$ in the ileum can induce an ileal brake and affect eating behavior to the same extent. This threshold for all three macronutrients is considerably lower than that in the duodenum. 


\section{The effects of length and site of intestinal contact on nutrient-driven satiety and food intake}

The different sites of the small intestine where nutrients are delivered are of utmost importance for the satiating effects. Table 2.2 provides an overview of the effects on food intake generated by the different macronutrients in the regions of the small intestine. This table provides evidence for a proximal to distal gradient in the small intestine; infusing nutrients in the distal small intestine generates a more potent effect on food intake. Figure 2.1 expands on the data from Table 2.2, revealing the percentage of decrease in energy intake in relation to the caloric infusion rate given for different locations with different macronutrients as well as the linear regression between the variables caloric infusion rate in kcal and the decrease in energy intake in \% per location. With duodenal delivery of nutrients, the higher the infusion rate in calories, the stronger the inhibitory effect on food intake. With ileal delivery of nutrients, the inhibitory effect on food intake is more pronounced compared to duodenal delivery, both at lower and at higher caloric delivery rates.

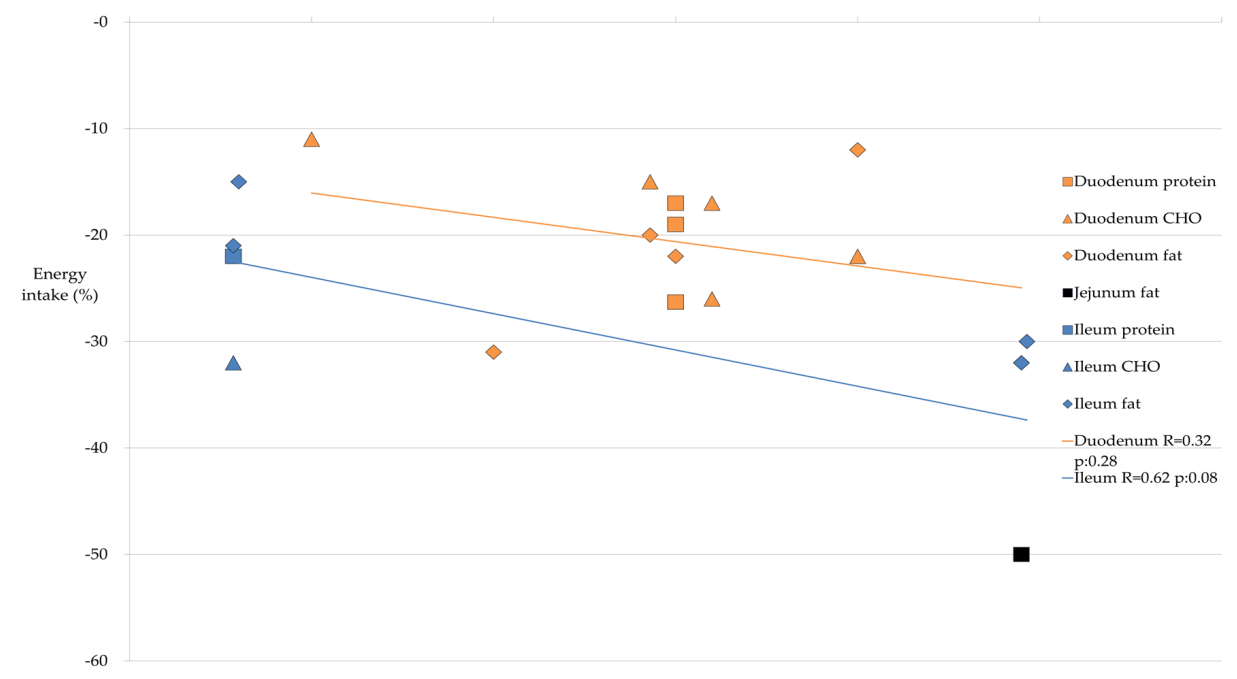

Figure 2.1 Caloric infusion rates $(\mathrm{kcal} / \mathrm{min})$ in the different regions of the small intestine and the decrease in food intake in percentage and linear regression for the duodenum and ileum.

Based on the studies mentioned above, we may conclude that each site of the small intestine is, when exposed to undigested macronutrients, able to induce a so-called intestinal brake, while the magnitude of these effects is site dependent. Meyer, et al. 
and Lin, et al. demonstrated that increasing the small intestinal area exposed to nutrients induces more potent effects on gastric emptying rate and food intake. 18,61 Increasing the small intestinal area that is exposed to undigested nutrients may also cause a more potent effect on food intake in humans. Maljaars, et al. investigated this hypothesis and found no significant differences in reduction of food intake when $2 \mathrm{~g}$ of fat ( $0.6 \mathrm{kcal} / \mathrm{min}$ ) was infused simultaneously ( $2 \mathrm{~g}$ each to all sites in the same time interval) or sequentially ( $2 \mathrm{~g}$ each to all sites in sequential time intervals) at different sites in the small intestine.$^{44}$ A possible explanation is that in the study of Meyer, et al. a higher rate of infusion was chosen. ${ }^{61}$ Taken together, it can be suggested based on surgical techniques and intestinal infusion studies that increasing the caloric load of an infusion expands the small intestinal area exposed to nutrients and increases the effect on food intake and GI motility.

\section{The effect of BMI, age, and gender on the intestinal brake effect of nutrients}

$\mathrm{BMI}$, age, and gender may influence the magnitude of the intestinal brake effects after infusion of nutrients. For BMI, Chapman, et al. compared the effect on food intake and satiety after intraduodenal infusion of fat and $\mathrm{CHO}$ between obese and non-obese men. ${ }^{34}$ Intraduodenal infusion of fat and $\mathrm{CHO}$ suppressed appetite and food intake in both obese and non-obese men. Thus, in this study, the effects of intraduodenal infusion of fat and $\mathrm{CHO}$ on food intake and satiety were not affected by BMI. In addition, Maljaars, et al. described altered gut peptide secretion and blunted vagal responses to nutrients when obesity develops. ${ }^{62}$ Thus, it can be suggested that obesity leads to altered gastrointestinal responses to nutrients. Still, the effect of an increase in BMI on the intestinal brake is not completely known.

Aging results in a physiological decline in food intake. This phenomenon is called "anorexia of aging". Cook, et al. studied the effect of intraduodenal nutrient infusion (fat and $\mathrm{CHO}$ ) in older and younger subjects. ${ }^{17}$ They observed no significant difference in food intake from a buffet meal between older and younger subjects. Increased feedback from intestinal nutrient infusion in the elderly seems not to be responsible for the "anorexia of aging". Other factors, for example alterations in taste and smell or changes in the gastrointestinal motility and secretion, may play a role.

Up to now, no data have been published with regard to gender differences in intestinal brake effects. 


\section{Conclusions}

There is substantial evidence that all regions of the small intestine are able to generate negative feedback signals that influence the functions of the more proximal parts of the Gl tract. Activation of the intestinal brake occurs after reaching a threshold to induce the release of mediators that are involved in intestinal brake activation. The inhibitory effect of this negative feedback mechanism differs between the different sites in the small intestine and the exposed area of infusion. The duodenum, jejunum, and ileum and their specific effects on the inhibition of motility, Gl peptide release, food intake, and satiety are frequently evaluated in humans. However, several studies have used a caloric infusion rate that surpassed the normal gastric emptying rate, resulting in increased concentrations of undigested nutrients in the more distal parts of the small intestine. It is very likely that this effect is also created by bariatric surgery procedures such as RYGB, where a high amount of nutrients is delivered into the jejunum and causes chronically sustained ileal brake activation.

Clinical studies evaluating the effect of small intestinal infusion of fat on food intake and satiety are numerous; these studies clearly demonstrate a suppression of food intake and increased satiety. Protein and $\mathrm{CHO}$ can suppress food intake and satiety to the same extent as equicaloric amounts of fat. It is concluded that a proximal to distal gradient exists with relation to the magnitude of the intestinal brake effect: the more distal the nutrients and their degradation products in the small intestine, the greater the effect on food intake and satiety (Table 2.2).

Prolonged activation of the ileal brake by means of naso-ileal tubes is not feasible in daily practice and is therefore not an option as treatment for obesity. Alternatives such as efficient delivery of encapsulated nutrients into the ileum should be explored with focus on efficacy and safety. Taken together, the observations described in this review point to the ileal brake as the most potent small intestinal feedback mechanism for controlling food intake and satiety. Access of nutrients to the distal part of the small intestine is necessary in order to achieve the most potent effects on food intake and satiety. Taking all relevant factors into account, the ileal brake can be seen as a most interesting target for food-based approaches in the continuing battle against overweight and obesity. 


\section{References}

1. WHO. Factsheet 311: Obesity and Overweight. Available online: http://www.who.int/ mediacentre/ factsheets/fs311/en/ (accessed on 1 January 2015).

2. Specchia ML, Veneziano MA, Cadeddu C, Ferriero AM, Mancuso A, lanuale C, Parente P, Capri S, Ricciardi W. Economic impact of adult obesity on health systems: A systematic review. Eur J Public Health. 2015:25:255-62.

3. Read NW, McFarlane A, Kinsman RI, Bates TE, Blackhall NW, Farrar GB, Hall JC, Moss G, Morris AP, O'Neill $B$, et al. Effect of infusion of nutrient solutions into the ileum on gastrointestinal transit and plasma levels of neurotensin and enteroglucagon. Gastroenterology. 1984:86:274-80.

4. Lin HC, Zhao XT, Wang L. Intestinal transit is more potently inhibited by fat in the distal (ileal brake) than in the proximal (jejunal brake) gut. Dig Dis Sci. 1997:42:19-25

5. Layer P, Peschel S, Schlesinger T, Goebell H. Human pancreatic secretion and intestinal motility: Effects of ileal nutrient perfusion. Am J Physiol. 1990;258:G196-G201.

6. Keller J. Holst JJ, Layer P. Inhibition of human pancreatic and biliary output but not intestinal motility by physiological intraileal lipid loads. Am J Physiol Gastrointest Liver Physiol. 2006;290:G704-9.]

7. Layer P. Holst JJ, Grandt D, Goebell H. Ileal release of glucagon-like peptide-1 (GLP-1). Association with inhibition of gastric acid secretion in humans. Dig Dis Sci. 1995:40:1074-82.

8. Welch I, Saunders K, Read NW. Effect of ileal and intravenous infusions of fat emulsions on feeding and satiety in human volunteers. Gastroenterology. 1985:89:1293-7.

9. Maljaars PW. Intestinal Fat and Eating Behavior: Role of the lleal Brake, Chapter 7: Both Intestinal Site and Timing of Fat Delivery Affect Appetite in Humans. Ph.D. Thesis, Maastricht University Medical Center, 22 October 2010:109-26.

10. Maljaars PW, Peters HP, Mela DJ, Masclee AA. Ileal brake: A sensible food target for appetite control. A review. Physiol Behav. 2008;95:271-81.

11. Shin HS, Ingram JR, McGill AT, Poppitt SD. Lipids, chos, proteins: Can all macronutrients put a "brake" on eating? Physiol Behav. 2013;120:114-23.

12. Borgstrom S, Arborelius M Jr. Influence of a fatty acid on duodenal motility. Scand J Gastroenterol. 1975:10:599-601.

13. Spiller RC, Trotman IF, Higgins BE, Ghatei MA, Grimble GK, Lee YC, Bloom SR, Misiewicz JJ, Silk DB. The ileal brake-Inhibition of jejunal motility after ileal fat perfusion in man. Gut. 1984:25:365-74.

14. Spiller RC, Trotman IF, Adrian TE, Bloom SR, Misiewicz JJ, Silk DB. Further characterisation of the "ileal brake" reflex in man-Effect of ileal infusion of partial digests of fat, protein, and starch on jejunal motility and release of neurotensin, enteroglucagon, and peptide YY. Gut. 1988;29:1042-51.

15. Heddle R, Collins PJ, Dent J, Horowitz M, Read NW, ChattertonB, Houghton LA. Motormechanisms associated with slowing of the gastric emptying of a solid meal by an intraduodenal lipid infusion. J Gastroenterol Hepatol. 1989:4:437-47.

16. Horowitz M, Dent J. Disordered gastric emptying: Mechanical basis, assessment and treatment. Baillieres Clin Gastroenterol. 1991:5:371-407.

17. Cook CG, Andrews JM, Jones KL, Wittert GA, Chapman IM, Morley JE, Horowitz M. Effects of small intestinal nutrient infusion on appetite and pyloric motility are modified by age. Am J Physiol. 1997:273. R755-R1.

18. Lin HC, Doty JE, Reedy TJ, Meyer JH. Inhibition of gastric emptying by sodium oleate depends on length of intestine exposed to nutrient. Am J Physiol. 1990;259:G1031-6.

19. Maljaars J, Haddeman E, Peters H, Masclee AA. Comparison of ileal and duodenal brake mechanisms on satiety and gastrointestinal transport. Gastroenterology. 2007:132:A207.

20. Jain NK, Boivin M, Zinsmeister AR, DiMagno EP. The ileum and carbohydrate-mediated feedback regulation of postprandial pancreaticobiliary secretion in normal humans. Pancreas. 1991:6:495-505.

21. Siegle ML, Schmid HR, Ehrlein HJ. Effects of ileal infusions of nutrients on motor patterns of canine small intestine. Am J Physiol. 1990;259:G78-G85

22. Welch IM, Cunningham KM, Read NW. Regulation of gastric emptying by ileal nutrients in humans. Gastroenterology. 1988:94:401-4. 
23. Lavin JH, Wittert G, Sun WM, Horowitz M, Morley JE, Read NW. Appetite regulation by carbohydrate: Role of blood glucose and gastrointestinal hormones. Am J Physiol. 1996;271:E209-14.

24. Mei N. Vagal glucoreceptors in the small intestine of the cat. J Physiol. 1978:282:485-506

25. Lavin JH, Wittert GA, Andrews J, Yeap B, Wishart JM, Morris HA, Morley JE, Horowitz M, Read NW. Interaction of insulin, glucagon-like peptide 1, gastric inhibitory polypeptide, and appetite in response to intraduodenal carbohydrate. Am J Clin Nutr. 1998:68:591-8.

26. MacIntosh CG, Horowitz M, Verhagen MA, Smout AJ, Wishart J, Morris H, Goble E, Morley JE, Chapman IM. Effect of small intestinal nutrient infusion on appetite, gastrointestinal hormone release, and gastric myoelectrical activity in young and older men. Am J Gastroenterol. 2001;96:997-1007.

27. Rayner CK, Park HS, Wishart JM, Kong M, Doran SM, Horowitz M. Effects of intraduodenal glucose and fructose on antropyloric motility and appetite in healthy humans. Am J Physiol Regul Integr Comp Physiol. 2000;278:R360-6.

28. Ryan AT, Feinle-Bisset C, Kallas A, Wishart JM, Clifton PM, Horowitz M, Luscombe-Marsh ND. Intraduodenal protein modulates antropyloroduodenal motility, hormone release, glycemia, appetite, and energy intake in lean men. Am J Clin Nutr. 2012;96:474-82.

29. Soenen S, Giezenaar C, Hutchison AT, Horowitz M, Chapman I, Luscombe-Marsh ND. Effects of intraduodenal protein on appetite, energy intake, and antropyloroduodenal motility in healthy older compared with young men in a randomized trial. Am J Clin Nutr. 2014:100:1108-15.

30. Ryan AT, Luscombe-Marsh ND, Saies AA, Little TJ, Standfield S, Horowitz M, Feinle-Bisset C. Effects of intraduodenal lipid and protein on gut motility and hormone release, glycemia, appetite, and energy intake in lean men. Am J Clin Nutr. 2013:98:300-11.

31. Steinert RE, Luscombe-Marsh ND, Little TJ, Standfield S, Otto B, Horowitz M, Feinle-Bisset C. Effects of intraduodenal infusion of L-tryptophan on ad libitum eating, antropyloroduodenal motility, glycemia, insulinemia, and gut peptide secretion in healthy men. J Clin Endocrinol Metab. 2014:99:3275-84.

32. Chaikomin R, Wu KL, Doran S, Meyer JH, Jones KL, Feinle-Bisset C, Horowitz M, Rayner CK. Effects of mid-jejunal compared to duodenal glucose infusion on peptide hormone release and appetite in healthy men. Regul Pept. 2008;150:38-42.

33. Pilichiewicz AN, Chaikomin R, Brennan IM, Wishart JM, Rayner CK, Jones KL, Smout AJ, Horowitz M, Feinle-Bisset C. Load-dependent effects of duodenal glucose on glycemia, gastrointestinal hormones, antropyloroduodenal motility, and energy intake in healthy men. Am J Physiol Endocrinol Metab. 2007: 293:E743-53.

34. Chapman IM, Goble EA, Wittert GA, Horowitz M. Effects of small-intestinal fat and carbohydrate infusions on appetite and food intake in obese and nonobese men. Am J Clin Nutr. 1999;69:6-12.

35. Pilichiewicz AN, Papadopoulos P, Brennan IM, Little TJ, Meyer JH, Wishart JM, Horowitz M, Feinle-BissetC. Load-dependent effects of duodenal lipid on antropyloroduodenal motility, plasma CCK and PYY, and energy intake in healthy men. Am J Physiol Regul Integr Comp Physiol. 2007:293:R2170-8.

36. Pilichiewicz AN, Little TJ, Brennan IM, Meyer JH, Wishart JM, Otto B, Horowitz M, Feinle-Bisset C. Effects of load, and duration, of duodenal lipid on antropyloroduodenal motility, plasma CCK and PYY, and energy intake in healthy men. Am J Physiol Regul Integr Comp Physiol. 2006;290:R668-77.

37. Castiglione KE, Read NW, French SJ. Food intake responses to upper gastrointestinal lipid infusions in humans. Physiol Behav. 1998:64:141-5.

38. Seimon RV, Feltrin KL, Meyer JH, Brennan IM, Wishart JM, Horowitz M, Feinle-Bisset C. Effects of varying combinations of intraduodenal lipid and carbohydrate on antropyloroduodenal motility, hormone release, and appetite in healthy males. Am. J. Physiol. Regul. Integr. Comp Physiol. 2009;296:R912-20.

39. Welch IM, Sepple CP, Read NW. Comparisons of the effects on satiety and eating behaviour of infusion of lipid into the different regions of the small intestine. Gut. 1988;29:306-11.

40. Feltrin KL, Little TJ, Meyer JH, Horowitz M, Rades T, Wishart J, Feinle-Bisset C. Effects of lauric acid on upper gut motility, plasma cholecystokinin and peptide $\mathrm{YY}$, and energy intake are load, but not concentration, dependent in humans. J Physiol. 2007:581:767-77.

41. Feltrin KL, Little TJ, Meyer JH, Horowitz M, Rades T, Wishart J, Feinle-Bisset C. Comparative effects of intraduodenal infusions of lauric and oleic acids on antropyloroduodenal motility, plasma cholecystokinin and peptide YY, appetite, and energy intake in healthy men. Am J Clin Nutr. 2008:87:1181-7. 
42. Van Avesaat M, Troost FJ, Ripken D, Hendriks HF, Masclee AA. Ileal brake activation: Macronutrientspecific effects on eating behavior? Int J Obes. 2015:39:235-43.

43. Maljaars PW, Symersky T, Kee BC, Haddeman E, Peters HP, Masclee AA. Effect of ileal fat perfusion on satiety and hormone release in healthy volunteers. Int J Obes. 2008:32:1633-9.

44. Maljaars PW, Peters HP, Kodde A, Geraedts M, Troost FJ, Haddeman E, Masclee AA. Length and site of the small intestine exposed to fat influences hunger and food intake. Br J Nutr. 2011:106:1609-15.

45. Poppitt SD, McCormack D, Buffenstein R. Short-term effects of macronutrient preloads on appetite and energy intake in lean women. Physiol Behav. 1998;64:279-85

46. Weigle DS, Breen PA, Matthys CC, Callahan HS, Meeuws KE, Burden VR, Purnell JQ. A high-protein diet induces sustained reductions in appetite, ad libitum caloric intake, and body weight despite compensatory changes in diurnal plasma leptin and ghrelin concentrations. Am J Clin Nutr. 2005;82:41-8.

47. Geraedts MC, Troost FJ, Munsters MJ, Stegen JH, de Ridder RJ, Conchillo JM, Kruimel JW, Masclee AA, Saris WH. Intraduodenal administration of intact pea protein effectively reduces food intake in both lean and obese male subjects. PLoS One 2011:6:e24878.

48. Steinert RE, Meyer-Gerspach AC, Beglinger $C$. The role of the stomach in the control of appetite and the secretion of satiation peptides. Am J Physiol Endocrinol Metab. 2012;302:E666-73.

49. Anderson GH, Tecimer SN, Shah D, Zafar TA. Protein source, quantity, and time of consumption determine the effect of proteins on short-term food intake in young men. J Nutr. 2004:134:3011-5.

50. Andrews JM, Doran S, Hebbard GS, Rassias G, Sun WM, Horowitz M. Effect of glucose supplementation on appetite and the pyloric motor response to intraduodenal glucose and lipid. Am J Physiol. 1998;274: G645-52.

51. Hunt JN, Smith JL, Jiang CL. Effect of meal volume and energy density on the gastric emptying of carbohydrates. Gastroenterology. 1985:89:1326-30.

52. Wen J, Phillips SF, Sarr MG, Kost LJ, Holst JJ. PYY and GLP-1 contribute to feedback inhibition from the canine ileum and colon. Am J Physiol. 1995:269:G945-52.

53. Izukura M, Hashimoto T, Gomez G, Uchida T, Greeley GH Jr, Thompson JC. Intracolonic infusion of bile salt stimulates release of peptide $Y Y$ and inhibits cholecystokinin-stimulated pancreatic exocrine secretion in conscious dogs. Pancreas. 1991;6:427-32.

54. Koopmans HS, Ferri GL, Sarson DL, Polak JM, Bloom SR. The effects of ileal transposition and jejunoileal bypass on food intake and Gl hormone levels in rats. Physiol Behav. 1984:33:601-9.

55. Chen DC, Stern JS, Atkinson RL. Effects of ileal transposition on food intake, dietary preference, and weight gain in zucker obese rats. Am J Physiol. 1990;258:R269-73.

56. Payne JH, DeWind LT. Surgical treatment of obesity. Am J Surg. 1969:118:141-7

57. Pilkington TR, Gazet JC, Ang L, Kalucy RS, Crisp AH, Day S. Explanations for weight loss after ileojejunal bypass in gross obesity. Br Med J. 1976;1:1504-5.

58. Griffen WO, Jr, Bivins BA, Bell RM. The decline and fall of the jejunoileal bypass. Surg Gynecol Obstet. 1983:157:301-8.

59. Layer P, Groger G. Fate of pancreatic enzymes in the human intestinal lumen in health and pancreatic insufficiency. Digestion. 1993:54:10-4.

60. Feinle C, O'Donovan D, Doran S, Andrews JM, Wishart J, Chapman I, Horowitz M. Effects of fat digestion on appetite, apd motility, and gut hormones in response to duodenal fat infusion in humans. Am J Physiol Gastrointest Liver Physiol. 2003:284:G798-G807.

61. Meyer JH, Tabrizi Y, DiMaso N, Hlinka M, Raybould HE. Length of intestinal contact on nutrient-driven satiety. Am J Physiol. 1998;275:R1308-19.

62. Maljaars J. Overeating makes the gut grow fonder; new insights in gastrointestinal satiety signaling in obesity. Curr Opin Gastroenterol. 2013:29:177-83. 


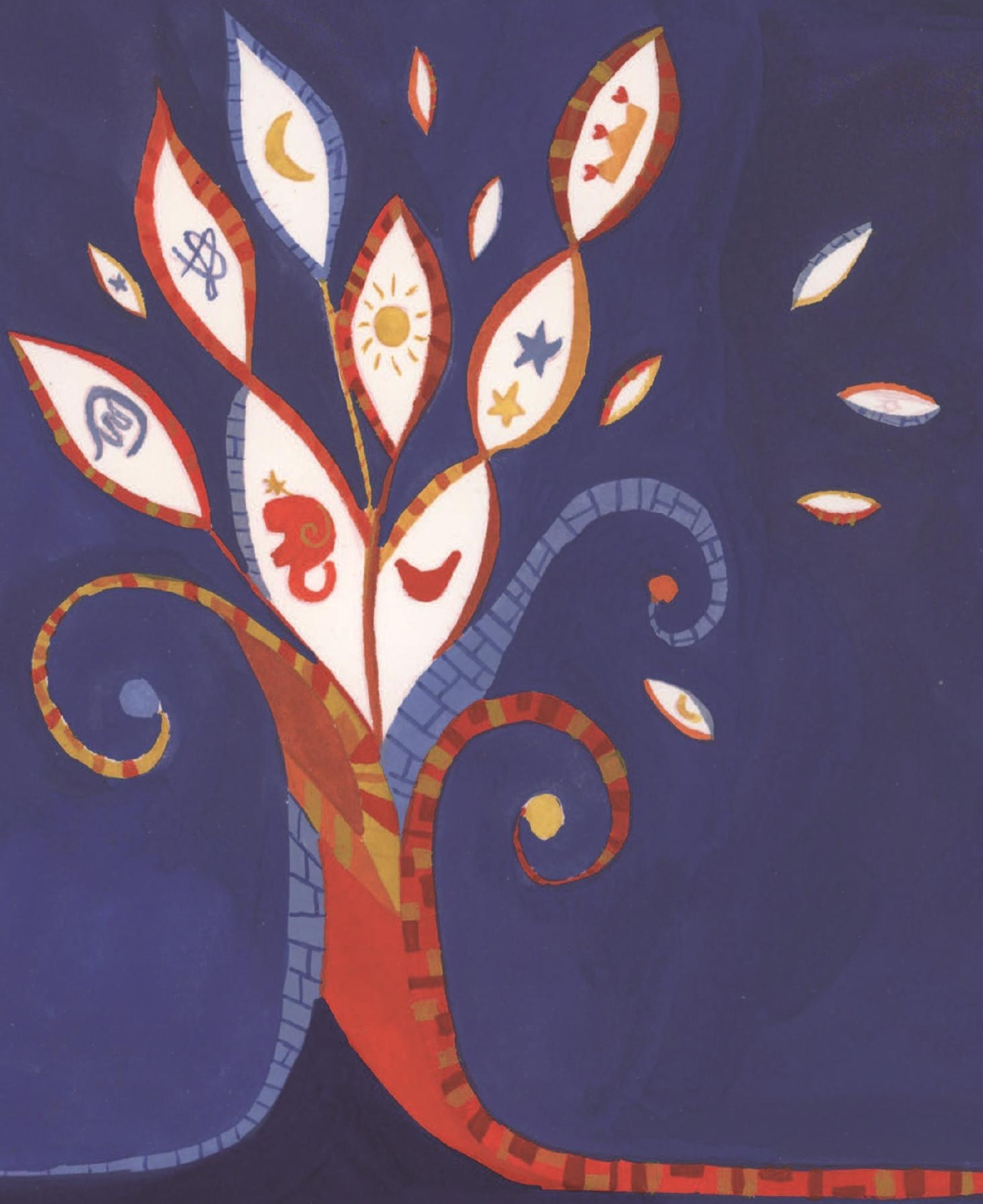




\section{CHAPTER 3}

The effect of an encapsulated nutrient mixture on food intake and satiety: a double-blind randomized cross-over proof of concept study

A.M.E. Alleleyn, M. van Avesaat, D. Ripken, S.B. Bleiel, D. Keszthelyi, E. Wilms, F.J.

Troost, H.F.J. Hendriks, A.A.M. Masclee 


\section{Abstract}

Activation of the intestinal brake by infusing nutrients into the distal small intestine with catheters inhibits food intake and enhances satiety. Encapsulation of macronutrients, which protects against digestion in the proximal gastrointestinal tract, can be a non-invasive alternative to activate this brake. In this study we investigate the effect of oral ingestion of an encapsulated casein and sucrose mixture (active) targeting the distal small intestine versus a control product designed to be released in the stomach on food intake, satiety and plasma glucose concentrations. Fifty-nine volunteers received the active and control product on two separate test days. Food intake was determined during an ad libitum meal 90 min after ingestion of the test product. Visual analogue scale scores for satiety and blood samples for glucose analysis were collected at regular intervals. Ingestion of the active product decreased food intake compared to the control product $655 \mathrm{kcal}$ compared with $699 \mathrm{kcal}$, respectively, $\mathrm{P}<0.05)$. The area under the curve (AUC) for hunger was decreased $(p<0.05)$ and $A \cup C$ for satiety was increased $(p<0.01)$ after the ingestion of the active product compared to the control product. Ingestion of an encapsulated proteincarbohydrate mixture resulted in inhibition of food intake compared to a nonencapsulated control product. 


\section{Introduction}

The intestinal brake consists of a negative feedback mechanism from distal to more proximal parts of the gastrointestinal (Gl) tract and is activated by intraluminal macronutrients and their digestive products. This brake controls not only Gl motility and secretion but also food intake and feelings of satiety. ${ }^{1-3}$ Previously, it was shown that all types of macronutrients are able to activate this intestinal brake and thereby influence eating behavior. ${ }^{4}$ While all parts of the small intestine (duodenum, jejunum and ileum) are able to activate this 'intestinal brake', the ileal brake is considered to induce the most potent feedback signals in the control of food intake and satiety. ${ }^{5,6}$ Therefore, ileal brake activation has emerged as a potential target to reduce caloric intake and, in the longer term, for weight management. ${ }^{7}$

Up to now, intestinal brake activation in humans has mainly been studied via intestinal intubation, that is by positioning naso-intestinal feeding catheters in order to infuse nutrients directly into the small intestine. ${ }^{4.5}$ These studies have provided clear evidence that infusion of small amounts of either fat or protein or

carbohydrates into the distal small bowel reduces food intake and increases satiety. For clinical applications, other less invasive strategies for macronutrient delivery into the small intestine ought to be developed.

Schellekens et al. and Varum et al. both have successfully designed systems for targeted and site-specific drug delivery in the Gl tract. ${ }^{8,9}$ A comparable approach can be used for targeted nutrient delivery. Encapsulation of nutrients with a food grade coating provides a barrier against digestion in the proximal Gl-tract, and is considered to be a non-invasive alternative for targeted nutrient delivery. Previous studies have employed an oil emulsion product (Fabuless ${ }^{\circledR}$, Olibra $\AA$ ) aiming at more distal delivery of fat. These products were based on specific physical-chemical properties of an emulsifier. ${ }^{10-12}$ The proposed mechanism for Fabuless is the activation of the ileal brake; the emulsified oils delay lipolysis and fat absorption from the proximal Gl tract and consequently exposes the distal Gl tract to a high intraluminal fat content. Fabuless was shown to decrease food intake and increase satiety in studies by Burns et al. ${ }^{7-9}$, although this was not confirmed by others. ${ }^{13-16}$ It was hypothesized that the processing of food may have diminished the ability of Fabuless to deliver undigested fat to the distal small intestine. ${ }^{16}$

This proof of concept study aimed to investigate the acute effect of an orally administered encapsulated nutrient mixture, targeting at more distal intestinal release, on food intake and satiety compared to a control product that disintegrates in the stomach in healthy overweight subjects. We hypothesized that the encapsulated nutrient mixture more potently induces satiety and reduces food intake during an ad 
libitum meal compared to control condition. We administered two macronutrients: protein (casein) and carbohydrate (sucrose). We chose not to administer fat, since administration of significant amounts of fat in the distal ileum may lead to Gl discomfort. ${ }^{17,18}$ In addition, fat requires a different encapsulation technique compared to carbohydrates and protein. ${ }^{19}$

\section{Materials and methods}

The study was approved by the Medical Ethics Committee of Maastricht University Medical Center+ and was conducted in full accordance with the principles of the Declaration of Helsinki of 1975 as amended in 2013, and with the Dutch Regulations on Medical Research involving Human Subjects (1998). All subjects gave written informed consent before participation. This trial was registered at www.clinicaltrials.gov as NCT02635659.

\subsection{Subjects}

Subjects were recruited between December 2015 and June 2016. Healthy volunteers were eligible to participate if they were aged between 18 and 65 years and had a body mass index (BMI) between 25 and $30 \mathrm{~kg} / \mathrm{m}^{2}$. Volunteers were recruited by local advertisements. Exclusion criteria were intake of more than 20 alcoholic consumptions per week, specific medication use or medical history of any relevant disorder or surgery possibly interfering with the study outcomes (as assessed by a physician), known Gl symptoms and dieting. All subjects reported to be weight stable for at least 6 months before screening and to be unrestrained eaters (assessed by the Dutch eating behavior questionnaire ${ }^{20}$ ) and reported not be on a diet during study period. After providing initial information verbally or by email, detailed written study information was provided in case subjects were interested. All subjects had to understand the study procedures before the informed consent was signed. Written informed consent was obtained after an interval of at least 7 days.

The power calculation was based on the decrease in food intake of $136 \mathrm{kcal}$ found in ileal carbohydrate infusion study performed by our group. ${ }^{4}$ We expected to find a decrease of $50 \%$, corresponding to $68 \mathrm{kcal}$. With a standard deviation of $175 \mathrm{kcal}$, a power of $80 \%$ and an alpha of 0.05 , a total number of 54 subjects was needed. Anticipating a 10-15\% dropout, we included 62 healthy subjects. 


\subsection{Study design}

This double-blind, randomized, controlled crossover study compared the effect of an encapsulated nutrient mixture targeting the distal small intestine with that of an identical control product (nutrient mixture with alginate encapsulation which disintegrates in the stomach). The study product was ingested 180 min after a standard breakfast, to allow the stomach to be emptied before ingestion of the test drinks. Test days were scheduled with a wash out period of 1 week in between to avoid possible carry-over effects. Test days were randomly assigned (by using Research Randomizer, www.randomizer.org). Subjects were randomized to treatment in randomized block designs. The primary randomization factors were gender and age.

\subsection{Study products}

The active product was an encapsulated nutrient mixture containing $16 \mathrm{~g}$ of sucrose (4 kcalg ${ }^{-1}$, van Gilse Automatensuiker, Oud Gastel, The Netherlands), $10 \mathrm{~g}$ of casein (energy density: $3.45 \mathrm{kcal} \mathrm{g}^{-1}$. Dutch Protein Services, Tiel, The Netherlands) and $2 \mathrm{~g}$ of whey protein, which was used to fabricate the microencapsulate (AnaBio Technologies, energy density $112 \mathrm{kcal}$ ). The control product contained $16 \mathrm{~g}$ of sucrose and $10 \mathrm{~g}$ of casein (AnaBio Technologies, energy density $107 \mathrm{kcal}$ ). The macronutrients in the control product were encapsulated with a sodium alginate encapsulation system characterized by extrusion of the respective micronutrient using $1.8 \%(w / v)$ sodium alginate, with subsequent drying. Samples were dissolved in a total volume of $80 \mathrm{ml}$ of water before consumption. The drinks were prepared by an independent researcher and offered in a black opaque bottle to blind both the investigator and the participant.

\subsection{Micro-encapsulation procedure}

The procedure of preparation of the micro-capsules is described in the patent WO 2016/096931 A1. ${ }^{21}$ All materials were produced according to Good Manufacturing Practice (GMP) guidelines. The micro-encapsulation system utilizes clean-label, foodgrade sources of sucrose and casein to generate micron-sized capsules for controlled delivery of native casein and sucrose to the distal small intestine for stimulation of the intestinal brake mechanism. Gastro-resistant micro-capsules were produced when the sucrose and casein formulation was extruded through an apparatus comprising of an outer nozzle concentrically arranged around an inner nozzle, and in which a denatured protein solution is extruded through the outer 
nozzle and the core-forming casein - sucrose solution is extruded through the inner nozzle. Micro-droplets were instantaneously polymerized in an acidic solution and batches were held at room temperature for max. 1 hour under aseptic conditions. This process avoids 1) blockage of sucrose - casein solution in the concentric nozzle and 2) flow discrepancies during encapsulation process which would affect encapsulation efficiency of the sucrose-casein micro-capsules.

\subsection{Characterization of micro-encapsulates}

\subsubsection{Size distribution and drying effects}

According to light microscopy, micro-beads demonstrated diameters of approximately $200 \mu \mathrm{m}$ with a narrow range size distribution $( \pm 1.2 \mu \mathrm{m})$. Laser diffractometry was also incorporated and confirmed a $D(v, 0.9)$ value for microencapsulates, revealing a diameter of $201.7 \pm 0.90 \mu \mathrm{m}$ and $183.42 \pm 0.90 \mu \mathrm{m}$, pre- and post-drying respectively.

\subsubsection{Stomach incubation and strength of micro-encapsulates}

Strength of micro-beads was analyzed as a function of gastric incubation time in vivo $\left(\mathrm{pH} 1.2-1.4 ; 37^{\circ} \mathrm{C}\right)$. No difference in micro-bead strength was reported for stomach incubation and enzyme-activated stomach conditions did not significantly change micro-bead strength. Tensile strength of micro-beads remained unchanged with no reported leakage or loss of encapsulated casein, pea protein or sucrose. After 180 min of gastric incubation, encapsulated casein, pea protein and sucrose microencapsulates maintained a high tensile strength $52.03 \pm 1.27 \mathrm{nN}, 60.31 \pm 0.27 \mathrm{nN}$ and $58.23 \pm 0.12 \mathrm{nN}$, respectively, to support a robust and high-yielding encapsulation systems for macronutrients.

\subsubsection{Intestinal incubation and degradation}

Transit time of microencapsulates was investigated during in vivo trials and they observed that $35 \mathrm{~min}$ after oral ingestion there was no degradation of the microencapsulates in the duodenum. The maintenance of micro-encapsulate integrity in small intestinal fluids was tested and degradation was not evident. As time progressed, the capsulate membrane gradually degrades to release to mononuclear core material. ${ }^{21}$ 


\subsection{Protocol}

On each test day, subjects arrived at 0745 hours, after a 10-hour overnight fast, at the Metabolic Research Unit at the Maastricht University Medical Center+. Subjects were instructed to abstain from heavy exercise and consumption of alcoholic beverages the evening before the test day and to consume the same habitual meal on the evening before each test day. On both test days, an intravenous cannula was placed in a forearm vein for collection of blood samples. At 0800 hours, a fasted blood sample was taken and Visual Analogue Scale (VAS) scores for satiety, hunger, fullness, desire to eat and Gl symptoms were obtained. Subsequently, a standardized breakfast meal (identical on both test days), consisting of a whole grain sandwich with cheese (Jumbo Supermarkt; energy $245 \mathrm{kcal}$ per served portion, $13.05 \mathrm{~g}$ protein, $5.1 \mathrm{~g}$ carbohydrates, $1.75 \mathrm{~g}$ lipid) and a $200 \mathrm{ml}$ water was consumed by each participant. Completion of the breakfast meal was considered as $t=-180$ min. (Figure 3.1). The subjects were allowed to drink $200 \mathrm{ml}$ water until $\mathrm{t}=-60 \mathrm{~min}$. $180 \mathrm{~min}$ after breakfast intake, subjects ingested the micro-encapsulated nutrient mixture or the control product in randomized order on different test days ( $\mathrm{t}=\mathrm{O} \mathrm{min}$ ). The participant was instructed to ingest the test drink within one min. At 90 min after the intake of the test drink, volunteers received a standardized ad libitum lunch meal (Lasagna Meal Jumbo Supermarkt; energy density per $100 \mathrm{~g}: 144 \mathrm{kcal}, 9.0 \mathrm{~g}$ protein, $15.2 \mathrm{~g}$ carbohydrates, and $4.9 \mathrm{~g}$ lipid) ( $\mathrm{t}=90 \mathrm{~min}$ ). The ad libitum lunch meal was offered in excess (approximately $1 \mathrm{~kg}$ of pasta meal) and subjects were instructed to eat until comfortably satiated. Ad libitum food intake was assessed by weighing the pasta meal that was not consumed and subtracting that from the weight of the provided meal. After finishing the lunch meal, the test day was finished and subjects were allowed to return home.

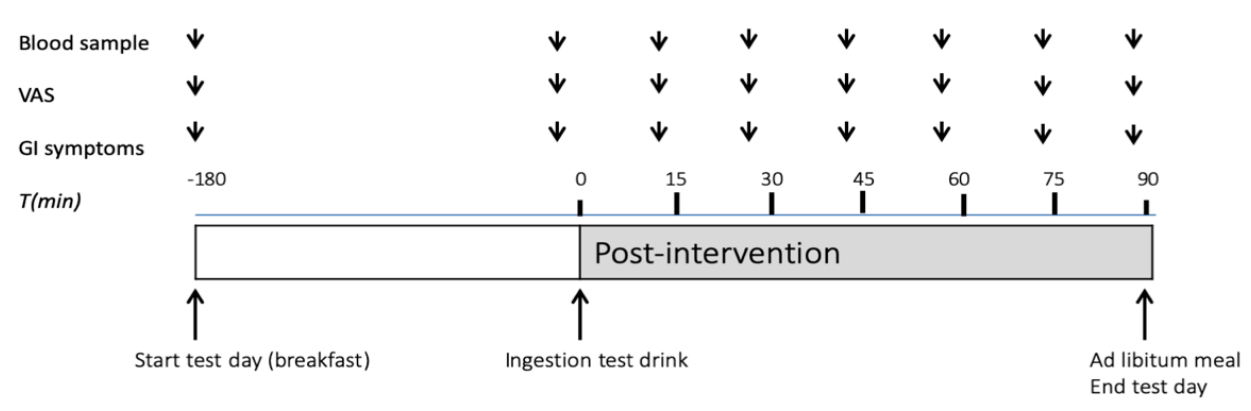

Figure 3.1 Timeline of the test day. A test drink (encapsulated nutrient mixture or control) was ingested 180 min after finishing the breakfast. Blood samples, VAS scores for satiety and Gl symptom scores were collected at regular intervals as indicated. 


\subsection{VAS scores for satiety, fullness, desire to eat, hunger, and evaluation of GI symptoms}

Satiety, hunger, fullness and desire to eat were measured using VAS scores (0-100 $\mathrm{mm}$ ) anchored at the low end with the most negative of lowest intensity feelings (extremely unpleasant, not at all) and with the opposing terms at the high end (extremely pleasant, very high, extreme). ${ }^{22}$ Gl symptoms were evaluated using a questionnaire which addressed complaints such as nausea, bloating, headache, and other symptoms. Symptoms were scored on a 4-point scale with grade 0 representing 'not present' to 3 'strongly present'. Subjects were asked to mark the VAS and Gl symptom scores before breakfast consumption. This was considered as $\mathrm{T}=-180$ min. Subjects also marked the VAS and Gl symptom scores before ingestion of the test drink. After ingestion of the test drink (between $\mathrm{t}=0 \mathrm{~min}$ and $\mathrm{t}=90 \mathrm{~min}$ ), the VAS and $\mathrm{Gl}$ symptoms were scored at 15 min intervals until starting the ad libitum lunch meal.

\subsection{Blood sample collection}

Venous blood samples were drawn before breakfast (fasted) and before ingestion of the test drink ( $t=0 \mathrm{~min}$ ). After ingestion of the test drink, blood samples were obtained every 15 min until the start of the ad libitum meal ( $t=90 \mathrm{~min}$ ) for glucose analysis. Glucose concentrations were analyzed as an indirect indicator for the site of delivery of the nutrients and subsequent nutrient absorption. Sodium fluoride tubes (Becton \& Dickinson, New Jersey, USA) were used to collect blood samples for plasma glucose concentrations. Glucose measurements were performed using a Roche Cobas C701 analyzer (GLUC3, Roche, Mannheim, Germany) with an inter-assay variation of $0.02 \mathrm{mmol} / \mathrm{l}$ at glucose concentration $3.27 \mathrm{mmol} / \mathrm{l}$.

\subsection{Statistical analyses}

Statistical analyses were performed with SPSS, version 22.0 (SPSS Inc., Chicago, IL, USA). Statistical analysis of food intake was performed on the amount of food eaten in kcal. Plasma glucose concentrations and VAS scores are displayed from before the start of ingestion of the test drink ( $t=0 \mathrm{~min}$ ) until the ad libitum meal $(t=90 \mathrm{~min})$. All variables were compared with a mixed model analysis of variance including the fixed factor treatment (encapsulated nutrient mixture and control). For the VAS scores and plasma glucose concentrations, time and the interaction between treatment and time 
were added to the model. To compare the intervention effects within subjects in this cross-over design, subject was included as a random factor. The mixed model included a random intercept model and a random slope (variance components) model. The final model was chosen based on the Akaike Information Criterion (AIC); the model with the lowest AIC was suitable for interpretation. Total VAS scores and plasma glucose concentrations in the 90 minute time frame after the ingestion of the test drink were expressed as the area under the curve (AUC), which was calculated with the use of the trapezoid rule and analyzed with the use of a paired $t$ test. Data are presented as the means \pm SD unless specified otherwise. $p<0.05$ was considered as statistically significant.

\section{Results}

Sixty-two subjects were included in this study (21 male, age: $43.3 \pm 15.9$ years, BMI $27.8 \pm 1.49 \mathrm{~kg} / \mathrm{m}^{2}$ ). Two subjects were excluded from analysis, because we were not able to reliably measure their ad libitum intake of the test meal; since these subjects finished the whole meal without being satiated. One participant dropped out during the study protocol, because of a traffic accident the day before the test day (Figure 3.2). 


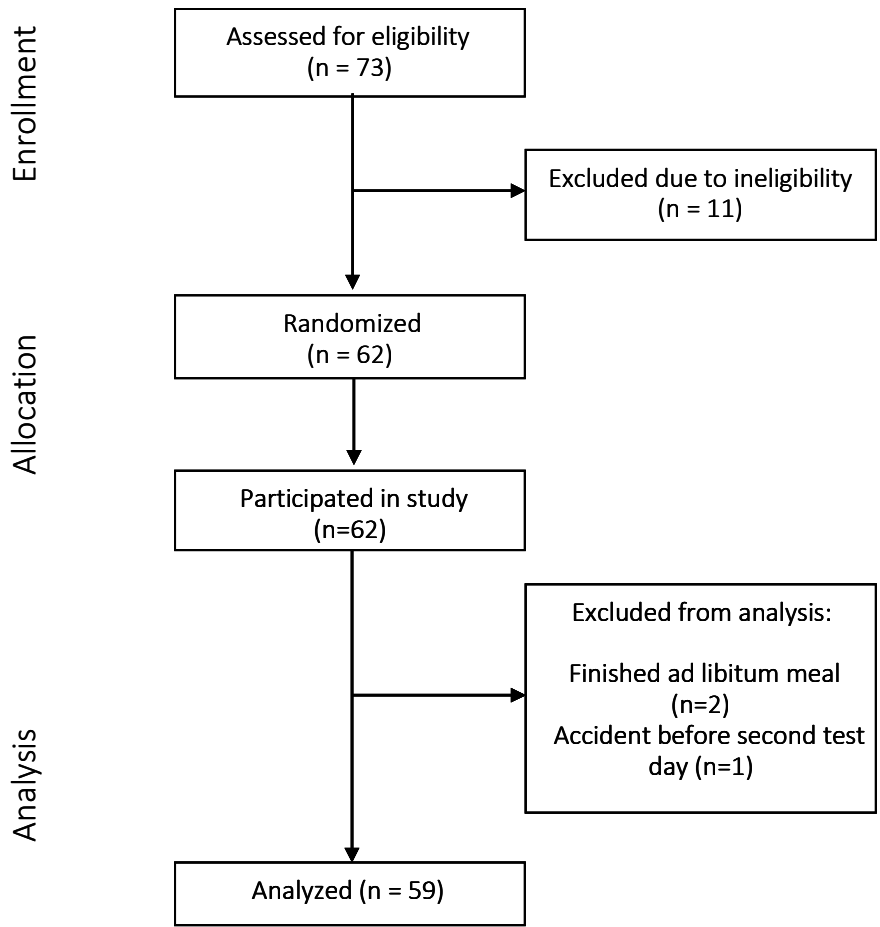

Figure 3.2 CONSORT flow diagram.

\subsection{Food intake}

Ingestion of an encapsulated nutrient mixture resulted in a significantly lower food intake during the ad libitum meal compared with control $655 \pm 30 \mathrm{kcal}$ compared with $699 \pm 30$ kcal respectively, $p=0.011$, Figure 3.3).

\subsection{Satiety, hunger, fullness and desire to eat scores}

Ingestion of both products decreased hunger and desire to eat and increased satiety and fullness. While this effect was more pronounced for the active product for all VAS parameters, there was no significant treatment $x$ time interaction observed for all the VAS parameters. With respect to the AUC (from o to $90 \mathrm{~min}$ ), significant differences between the active and control product were observed for satiety $(p<0.01)$ and for hunger ( $p<0.05$ ) (Figure 3.4). 


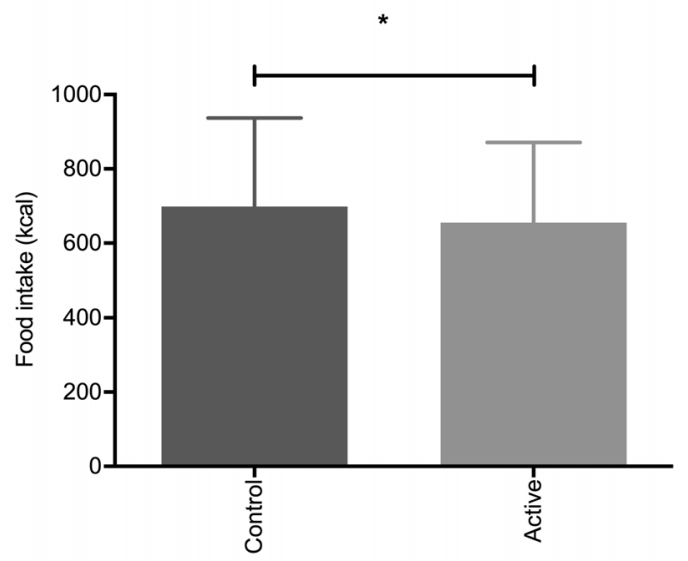

Figure 3.3 Food intake in kcal (mean \pm SD) of the ad libitum meal offered 90 minutes after the ingestion of the active or control product. $\mathrm{p}<0.05$.

\subsection{Gl symptoms}

Mean scores for pain, bloating, flatulence, heartburn, nausea, belching, cramps and urge to defecate did not differ between the ingestion of the encapsulated nutrient mixture and the control. Subjects did not experience any Gl symptoms after ingestion of both treatments (data not shown).

\subsection{Glucose concentrations}

The plasma glucose concentration before ingestion of the products ( $t=0 \mathrm{~min}$ ) did not differ between the test days ( $p>0.05$ ). There was a treatment $x$ time interaction for plasma glucose concentration; plasma glucose concentrations increased after ingestion of the control product over time, whereas the active product did not result in changes in plasma glucose concentrations, $p<0.001$. A significant increase in AUC of the plasma glucose concentration was observed after the control compared with to the active product, $p<0.001$ (Figure 3.5). 

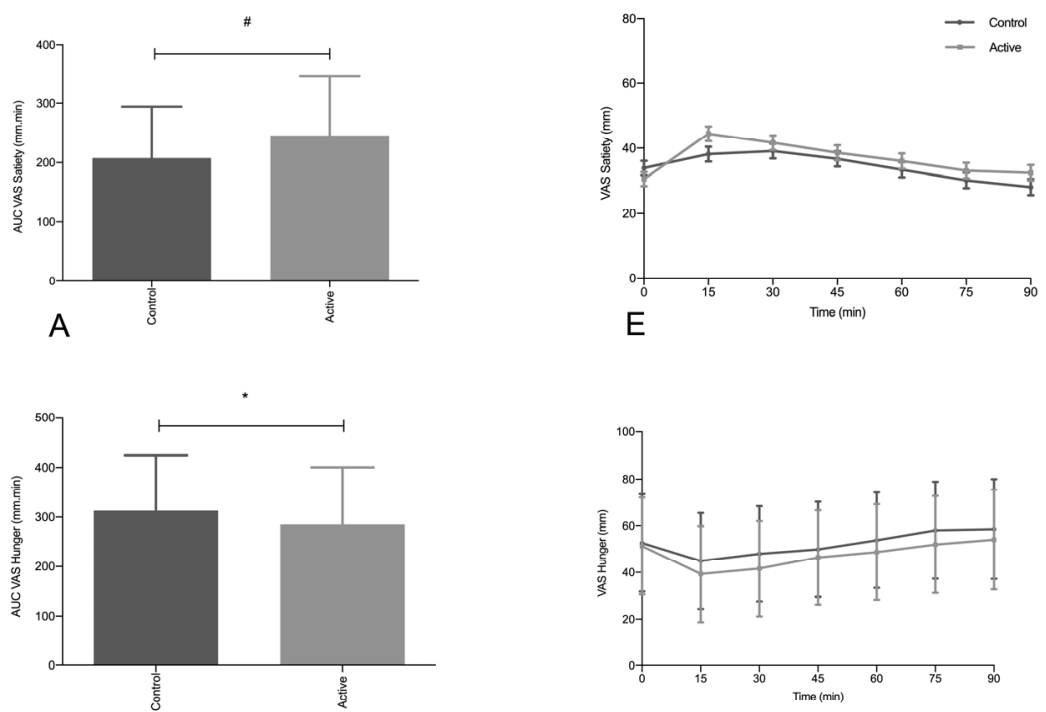

F
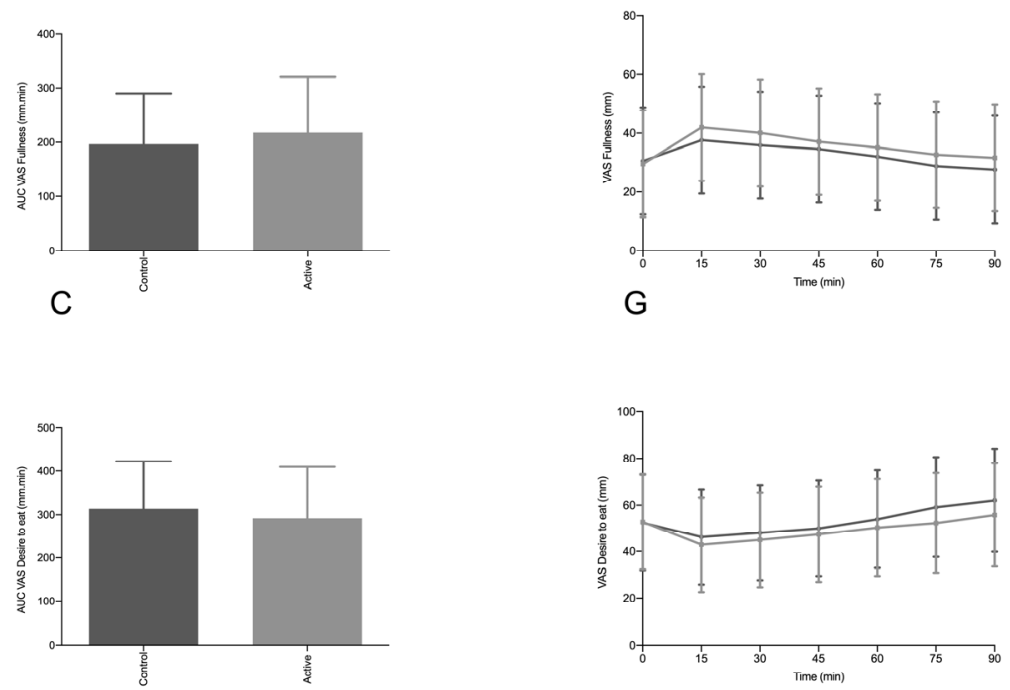

D

$\mathrm{H}$

Figure 3.4 AUCs (0-90 min) for Satiety (A), Hunger (B), Fullness (C) and Desire to eat (D) (mean \pm SD). VAS scores for Satiety (E), Hunger (F), Fullness (G), and Desire to eat (H) after intake of active or control product (mean $\pm \mathrm{SD}$ ). Ingestion of the test drink took place at $\mathrm{t}=0 \mathrm{~min}$ (180 min after consumption of the breakfast). An ad libitum meal was offered at $t=90$ min. AUCs were calculated by using the trapezoid rule. ${ }^{*} p<0.05$ and ${ }^{\#} p<0.01$. 
$\$$

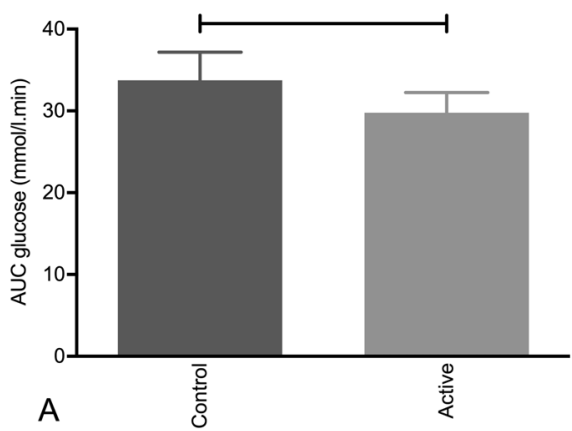

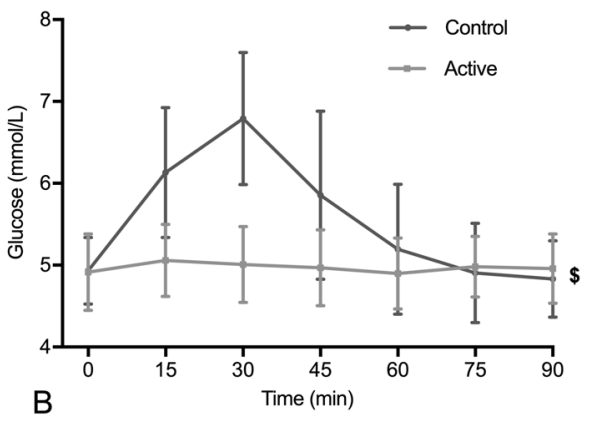

B

Figure 3.5 AUC of the plasma glucose concentration (mean $\pm \mathrm{SD}, \mathrm{A}$ ) and plasma glucose concentrations over time (mean $\pm \mathrm{SD}$, B) during the period after ingestion of the test drink (active and control) scheduled from o to $90 \mathrm{~min}$. AUCs were calculated by using the trapezoid rule. ${ }^{\$} \mathrm{p}<0.001$.

\section{Discussion}

In this proof of concept study, we have shown that oral ingestion of an encapsulated nutrient mixture of sucrose and casein, targeted at delivery into the more distal part of the intestine of healthy overweight individuals, resulted in a decreased caloric intake of a subsequent lunch intake when compared to the control product. The decrease in food intake was accompanied by increased feelings of satiety and decreased feelings of hunger.

The effect of an orally ingested encapsulated nutrient mixture to reduce food intake has not been evaluated previously in humans. Our data confirm that the concept of inhibition of food intake by encapsulated nutrients indeed is effective in an acute intervention experiment. Our test product induced significant effects on food intake and satiety after one single administration of the orally ingested product. This finding is promising for clinical applications but needs confirmation in longer term, repetitive experiments. Previously van Avesaat et al., have investigated the effects of ileal infusion of protein and carbohydrate separately on the ileal brake targeting on food intake and satiety in normal weight subjects using a naso-ileal intubation technique. ${ }^{4}$ It was shown that infusion of protein and carbohydrate in a total concentration of $51.7 \mathrm{kcal}$ resulted in a decrease in food intake of respectively $128.7 \mathrm{kcal}$ and $187.7 \mathrm{kcal}^{4}{ }^{4}$ We here observed a decrease in food intake of $44 \mathrm{kcal}$, an effect of considerably lesser magnitude. A possible explanation for the less pronounced effect on food intake in our current study may result from several factors. First, it may be caused by the method of nutrient delivery, resulting in differences in amounts of the 
macronutrients present in the more distal intestinal lumen during the study. Avesaat et al. infused $51.7 \mathrm{kcal}$ of carbohydrate and protein separately over 90 minutes directly into the ileum. This resulted in a caloric load of $0.57 \mathrm{kcal} / \mathrm{min}$. In our study protocol, subjects acutely and completely ingested both test drinks 90 minutes before start of the ad libitum meal. We are not informed about the amount of protein and carbohydrate calories present in the distal intestine (ileum and more distally) before start of the ad libitum meal in the present study, and thus on the magnitude of the intestinal brake activation. Furthermore, we chose a combination of two macronutrients. Several studies have shown that infusion of a combination of different macronutrients in the duodenum did not result in synergic effects on food intake and satiety. ${ }^{18,23}$ It is thought that a critical, minimum amount of amino acids and monosaccharides should be present in the intestinal lumen in order to reach a threshold value for activating the ileal brake. ${ }^{5}$ One of the two macronutrients may not have reached the critical threshold level for intestinal brake activation. It should also be taken into account that not all of the encapsulated nutrients will have reached the ileum, either through more rapid and proximal delivery or through spill over into the colon.

The effect of the intestinal brake on food intake and satiety feelings has mainly been evaluated in normal weight subjects. ${ }^{24,25}$ The effect of distal delivery of nutrients and the effectiveness of the ileal brake is less well understood in overweight and obese subjects. For the duodenal brake, a less pronounced suppression of food intake was observed after intraduodenal lipid infusion in obese subjects compared to lean subjects. $^{26,27}$ According to our study protocol we included healthy overweight subjects with a BMI between 25 and $30 \mathrm{~kg} / \mathrm{m}^{2}$ and observed a significant decrease in food intake. It is not known whether the effect of more distally delivered nutrients on food intake is different in overweight compared to normal weight subjects. On the other hand, several studies investigating the mechanisms of weight loss after bariatric surgery, such as Roux-en-Y gastric bypass, have provided clear evidence of increased delivery of nutrients in the jejunum and ileum, ileal brake activation and a sustained decrease in body weight years after intervention. ${ }^{28}$

This study was explorative in design: our aim was to deliver proof for the concept that encapsulates nutrients, targeting at a more distal intestinal release, will inhibit subsequent caloric intake. Ileal brake activation is associated with more pronounced release of distal gut peptide into the systemic compartment. We have not measured gut peptide release, so proof for more distal gut delivery of the encapsulated proteincarbohydrates mixture cannot be delivered. However, we measured plasma glucose concentrations at regular intervals for $90 \mathrm{~min}$ after ingestion of the encapsulated mixture and after ingestion of the non-encapsulated identical mixture. While plasma 
glucose concentrations increased significantly within thirty min after ingestion of the non-encapsulated product, this increase was not found after ingestion of the encapsulated nutrient mixture, pointing to at least delayed, more gradual and possibly more distal delivery of the sucrose from the encapsulate.

Several limitations of this study should be acknowledged. First, our study was designed to deliver evidence for the proof of concept, providing first-in-human data whether an encapsulated nutrient mixture is able to reduce food intake in an acute intervention setting. Second, we have not measured timing or location of release of nutrients from the encapsulate into the lumen nor have we measured distal gut peptide like PYY and GLP-1 to obtain further insight whether the more distal part of the small intestine indeed was activated. Subsequent studies are needed to deliver further proof of ileal brake activation. Third, we evaluated food intake in the acute setting, that is after intake of only a single ingestion of the encapsulated nutrient mix. Fourthly, it is not known whether encapsulated nutrients are able to repetitively activate ileal brake mechanisms and hereby result in a sustained effect on food intake and satiety. Due to the encapsulation material, the encapsulated nutrient mixture consisted of slightly more calories than the control product. It is however not expected that this small difference would have affected the results. Increasing the number of calories in the test drink would lead to more potent ileal brake activation and consequently a more pronounced effect on the inhibition on food intake. While the decrease in food intake in terms of calories appears rather modest after a single use, future studies should reveal whether this effect is sustained after repetitive ingestion of this encapsulated nutrient mixture. Another focus for future studies is on the exact behavior of the encapsulated nutrient mixture in the Gl tract, to provide proof of ileal brake activation. The question needs to be answered whether such a slow release, repetitive ingestion strategy wil have a potential role in long term weight management.

In conclusion, this is the first-in-human study to demonstrate that ingestion of an encapsulated protein and carbohydrates mix targeting the distal small intestine is able to decrease food intake and increase satiety in overweight subjects in an acute setting. 


\section{References}

1.

16. Smit HJ, Keenan E, Kovacs EM, Wiseman SA, Peters HP, Mela DJ, et al. No efficacy of processed Fabuless (Olibra) in suppressing appetite or food intake. Eur J Clin Nutr. 2011; 65(1):81-6.

17. Hernando-Harder AC, Serra J. Azpiroz F. Malagelada JR. Sites of symptomatic gas retention during intestinal lipid perfusion in healthy subjects. Gut. 2004:53(5):661-5.

18. Ryan AT, Luscombe-Marsh ND, Saies AA, Little TJ, Standfield S, Horowitz M, et al. Effects of intraduodenal lipid and protein on gut motility and hormone release, glycemia, appetite, and energy intake in lean men. Am J Clin Nutr. 2013:98(2):300-11.

19. Corstens MN, Berton-Carabin CC, de Vries R, Troost FJ, Masclee AA, Schroen K. Food-grade microencapsulation systems that may induce satiety via delayed lipolysis: A review. Crit Rev Food Sci Nutr. 2017:57(10):2218-44.

20. Van Strien T, Rookus MA, Bergers GP, Frijters JE, Defares PB. Life events, emotional eating and change in body mass index. Int J Obes. 1986;10(1):29-35. 
21. Bleiel S. (2016). International publication number WO 2016/096931 A1. Dublin, Ireland; Purdy Lucey Intellectual Property.

22. Parker BA, Sturm K, MacIntosh CG, Feinle C, Horowitz M, Chapman IM. Relation between food intake and visual analogue scale ratings of appetite and other sensations in healthy older and young subjects. Eur J Clin Nutr. 2004:58(2):212-8.

23. Seimon RV, Feltrin KL, Meyer JH, Brennan IM, Wishart JM, Horowitz $M$, et al. Effects of varying combinations of intraduodenal lipid and carbohydrate on antropyloroduodenal motility, hormone release, and appetite in healthy males. Am J Physiol Regul Integr Comp Physiol. 2009;296(4):R912-20.

24. Pilichiewicz AN, Little TJ, Brennan IM, Meyer JH, Wishart JM, Otto B, et al. Effects of load, and duration, of duodenal lipid on antropyloroduodenal motility, plasma CCK and PYY, and energy intake in healthy men. Am J Physiol Regul Integr Comp Physiol. 2006;290(3):R668-77.

25. Welch IM, Sepple CP. Read NW. Comparisons of the effects on satiety and eating behaviour of infusion of lipid into the different regions of the small intestine. Gut. 1988;29(3):306-11.

26. Stewart JE, Seimon RV, Otto B, Keast RS, Clifton PM, Feinle-Bisset C. Marked differences in gustatory and gastrointestinal sensitivity to oleic acid between lean and obese men. Am J Clin Nutr. 2011;93(4): 703-11.

27. Duca FA, Swartz TD. Sakar Y, Covasa M. Decreased intestinal nutrient response in diet-induced obese rats: role of gut peptides and nutrient receptors. Int J Obes (Lond). 2013: 37(3):375-81.

28. Sjostrom L. Review of the key results from the Swedish Obese Subjects (SOS) trial - a prospective controlled intervention study of bariatric surgery. J Intern Med. 2013;273(3): 219-34. 


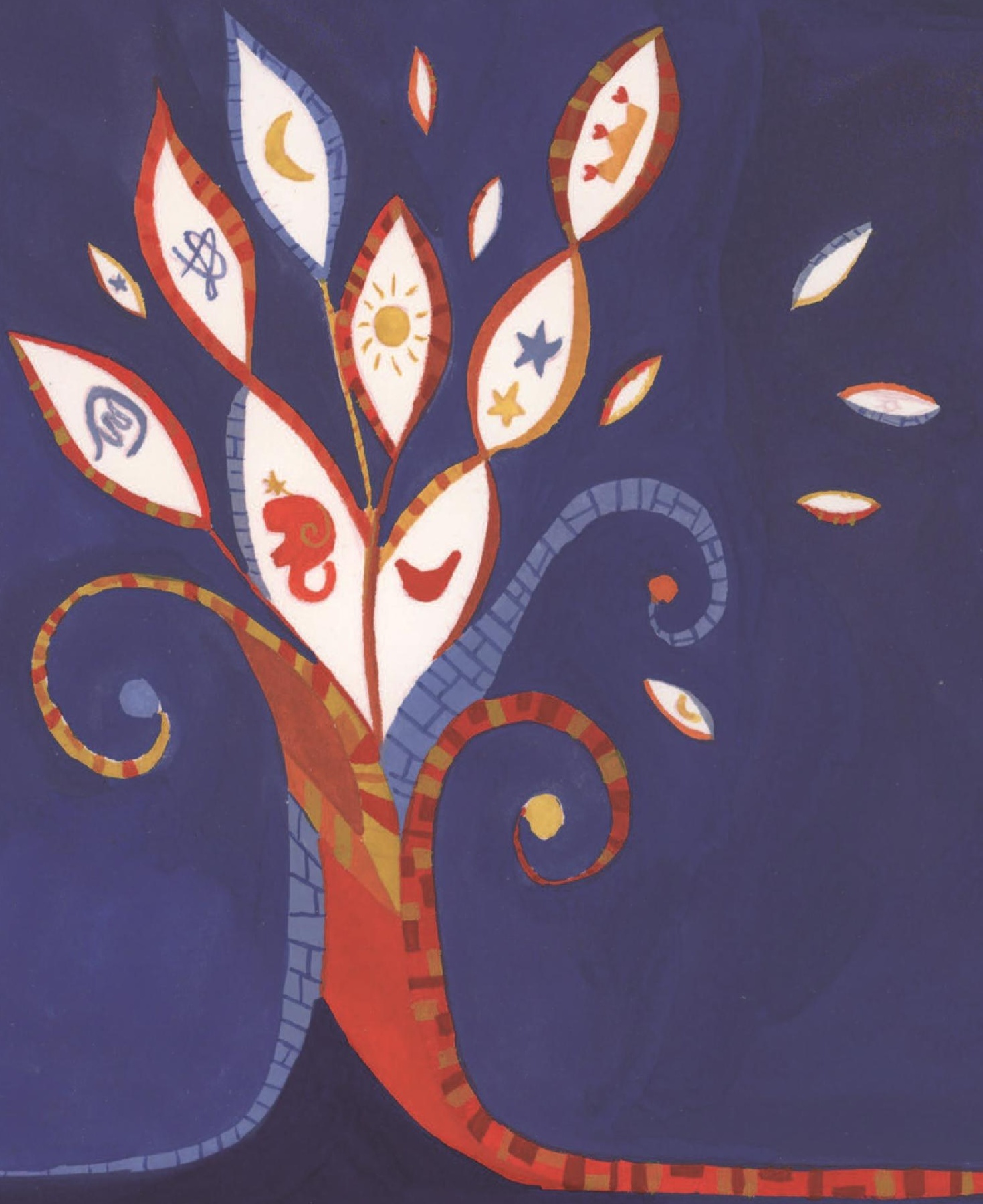




\section{CHAPTER 4}

Encapsulation of lipids as emulsion-alginate beads reduces food intake: a randomized placebo-controlled cross-over human trial in overweight adults 


\section{Abstract}

\section{Background}

The ileal brake mechanism, which induces satiety after sensing nutrients or their metabolites in the ileum, is considered a potent feedback mechanism. Triggering this mechanism through oro-ileal lipid delivery could be the basis for a weight management strategy. We hypothesize that emulsion-alginate beads prevent proximal digestion and absorption of the encapsulated lipid, and that its more distal (ileal) release induces feelings of satiety and reduces food intake.

\section{Objective}

This study investigates the ability of ingested emulsion-alginate beads to decrease food intake, and to increase feelings of satiety without increasing gastrointestinal (Gl) symptoms.

\section{Design}

Thirty-three healthy overweight volunteers (mean age: 43 yrs.; mean BMI: $27.7 \mathrm{~kg} / \mathrm{m}^{2}$; 14 male) received two treatments in a randomized placebo-controlled trial with crossover design. Test days started with intake of a standardized small breakfast $(\mathrm{t}=0)$, followed by a yogurt ( $\mathrm{t}=90 \mathrm{~min}$ ) that contained either encapsulated lipid as emulsionalginate beads (active) or an equicaloric mixture of non-encapsulated nutrients with similar sensory properties (control). Feelings of satiety and Gl symptoms were monitored prior to and after consumption of the yogurt, and food intake was measured during ad libitum pasta meal consumption ( $\mathrm{t}=210 \mathrm{~min}$ ).

\section{Results}

Food intake was significantly reduced with $51 \pm 20 \mathrm{kcal}(\mathrm{p}=0.016)$ after intake of the active yogurt (770 $\pm 38 \mathrm{kcal}$ ) compared to the control ( $821 \pm 40 \mathrm{kcal}$ ). Satiety was increased after intake of the active yogurt compared to the control $(p=0.013)$, but fullness, hunger, desire to eat, and desire to snack were not altered by the intervention.

\section{Conclusions}

Ingested emulsion-alginate beads reduce food intake, suggesting that release of encapsulated lipids in the distal small intestine activated the ileal brake. These findings have important implications for understanding satiety mechanisms, and moreover, the development of a product for weight management. 


\section{Introduction}

The worldwide rapid expansion of obesity demands new noninvasive treatment strategies, which may be obtained via dietary interventions that suppress appetite sensations and regulate food intake., ${ }^{1,2}$ Among others, oral and gastrointestinal (GI) processes involved in food intake regulation, and nutrient sensing in the small intestine can induce negative feedback signals to the proximal Gl tract and central nervous system to inhibit digestion, appetite sensations, and food intake. ${ }^{3.4}$ The ileumis believed to provide the strongest signal, through "the ileal brake" ${ }^{5,6}$ Ileal brake activation has been proven via direct intraileal infusion of macronutrients, applying nasointestinal feeding catheters in human volunteers. ${ }^{6}$ Already 30 years ago, ileal infusion of lipids was shown to reduce food intake ${ }^{7,8}$; however, as part of a long-term weight management strategy, ileal lipid delivery needs to be achieved via oral ingestion, so without need for intubation.

The degradation products of lipid digestion (ie, free fatty acids, monoglycerides) activate the ileal brake more than the intact lipids itself ${ }^{19,10}$, but to achieve this lipid degradation, products need to be delivered to the ileum without proximal absorption. Under physiological conditions, orally ingested lipids are not likely to deliver discernible amounts of such degradation products to the ileum due to a range of processes that allow efficient lipolysis and absorption in the proximal small intestine. ${ }^{11}$ To enable delivery of the lipolysis products, lipids need to be protected by a carrier that remains intact under the acidic conditions in the stomach and that slowly releases degradation products in the distal small intestine. ${ }^{1}$

Many attempts have been made to control in vitro lipid digestion, mainly through designing a protective interface structure around nanometer- or micrometer-sized emulsion droplets. ${ }^{12}$ However, such strategies are not effective enough to deliver lipolysis products to the distal small intestine even when sophisticated particlestabilized interfaces ${ }^{13,14}$ or multilayered interfaces ${ }^{15,16}$ are used. This has led us to conclude that to truly control lipolysis, a different approach is needed that focuses on controlling the exposure of the lipids to digestive enzymes in the Gl tract by incorporating lipids in a gel. ${ }^{17}$ Oilin-water emulsions encapsulated in calcium-alginate beads (named emulsion-alginate beads from hereon) have been suggested for this purpose, as the indigestibility of alginate preserves the structure of the beads, and the $\mathrm{pH}$-dependent response favors lipase diffusion toward encapsulated emulsified lipids in the small intestine; namely, the beads shrink under acidic conditions and have a smaller mesh size, thereby protecting the encapsulated emulsion in the stomach. At increasing $\mathrm{pH}$, such as in the small intestine, the beads swell and increase in mesh 
size. ${ }^{18-22}$ This makes the oil droplets more accessible for lipase, but lipase diffusion in the beads is still considerably lower compared to free diffusion.

Emulsion-alginate beads have been shown to improve the integrity of the encapsulated lipids (as observed bymicroscopy) during gastric transit and to delay intestinal lipid absorption compared to free emulsion droplets or emulsion microclusters in rats. ${ }^{23}$ These findings were in line with a human trial in which large $(0.5 \mathrm{~cm})$ lipid-core alginate-shell capsules were shown to delay intestinal lipolysis and absorption. ${ }^{24}$ For the current human intervention study, small alginate beads $\left(d_{32}=0.5-1.2 \mathrm{~mm}\right)$ that encapsulate emulsion droplets $\left(d_{32} \sim 25 \mu \mathrm{m}\right.$; safflower oil as appetite suppressor ${ }^{25}$ ) were developed to delay intestinal lipolysis. In earlier work, it was shown that these beads can be designed to control in vitro lipolysis after prior gastric incubation by altering bead and mesh size. ${ }^{22}$ Monitoring dynamic in vitro lipolysis of such emulsion-alginate beads confirmed lipolysis at time scales relevant for delivery to the more distal part of the small intestine, whereas in vitro lipolysis of nonencapsulated emulsions was almost completed when leaving the duodenal compartment. $^{26}$

The hypothesis for this study was that delayed release of encapsulated lipids suppresses appetite sensations and reduces food intake. The primary objective was to investigate the efficacy of encapsulated emulsions in calcium-alginate beads at reducing food intake during ad libitum meal consumption. The second objective was to investigate the efficacy of these beads at suppressing appetite sensations. The emulsion-alginate beads were ingested in a yogurt (active) and compared to a yogurt with an equienergetic mixture of nonencapsulated nutrients with comparable sensory properties (control) in a randomized placebo-controlled trial with crossover design. The present work is an explorative study to prove the concept of ileal brake activation in healthy overweight individuals.

\section{Materials and methods}

\section{$2.1 \quad$ Materials}

Safflower oil was purchased from De Wit Specialty oils (19200 Safflower Oil High Linoleic Refined; de Waal, the Netherlands), whey protein isolate (WPI) from Davisco Foods International (BiPro, purity 97.5\%; Eden Prairie, MN, USA), calcium chloride from Boom BV (Prills Food grade; Meppel, the Netherlands), and sodium alginate (W201502) from Sigma Aldrich (St Louis, MO, USA). Fat-free yogurt, bread, marmalade, lemon juice, and the pasta meals were purchased at a local supermarket. 
All materials were certified for food-grade use and used directly without further purification.

\subsection{Preparation of the enriched yogurts}

Commercial fat-free yogurt (Campina Magere yogurt; Amersfoort, the Netherlands; energy density per $100 \mathrm{~g}$ : $39 \mathrm{kcal}$ (163 kJ), o g lipid, $4 \mathrm{~g}$ carbohydrates, 4.7 g protein) was enriched with emulsified safflower oil $(6 \mathrm{~g})$ being either encapsulated in alginate beads (active) or nonencapsulated (control; in presence of "empty" beads), as schematically shown in Figure 4.1.

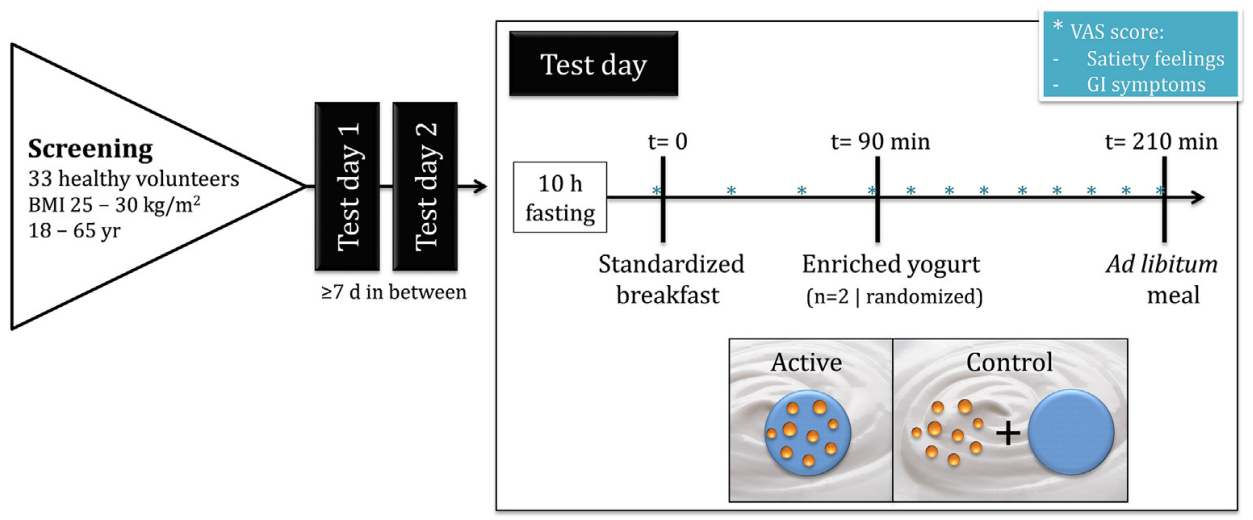

Figure 4.1 Overview of the study design on the effect of encapsulation of lipids on appetite sensations and food intake. Yogurts were enriched with 2 types of lipid carrier: either encapsulated as emulsionalginate beads for ileal delivery (active) or nonencapsulated with comparable sensory properties (control). "VASs were used for 9 attributes per time point.

\subsubsection{Emulsion}

Safflower oil was added to a WPI solution (20 wt\% oil, $10 \mathrm{~g} \cdot \mathrm{L}_{-1}$ WPI in the aqueous phase) and mixed using a rotor stator homogenizer (Ika T18 basic Ultra-Turrax homogenizer equipped with a S18N-19G dispersion tool, Staufen, Germany) for 5 minutes at $13000 \mathrm{rpm}$ to obtain an emulsion with a droplet size $\left(\mathrm{d}_{32}\right)$ of $25 \mathrm{\mu m}$.

\subsubsection{Emulsion-alginate beads}

Fresh emulsion ( $<5$ minutes after production)was mixed with an alginate solution (36 $\mathrm{g} \cdot \mathrm{L}^{-1}$ ) in volume ratio 1:1 (final composition: $10 \mathrm{wt} \%$ oil, $20 \mathrm{~g} \cdot \mathrm{L}^{-1}$ alginate in the aqueous phase, Table 4.1). This alginate-emulsion mixture was added drop wise to a gently stirred calcium bath ( $5 \mathrm{wt} \% \mathrm{CaCl}_{2}$ with some drops of lemon juice to lower the 
$\mathrm{pH}$ and fully dissolve the calcium), as described previously. ${ }^{22}$ The needle tip (inner diameter $0.41 \mathrm{~mm}$; Nordson EFD, Dunstable, UK) was positioned 5-6 cm above the calcium bath, and a syringe pump was used to regulate the flow rate $(3.0 \mathrm{ml} / \mathrm{min})$. To control the bead size, an air flow was applied (Jun-Air 86R-4B compressor, Benton Harbor, MI, USA) such that it passed the needle in a homogeneous way, resulting in a bead size $\left(\mathrm{d}_{32}\right)$ of $1.10 \pm 0.05 \mathrm{~mm}$. After production, the emulsion-alginate beads were stored at $4^{\circ} \mathrm{C}$ at least overnight to harden completely and not more than 4 days to prevent microbial spoilage. On the test day, the beads were filtered and washed with tap water (10 times volume, >10 minutes) and filtered again to obtain weighable beads.

\subsubsection{Empty beads}

Alginate beads were produced from $20 \mathrm{~g}^{\mathrm{L}} \mathrm{L}^{-1}$ alginate solution in the same way as described above $e^{22}$ but not mixed with emulsion. The bead size was $1.21 \pm 0.02 \mathrm{~mm}$, so it was similar to the emulsion-alginate beads. These beads were also stored at $4^{\circ} \mathrm{C}$ for 1 to 4 days and washed and filtered before use.

\subsubsection{Active yogurt}

Fat-free yogurt $(120 \mathrm{~g}$ ) was mixed with $60 \mathrm{~g}$ emulsion-alginate beads (containing $6 \mathrm{~g}$ safflower oil). The composition was matched to the control yogurt by adding $24 \mathrm{~g}$ water. The active yogurts contained $105 \mathrm{kcal}$ (439 kJ), of which $51 \mathrm{kcal} \%$ came from the encapsulated lipids (Table 4.1).

\subsubsection{Control yogurt}

Fat-free yogurt ( $120 \mathrm{~g}$ ) was mixed with $30 \mathrm{~g}$ emulsion (containing $6 \mathrm{~g}$ safflower oil), and $54 \mathrm{~g}$ empty beads to match the composition and sensory properties of the active yogurt. This makes the control yogurt an equienergetic mixture of nonencapsulated nutrients that also contained $105 \mathrm{kcal}(439 \mathrm{~kJ})$, of which $51 \mathrm{kcal} \%$ came from the nonencapsulated lipids (Table 4.1).

\subsubsection{Particle size distribution}

The particle size distribution of the emulsions and beads was determined using static light scattering (Mastersizer 2000 with Hydro SM dispersion unit, Malvern Instruments, UK). For the emulsions, the refractive index of safflower oil was set at 1.460 and that of the dispersant at 1.333 . For the beads, the refractive index was set at 1.470 (with an absorption index of 0.02) and the refractive index of the dispersant at 1.333. 
Table 4.1 Composition and energy content of the studied yogurts.

\begin{tabular}{lcc}
\hline Name & Active & Control \\
\hline Safflower oil (g) & 6.0 & 6.0 \\
Whey protein (g) & $\leq 0.24$ & 0.24 \\
Alginate (g) & 1.08 & 1.08 \\
Water $^{*}$ g) & 76.9 & 76.9 \\
Yogurt (g) & 120 & 120 \\
Total (g) & 204 & 204 \\
Total (kcal) & 105 & 105 \\
Lipid contribution (kcal\%) & $51 \%$ & $51 \%$ \\
\hline
\end{tabular}

Sum of the water added (in emulsion) and the water in beads.

\subsection{Study population}

The study population included 33 healthy overweight volunteers (male and female, 18-65 years, body mass index [BMI] $25-30 \mathrm{~kg} / \mathrm{m}^{2}$ ). Participants received 75 euro after completing the study. Thirty-one subjects were needed to complete the study based on an a priori power analysis for expected effect on our primary outcome, i.e., food intake, so 33 subjects were included to account for possible dropouts. The expected effect size was based on differences in reduction of energy intake of the next meal from previous ${ }^{4,5}$ and unpublished work: average difference of $82 \mathrm{kcal}(343 \mathrm{~kJ})$ with an average SD of $156 \mathrm{kcal}(653 \mathrm{~kJ})$.

The volunteers were recruited from a pool of subjects and via advertisements. Subjects were excluded from participation when they reported milk (protein or lactose) allergy/intolerance, dieting, pregnancy, lactation, excessive alcohol consumption (>20 U per week), intention to stop smoking, self-admitted HIV-positive state, abnormal eating behavior, or unexplained weight loss/gain in the month prior to screening. Subjects were also excluded when taking medication that may affect appetite and sensory function or who reported metabolic or endocrine disease, Gl disorders, or a history of medical or surgical events that may have affected study outcome. All included subjects ( $n=33$; mean age: 43 years; mean BMl: $27.7 \mathrm{~kg} / \mathrm{m}^{2}$; 14 male) completed the protocol.

\subsection{Study design}

In this randomized, single-blind, placebo-controlled trial, the effect of 2 enriched yogurts was compared in a crossover design and focused on food intake and appetite sensations. The yogurts differed in the carrier of the lipid: either encapsulated inside alginate beads for ileal delivery (active) or nonencapsulated with comparable sensory properties (control). For an overview of the study design, see Figure 4.1. 


\subsection{Protocol}

Every subject received 2 treatments on 2 different days with at least 1 week of washout period, following a randomized crossover design. On each test day, the subject arrived after a 10-hour fast at the Metabolic Research Unit at the Maastricht University Medical Center+. Per test day, 1 to 4 subjects were present simultaneously and were allowed to bring a book or laptop, but they could not see each other during meal intake. First, compliance to the previously mentioned rules was checked, and baseline measurements were done for appetite sensations and Gl symptoms. The experiment started with intake of a standardized small breakfast (bread with marmalade; overall composition per $100 \mathrm{~g}$ breakfast: $235 \mathrm{kcal}(983 \mathrm{~kJ}), 0.8 \mathrm{~g}$ fat, $6.8 \mathrm{~g}$ protein, $48 \mathrm{~g}$ carbohydrate, $3.5 \mathrm{~g}$ fiber; with $150 \mathrm{~mL}$ water or tea; $\mathrm{t}=0$ minute) that was identical on both test days. This small breakfast was provided because ileal brake feedback is less pronounced after a prolonged fasting state. When all or most of the breakfast was expected to have been emptied from the stomach ( $\mathrm{t}=90$ minutes), the subject received 1 of the 2 yogurts (active or control) with $150 \mathrm{ml}$ water or tea. Visual analog scale (VAS) scores for appetite sensations and Gl symptoms were collected at a 30-minute interval before ingestion of the yogurt and a 15-minute interval after ingestion. Ad libitum food intake was assessed 2 hours after intake of the test yogurts, as this reflects the anticipated application of an ileal brake-inducing food product, which targets to decrease energy intake during a subsequent meal. Food intake was calculated ( $\mathrm{kcal}$ ) from the difference in weight of the plate before and after ad libitum food intake of a large pasta meal ( $>1$ kg; Lasagna Bolognese, PLUS Supermarket; Utrecht, the Netherlands; energy density per $100 \mathrm{~g}: 152 \mathrm{kcal}$ (636 kJ), $8.6 \mathrm{~g}$ lipid, $11.0 \mathrm{~g}$ carbohydrates, $7.1 \mathrm{~g}$ protein). After meal consumption, the test day finished.

\subsubsection{Appetite sensations and Gl symptoms}

VAS scores ${ }^{27,28}$ were used to determine appetite sensations (satiety, fullness, hunger, desire to eat, desire to snack) and Gl symptoms (bloating, discomfort, pain, nausea), in total at 12 time points ( $t=0,30,60,90,105,120,135,150,165,180,195$, and 210 minutes) per test day. All attributes were measured using a VAS from 0 to $100 \mathrm{~mm}$, with the most negative or lowest-intensity feelings at the low end and the opposing terms at the high end. The subjects indicated their feeling at that moment; scoring forms were collected immediately to prevent use as reference for later scorings. 


\subsection{Ethics}

The study was approved by the Medical Ethics Committee of the Maastricht University Medical Center+ and was conducted in full accordance with the principles of the Declaration of Helsinki of 1975 as amended in 2013 and with the Dutch Regulations on Medical Research involving Human Subjects (1998). All participants gave written informed consent before participation. This trial was registered at clinicaltrials.gov as NCT03025997 and was performed at the Maastricht University Medical Center+ from January until March 2017.

\subsection{Statistical analyses}

The SPSS statistical software package Version 23.0.0.2 (IBMSPSS Statistics, Chicago, IL, USA) was used for statistical analysis. Statistical significance was set at $p<0.05$ in all tests. A descriptive analysis of the study population was performed first, including the independent variables age, sex, and BMI, and reported as means \pm standard errors of the means (SEMs). According to an a priori power analysis based on the expected effect size, 31 subjects needed to complete the study for a power of $80 \%$ and $P$ value of $5 \%$ (2-sided significance level). The dependent variables were checked to meet homogeneity of variance, and normality was checked and tested (Shapiro-Wilk test). To compare food intake ( $\mathrm{kcal}$ ) after intake of the control and active yogurt, a pairedsamples t test was performed ( $n=33$ ).

Because the raw VAS data did not meet the requirements of normality, we tested the difference between control and active yogurt $(n=33)$ through area under the VAS curves from ingestion of the yogurt ( $t=90$ minutes) until ad libitum meal consumption $(\mathrm{t}=210$ minutes). Total areas under the curve of VAS scores were calculated using the trapezoid rule ${ }^{27}$ and did meet normality (Shapiro-Wilk test) for satiety, fullness, hunger, and desire to eat. Therefore, the effect of yogurt on these area under the curve (AUC) VAS scores was tested with paired-samples t tests $(n=33)$, with Bonferroni correction for multiple comparisons to eliminate type I errors. For Gl symptoms, scores were all very low, and the difference in AUC VAS did not meet normality (Shapiro-Wilk test), so nonparametric tests for related samples (Wilcoxon signed ranks test, $n=33$ ) were performed. All data are reported as means \pm SEM in the "Results" section. 


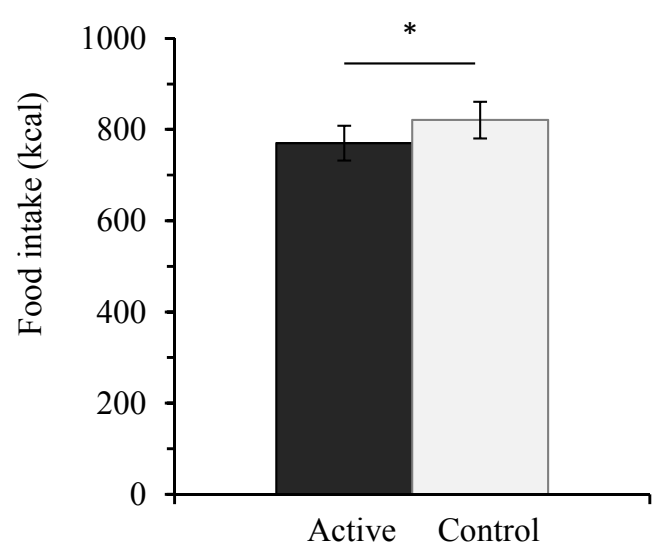

Figure 4.2 Food intake (mean \pm SEM) measured during ad libitum meal consumption, $2 \mathrm{~h}$ after ingestion of the active yogurt (black bar) or control yogurt (light bar). The difference is significant in a pairedsamples T-test ( $\left.{ }^{*} \mathrm{p} \leq 0.05\right)$.

\section{Results}

\subsection{Food intake}

The primary goal of the study was to assess the efficacy of emulsion-alginate beads to reduce food intake through activation of the ileal brake. Figure 4.2 shows the food intake during ad libitum meal consumption 2 hours after ingestion of the active yogurt (black bar; $770 \pm 38 \mathrm{kcal}(3222 \pm 159 \mathrm{~kJ})$ ) or control yogurt (light bar; $821 \pm 40 \mathrm{kcal}$ $(3435 \pm 167 \mathrm{~kJ})$ ). After ingestion of the active yogurt, food intake was significantly lower $(51 \pm 20 \mathrm{kcal}(213 \pm 84 \mathrm{~kJ}) ; \mathrm{p}=0.016)$ compared to the control, which accounts for a reduction of $6.2 \%$ in energy intake.

\subsection{Appetite sensations}

The efficacy of the test product to suppress appetite (increased feelings of satiety and fullness; reduced feelings of hunger, desire to eat, and desire to snack)was determined as secondary study parameter by comparing VAS scores. Figure 4.3 shows comparable VAS scores for appetite sensations after ingestion of the active yogurt (filled symbols) and control yogurt (open symbols).

None of the attributes differed significantly in AUC VAS scores when comparing active and control (Figure 4.4; AUC VAS for satiety, $p=0.5$; for hunger, $p=0.8$; for desire to eat, $p=0.8$; for desire to snack, $p=0.6$; for fullness, $p=0.7$ ). 

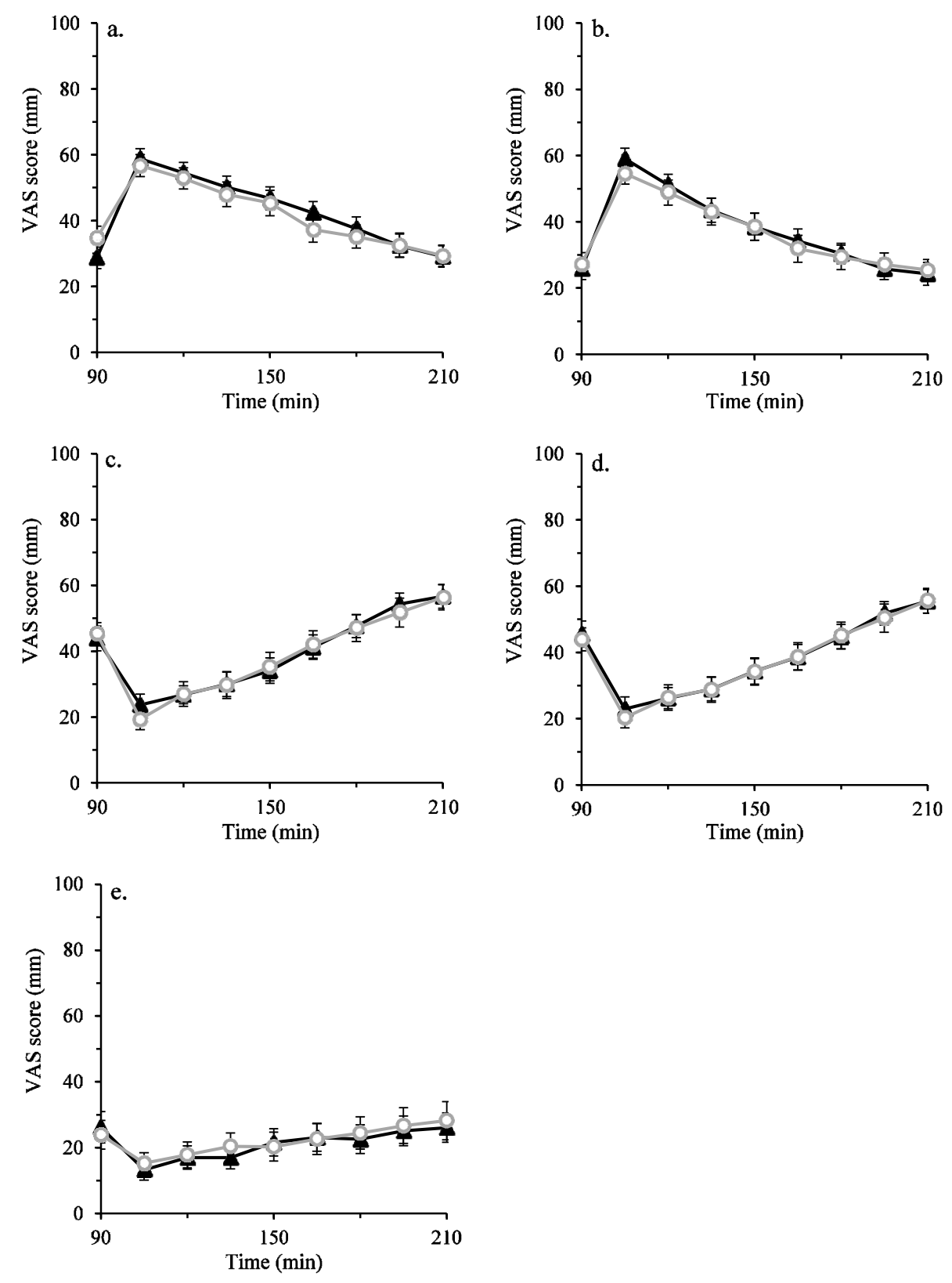

Figure 4.3 Evolution of Visual Analog Scale (VAS) scores (mean \pm SEM) for a) satiety, b) fullness, c) hunger, d) desire to eat, and e) desire to snack, after ingestion of the active yoghurt (filled symbols) and control yoghurt (open symbols), measured on a $100 \mathrm{~mm}$ scale. The yoghurt was ingested at $\mathrm{t}=90$ min (90 min after breakfast) and ad libitum meal was consumed at $\mathrm{t}=210 \mathrm{~min}$. 


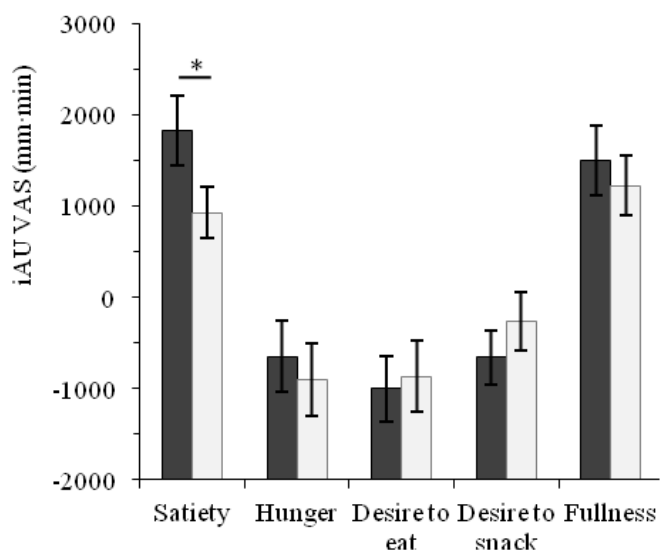

Figure 4.4 Total AUCs of VAS scores for appetite sensations from ingestion of the active (black bar) or control (light bar) yogurt ( $\mathrm{t}=90$ minutes) until ad libitum meal consumption ( $\mathrm{t}=210$ minutes).Values are means \pm SEM. No significant differences $(n=33$, paired-samples $t$ tests).

\subsection{Gl symptoms}

Figure 4.5 shows that all measured Gl symptoms were low ( $<10 \mathrm{~mm}$, measured on a $100-\mathrm{mm}$ scale) and none of the attributes differed significantly in AUC VAS scores between active and control (Wilcoxon signed ranks test, $n=33$; bloating, $p=0.9$; discomfort, $p=0.5$; pain, $p=0.5$; nausea, $p=0.4$ ). Evaluation of adverse events only showed 3 subjects with short-term diarrhea: 2 on the day of the control yogurt and 1 on the day after the active yogurt.

\subsection{Subject expectation of ingested intervention}

After finishing the second test day, subjects were asked to indicate on which test day(s) they thought to have consumed the active and control yogurt; 15 subjects indicated correctly the test day on which they consumed the control yogurt (feeling hungrier), and 7 subjects indicated the wrong intervention; 11 subjects indicated to have perceived no difference in hunger feelings between the 2 days. 

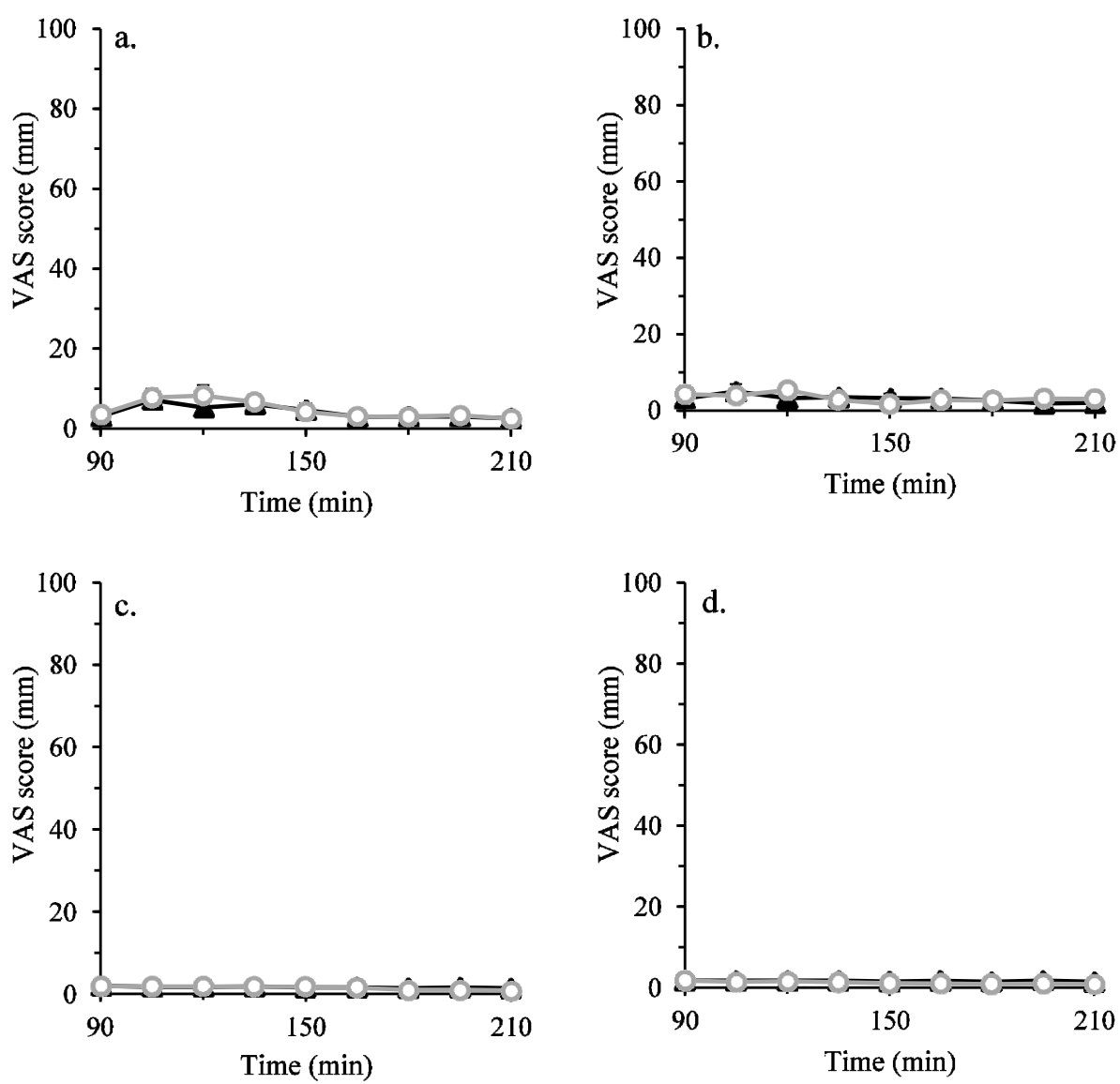

Figure 4.5 Evolution of Visual Analog Scale (VAS) scores (mean \pm SEM) for a) bloating, b) discomfort, c) pain, and $\mathbf{d}$ ) nausea, after ingestion of the active yogurt (filled symbols) and control yogurt (open symbols), measured on a $100 \mathrm{~mm}$ scale. The yogurt was ingested at $\mathrm{t}=90 \mathrm{~min}$ (90 $\mathrm{min}$ after breakfast) and ad libitum meal was consumed at $\mathrm{t}=210 \mathrm{~min}$.

\section{Discussion}

We have shown that ingestion of a yogurt containing emulsion-alginate beads results in a small but statistically significant reduction in food intake during a subsequent meal $(-6.2 \%$ energy intake) compared to the control yogurt that contained an equienergetic mixture of nonencapsulated nutrients with comparable sensory properties. We therefore accept the hypothesis that delayed release of encapsulated lipids reduces food intake. When extrapolating our findings directly to a daily basis, a 
reduction of $155 \mathrm{kcal}(649 \mathrm{~kJ})$ could be achieved for a $2500-\mathrm{kcal}(10460 \mathrm{~kJ})$ intake. This is considered to be a relevant reduction, as a daily reduction of $50 \mathrm{kcal}(20 \mathrm{gJ})$ could already prevent weight gain in about $90 \%$ of the population. ${ }^{29}$

To the best of our knowledge, this is the first human intervention study exploring the effects of emulsion encapsulation in calcium-alginate beads on food intake and appetite sensations. In other studies, lipid-core alginateshell capsules have been shown to control the gastrointestinal fate of lipids and to slightly increase satiety scores $^{24}$, but in the present work, we use smaller lipid droplets and therefore smaller beads.

None of the appetite attributes differed significantly between active and control (satiety, fullness, hunger, desire to eat, and desire to snack). Thus, although emulsionalginate beads clearly affect eating behavior, no relevant change in appetite sensations was observed.

Reduced food intake through activation of the ileal brake has previously been proven with direct intraileal infusion of lipids ${ }^{4.5 .7}$ but not after oral ingestion. Up until now, the most promising emulsion system to deliver degradation products of lipid digestion in the distal small intestine was an emulsion of palm oil and oat oil fractions that naturally contain galactolipids, which was commercialized as Fabuless, Olibra, and Reducal. The galactolipids were expected to induce nucleation and growth of saturated fatty acids crystals, which are absorbed more slowly from the intestine ${ }^{30}$ and were claimed to improve weight management. ${ }^{31}$ However, Fabuless loses its functionality during normal food-manufacturing processes (thermal and shear processing). ${ }^{32}$ Compared to intubation studies that deliver exact amounts of lipids directly to the target position ${ }^{6}$, the effect that we find here is less pronounced. This may be related to less optimal timing and dosages of the release of lipids. Secondly, lean subjects were used in the intubation studies, whereas we studied overweight subjects, who are known to be less sensitive for intraluminal lipids. ${ }^{33}$

We also anticipated that part of the encapsulated lipids will have remained unabsorbed. Ad libitum food intake was assessed 2 hours after intake of the test yogurts, as this reflects the anticipated application of an ileal brake-inducing food product, which targets to decrease energy intake during a subsequent meal. Within this time scale, we observed no significant effect of the yogurt type on scores of appetite sensations. Based on the average gastric emptying profile of yogurt, about half of the emulsion-alginate beads was expected to reach the small intestine within 45 minutes after ingestion ${ }^{34}$, and once in the small intestine, half of the lipid digestion products was expected to be released within 2.5 hours based on previous observations in a static in vitro model. ${ }^{22}$ Based on the in vitro observations, it is likely that only a part of the encapsulated lipids will have been digested before subsequent 
meal consumption started. This may explain why both interventions did not show differences in appetite sensations.

Further optimization of the emulsion-alginate beads is still possible to increase practical significance for the treatment of obesity. To tailor the release of lipids, not only the size of the beads and/or the mesh size can be considered as described previously for in vitro studies ${ }^{22}$, but also the emulsion droplet size can be used to greatly influence lipolysis by changing the available interfacial area. ${ }^{35-37}$ Increasing the amount of lipids per bead volume is not considered an option because this decreases density and will result in floating of the beads in the stomach ${ }^{38}$ and, thus, delays emptying of the active components into the small intestine.

The control yogurt is considered an appropriate reference for the active yogurt, as the free emulsion is rapidly digested and the lipid metabolites will probably be absorbed completely before reaching the distal small intestine. ${ }^{1,9,10}$ Moreover, the empty beads can be conveniently used to design equienergetic products that have no difference in mouth feel, as none of the subjects indicated a difference in sensory properties between the 2 yogurts.

A limitation of the present study is that the distal release of lipids from the used encapsulates was not tested during the in vivo experiment, but instead, the digestion dynamics of the encapsulated lipids were anticipated based on in vitro observations. Additional mechanistic studies would be the next step to take, which includes measuring delivery of lipids from ingested emulsion-alginate beads in vivo in the intestinal lumen. Besides, although we took the best possible care, it is always possible that, in single-blind design, the researcher may (un)intentionally have given subconscious cues which influence the subjects. A third limitation of the present study is the rather short period of controlled behavior prior to starting the test day in the research facility (10-hour fast). This might have been too short to minimize influences from the day before on the test day, such as within-person variation in eating behavior and physical exercise. The crossover study design minimized the influence of between person variations.

Before this product can be used in weight management applications, additional studies will need to be conducted. The duration and impact of the single-dose effect will have to be determined, with concomitant assessment of biological markers (ie, gut hormones as PYY and GLP-1) to gain insight in the involved satiating mechanisms. In a next phase, the effects of this product concept on body weight regulation will have to be investigated in long-term intervention studies, while also charting possible habituation and compensation.

The future perspectives of emulsion-alginate beads for noninvasive weight management are promising because these beads can be incorporated into a yogurt- 
like food product that is part of a normal diet. It is also good to mention that there are positive developments in production technology to produce similar emulsions and beads at a large scale. ${ }^{39}$

In conclusion, we demonstrated that ingested emulsionalginate beads significantly decreased food intake in overweight individuals compared to an equienergetic mixture of nonencapsulated nutrients with comparable sensory properties. We hypothesize that this reduction in food intake is caused by delayed release of encapsulated lipids in the distal small intestine, which activates the ileal brake mechanism. To gain further understanding of ileal brake activation via dietary routes for weight management, additional studies on dose-response relations and long-term effectiveness need to be conducted. If successful, this strategy could result in noninvasive methods for weight control. 


\section{References}

1. Camilleri M, Sweetser S. Would free fatty acids enhance treatment of obesity? Gastroenterology. 2007:133:1367-70.

2. Krop EM, Hetherington MM, Nekitsing C, Miquel S, Postelnicu L, Sarkar A. Influence of oral processing on appetite and food intake-a systematic review and meta-analysis. Appetite. 2018;125:253-69.

3. Maljaars PWJ, Peters HPF, Mela DJ, Masclee AAM. Ileal brake: a sensible food target for appetite control. A review. Physiol Behav. 2008:95:271-81

4. van Avesaat M, Troost FJ, Ripken D. Hendriks HF, Masclee AAM. Ileal brake activation: macronutrient specific effects on eating behavior? Int J Obes (Lond). 2015:39:235-43.

5. Maljaars PWJ, Peters HPF, Kodde A, Geraedts M, Troost FJ, Haddeman E, et al. Length and site of the small intestine exposed to fat influences hunger and food intake. Br J Nutr. 2011;106:1609-15.

6. Alleleyn AME, van Avesaat M. Troost FJ, Masclee AAM. Gastrointestinal nutrient infusion site and eating behavior: evidence for a proximal to distal gradient within the small intestine? Nutrients. 2016;8:117-32.

7. Welch I, Saunders K, Read NW. Effect of ileal and intravenous infusions of fat emulsions on feeding and satiety in human volunteers. Gastroenterology. 1985;89:1293-307.

8. Welch I, Sepple CP. Read NW. Comparisons of the effects on satiety and eating behaviour of infusion of lipid into the different regions of the small intestine. Gut. 1988;29:306-11.

9. Van Citters GW, Lin HC. The ileal brake: a fifteen-year progress report. Curr Gastroenterol Rep. 1999;1: 404-9.

10. Little TJ, Russo A, Meyer JH, Horowitz M, Smyth DR, Bellon M, et al. Free fatty acids have more potent effects on gastric emptying, gut hormones, and appetite than triacylglycerides. Gastroenterology. 2007:133:1124-31.

11. Bakala N'Goma J-C, Amara S, Dridi K, Jannin V. Carrière F. Understanding the lipid-digestion processes in the GI tract before designing lipid-based drug-delivery systems. Ther Deliv. 2012;3:105-24.

12. Corstens MN, Berton-Carabin CC, de Vries R, Troost FJ, Masclee AAM, Schroën K. Food-grade microencapsulation systems that may induce satiety via delayed lipolysis: a review. Crit Rev Food Sci Nutr. 2017:57:2218-44.

13. Sarkar A, Murray B, Holmes M. Ettelaie R, Abdalla A, Yang X. In vitro digestion of Pickering emulsions stabilized by soft whey protein microgel particles: influence of thermal treatment. Soft Matter. 2016;12: 3558-69

14. Sarkar A, Ademuyiwa V, Stubley S, Esa NH, Goycoolea FM, Qin X, et al. Pickering emulsions co-stabilized by composite protein / polysaccharide particle-particle interfaces : impact on in vitro gastric stability. Food Hydrocoll. 2018:84:282-91.

15. Corstens MN, Osorio Caltenco LA, de Vries R, Schroën K, Berton-Carabin CC. Interfacial behaviour of biopolymer multilayers: influence of in vitro digestive conditions. Colloids Surf B Biointerfaces. 2017:153:199-207.

16. Corstens MN, Berton-Carabin CC, Kester A, Fokkink R, van.den Broek JM, de Vries R, et al. Destabilization of multilayeredinterfaces in digestive conditions limits their ability to.prevent lipolysis in emulsions. Food Struct. 2017:12:54-63.

17. Sarkar A, Juan J-M, Kolodziejczyk E, Acquistapace S, Donato-Capel L, Wooster TJ. Impact of protein gel porosity on the digestion of lipid emulsions. J Agric Food Chem. 2015;63:8829-37.

18. Li Y, Hu M, Du Y, Xiao H, McClements DJ. Control of lipase.digestibility of emulsified lipids by encapsulation within.calcium alginate beads. Food Hydrocoll. 2011:25:122-30.

19. Rayment P, Wright P, Hoad C, Ciampi E, Haydock D, Gowland.P, et al. Investigation of alginate beads for gastro-intestinal.functionality, part 1: in vitro characterisation. Food Hydrocoll..2009;23:816-22.

20. Wright PJ, Ciampi E, Hoad CL, Weaver AC, van Ginkel M,.Marciani L, et al. Investigation of alginate gel inhomogeneity.in simulated gastro-intestinal conditions using magnetic.resonance imaging and transmission electron microscopy...Carbohydr Polym. 2009:77:306-15.

21. Zeeb B, Saberi AH, Weiss J, McClements DJ. Retention and.release of oil-in-water emulsions from filled hydrogel beads.composed of calcium alginate: impact of emulsifier type and.pH. Soft Matter. 2015:11:2228-36. 
22. Corstens MN, Berton-Carabin CC, Elichiry-Ortiz PT, Hol K, Troost FJ, Masclee AAM, et al. Emulsionalginate beads.designed to control in vitro intestinal lipolysis: towards.appetite-control. J Funct Foods. 2017:34:319-28

23. Li Y, Kim J, Park Y, McClements DJ. Modulation of lipid.digestibility using structured emulsion-based delivery systems..comparison of in vivo and in vitro measurements. Food.Funct. 2012;3:528-36.

24. Hoad C, Rayment P. Risse V, Cox E, Ciampi E, Pregent S, et al. Encapsulation of lipid by alginate beads reduces bio- accessibility: an in vivo 13C breath test and MRI study. Food Hydrocoll. 2011;25:1190-200.

25. Maljaars PWJ, Romeyn EA, Haddeman E, Peters HPF, Masclee AAM. Effect of fat saturation on satiety, hormone release, and food intake. Am J Clin Nutr. 2009;89:1019-24.

26. Corstens MN, Berton-carabin CC, Schroën K, Viau M, Meynier A. Emulsion encapsulation in calciumalginate beads delays lipolysis during dynamic in vitro digestion. J Funct Foods .2018:46:394-402.

27. Blundell J, De Graaf C. Hulshof T, Jebb S, Livingstone B, Lluch A, et al. Appetite control: methodological aspects of the evaluation of foods. Obes Rev. 2010;11:251-70.

28. Flint A, Raben A, Blundell J, Astrup A. Reproducibility, power and validity of visual analogue scales in assessment of appetite sensations in single test meal studies. Int J Obes (Lond). 2000;24:38-48.

29. Hill JO, Wyatt HR, Reed GW, Peters JC. Obesity and the environment:where dowe go from here? Science. 2003:299:853-5.

30. Knutson L, Fridblom H, Viberg A, Sein A, Lennerna H. Gastrointestinal metabolism of a vegetable-oil emulsion in healthy. Am J Clin Nutr. 2010;92:515-24.

31. Diepvens K, Soenen S, Steijns J, Arnold M, Westerterp-Plantenga M. Long-term effects of consumption of a novel fat emulsion in relation to body-weight management. Int J Obes (Lond). 2007:31:942-9.

32. Smit HJ, Keenan E, Kovacs EMR, Wiseman SA, Peters HPF, Mela DJ, et al. No efficacy of processed Fabuless (Olibra) in suppressing appetite or food intake. Eur J Clin Nutr. 2011;65:81-6.

33. Stewart JE, Seimon RV, Otto B, Keast RSJ, Clifton PM, Feinle-Bisset C. Marked differences in gustatory and gastrointestinal sensitivity to oleic acid between lean and obesemen. AmJ Clin Nutr. 2011;93: 703-11.

34. Berrada N, Lemeland JF, Laroche G. Thouvenot P. Piaia M. Bifidobacterium from fermented milks: survival during gastric transit. J Dairy Sci. 1991;74:409-13.

35. Cho HT, Salvia-Trujillo L, Kim J, Park Y, Xiao H, McClements DJ. Droplet size and composition of nutraceutical nanoemulsions influences bioavailability of long chain fatty acids and Coenzyme Q10. Food Chem. 2014:156:117-22.

36. Lett AM, Norton JE, Yeomans MR. Emulsion oil droplet size significantly affects satiety: a pre-ingestive approach. Appetite. 2016:96:18-24.

37. Maljaars PWJ, van der Wal RJP,Wiersma T, Peters HPF, Haddeman E, Masclee AAM. The effect of lipid droplet size on satiety and peptide secretion is intestinal site-specific. Clin Nutr. 2012:31:535-42.

38. Murata Y, Sasaki N, Miyamoto E, Kawashima S. Use of floating alginate gel beads for stomach-specific drug delivery. Eur J Pharm Biopharm. 2000:50:221-6.

39. Schroën K, Bliznyuk O, Muijlwijk K, Sahin S, Berton-Carabin CC. Microfluidic emulsification devices: from micrometer insights to large-scale food emulsion production. Curr Opin Food Sci. 2015:3:33-40. 



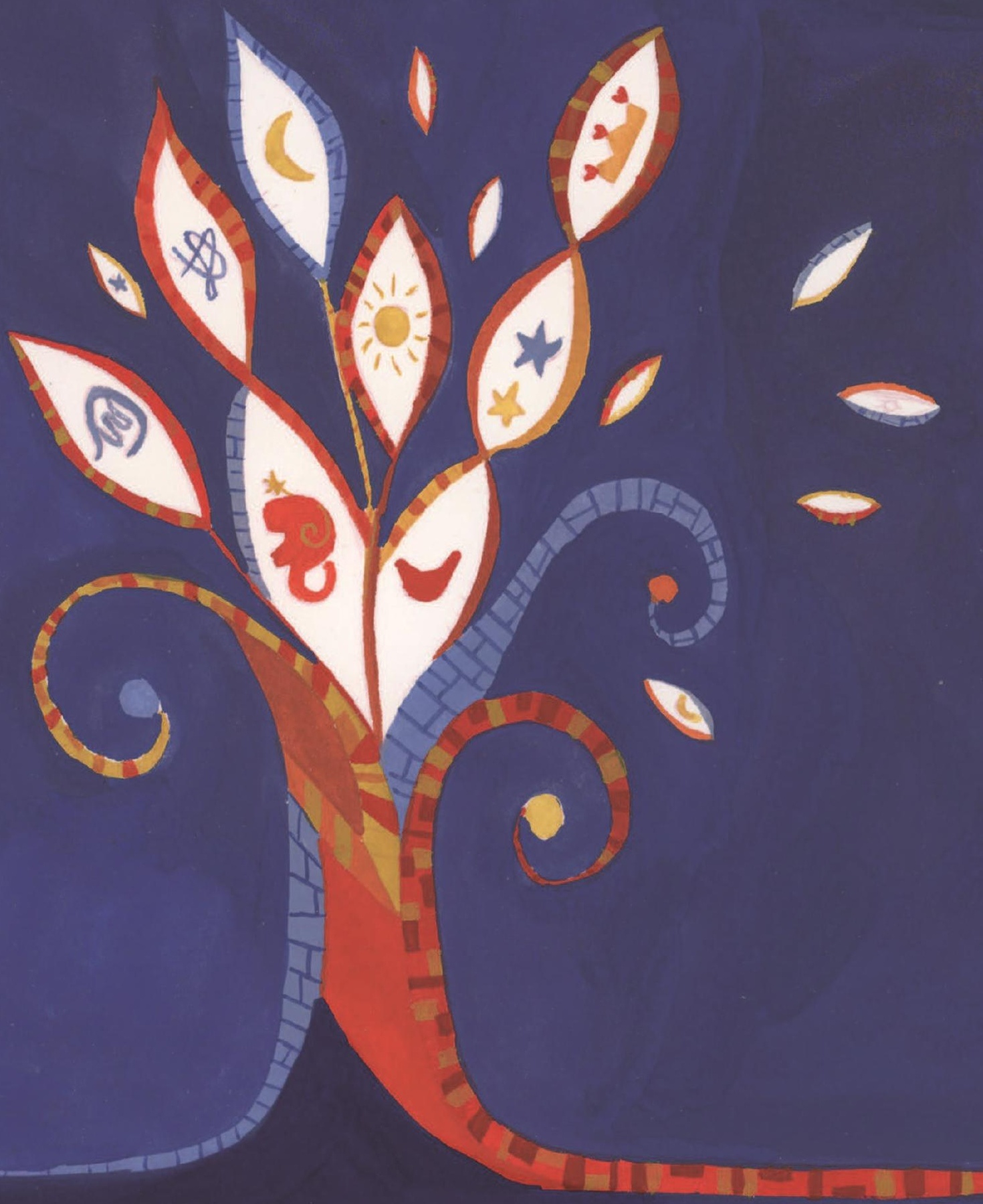




\section{CHAPTER}

Effect of intragastric lidocaine on ad libitum food intake and satiation in healthy male volunteers: a doubleblind randomised crossover study

A.M.E. Alleleyn, T. Klaassen, M. van Avesaat, B. Winkens, B.W.M.M. Peeters, C.L Broekkamp, D. Keszthelyi, A.A.M. Masclee,

To be submitted 


\section{Abstract}

\section{Background}

Food intake is partly regulated by feedback mechanisms within the gastrointestinal tract. One of those is distension of the stomach which leads to activation of mechanoreceptors in the gastric mucosa resulting in food intake termination. We investigated whether signals of distension can be blunted by administration of a local anaesthetic into the stomach. To this end the effect and safety of infusion of lidocaine into the stomach of healthy volunteers on food intake and appetite was measured.

\section{Design}

Twentysix healthy male volunteers completed a doubleblind, randomised crossover study. After a standardised breakfast, volunteers received lidocaine infusion (200 mg) or placebo infusion (100 $\mathrm{mL}$ water) via a nasogastric catheter. Fifteen min after the end of the infusion, an ad libitum meal was provided. Pulse rate and blood pressure were monitored. Gastrointestinal (GI) symptoms and appetite feelings were measured by using visual analogue scales (VAS) scores at regular time intervals.

\section{Results}

Lidocaine infusion of $200 \mathrm{mg}$ into the stomach resulted in a modest nonsignificant increase in food intake on condition of a preceding familiarisation with the procedure. GI symptoms and appetite feelings recorded with VAS scales confirmed this lidocaine effect. No cardiovascular safety issues were detected.

\section{Conclusions}

Infusion of lidocaine in the stomach of lean healthy male volunteers was safe and resulted in a modest nonsignificant increase in food intake. An order effect was observed for test days: food consumption was significantly higher on test day 2 compared to test day 1. 


\section{Introduction}

Overweight and obesity are major health problems in the western world. ${ }^{1,2}$ One of the causal factors for overweight is the overconsumption of energyrich food items that are widely available. ${ }^{3.4}$ Despite these overweight problems, there still are large groups of subjects suffering from malnutrition. This is especially true for patients with chronic or oncological disorders, for hospitalised patients, and for patients with gastrointestinal disorders. ${ }^{57}$ Oncology patients ${ }^{8,9}$ and many elderly ${ }^{1015}$ not only suffer from malnutrition but also from cachexia, which is often correlated with early death. ${ }^{1618}$ The underlying causes of low food consumption are often unknown, but it is well accepted that these patients will benefit from measures that result in an increase in energy intake. ${ }^{1922}$ Thus, there is an urgent need for interventions or drugs that help to increase food intake in chronic or critically ill subjects.

Local mechanisms in the gastrointestinal (Gl) tract are important in the regulation of food intake. The satiating effect that occurs after ingestion of a meal mainly results from distension of the stomach wall. Several studies have investigated the effect of gastric balloon distension in humans and observed that hunger feelings are negatively correlated with gastric distension. ${ }^{23,24}$ During gastric distension, stretch and tension mechanoreceptors are triggered that activate vagal and splanchnic nerve endings, which relay their information to several brain areas resulting in satiation and meal termination. ${ }^{25}$ In elderly subjects, postprandial fullness and satiation are increased when compared to younger subjects. This has been related to a delay gastric emptying with a larger antral area and an overactive sensing profile of gastrointestinal mechanoreceptors. ${ }^{26}$

We hypothesise that inhibition of the mechanoreceptors in the mucosa of the stomach will allow a greater distension of the stomach during a meal. A diminished perception of fullness will possibly result in an increase in food intake.

In animal studies, it has been shown that application of a local anaesthetic into the stomach of rats indeed results in a significant increase of food intake during a subsequent meal. ${ }^{27}$

Aim of the present study was to explore the effect of lidocaine infusion into the stomach, on food intake, as primary parameter, and appetite feelings in healthy young male volunteers. Moreover, we wanted to explore the tolerability (Gl symptoms) and safety (cardiac side effects) during and after infusion of lidocaine into the stomach in this population, with the purpose to check whether this drug can be safely tested in target populations, for example in elderly or in patients with impaired food intake. 


\section{Subjects and methods}

The study was approved by the Medical Ethics Committee of Maastricht University Medical Centre+ and was conducted in full accordance with the principles of the Declaration of Helsinki of 1975 as amended in 2013, and with the Dutch Regulations on Medical Research involving Human Subjects (1998). All volunteers gave written informed consent before participation. This trial was registered at www.clinicaltrials.gov as NCT03227900.

\subsection{Subjects}

Healthy male volunteers were included in this study. Inclusion criteria were an age between 18 and 50 years, a body mass index (BMI) between 20 and $25 \mathrm{~kg} / \mathrm{m}^{2}$ and no history of $\mathrm{Gl}$ diseases. Females were excluded in order to avoid a possible influence of the hormonal cycle on eating behaviour. Exclusion criteria included intake of more than 20 alcoholic consumptions per week, specific medication use or medical history of any relevant disorder or surgery possibly interfering with the study outcomes, allergy to lidocaine in the past, known Gl symptoms, dieting or eating disorder. After providing initial information verbally or by email, detailed written study information was provided in case volunteers were interested and understood the study procedures. Written informed consent was obtained after an interval of at least 7 days.

\subsection{Study design}

This was a randomised, doubleblind, placebocontrolled crossover study with two different treatments with a minimum washout period of 7 days between test days. On each test day, volunteers received intragastric lidocaine dissolved in water for injection or a placebo (water for injection). Treatment order (lidocaine on first test day and placebo on second test day, or vice versa) was randomly assigned to each participant after inclusion by an independent researcher (using Research Randomizer, www.randomizer.org). Volunteers were instructed to abstain from alcohol consumption and exhaustive physical exercise on the day prior to testing. Two days prior to both test days subjects received the proton pump inhibitor (PPI) pantoprazole (3 times $40 \mathrm{mg}$ ) in order to inhibit gastric acid production to avoid protonation of lidocaine in the gastric lumen. 


\subsection{Intervention}

Volunteers were requested to arrive at 08:15 am at the Metabolic Research Unit of the Maastricht University Medical Centre+ (Figure 5.1). Volunteers received a standardised $250 \mathrm{~mL}$ liquid breakfast meal (a diary product of Friesland Campina; energy $152.5 \mathrm{kcal}$ per served portion, 8.5 grams (g) protein, $21.25 \mathrm{~g}$ carbohydrates, $2 \mathrm{~g}$ lipid) provided by the researchers. After finishing breakfast, a nasogastric feeding catheter was placed (Nutricia Flocare ${ }^{\circledR}$ Pur) with the catheter tip positioned in the stomach. The position of the catheter was checked by infusing $10 \mathrm{~mL}$ of air via the catheter whilst simultaneously auscultating (with stethoscope) the stomach region. After correct positioning of the catheter, volunteers waited $150 \mathrm{~min}$ to get used to the catheter. The infusion started 180 min after the ingestion of the standardised breakfast. Hereby, the infusion of lidocaine or placebo in the stomach took place in an empty stomach (standardised condition). Start of the infusion was considered as $\mathrm{t}=0 \mathrm{~min}$ and the volunteers were connected to an infusion pump, which infused the solution at a speed of $6.67 \mathrm{~mL} / \mathrm{min}$ for $15 \mathrm{~min}$. This infusion rate was chosen in order to infuse a large volume (100 mL in $15 \mathrm{~min}$ ). The catheter was removed directly after the discontinuation of the infusion. At $15 \mathrm{~min}$ after the discontinuation of the infusion, the volunteers received a standardised ad libitum chili con carne meal (vanBLIK ${ }^{\mathrm{TM}}$; energy density per $100 \mathrm{~g}: 98 \mathrm{kcal}, 6.5 \mathrm{~g}$ protein, $9.5 \mathrm{~g}$ carbohydrates, and $3.5 \mathrm{~g}$ lipid). Ad libitum food intake was assessed by weighing the chili con carne meal that was not consumed, subtracting that from the weight of the provided meal and finally converting this difference to kilocalories.

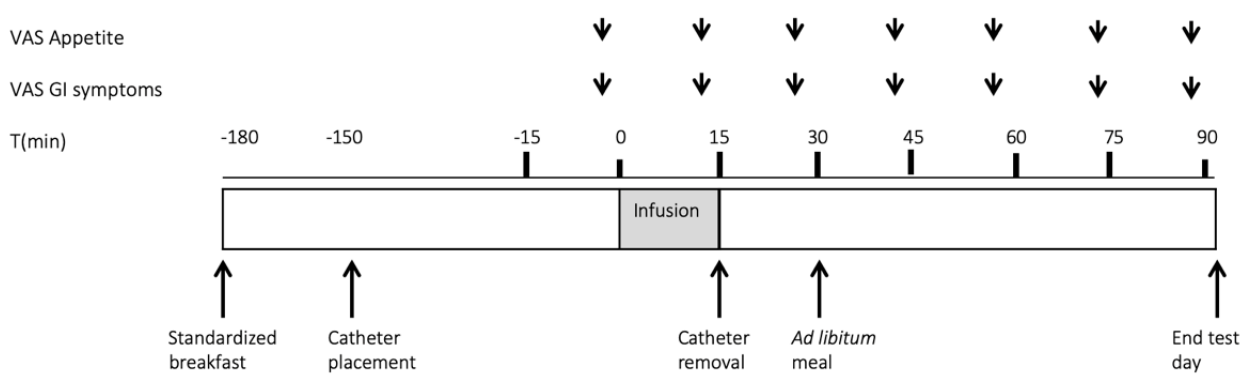

Figure 5.1 Timeline of the test day. The catheter was placed after finishing the standardized breakfast. Infusion of lidocaine or placebo took place $180 \mathrm{~min}$ after the standardized breakfast. After 15 min infusion, the catheter was removed and infusion of lidocaine stopped. Fifteen min after cessation of the infusion, an ad libitum meal was offered to each subject. VAS scores for appetite and GI symptoms were collected at regular intervals as indicated. Gl: gastro-intestinal; VAS: visual analogue scale. 


\subsection{Preparation of the solutions}

An independent researcher prepared the solutions prior to the test day. The solutions were both transparent and therefore the type of solution in the syringe was blinded for the researcher and the participant. The amount of $10 \mathrm{~mL}$ of lidocaine $\mathrm{HCl}$ $20 \mathrm{mg} / \mathrm{mL}$ (B. Braun Melsungen, Germany) was dissolved in $90 \mathrm{~mL}$ water for injection (B. Braun Melsungen, Germany). A total dose of $200 \mathrm{mg}$ lidocaine was infused per subject. The reported maximum single dose of lidocaine parenterally administered is $200 \mathrm{mg}$. Due to the low bioavailability and a relatively strong liver first pass effect of lidocaine, we did not expect side effects to occur with administration of this dose. ${ }^{28}$ For the placebo infusion, $100 \mathrm{~mL}$ of water for injection (room temperature) was prepared in a syringe.

\subsection{VAS scores appetite and GI symptoms}

VAS scores for appetite (hunger, satiation, fullness and desire to eat) and Gl symptoms (stomach pain, belly pain, heartburn, cramps, belching, bloating, flatulence, nausea) were collected at $\mathrm{t}=15,0,15,30,45,60,75$, and $90 \mathrm{~min}$. Appetite and $\mathrm{Gl}$ symptoms were measured by using VAS scores $(0-100 \mathrm{~mm}$ ) that were anchored at the low end with the mostnegative or lowestintensity feelings (e.g., extremely unpleasant and not at all) and with opposing terms at the high end (e.g., extremely pleasant, very high, and extreme).

\subsection{Cardiac side effects}

The occurrence of cardiac side effects was measured by continuous recording of the heart rate during the test procedure. Blood pressure was measured at baseline $(t=0$ min), during and immediately after the infusion period. Mean arterial pressure (MAP) was calculated.

\subsection{Statistical analysis}

Statistical analyses were performed using IBM SPSS Statistics for Windows (Version 25.0 Armonk, NY: IBM Corp.). Normal distribution was tested by the Shapiro Wilk test, models with and without interaction terms.

Analysis of food intake was performed on the amount of food eaten in kilocalories (kcal). A linear mixed model analysis was performed, where treatment (lidocaine or placebo), test day ( 1 or 2) and interaction between treatment and test day were included as fixed factors. A random intercept for volunteers was included to account for the correlation between repeated measures. In case the interaction was not 
significant, this interaction term was removed from the model and only main effects, corrected for the other variable in the model, were reported.

For the VAS scores for appetite or Gl symptoms, blood pressure and heart rate, a threeway interaction between treatment, time and testday was performed. Time was entered in the model as fixed factor, next to treatment and testday, where twoway interactions between time, treatment and testday were included as well. As a sensitivity analysis, a threeway interaction between treatment, time and test day was added to the model in order to analyse whether the treatment effect over time was different for the two test days. A random intercept and/or slope (time) were included and different covariance structures (unstructured and variance components) were considered for these random effects, where the final structure was chosen based on Akaike's information criterion (AIC).

Data are presented as the mean (standard error of the mean, SEM) unless specified otherwise. A twosided p-value $\leq 0.05$ was considered as statistically significant. The normality assumption for residuals was checked.

\subsection{Sample size calculation}

A sample size calculation was based on the average food intake during a previous crossover intervention study from our department (mean intake $586 \mathrm{kcal}$ ) and on the increase in food intake after gastric administration of lidocaine in animals (16\%). ${ }^{27,29}$ Since it was unknown whether the same increase of $16 \%$ could be expected in humans, we performed the calculation with a smaller margin. Therefore, we decreased the margin from $94 \mathrm{kcal}$ to $76 \mathrm{kcal}(13 \%)$. Using the withinpatient standard deviation of $93 \mathrm{kcal}$ that was found in our previous study ${ }^{15}$, a power of $80 \%$, and an alpha of $5 \%$, a total number of 26 participants was needed. Anticipating on possible dropouts of $30 \%$ during screening and test days, a maximum number of 38 volunteers was considered necessary for inclusion.

\section{Results}

Thirty healthy male participants were assessed for eligibility. Two volunteers were excluded after the screening visit because they did not meet the inclusion and exclusion criteria. Two volunteers dropped out of the study before completing the first test day (Figure 5.2). Twentysix healthy male volunteers completed this study (mean \pm SEM, age: $27.12 \pm 1.40$ years, BMl $22.77 \pm 0.28 \mathrm{~kg} / \mathrm{m}^{2}$ ). 


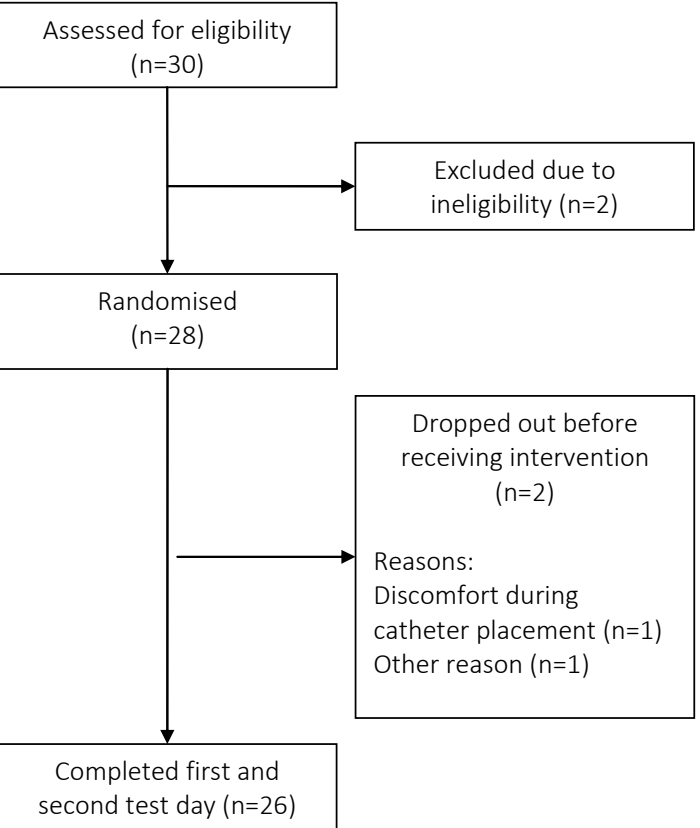

Figure 5.2 CONSORT flow diagram.

\subsection{Primary outcome: food intake}

The data showed a normal distribution (Shapiro Wilk test: model with interaction term p-value 0.493 and model without interaction term p-value 0.498). As there was no significant interaction between treatment and test day ( $p$-value=0.921), overall effects were reported. Infusion of lidocaine in the stomach of healthy volunteers resulted in a mean, nonsignificant increase in food intake during the ad libitum meal of $31 \mathrm{kcal}$ compared to placebo (estimated mean (95\% Cl) for lidocaine: 1022.0 (8931150.9) kcal vs. placebo: $990.8(861.81119 .7) \mathrm{kcal}, \mathrm{p}$-value=0.294). The amount of total food intake for both interventions was significantly different between test days (day 1: 967.1 (62.9) kcal vs. day 2: 1045.6 (62.9) kcal, p-value=0.013).

The effects of lidocaine on food intake at individual level are shown in Figure 5.3. As we observed a significant testday effect, the individual results are presented by sequence (lidocaine first, placebo first). In Figure 5.3A the treatment effect (lidocaine versus placebo) minus testday effect (day 2 versus day 1 ) is presented, while the treatment effect plus testday effect is shown in Figure 5.3B. These data reveal that 
18 out of 26 volunteers (69\%) consumed more of the ad libitum meal after lidocaine than after placebo infusion.
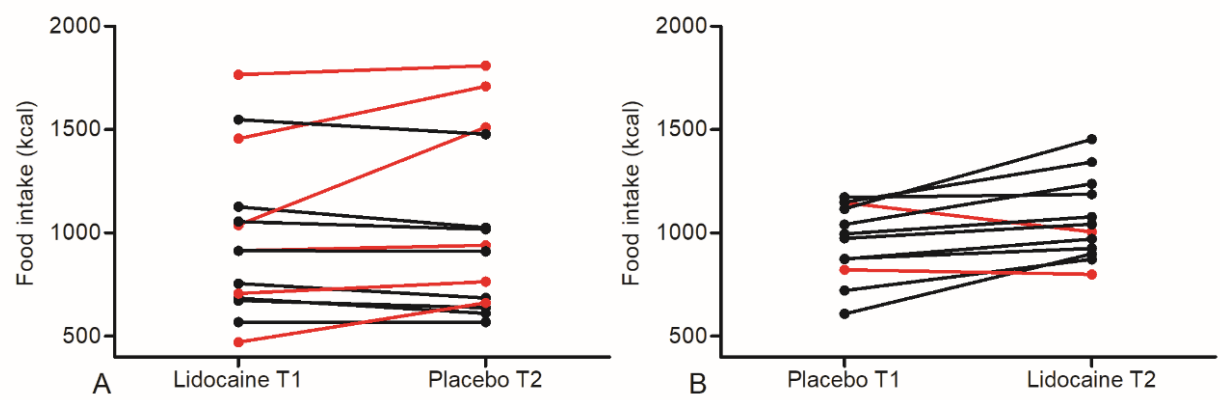

Figure 5.3 Individual data points for food intake during the ad libitum meal. Figure A represents all participants who received lidocaine on the first test day and placebo on the second test day $(n=14)$. Figure B represents all participants who received the other sequence $(n=12)$. The black lines represent all participants who consumed more calories during the ad libitum meal after lidocaine infusion compared to placebo infusion. T1: test day 1; T2: test day 2.

\subsection{VAS scores appetite}

As shown in Figure 5.4, neither infusion of lidocaine nor of placebo influenced pre meal VAS scores. Consumption of the meal resulted in significant increases in satiation and fullness, and significant reductions in hunger and desire to eat. For the appetite scores, no significant interactions between treatment, time and test day were obtained (all p-values 20.093 ). As a consequence, the results for appetite were reported for both test days combined.

\subsection{VAS scores for GI symptoms}

For the Gl symptoms, no significant interaction between treatment, time and test day was observed for stomach pain ( $p$-value 0.540), belly pain ( $p$-value 0.122), heartburn ( $p$-value 0.706 ) or cramps ( $p$-value 0.665) (Figure 5.5). There was a significant interaction between treatment, time and test day for the VAS scores bloating ( $p$-value 0.001), flatulence ( $p$-value 0.041), nausea ( $p$-value 0.024) and belching ( $p$-value 0.006).

\subsection{Cardiac side effects}

There were no significant differences in mean arterial blood pressure (MAP) and pulse rate at baseline, during and at the end of the infusion between infusion of the placebo 
or lidocaine (all p-values $\geq 0.077$; data not shown). No serious adverse events were observed.
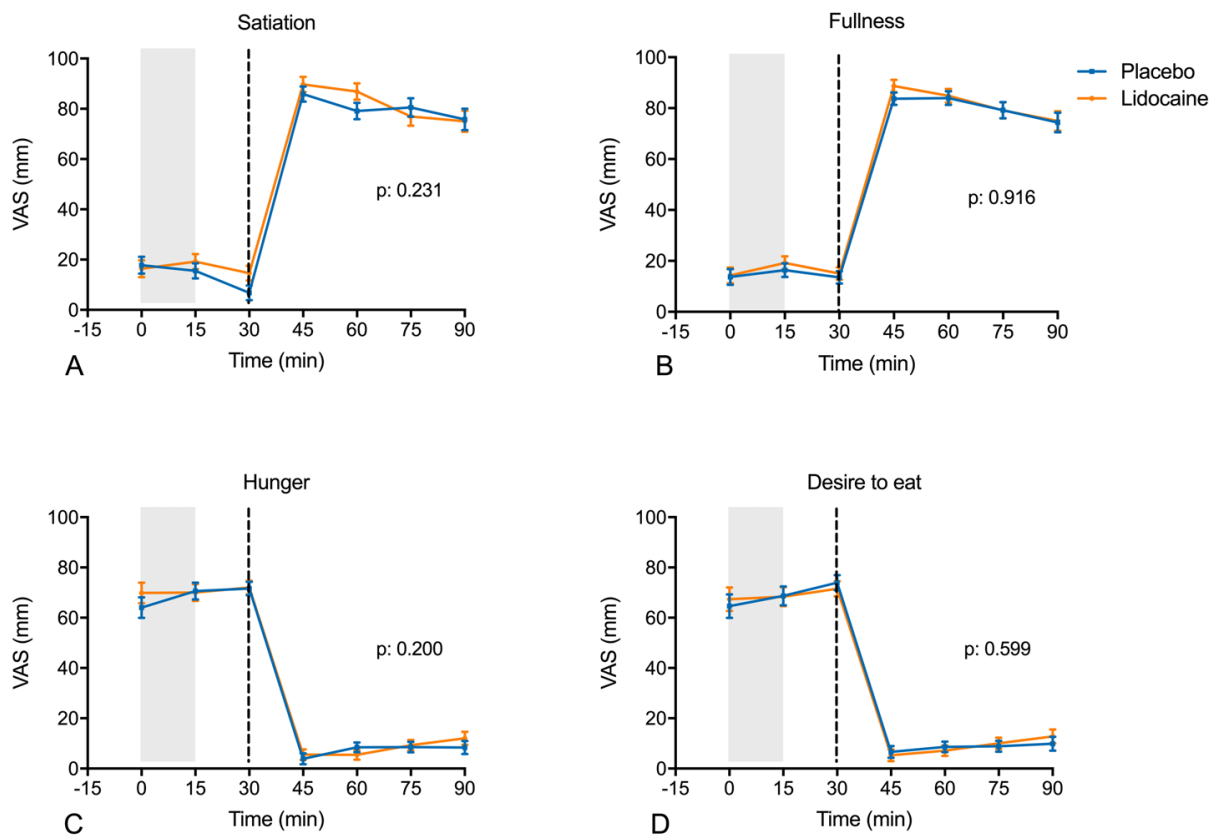

Figure 5.4 VAS scores for Satiation (A), Fullness (B), Hunger (C) and Desire to eat (D) (estimated means \pm SEM). Because the treatment effect over time was not significantly different between the two test days, no separate plots were made for test day 1 and test day 2. Grey box 0-15 min: infusion period. Dashed line: ad libitum meal. P-values presented in the figures represent the statistical significance of the treatment effect over time.

Stomach Pain

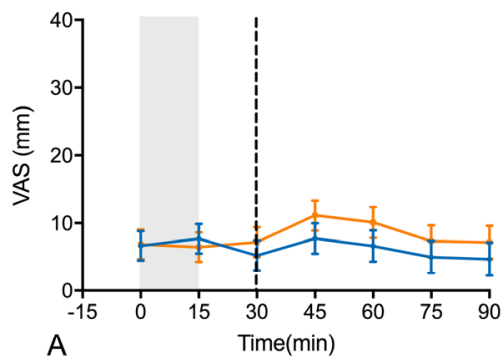

Belly Pain

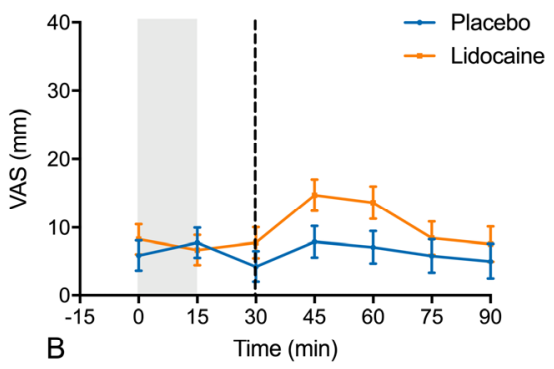



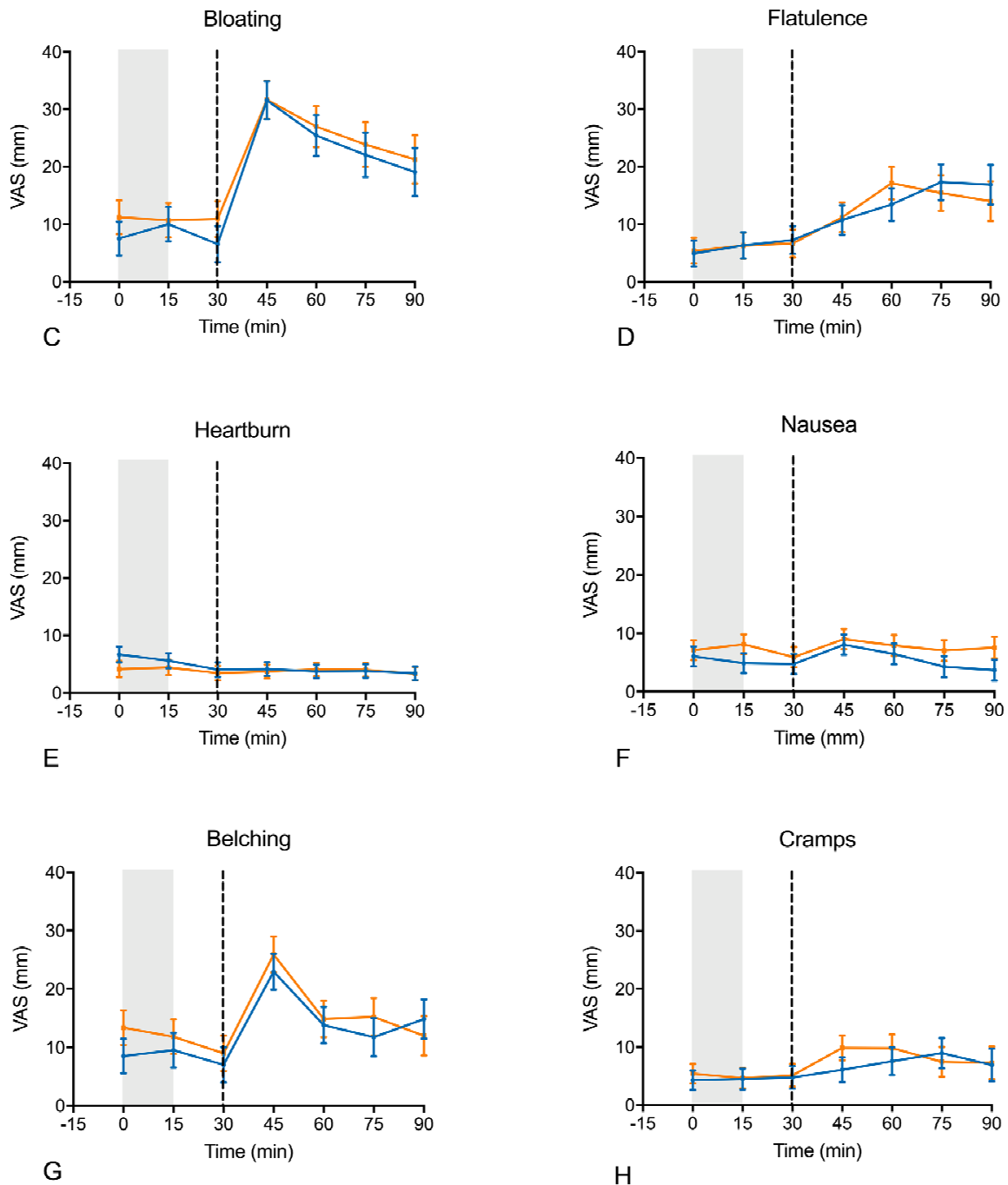

Figure 5.6 VAS scores for Stomach Pain (A), Belly Pain (B), Bloating (C) and Flatulence (D), Heartburn (E), Nausea (F). Belching (G) and Cramps (H) (means \pm SEM). Grey box 0-15 min: infusion period. Dashed line: ad libitum meal.

\section{Discussion}

This is the first-in-human explorative study that investigated the safety and acute effects of infusion of $200 \mathrm{mg}$ lidocaine into the stomach on food intake and appetite 
feelings. The most salient findings of this study are 1) that local administration of lidocaine in the stomach was demonstrated to be safe and was well tolerated by all participants; no cardiac side effects occurred. 2) that administration of lidocaine into the stomach resulted in a modest but nonsignificant increase in food intake of the ad libitum meal compared to placebo 3) an order effect was observed for test days: food consumption was significantly higher on test day 2 compared to test day 1 .

The study design we employed was chosen, based on previous investigations. ${ }^{2931}$ In the crossover design in those studies no clear differences in response were observed between treatment day 1 and day 2 . In the present study it was observed that participants ate on average more during the second test day compared to the first test day. This can be understood in view of subjects not being familiar with the procedures of catheter placement and removal, resulting in stress and discomfort. Stressors are known to influence food intake be it in either direction, dependent on the type, strength and impact of the stressor. ${ }^{3234}$

In the present study, only young male volunteers with an age between 18 and 50 years were included. This strict inclusion criterion was based on the possible chance of inducing cardiac side effects during intragastric lidocaine administration. ${ }^{35.36}$ Changes in cardiovascular function are known to be age related and to result in an increased risk for cardiovascular morbidity. ${ }^{37}$ Lidocaine did not induce any effects on heartrate or blood pressure in the young study population.

Previously we have shown a significant increase in food intake in an animal study, where $20 \mathrm{mg} / \mathrm{kg}$ bodyweight lidocaine was infused into the stomach. ${ }^{10,25}$ In the present study, we observed only a modest, non significant increase in food intake. This lack of a significant effect may be related to several factors. First, the dose per $\mathrm{kg}$ infused in our study $(2.6 \mathrm{mg} / \mathrm{kg}$ body weight) was much lower compared with the lidocaine of $20 \mathrm{mg} / \mathrm{kg}$ bodyweight infused into the rats' stomach. Second, it should be noted that not the systemic exposure of lidocaine is important, but the local concentration around the stretch receptors in the stomach wall. It is therefore difficult to compare the doses between species with different stomach sizes and anatomies. Third, the order effect with a significant larger food intake on the second test day may have influenced the results. This indicates that familiarisation with the procedure is important and should be taken into account in future study designs.

The study was explorative in design, therefore we additionally screened with the Thompson Tau test for outliers. In fact, three outlier subjects were identified who all consumed a very large amount of chili con carne (>1500 kcal) after placebo infusion. We speculated that in these young male healthy participants, maximum distension of the stomach had occurred after food intake. In case the stomach is already distended 
to a maximum degree, no further distension by administration of a local anaesthetic is to be expected.

The VAS scores for appetite are in line with the data of food intake: no significant differences were present between lidocaine and placebo, neither before nor after the meal intake. It should be noticed that we studied healthy volunteers and not patients with disturbed gastrointestinal sensory perception. Previous studies have shown that sensory pathways in the gastrointestinal tract are affected by age. ${ }^{3840}$ Healthy aging is associated with a reduction in appetite and food intake, which may predispose to pathologic weight loss and malnutrition. We hypothesise that the effect of lidocaine infusion in the stomach on food intake will be of a greater magnitude in older subjects. This may also hold true for patients with chronic or malignant disorders.

In conclusion, this explorative study showed that infusion of lidocaine in the stomach of lean healthy male volunteers was safe and resulted in a modest nonsignificant increase in food intake. The effect of lidocaine on food intake deserves further evaluation in conditions with impaired food intake such as in the elderly or in patients with chronic or malignant disorders. 


\section{References}

1. Kushner RF. Weight loss strategies for treatment of obesity. Progress in cardiovascular diseases. 2014:56(4):465-72.

2. Kumar MS. Peptides and Peptidomimetics as Potential Antiobesity Agents: Overview of Current Status. Frontiers in nutrition. 2019:6:11.

3. Salter AM. The effects of meat consumption on global health. Revue scientifique et technique. 2018:37(1):47-55.

4. Tappy L. Fructose-containing caloric sweeteners as a cause of obesity and metabolic disorders. The Journal of experimental biology. 2018;221(Pt Suppl 1).

5. Enck P, Azpiroz F, Boeckxstaens G, Elsenbruch S, Feinle-Bisset C, Holtmann G, et al. Functional dyspepsia. Nature reviews Disease primers. 2017:3:17081.

6. Tack J. Carbone F. Functional dyspepsia and gastroparesis. Current opinion in gastroenterology. 2017:33(6):446-54.

7. Talley NJ. Walker MM, Holtmann G. Functional dyspepsia. Current opinion in gastroenterology. 2016:32(6):467-73.

8. Simone CB, 2nd. Cancer cachexia: definitions, outcomes, and treatments. Ann Palliat Med. 2019;8(1): E1-E3.

9. Brown JC, Cespedes Feliciano EM, Caan BJ. The evolution of body composition in oncologyepidemiology, clinical trials, and the future of patient care: facts and numbers. Journal of cachexia, sarcopenia and muscle. 2018:9(7):1200-8.

10. Tieland M, Trouwborst I, Clark BC. Skeletal muscle performance and ageing. Journal of cachexia, sarcopenia and muscle. 2018:9(1):3-19.

11. Cereda E, Veronese N, Caccialanza R. The final word on nutritional screening and assessment in older persons. Current opinion in clinical nutrition and metabolic care. 2018;21(1):24-9

12. Clarkston WK, Pantano MM, Morley JE, Horowitz M, Littlefield JM, Burton FR. Evidence for the anorexia of aging: gastrointestinal transit and hunger in healthy elderly vs. young adults. Am J Physiol. 1997:272(1 Pt 2):R243-8.

13. Wurtman JJ, Lieberman H, Tsay R, Nader T, Chew B. Calorie and nutrient intakes of elderly and young subjects measured under identical conditions. J Gerontol. 1988;43(6):B174-80.

14. Morley JE. Anorexia of aging: physiologic and pathologic. Am J Clin Nutr. 1997:66(4):760-73.

15. Fielding RA, Vellas B, Evans WJ, Bhasin S, Morley JE, Newman AB, et al. Sarcopenia: an undiagnosed condition in older adults. Current consensus definition: prevalence, etiology, and consequences. International working group on sarcopenia. J Am Med Dir Assoc. 2011;12(4):249-56.

16. Daly LE, Prado CM, Ryan AM. A window beneath the skin: how computed tomography assessment of body composition can assist in the identification of hidden wasting conditions in oncology that profoundly impact outcomes. The Proceedings of the Nutrition Society. 2018:77(2):135-51.

17. Shyh-Chang N. Metabolic Changes During Cancer Cachexia Pathogenesis. Advances in experimental medicine and biology. 2017:1026:233-49.

18. Ryan AM, Power DG, Daly L, Cushen SJ, Ni Bhuachalla E, Prado CM. Cancer-associated malnutrition, cachexia and sarcopenia: the skeleton in the hospital closet 40 years later. The Proceedings of the Nutrition Society. 2016:75(2):199-211.

19. Giles K, Guan C, Jagoe TR, Mazurak V. Diet composition as a source of variation in experimental animal models of cancer cachexia. Journal of cachexia, sarcopenia and muscle. 2016:7(2):110-25.

20. Wheelwright SJ, Darlington AS, Hopkinson JB, Fitzsimmons D, White A, Johnson CD. A systematic review to establish health-related quality-of-life domains for intervention targets in cancer cachexia. BMJ supportive \& palliative care. 2016:6(3):307-14.

21. Liu $Q$, Jiang $H, X u D$, Jin J. Effect of gum chewing on ameliorating ileus following colorectal surgery: A meta-analysis of 18 randomized controlled trials. International journal of surgery. 2017:47:107-15

22. Vazquez-Sandoval A, Ghamande S, Surani S. Critically ill patients and gut motility: Are we addressing it? World journal of gastrointestinal pharmacology and therapeutics. 2017:8(3):174-9.

23. Rigaud D, Trostler N, Rozen R, Vallot T, Apfelbaum M. Gastric distension, hunger and energy intake after balloon implantation in severe obesity. Int J Obes Relat Metab Disord. 1995:19(7):489-95. 
24. Nieben OG, Harboe $\mathrm{H}$. Intragastric balloon as an artificial bezoar for treatment of obesity. Lancet. 1982;1(8265):198-9.

25. Phillips RJ, Powley TL. Tension and stretch receptors in gastrointestinal smooth muscle: re-evaluating vagal mechanoreceptor electrophysiology. Brain Res Brain Res Rev. 2000;34(1-2):1-26.

26. Sturm K, Parker B, Wishart J, Feinle-Bisset C, Jones KL, Chapman I, et al. Energy intake and appetite are related to antral area in healthy young and older subjects. Am J Clin Nutr. 2004;80(3):656-67.

27. http://patentscope.wipo.int/search/en/detail.jsf?docld=WO2013171252\&recNum=36\&maxRec=105995 \&office $=$ \&prevFilter $=\&$ sortOption=\&queryString=\&tab=PCTDescription. BCPMtFFlaFRIAf, inventor.

28. Liu J, LV X. The pharmacokinetics and pharmacodynamics of lidocaine- loaded biodegradable poly(lacticco-glycolic acid) microspheres. Int J Mol Sci. 2014;15(10):17469-77.

29. Maljaars PW. Symersky T, Kee BC. Haddeman E, Peters HP, Masclee AA. Effect of ileal fat perfusion on satiety and hormone release in healthy volunteers. Int J Obes (Lond). 2008:32(11):1633-9.

30. Maljaars PW, van der Wal RJ, Wiersma T, Peters HP. Haddeman E, Masclee AA. The effect of lipid droplet size on satiety and peptide secretion is intestinal site-specific. Clinical nutrition. 2012;31(4):535-42.

31. Maljaars PW. Peters HP. Mela DJ, Masclee AA. Ileal brake: a sensible food target for appetite control. A review. Physiol Behav. 2008:95(3):271-81.

32. Greeno CG, Wing RR. Stress-induced eating. Psychol Bull. 1994;115(3):444-64.

33. Ulrich-Lai YM, Fulton S, Wilson M, Petrovich G, Rinaman L. Stress exposure, food intake and emotional state. Stress. 2015;18(4):381-99.

34. Kistenmacher A, Goetsch J, Ullmann D, Wardzinski EK, Melchert UH, Jauch-Chara K, et al. Psychosocial stress promotes food intake and enhances the neuroenergetic level in men. Stress. 2018:1-10.

35. Man RY, Dresel PE. Effect of lidocaine and methyl lidocaine on cardiac conduction. The Journal of pharmacology and experimental therapeutics. 1977:201(1):184-91.

36. Rosen MR, Hoffman BF, Wit AL. Electrophysiology and pharmacology of cardiac arrhythmias. V. Cardiac antiarrhythmic effects of lidocaine. American heart journal. 1975;89(4):526-36.

37. Houghton D, Jones TW, Cassidy S, Siervo M, MacGowan GA, Trenell MI, et al. The effect of age on the relationship between cardiac and vascular function. Mech Ageing Dev. 2016;153:1-6.

38. Weusten BL, Lam HG, Akkermans LM, Van Berge-Henegouwen GP, Smout AJ. Influence of age on cerebral potentials evoked by oesophageal balloon distension in humans. Eur J Clin Invest. 1994:24(9): 627-31.

39. Gabella G. Fall in the number of myenteric neurons in aging guinea pigs. Gastroenterology. 1989;96(6): 1487-93.

40. Meciano Filho J, Carvalho VC, de Souza RR. Nerve cell loss in the myenteric plexus of the human esophagus in relation to age: a preliminary investigation. Gerontology. 1995:41(1):18-21. 


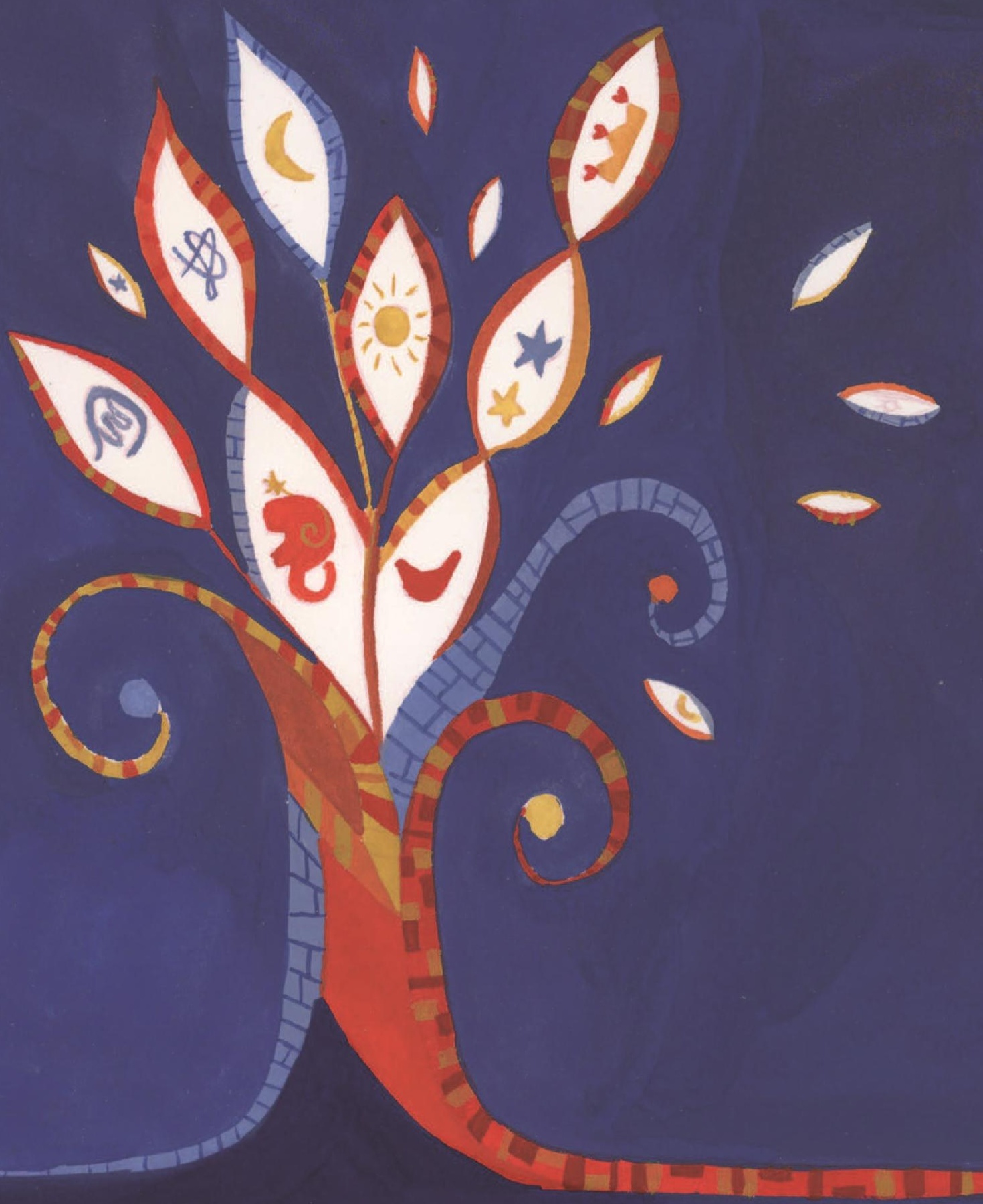




\section{CHAPTER 6}

Intraintestinal delivery of tastants using a nasoduodenal-illeal catheter does not influence

food intake or satiation

T. Klaassen, A.M.E. Alleleyn, M. van Avesaat, F.J. Troost, D. Keszthelyi, A.A.M. Masclee Nutrients 2019:11:472 


\section{Abstract}

Intraduodenal activity of taste receptors reduces food intake. Taste receptors are expressed throughout the entire gastrointestinal tract. Currently, there are no data available on the effects of distal taste receptor activation. In this study, we investigate the effect of intraduodenal and/or intraileal activation of taste receptors on food intake and satiation. In a single-blind randomised crossover trial, fourteen participants were intubated with a naso-duodenal-ileal catheter and received four infusion regimens: duodenal placebo and ileal placebo (DPIP), duodenal tastants and ileal placebo (DTIP), duodenal placebo and ileal tastants (DPIT), duodenal tastants and ileal tastants (DTIT). Fifteen minutes after cessation of infusion, subjects received an ad libitum meal to measure food intake. Visual analogue scale scores for satiation feelings were collected at regular intervals. No differences in food intake were observed between the various interventions (DPIP: $786.6 \pm 79.2 \mathrm{Kcal}$, DTIP: $803.3 \pm 69.0$ Kcal, DPIT: $814.7 \pm 77.3 \mathrm{Kcal}$, DTIT: $834.8 \pm 59.2 \mathrm{Kcal}, \mathrm{p}=0.59$ ). No differences in satiation feelings were observed. Intestinal infusion of tastants using a naso-duodenal-ileal catheter did not influence food intake or satiation feelings. Possibly, the burden of the four-day naso-duodenal-ileal intubation masked a small effect that tastants might have on food intake and satiation. 


\section{Introduction}

Obesity is considered a major healthcare problem with worldwide obesity almost being tripled since $1975 .{ }^{1}$ Therefore, there is an increasing need for non-invasive therapies for weight management. Gastrointestinal (GI) hormones, such as cholecystokinin (CCK) and glucagon-like peptide-1 (GLP-1), have been shown to reduce food intake and hunger after intravenous administration. ${ }^{2-4}$ Therefore, the Gltract is an interesting target for non-invasive therapies to reduce food intake and induce satiety/satiation.

Intestinal macronutrient infusion decreases food intake and induces the release of CCK, GLP-1, and peptide YY (PYY). ${ }^{5}$ This mechanism is commonly referred to as intestinal- or ileal brake. ${ }^{6.7} \mathrm{~A}$ recent review proposed a proximal to the distal gradient in the small intestine, where a more profound effect on food intake can be found after distal compared to proximal macronutrient infusion. ${ }^{8}$ Previous studies have demonstrated that besides macronutrients, substances referred to as tastants are able to activate certain taste receptors in the Gl-tract which are coupled to enteroendocrine cells (EEC) and can trigger the release of satiety hormones (i.e., CCK, GLP-1, and PYY) ${ }^{9-13}$ These taste receptors can be found throughout the entire GItract. Expression levels for the various taste receptor differ throughout the gut. Table 6.1 gives a simplified visual representation of the relative expression of taste receptors throughout the human gut based on current literature. ${ }^{14-17}$

In a recent study, van Avesaat et al. have shown that duodenal infusion of a combination of sweet, bitter, and umami tastants significantly decreased ad libitum meal intake, whilst increasing satiation and decreasing hunger feelings. These effects were not accompanied by changes in systemic levels of GLP-1, PYY, and CCK. ${ }^{18}$ Up to now, no data are available on the effect of activation of taste receptors in the more distal small intestine. Since one of the functions of taste receptors in the gut is to sense food being present in the lumen, it should be investigated whether the before mentioned proximal to distal gradient found for the intestinal brake is operative for taste receptor activation.

Therefore, in the present study, we compared the effects of intraduodenal infusion versus intraileal infusion of a combination of tastants (sweet, bitter, and umami) on ad libitum food intake, satiation, and Gl-complaints in healthy subjects. Since sweet and umami taste are sensed by various subtypes of the taste receptor family 1 (TAS1R) taste receptor family and bitter taste is sensed by the taste receptor family 2 (TAS2R), the combination will activate a wide range of taste receptors. We hypothesised that infusing tastants at both infusion sites (duodenum and ileum) will decrease food intake and increase satiation to the greatest extent when compared with infusion of 
placebo or single port infusion. Infusing in solely the duodenum or the ileum will also decrease food intake and increase satiation when compared to placebo, albeit to a lesser degree than infusing at both infusion sites simultaneously. Furthermore, we expect intraileal delivery of tastants will decrease food intake and increase satiation to a greater extent when compared with intraduodenal delivery of tastants.

Table 6.1 A simplified visual representation of the relative expression of taste receptors and gustducin throughout the human Gl-tract.

\begin{tabular}{|c|c|c|c|c|c|}
\hline & Stomach & Duodenum & Jejunum & Ileum & Colon \\
\hline $\begin{array}{c}\text { TAS1R1 } \\
\left(\text { Bezencon et } \text { al. }^{14}\right)\end{array}$ & ++ & + & ++ & + & $+/-$ \\
\hline $\begin{array}{c}\text { TAS1R2 } \\
\text { (Bezencon et al. }{ }^{14} \text { ) }\end{array}$ & - & ++ & + & $+/-$ & + \\
\hline $\begin{array}{c}\text { TAS1R2 } \\
\left(\text { Young et } a l^{15} \text { ) }\right.\end{array}$ & $--^{\$}$ & + & $++\#$ & $N / A$ & $N / A$ \\
\hline $\begin{array}{c}\text { TAS1R3 } \\
\text { (Bezencon et al. }{ }^{14} \text { ) }\end{array}$ & + & ++ & ++ & + & + \\
\hline $\begin{array}{c}\text { TAS1R3 } \\
\text { (van der Wielen et } \text { al. }^{16} \text { ) }\end{array}$ & $\mathrm{N} / \mathrm{A}$ & + & + & + & + \\
\hline $\begin{array}{c}\text { TAS1R3 } \\
\text { (Young et } a l^{15} \text { ) }\end{array}$ & $+\$$ & ++ & $++\#$ & $N / A$ & $N / A$ \\
\hline $\begin{array}{c}\text { TAS2R102-TAS2R144 } \\
\left.\text { (Gu et } a l^{17}{ }^{17}\right)\end{array}$ & $N / A$ & + & + & + & $N / A$ \\
\hline $\begin{array}{c}\text { Gustducin } \\
\text { (Bezencon et al. }{ }^{14} \text { ) }\end{array}$ & -- & ++ & ++ & + & - \\
\hline $\begin{array}{c}\text { Gustducin } \\
\text { (Young et } a l^{15} \text { ) }\end{array}$ & $-\$$ & + & ${ }_{++} \#$ & N/A & $N / A$ \\
\hline
\end{tabular}

Expression levels are relative to each other and a simplified visual representation with ++ indicating very high expression, + indicating high expression, +/ indicating medium expression, - indicating low expression, and -- indicating very low expression. \$ Young et al. displayed the stomach as fundus, body, and antrum. For details, please refer to Young et al. ${ }^{15}$ \# Young et al. displayed jejunum as proximal jejunum and distal jejunum. For details, please refer to Young et $a l^{15} \mathrm{~N} / \mathrm{A}$ : not available. ${ }^{*} \mathrm{~T} 2 \mathrm{R}$ family is expressed throughout the entire small intestine in a comparable fashion with some subtypes more abundant proximally and some distally. For details, please refer to Gu et al. ${ }^{17}$

\section{Materials and methods}

This study was approved by the Medical Ethics Committee of the Maastricht University Medical Centre+ (MUMC+), Maastricht, the Netherlands, and performed in full accordance with the Declaration of Helsinki (latest amendment by the World Medic Association in 2013) and Dutch Regulations on Medical Research Involving Human Subjects (WMO, 1998). This study was registered in the US National Library of Medicine (http://www.clinicaltrials.gov, ID NCT03140930). All subjects gave written informed consent before screening. 


\subsection{Subjects}

Healthy men and women were recruited by local advertisements. Inclusion criteria were age between 18 and 65 years, a body mass index (BMI) between 18 and $25 \mathrm{~kg} / \mathrm{m}^{2}$, with a stable weight over the past six months ( $<5 \%$ body weight change). Exclusion criteria were gastrointestinal complaints, history of chronic or severe disease, use of medication influencing endpoints within 14 days prior to testing, administration of investigational drugs which interfere with this study, major abdominal surgery, dieting, pregnancy or lactation, excessive alcohol consumption (>20 alcoholic consumptions per week), smoking, weight $<60 \mathrm{~kg}$, non-tasters of sweet, bitter or umami stimuli, evidence of monosodium glutamate (MSG)hypersensitivity.

Prior to testing, screening was performed where abovementioned inclusion and exclusion criteria were checked, and a taste perception test was performed. Subjects tasted quinine $(0.5 \mathrm{mmol} / \mathrm{L}$ ), Reb A (50 mmol/L), MSG (50 mmol/L), and tap water blindly and had to indicate their sense of taste. Subjects had to identify each taste correctly in order to be eligible for the study. Furthermore, their length and weight were measured to calculate their BMI.

A sample size calculation was based on the difference in meal intake between duodenal infusion of a combination of tastants and duodenal infusion of placebo as reported by van Avesaat et al. ${ }^{18}$ Using a difference in means of $64 \mathrm{Kcal}$, a standard deviation of difference of 63 , a power of $80 \%$, and an alpha of $1.67 \%$, a total number of 13 subjects were needed. An alpha of $1.67 \%$ was used to correct for multiple testing.

\subsection{Study design}

In this single-blind randomised, placebo-controlled crossover study, subjects received the combination of tastants (sweet, bitter, and umami) and/or placebo (tap water) in the duodenum and/or the ileum for four consecutive test days. This results in four combinations which were infused on the various test days: duodenal placebo and ileal placebo (DPIP), duodenal tastants and ileal placebo (DTIP), duodenal placebo and ileal tastants (DPIT), duodenal tastants and ileal tastants (DTIT).

\subsection{Catheter positioning}

A $305 \mathrm{~cm}$ long silicon 9-lumen (8-lumen, 1 balloon inflation channel, the outer diameter of $3.5 \mathrm{~mm}$ ) custom-made naso-ileal reusable catheter (Dentsleeve International, Mui Scientific, Mississauga, Canada) was used for intubation. 
One day prior to the first test day, subjects arrived at 7:40 AM at the Maastricht University Medical Centre+ (MUMC+) after an overnight fast. If preferred by the subject, local anaesthesia of nasal mucosa using xylocaine (10\% spray, AstraZeneca, Zoetermeer, the Netherlands) was applied. After placement of the catheter in the stomach, the catheter was guided through the pylorus and into the duodenum under intermittent fluoroscopic control. Progression of the catheter from duodenum to ileum was performed as described earlier. ${ }^{19}$ Fluoroscopy was used to check the positioning of the catheter on the first and the last test day. Radio-opaque markers were added to the infusion ports on the catheter, which accounted for the determination of the catheter position. On all test days, intestinal fluid was sampled from various infusion ports, and $\mathrm{pH}$ was measured using $\mathrm{pH}$ strips (MColorpHast ${ }^{\mathrm{TM}}$, Merck, Darmstadt, Germany) in order to estimate the catheter positioning.

\subsection{Preparation and infusion of tastants}

The combination of three tastants was infused in the duodenum, the ileum, or both the duodenum and the ileum. In order to prevent side effects from occurring, $75 \%$ of acceptable daily intake (ADI) of these tastants was infused. $540 \mathrm{mg}$ Rebaudioside A (Reb A, Stevija Natuurlijk, Drachten, the Netherlands), 75 mg Quinine (Arnold Suhr, Hilversum, the Netherlands), and $2 \mathrm{~g}$ Monosodium Glutamate (MSG, Ajinomoto, Hamburg, Germany) were dissolved in $120 \mathrm{~mL}$ tap water and was used as tastant mixture for infusion, as was done by van Avesaat et $a l^{18}$ All tastants used were noncaloric and yielded no nutritional value. The placebo infusion consisted of $120 \mathrm{~mL}$ of tap water. A magnetic stirrer was used to dissolve the tastants. The mixture was infused over a 60-min period with an infusion rate of $2 \mathrm{~mL} / \mathrm{min}$. This was consistent with the infusion rate of van Avesaat et al. mimicking the slow influx from the stomach to duodenum and slow transit through the gut in the ileum.

\subsection{Protocol}

On each test day, after an $8 \mathrm{~h}$ overnight fast, subjects arrived at 8:00 AM at the MUMC+. Subjects were instructed to consume the same habitual meal on the evening prior to testing. Hereafter, at $\mathrm{t}=0 \mathrm{~min}$, a standardised liquid breakfast meal $(250 \mathrm{~mL}$ Goedemorgen drinkontbijt (Vifit); energy $145 \mathrm{Kcal}$ per portion, $20.25 \mathrm{~g}$ carbohydrates, $8.5 \mathrm{~g}$ protein, and $2 \mathrm{~g}$ fat) was consumed. One hundred and fifty min (at t=150 min) after breakfast consumption, a syringe containing the mixture for infusion was connected to the duodenal and ileal infusion port. The infusion was performed in $60 \mathrm{~min}$ at an infusion rate of $2 \mathrm{ml} / \mathrm{min}$. Subjects received a standardised ad libitum lunch meal (Lasagne Bolognese (Plus supermarket); energy density per $100 \mathrm{~g}$ : 
$152 \mathrm{Kcal}, 11 \mathrm{~g}$ carbohydrates, $7.1 \mathrm{~g}$ protein, and $8.6 \mathrm{~g}$ fat) fifteen min (at t=225 min) after cessation of the infusion. The test meal was offered in excess and subjects were instructed to eat until they felt satiated.

\subsection{VAS for satiation and GI-complaints}

Feelings of satiation-/satiety and Gl-complaints (e.g., satiation, hunger, stomach pain, and nausea) were measured using visual analogue scales (VAS, 0-100 mm) scores at various time points $(t=-30,30,90,150,165,180,195,210$, and $240 \mathrm{~min}$ ) during the day. Subjects were asked to indicate on a line, anchored at the low end with the lowest intensity feelings, with opposing terms at the high end, which place on the scale best reflected their feeling at that moment. ${ }^{20}$

\subsection{Statistical analyses}

Data were analysed using IBM SPSS statistics 24 (IBM Corporation, Armonk, NY, USA). A visual check of the normality of the data was performed. The primary outcome of this study was the amount of food intake in Kcal during an ad libitum lunch meal. Secondary outcomes were VAS scores for satiation-/satiety feelings and GIsymptoms.

Age, BMI, and gender were calculated by descriptive statistics. Food intake in Kcal and area under the curve (AUC) for VAS scores were compared using a linear mixed model with intervention (DTIP, DPIT, and DTIT, and DPIP), test day and the interaction of intervention $\times$ test day as fixed factors. When no significant interaction was found, the interaction was removed from the model to get the best model fit.

For VAS scores, a linear mixed model that included abovementioned fixed factors with the addition of fixed factors time and time $\times$ treatment interaction was also performed.

Data are presented as mean \pm standard error of the mean (SEM) (unless specified otherwise), and a $p<0.05$ was considered statistically significant.

\section{Results}

\subsection{Subjects}

In total, 19 subjects met the inclusion and exclusion criteria. Two subjects dropped out due to discomfort induced by the naso-ileal catheter, two subjects dropped out due to incorrect position of the catheter on the first test day, and one subject was 
excluded after not properly following the instructions for the ad libitum meal on the first test day. Therefore, 14 healthy volunteers (11 female, age $25.6 \pm 10.5$ years, BMI 22.3 $\pm 1.7 \mathrm{~kg} / \mathrm{m}^{2}$ ) completed the study protocol and were included in the analyses.

\subsection{Food intake}

No intervention $\times$ test day interaction was found. No differences in ad libitum food intake in Kcal were observed after intraduodenal, intraileal or combined infusion of tastants versus placebo infusion (DPIP: $786.6 \pm 79.2 \mathrm{Kcal}$, DTIP: $803.3 \pm 69.0 \mathrm{Kcal}, \mathrm{DPIT}$ : $814.7 \pm 77.3 \mathrm{Kcal}$, DTIT: $834.8 \pm 59.2 \mathrm{Kcal} ; \mathrm{p}=0.59$ ) (Figure 6.1). Furthermore, as depicted in Figure 6.2, no trends in individual responses were found.

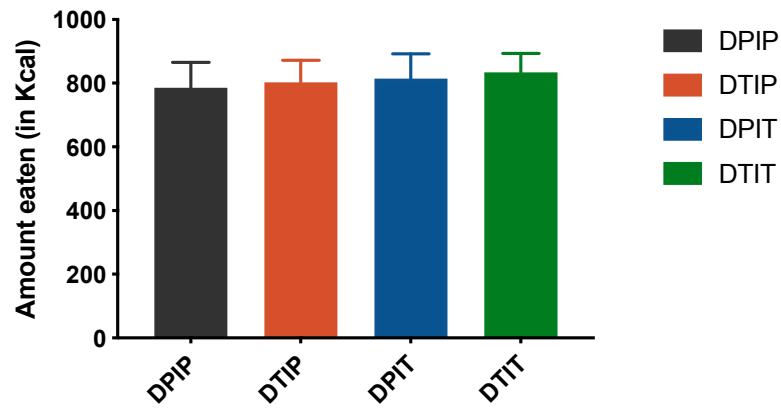

Figure 6.1 The amount eaten in Kcal (mean + SEM) 15 min after cessation of the infusion of placebo both intraduodenal and intraileal (DPIP), tastants intraduodenal and placebo intraileal (DTIP), placebo intraduodenal and tastants intraileal (DPIT), and tastants both intraduodenal and intraileal (DTIT). Based on a linear mixed model, no difference in food intake was observed between the conditions $(p=0.59)$.

\subsection{Satiation/Satiety scores}

The mean VAS scores for the desire to eat, hunger, satiation, and fullness are depicted in Figure 6.3. No differences in area under the curve $\left(A \cup C_{150-210}\right)$ for these VAS scores were observed between the various interventions. Furthermore, no intervention $\times$ time point interactions were found for these VAS scores. 


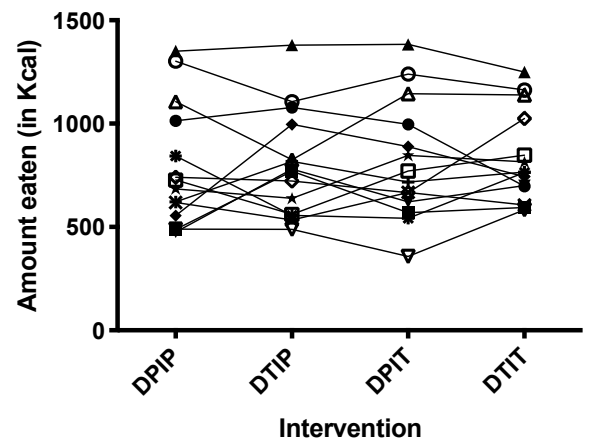

Figure 6.2 An individual representation per subject of amount eaten in Kcal 15 min after cessation of the infusion of placebo both intraduodenal and intraileal (DPIP), tastants intraduodenal and placebo intraileal (DTIP), placebo intraduodenal and tastants intraileal (DPIT), and tastants both intraduodenal and intraileal (DTIT). Treatment order was randomised for each subject. Each line with a unique symbol represents an individual subject. Based on a linear mixed model, no difference in food intake was observed between the conditions $(p=0.59)$.

A

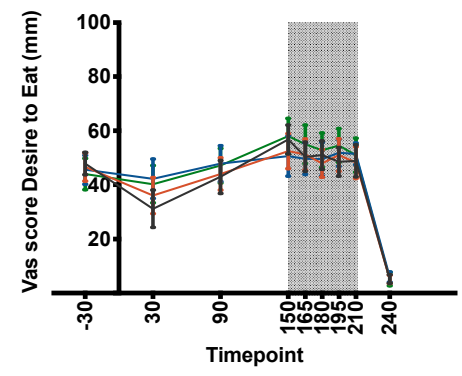

C

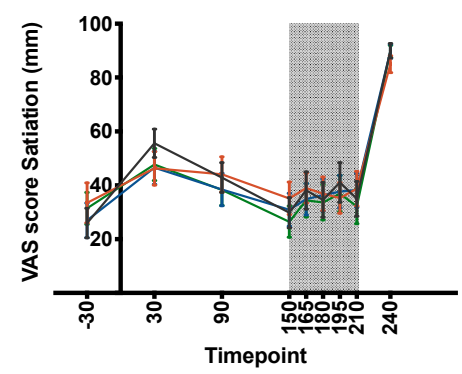

B
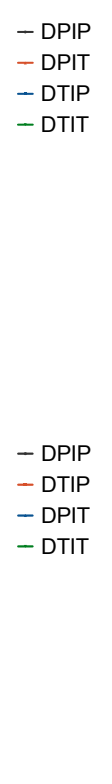

D
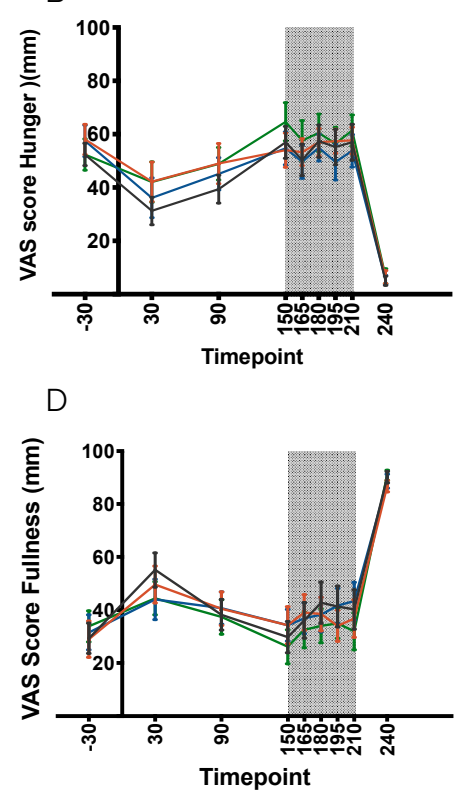

- DPIP
- DTIP
- DPIT
- DTIT

- DPIP

- DTIP

- DPIT

- DTIT

Figure 6.3 VAS scores for desire to eat (A), hunger (B), satiation (C), and fullness (D) (mean + SEM) before, during, and after the infusion of placebo both intraduodenal and intraileal (DPIP), tastants intraduodenal and placebo intraileal (DTIP), placebo intraduodenal and tastants intraileal (DPIT), and tastants both intraduodenal and intraileal (DTIT). VAS scores were measured at $t=-30,30,90$, $150,165,180,195,210$, and $240 \mathrm{~min}$. No VAS scores were taken at $\mathrm{t}=225 \mathrm{~min}$. At $\mathrm{t}=0 \mathrm{~min}$, subjects received a standardised breakfast, infusion of mixtures was performed from $t=150$ until $t=210$ min, and ad libitum test meal was presented at $\mathrm{t}=225$. Based on a linear mixed model of mean scores and area under the curve $\left(\mathrm{AUC}_{150-210}\right)$, no differences in desire to eat, hunger, satiation, and fullness were observed between the various conditions. 


\subsection{Gl-complaints}

The mean VAS scores for stomach pain, bloating, and nausea are depicted in Figure 6.4. No differences in area under the curve $\left(\mathrm{AUC}_{150-210}\right)$ for these VAS scores were observed between the various interventions. Furthermore, no intervention $\times$ time point interactions were found for these VAS scores.

A

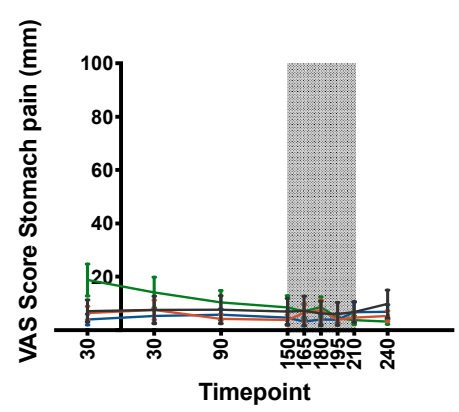

C

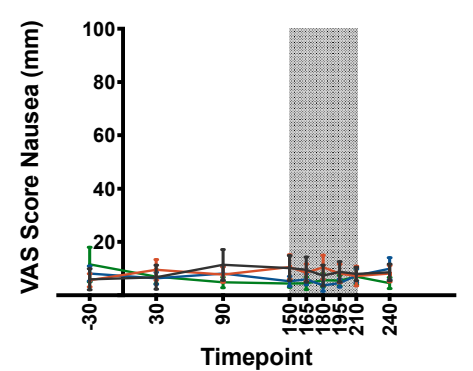

B
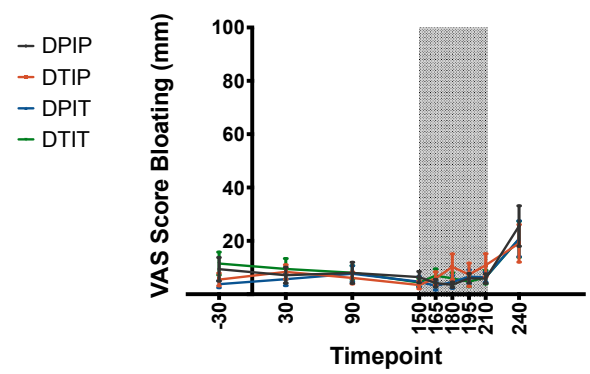

- DPIP

$-D T I P$

- DPIT

- DTIT

$$
\begin{aligned}
& \text { - DPIP } \\
& \text { - DTIP } \\
& \text { - DPIT } \\
& \text { - DTIT }
\end{aligned}
$$

Figure 6.4 VAS scores for stomach pain (A), bloating (B), and nausea (C) (mean + SEM) before, during, and after the infusion of placebo both intraduodenal and intraileal (DPIP), tastants intraduodenal and placebo intraileal (DTIP), placebo intraduodenal and tastants intraileal (DPIT), and tastants both intraduodenal and intraileal (DTIT). $t=-30,30,90,150,165,180,195,210$, and $240 \mathrm{~min}$. No VAS scores were taken at $\mathrm{t}=225 \mathrm{~min}$. At $\mathrm{t}=0 \mathrm{~min}$, subjects received a standardised breakfast, infusion of mixtures was performed from $\mathrm{t}=150$ until $\mathrm{t}=210 \mathrm{~min}$, and ad libitum test meal was presented at $t=225 \mathrm{~min}$. Based on a linear mixed model of mean scores and area under the curve $\left(A \cup C_{150}-210\right)$, no differences in stomach pain, bloating, and nausea were observed between the various conditions. 


\section{Discussion}

Our results do not reveal any difference in satiation or food intake between duodenal and ileal administration of placebo, duodenal administration of-, ileal administration of-, or combined duodenal and ileal administration of a tastant mixture (sweet, bitter, and umami). Moreover, no Gl-complaints were caused by infusing a tastant mixture or placebo into the duodenum and/or the ileum.

Van Avesaat et al. have investigated the effect of intraduodenal infusion of the same tastant mixture on food intake. ${ }^{18}$ In that study, intraduodenal infusion of this combination of tastants, in similar study design, using the same amount of tastants significantly reduced food intake by $64 \mathrm{Kcal}$ and was accompanied by changes in satiation/satiety feelings. However, it must be noted that this is a small difference, which on its own might not be clinically significant. Repeating this effect multiple times per day with each meal might result in a clinically significant decrease of caloric intake. This difference in results of food intake between the two studies may be related to differences in study design. In the study of van Avesaat et al., the subjects were intubated with a naso-duodenal catheter on every test day for the administration of tastants. The catheter was removed immediately thereafter before the subjects were presented with the ad libitum test meal. In the present study, subjects were intubated for several days with a naso-ileal catheter, and therefore this catheter was present while meals were offered and ingested. We hypothesise that having a naso-ileal catheter in situ for multiple days negatively influences meal ingestion to such a degree that this masks the smaller magnitude of effect that infusion of non-caloric tastants into the intestine has. On the other hand, mean caloric intake showed no major differences between the two studies.

Previous studies from our group investigating the 'intestinal brake' by infusing macronutrients in the ileum have repeatedly shown that infusion of even low doses of macronutrients results in a significant reduction of food intake, ranging between 64$188 \mathrm{Kcal}$, corresponding to a percentual decrease of $11.7 \%-32 \%$ of caloric intake during a single meal. ${ }^{521}$ This indicates a negative feedback mechanism on food intake that arises from nutrient sensing. These data demonstrate that magnitude of the effect of macronutrient infusion on food intake is greater than the effects of infusing tastants.

Conclusively, studies investigating differences in food intake should be aware that naso-ileal intubation might mask a small effect. Therefore, other delivery options, such as encapsulation, should be considered in the future.

Results of studies investigating the effects of single tastants on food intake, satiation/satiety, and Gl peptides are not consistent. An initial strong decrease of 
hunger with a steep increase thereafter has been observed after administration of a non-caloric sweetener. ${ }^{22}$ Ingestion of low caloric sweeteners did not influence energy intake compared with a control condition (intake of water). ${ }^{23}$ Adding an umami tastant to a meal did not affect appetite sensations but has been shown to result in an increase of subsequent food intake. ${ }^{24}$ Recently, increased attention has been given to the effects of bitter substances on satiation and food intake. Intake or infusion of bitter substances (quinine, denatonium benzoate) not only reduced antral motility ${ }^{25,26}$ but also increased satiation/satiety scores and resulted in a significant decrease in food intake. ${ }^{27}$ A possible mechanism explaining the strong aversive effects of bitter tastants is that bitter taste is evolutionarily linked to toxic substances, as has been showed by presenting new-born infants with bitter substances. ${ }^{28}$

Alleleyn et al. have shown that the inhibition of food intake shows a proximal to the distal gradient, with higher effects observed after distal versus proximal administration of nutrients. ${ }^{8}$ Based on our data, such a gradient was not observed for intestinally administered tastants. Intestinal taste receptor expression varies for various taste receptors, where some taste receptors are more profound proximally in the Gl-tract, while expression of other taste receptors is higher in the more distal intestine. $^{14-17}$

We thought the proximal to distal gradient found for macronutrient infusion might be operable for taste receptor activation, which was clearly not the case. It is possible that taste receptors inhibit food intake in a different fashion than macronutrients. For instance, it has been speculated that taste receptors function by sensing the type of food (i.e., sweet for carbohydrates, umami for amino acids, and bitter for toxic substances). ${ }^{29}$ Since bitter tastants are linked to toxic substances, another working mechanism for bitter tastants could be through an aversive reaction of subsequent food intake.

From an evolutionary perspective, a more pronounced inhibitory or aversive effect for toxic substances could be expected to occur in the most proximal parts of the Gl tract. However, there are no data available with respect to activation of oral (bitter) taste receptors on subsequent food intake. It is therefore unclear, whether activation of more proximal taste receptors will reveal more pronounced effects on food intake and satiation/satiety. Consequently, further studies are needed to investigate whether more proximal activation of taste receptors results in a stronger decrease in food intake.

Published data on the role of $\mathrm{Gl}$ peptides in the regulation of food intake after administration of tastants are not in line. Van Avesaat et al. found a clear effect of intraduodenal administration of tastants on food intake that was not accompanied by changes in GLP-1- or PYY level. ${ }^{18}$ Other studies, however, did show a decrease in 
systemic ghrelin- and motilin levels ${ }^{25,26}$ and an increase in systemic CCK levels ${ }^{27}$ after administration of a bitter tastant.

A limitation of our study is that the wash-out period consisted of only one day. Prolonging the wash-out period over one day would have resulted in a longer period of naso-ileal catheter intubation increasing the discomfort to our volunteers. No interaction effect between intervention and test day was found on food intake, satiation scores or Gl-complaints, indicating that no carry-over effect was present.

Another limitation of the present study was the absence of systemic Gl hormone measurements. This would have provided a complete analysis of the effects of intestinal tastant administration on eating behaviour. However, van Avesaat et al. showed a decrease in food intake and an increase in satiation scores, which was not accompanied by changes in systemic Gl hormone levels. ${ }^{18}$ Therefore, no systemic Gl hormone measurement was conducted in the present study.

It has to be noted that the ideal duration of administration of the intervention and of the timing between intervention and serving the ad libitum meal is unknown. We employed a design similar to that of van Avesaat et al. based on their positive results. ${ }^{18}$ Future research protocols should consider these factors.

Studies investigating the effects of tastants on food intake up to now focus on only acute effects in a single ad libitum meal. It is not known whether repetitive or chronic administration of tastants will lead to other results. More data are needed on the longterm effects of tastants, especially on daily energy intake. 


\section{References}

1. WHO. Obesity and Overweight 2018. Available online: http://www.who.int/en/news-room/fact-sheets/ detail/obesity-and-overweight (accessed on 3 August 2018).

2. Lieverse RJ, Jansen JB, Masclee AA, Lamers CB. Satiety effects of a physiological dose of cholecystokinin in humans. Gut. 1995:36:176-9.

3. Lieverse RJ, Jansen JB, van de Zwan A, Samson L, Masclee AA, Lamers CB. Effects of a physiological dose of cholecystokinin on food intake and postprandial satiation in man. Regul Pept. 1993:43:83-9.

4. Verdich C, Flint A, Gutzwiller JP, Naslund E, Beglinger C, Hellstrom PM, et al. A meta-analysis of the effect of glucagon-like peptide-1 (7-36) amide on ad libitum energy intake in humans. J Clin Endocrinol Metab. 2001:86:4382-9.

5. van Avesaat M, Troost FJ, Ripken D, Hendriks HF, Masclee AA. Ileal brake activation: Macronutrientspecific effects on eating behavior? Int J Obes. 2015:39:235-43.

6. Maljaars PW, Peters HP, Mela DJ, Masclee AA. Ileal brake: A sensible food target for appetite control. A review. Physiol Behav. 2008:95:271-81.

7. Shin HS, Ingram JR, McGill AT, Poppitt S. Lipids, CHOs, proteins: Can all macronutrients put a 'brake' on eating? Physiol Behav. 2013:120:114-23.

8. Alleleyn AM, van Avesaat M. Troost FJ, Masclee AA. Gastrointestinal Nutrient Infusion Site and Eating Behavior: Evidence for A Proximal to Distal Gradient within the Small Intestine? Nutrients. 2016:8:117.

9. Sternini C, Anselmi L, Rozengurt E. Enteroendocrine cells: A site of 'taste' in gastrointestinal chemosensing. Curr Opin Endocrinol Diabetes Obes. 2008:15:73-8.

10. Jang HJ, Kokrashvili Z, Theodorakis MJ, Carlson OD, Kim BJ, Zhou J, et al. Gut-expressed gustducin and taste receptors regulate secretion of glucagon-like peptide-1. Proc Natl Acad Sci USA. 2007:104: 15069-74.

11. Rozengurt N, Wu SV, Chen MC, Huang C, Sternini C, Rozengurt E. Colocalization of the alpha-subunit of gustducin with PYY and GLP-1 in L cells of human colon. Am J Physiol Gastrointest Liver Physiol. 2006;291:G792-G802.

12. Sutherland K, Young RL, Cooper NJ. Horowitz M, Blackshaw LA. Phenotypic characterization of taste cells of the mouse small intestine. Am J Physiol Gastrointest Liver Physiol. 2007:292:G1420-8.

13. Wu SV, Rozengurt N, Yang M, Young SH, Sinnett-Smith J, Rozengurt E. Expression of bitter taste receptors of the T2R family in the gastrointestinal tract and enteroendocrine STC-1 cells. Proc Natl Acad Sci USA. 2002:99:2392-7.

14. Bezencon C, le Coutre J, Damak S. Taste-signaling proteins are coexpressed in solitary intestinal epithelial cells. Chem Senses. 2007:32:41-9.

15. Young RL, Sutherland K, Pezos N, Brierley SM, Horowitz M, Rayner CK, et al. Expression of taste molecules in the upper gastrointestinal tract in humans with and without type 2 diabetes. Gut. 2009:58:337-46.

16. van der Wielen N, van Avesaat M, de Wit NJ, Vogels JT, Troost F, Masclee A, et al. Cross-species comparison of genes related to nutrient sensing mechanisms expressed along the intestine. PLoS One. 2014l9: e107531.

17. Gu F, Liu X, Liang J, Chen JY, Chen FX, Li F. Bitter taste receptor mTas2r105 is expressed in small intestinal villus and crypts. Biochem Biophys Res Commun. 2015; 463: 934-41.

18. van Avesaat M. Troost FJ, Ripken D, Peters J. Hendriks HF, Masclee AA. Intraduodenal infusion of a combination of tastants decreases food intake in humans. Am J Clin Nutr. 2015;102:729-35.

19. Maljaars PW, Symersky T, Kee BC, Haddeman E, Peters HP, Masclee AA. Effect of ileal fat perfusion on satiety and hormone release in healthy volunteers. Int J Obes. 2008; 32:1633-9.

20. Parker BA, Sturm K, Maclntosh CG. Feinle C. Horowitz M, Chapman IM. Relation between food intake and visual analogue scale ratings of appetite and other sensations in healthy older and young subjects. Eur J Clin Nutr.2004:58:212-8

21. van Avesaat M, Ripken D, Hendriks HF, Masclee AA, Troost FJ. Small intestinal protein infusion in humans: Evidence for a location-specific gradient in intestinal feedback on food intake and Gl peptide release. Int J Obes. 2017:41:217-24.

22. Meyer-Gerspach AC, Biesiekierski JR, Deloose E, Clevers E, Rotondo A, Rehfeld JF, et al. Effects of caloric and noncaloric sweeteners on antroduodenal motility, gastrointestinal hormone secretion and appetiterelated sensations in healthy subjects. Am J Clin Nutr. 2018;107:707-16.

23. Fantino M, Fantino A, Matray M. Mistretta F. Beverages containing low energy sweeteners do not differ from water in their effects on appetite, energy intake and food choices in healthy, non-obese French adults. Appetite. 2018;125:557-65.

24. Luscombe-Marsh ND, Smeets AJ, Westerterp-Plantenga MS. The addition of monosodium glutamate and inosine monophosphate- 5 to high-protein meals: Effects on satiety, and energy and macronutrient intakes. Br J Nutr/ 2009;102:929-37.

25. Deloose E, Corsetti M, Van Oudenhove L, Depoortere I, Tack J. Intragastric infusion of the bitter tastant quinine suppresses hormone release and antral motility during the fasting state in healthy female volunteers. Neurogastroent Motil. 2018:30(1). 
26. Deloose $E$, Janssen $P$, Corsetti M, Biesiekierski J, Masuy I, Rotondo A, et al. Intragastric infusion of denatonium benzoate attenuates interdigestive gastric motility and hunger scores in healthy female volunteers. Am J Clin Nutr. 2017:105: 580-8.

27. Andreozzi P, Sarnelli G, Pesce M, Zito FP, Alessandro AD, Verlezza V, et al. The Bitter Taste Receptor Agonist Quinine Reduces Calorie Intake and Increases the Postprandial Release of Cholecystokinin in Healthy Subjects. J Neurogastroenterol Motil. 2015:21:511-9.

28. Steiner JE, Glaser D. Hawilo ME, Berridge KC. Comparative expression of hedonic impact: Affective reactions to taste by human infants and other primates. Neurosci Biobehav Rev. 2001;25:53-74.

29. Breslin PA, Spector AC. Mammalian taste perception. Curr Biol. 2008;18:R148-55. 


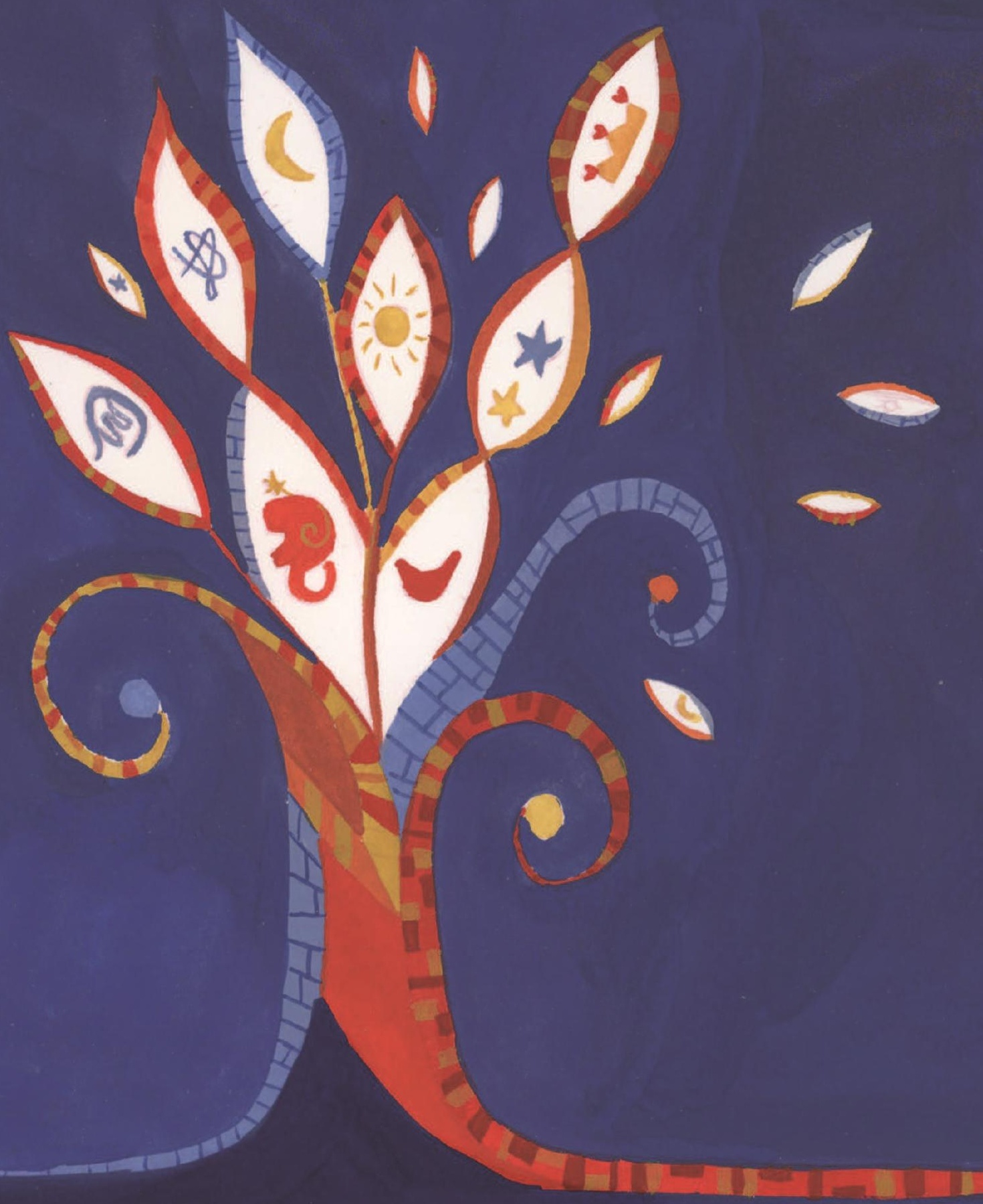




\title{
CHAPTER
}

\author{
Evidence for the role of impaired mucosal \\ integrity in the generation of esophageal pain \\ using capsaicin in humans
}

A.M.E. Alleleyn, D. Keszthelyi, N.F. Rinsma, K. Csekö, B. Kajtár, Z. Helyes, B. Winkens, A.A.M. Masclee, J.M. Conchillo 


\section{Abstract}

\section{Objectives}

Esophageal pain is mediated by sensory nerves, most importantly via the activation of the Transient Receptor Potential Vanilloid 1 (TRPV1) capsaicin receptor. TRPV1 is activated and sensitized by a broad range of pungent compounds, as well as inflammatory mediators and tissue irritants. Luminal stressors are suggested to impair the barrier function, which results in consequent activation of these sensory nerve terminals and pain. Here we investigated the role of esophageal TRPV1 activation by capsaicin perfusion on mucosal barrier integrity and pain in healthy humans.

\section{Methods}

Thirteen volunteers completed a single blind, saline-controlled, randomized crossover study. Capsaicin or saline was perfused for $30 \mathrm{~min}$ in the distal oesophagus. Visual Analogue Scale (VAS) pain intensity scores and intraluminal impedance indicating mucosal integrity were determined. Distal and proximal biopsies were obtained 10 min later to measure TRPV1 mRNA and immunopositivity, as well as the intercellular space width.

\section{Results}

Capsaicin perfusion resulted in significantly greater pain intensity $(p=0.047)$ and impaired recovery of the baseline impedance compared to saline-treated controls $(p=0.027)$. Pain response was significantly associated with decreased baseline impedance. Similar dynamics were seen in the proximal esophagus, but baseline impedance recovered entirely to the pre-infusion values there. There was a significant association between baseline impedance and intercellular space width in the distal esophagus. TRPV1 transcription and expression were not significantly altered within this observation period.

\section{Conclusions}

Esophageal TRPV1 activation results in pain, which is likely to be explained by an impaired mucosal barrier and the defective restoration capacity in the distal esophagus. 


\section{Introduction}

Gastroesophageal reflux disease (GERD) is a highly prevalent disorder characterized by reflux of gastric contents that cause pain symptoms. ${ }^{1}$ In patients with erosive esophagitis, macroscopic disruption of the mucosa is apparent. However, in a substantial proportion of patients with reflux symptoms, there is no evidence of macroscopic damage of the mucosa and symptoms can therefore be attributed to non-erosive gastroesophageal reflux disease (NERD). ${ }^{2}$ Several studies have identified subtle mucosal injury at microscopic level in these patients. ${ }^{3.4}$ It is hypothesized that this disruption of the esophageal mucosal barrier is an important factor in the generation of reflux symptoms in NERD by facilitating excitation of mucosal neural afferents responsible for pain signaling.

The question however arises whether such mechanism is primarily related to impaired mucosal integrity or rather increased sensitivity of afferents in an otherwise intact mucosa. In order to understand these mechanisms, baseline impedance has been introduced to determine esophageal mucosal integrity. ${ }^{5}$ Another tool to investigate the mucosal barrier is the evaluation of dilated intercellular spaces (DIS). The presence of DIS within the squamous epithelium is believed to be a marker for esophageal mucosal barrier damage. ${ }^{6}$

For the investigation of sensory nerve function, previous studies have focused on molecules responsible for nociceptive signalling. Transient Receptor Potential (TRP) cation channels, particularly the Vanilloid 1 (TRPV1) capsaicin receptor, play an important role in nociceptive signaling of somatic and visceral pain. Capsaicin perfusion in the esophagus leads to the sensation of heartburn. ${ }^{7}$ TRPV1 expression was shown to be upregulated in the esophageal mucosa of NERD patients. ${ }^{8,9}$ In a mouse NERD model, TRPV1 overexpression and impaired mucosal integrity were detected in comparison with control animals. ${ }^{10}$ In addition, proximity of sensory afferents to the lumen is also believed to contribute to increased hypersensitivity in NERD. ${ }^{11}$ These results suggest that an impairment of the mucosal barrier results in an increased exposure of the sensory nerve endings to the refluxate and consequently pain generation via TRPV1 receptor activation.

Several studies have shown that the threshold for induction of symptoms in GERD patients and controls is lower in the proximal compared to the distal part of the esophagus. $^{12-15}$ Woodland et al. observed that nerve endings in the proximal esophageal mucosa are closer to the proximity of the lumen compared to the distal esophagus. ${ }^{16}$ The proximal to distal gradient in afferent sensitity of the esophagus may reflect an important biological and homeostatic function. 
There were 3 main aims of the present study performed in healthy volunteers: 1) to test the hypothesis that exposure of the esophageal mucosa to the TRPV1 agonist capsaicin results in an impairment of the mucosal barrier function, measured by baseline impedance and DIS in the 'exposed' distal segment of the esophagus; 2) to assess these effects in the 'non-exposed' proximal segment of the esophagus; 3) to study the relation between symptom perception, mucosal integrity and TRPV1 expression.

\section{Materials and methods}

The study was approved by the Medical Ethics Committee of Maastricht University Medical Center+ and was conducted in full accordance with the principles of the Declaration of Helsinki of 1975 as amended in 2013, and with the Dutch Regulations on Medical Research involving Human Subjects (1998). All volunteers gave written informed consent before participation. This trial was registered at www.clinicaltrials.gov as NCT02603783.

\subsection{Subjects}

Subjects between 18 and 65 years with a body mass index (BMI) between 18 and $25 \mathrm{~kg} / \mathrm{m}^{2}$ were enrolled in this study. Subjects were recruited by local advertisements. Subjects were excluded if they: 1) had any history of gastrointestinal diseases including esophageal motility disorders, reflux disease or any previous esophageal or gastric surgery; 2) intake of more than 14 alcoholic consumptions per week or smoking; 3) regularly use of capsaicin-containing foods (>1 per week); 4) known allergy to capsaicin. Informed consent was obtained after an interval of at least 7 days.

\subsection{Experimental design}

Participants underwent esophageal perfusion of capsaicin and physiological saline (control) in a randomized order with a minimal wash-out period of 10 days in between the two test days. Only the participant was blinded for the type of solution perfused. Therefore, the researcher was able to stop the infusion of capsaicin when the participant experienced maximun pain scores. Randomization occurred using randomizer.org. Participants were requested to arrive at $9.00 \mathrm{am}$ after an overnight fast at the motility lab of the Gastroenterology-Hepatology department of the Maastricht University Medical Centre+. First, esophageal manometry was performed 
to locate the proximal margin of the lower esophageal sphincter (LES). A single lumen naso-esophageal infusion catheter G-84300 (Medical Measurement Systems, Enschede, The Netherlands) was placed $12 \mathrm{~cm}$ proximal to the upper margin of the LES and connected to an infusion pump (Perfusor Space Infusion Pump System, B. Braun, Melsungen, Germany). Impedance measurements were performed using a combined $\mathrm{pH}$-impedance catheter assembly that consisted of six impedance segments located at 3, 5, 7, 9, 15 and $17 \mathrm{~cm}$ above the upper border of the LES and one ISFET pH electrode (Unisensor AG, Attikon, Switzerland). The $\mathrm{pH}$ electrode was positioned $5 \mathrm{~cm}$ above the upper margin of the LES. Baseline impedance and $\mathrm{pH}$ signals were stored on a digital data logger (Ohmega, Medical Measurement Systems, Enschede, The Netherlands), using a sampling frequency of $50 \mathrm{~Hz}$. The position of which the baseline impedance was measured in the more proximal esophagus was at $15 \mathrm{~cm}$ above the upper border of the LES. The distal esophagus was considered at $5 \mathrm{~cm}$ above the upper border of the LES. ${ }^{17}$

After positioning of the catheters, the subjects were instructed to stay in a semirecumbent position. Prior to the start of the perfusion, esophageal impedance was recorded for $20 \mathrm{~min}$ under basal conditions. Perfusions were performed at an rate of $2.5 \mathrm{~mL} / \mathrm{min}$ for $30 \mathrm{~min}$ or until participants experience maximum tolerable discomfort (a single Visual Analogue Scale (VAS) score of $100 \mathrm{~mm}$ or two subsequent VAS scores of $\geq 80 \mathrm{~mm}$ ). After esophageal perfusion was ended, recording of impedance was continued for $10 \mathrm{~min}$. Directly after the removal of both catheters, a standard gastroscopy was performed by an experienced gastroenterologist (JC) to obtain eight esophageal biopsies (4 distal at 3-5 cm above LES and 4 proximal $15-17 \mathrm{~cm}$ above LES) specimens. Timeline of the test day is visualized in Figure 7.1.

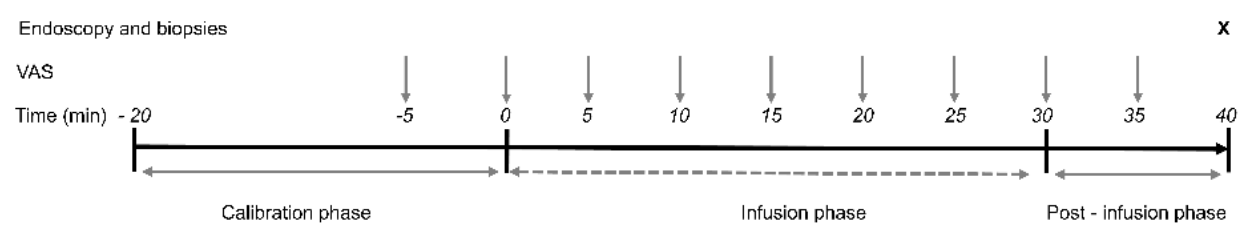

Figure 7.1 Timeline of the test day. Infusion of capsaicin solution or $\mathrm{NaCl}$ started at $\mathrm{t}=\mathrm{O}$ min after an overnight fast. $10 \mathrm{~min}$ after the end of the perfusion an endoscopy was performed to obtain biopsies from the esophageal mucosa. VAS scores for retrosternal pain and heartburn were collected at regular intervals as indicated. Baseline impedance was measured according to the following protocol; 20 min before (calibration phase), 30 min during perfusion and 10 min after the end of the perfusion (see Figure 7.1). VAS; visual analogue scale. 


\subsection{Solutions}

The total amount of capsaicin administered in this study was $1.5 \mathrm{mg}$ in $75 \mathrm{~mL}$ solution (Capsaicine Oleoresina 8.3\% capsaicin, Tiofarma BV, Oud Beijerland, the Netherlands). This dose is equivalent to the allowed maximum daily intake according to the Scientific Committee on Food of the European Commission ${ }^{18}$ and has been used by our group in previous studies for duodenal stimulation. ${ }^{19}$ In brief, first, 24 milligrams of Capsicum Oleoresin was dissolved in $1 \mathrm{~mL}$ 96\% ethanol (Brouwland bvba) and diluted with saline to $100 \mathrm{~mL}$ (Fresenius Kabi). Of this solution, $75 \mathrm{~mL}$ was infused. The $\mathrm{pH}$ of the capsaicin solution was 5.5. A total $75 \mathrm{ml}$ of physiological saline (Braun Melsungen AG, Germany) ( $\mathrm{pH}$ 6.2) was used as control solution, similar to previous studies investigating esophageal mucosal integrity. ${ }^{5,17}$

\subsection{Baseline impedance measurements}

Baseline impedance was measured according to the following protocol; 20 min before (calibration phase), 30 min during perfusion and 10 min after the end of the perfusion (see Figure 7.1). Following the positioning the catheters a 10 min acclimatization period was allowed, thereafter registration was started. We calculated the mean impedance value over a 10 min period before the start of the perfusion. The impedance recovery after perfusion was calculated as follows; we included the mean impedance during the period between the third and the fifth minute after cessation of perfusion. The baseline impedance in the first two min after the cessation of the perfusion was not included in the analysis in order to allow for complete capsaicin/saline bolus clearance from the distal esophagus. We excluded all reflux events and belching events from this calculation.

The analysis of impedance changes before, during and after the perfusion was performed by one of the investigators (JC) with extensive experience in the interpretation of these impedance measurements who was blind to the treatment order.

\subsection{VAS scores for heartburn and retrosternal pain}

All participants scored the intensity of heartburn and retrosternal pain, measured using VAS scores $(0-100 \mathrm{~mm}$ ) anchored at the low end with the most positive or lowest intensity feelings (extremely pleasant, not at all) and with the opposing terms at the high end (extremely unpleasant, very high, extreme). ${ }^{20}$ The VAS scores were collected at $\mathrm{t}=-5,0,5,10,15,20,25,30$ and $35 \mathrm{~min}$. 


\subsection{TRPV1 immunohistochemistry and scoring}

$4 \mu \mathrm{m}$ sections from paraffin embedded esophagus biopsy blocks were stained with a 1:100 dilution of guinea pig polyclonal anti-TRPV1 (GP14100, Neuromics, Edina, MN, USA) primary antibodies. Slides were incubated VECTASTAIN ${ }$ ABC-Peroxidase KitGuinea Pig lgG (PK-4007, BioMarker Ltd., Budapest, Hungary). The reaction was visualized by $0.01 \%$ hydrogen peroxide containing 3.3-diaminobenzidine tetrachloride, histological counterstaining was performed with hematoxylin. ${ }^{21}$ TRPV1 immunopositivity was quantified by the individual assessment of 100 cells on each slide scored between 0 - 3 ( 0 - negative, 1 - minimal positivity, 2- moderate, 3- strong positivity), performed by an experienced pathologist who was blind to the treatment order (BK). A histological $\mathrm{H}$-score was determined by the sum of the scores of the individual cells on each slide (ranging between 0-300). Incubating esophagus mucosa with Tris-buffered saline instead of the primary antibodies served as the negative control, while sections of human dorsal root ganglia expressing TRPV1 abundantly were used as positive controls. The antibody specificity has been validated by preabsorption of the respective blocking peptide (P14100 Neuromics, Edina, MN, USA) as described previously. ${ }^{22}$

\subsection{Trpv1 mRNA analysis}

Sample homogenization was performed in $1 \mathrm{~mL}$ TRI Reagent (Molecular ResearchCentre Inc., Cincinatti, OH, USA) and total RNA was isolated with Direct-Zol RNA MiniPrep isolation kit (Zymo Research, Irvine, CA) following the manufacturer's protocol. Samples were then measured by NanoDrop ND-1000 spectrophotometer (NanoDrop Technologies Inc., Wilmington, DE) to assess RNA quantity and purity. After treatment with deoxyribonuclease I enzyme (Zymo Research, Irvine,CA) total RNA (100 ng) was reverse transcribed with Maxima First Strand cDNA Synthesis Kit (Thermo Fisher Scientific, Waltham, MA) according to the manufacturer's instructions. To amplify trancripts real-time qPCR was performed on a Stratagene M×3000P qPCRSystem (Agilent Technologies, Santa Clara, CA) using Luminaris HiGreen LowROX qPCR Master Mix (Thermo Fisher Scientific) (Bohonyi et al, 2017). The following primer pairs were used to amplify the genes of interest: Trpv1 (NM_080706.3) (sense): 5'-CAGCTCAATTGCTGTGCAGGTTA-3' and (antisense): 5'-TGCCAGTATGGATGGAGTGGAA-3'. All reactions were measured in triplicates and the geometric mean of their $\mathrm{Ct}$ values were calculated which was normalized to transcripts of the glyceraldehyde 3-phosphate dehydrogenase (Gapdh) (NM_001289746.1) (sense): 5'- CCTGCACCACCAACTGCTTA -3' and (antisense): 5'TAGAGGCAGGGATGATGTTCTG-3', used as reference gene. Primers with similar 
efficiencies were used and melt curve analyses were performed to verify primer specificity. The determination of relative messenger RNA (mRNA) expression levels was performed according to the comparative DCt method. Analyses were performed by an investigator (KC) blind to the treatment order.

\subsection{Transmission electron microscopy}

A single esophageal biopsy was directly immersed in 3\% glutaraldehyde fixative buffered in $0.09 \mathrm{M} \mathrm{KH} 2 \mathrm{PO}_{4}$ at $\mathrm{pH} 7.4$ at room temperature. After a minimum of 24 hours of immersion, samples were then washed in $0.09 \mathrm{M} \mathrm{KH} 2 \mathrm{PO}_{4}$ buffer with $7.5 \%$ sucrose and transferred to a $1 \% \mathrm{OsO}_{4}+1.5 \%$ ferrocyanide solution and buffered to $\mathrm{pH}$ 7.4 with $0.1 \mathrm{M}$ veronalacetate for subsequent post-fixation for $1 \mathrm{~h}$ at $4^{\circ} \mathrm{C}$. After washing in phosphate veronalacetate buffer containing $7 \%$ sucrose at $\mathrm{pH} 7.4$, dehydration was carried out rapidly in graded ethanol series followed by embedding in Epon. Ultrathin tissue sections were cut and examined with a Philips CM 100 electron microscope. Of each biopsy specimen 3-5 TEM photographs were taken. TEM photographs were obtained from the basal and suprabasal layers of the epithelium at $\times 4000$ magnification by an independent researcher, who was experienced in the recognition of the different layers of the epithelium and blinded for the status of the subject.

\subsection{Intercellular space width}

Intercellular space area (ISA) was evaluated in 3 representative TEM photographs per subject. For the assessment, based on the division of the area by the corresponding length (an estimation of the perimeter of the cell), first a single line was drawn through the intercellular space around 2-3 cells in the microphotograph. The researcher was blinded for the treatment order. Multiple lines were drawn which were optically the most suitable for calculation of cellular space. A region of interest (ROI) around this line was defined to include the intercellular space between the two cells, without inclusion of intracellular content. The software allowed us to customize a ROI of different $\mu \mathrm{m}$ in each case. Then, the pixel threshold was chosen to include only pixels from the intercellular space. Pixels considered for the analysis were visualized in yellow. Based on this threshold, the area around the line included in the $\mathrm{ROI}$ was automatically calculated and divided by the length of this line using custom-written image analysis software in IGOR Pro (WaveMetrics Inc., Oregon, USA). Per subject, the average of the area of different regions of interest from the 3 TEM photographs was used for the analysis (Figure 7.2). 
A

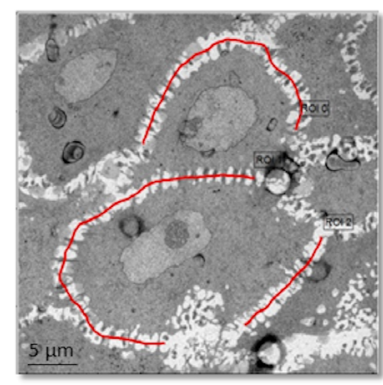

B

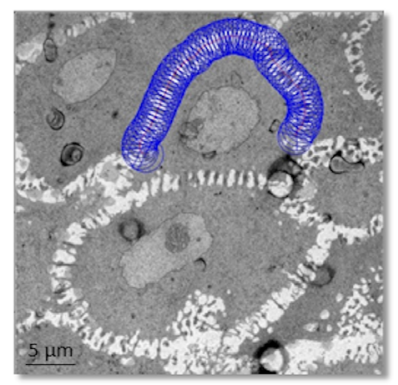

C

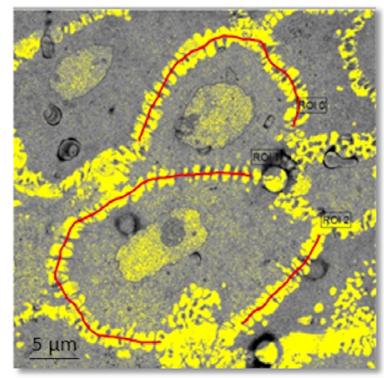

Figure 7.2 Illustrative image of assessment of intracellular space area (ISA). A) Multiple lines (red) are drawn through the intercellular space. Crossings where intercellular spaces merge are not included. B) A region of interest is marked around the lines to cover the selected intercellular space. C) Based on the pixel threshold, the intercellular space area is then calculated and divided by its corresponding length.

\subsection{Statistical analyses}

Statistical analyses were performed with SPSS, version 25.0 (SPSS Inc., Armonk NY, USA).

A linear mixed model was performed to analyze the baseline impedance in the proximal and distal esophagus separately and VAS scores and the relation between these two variables. For the baseline impedance and VAS scores for heartburn and retrosternal pain, a three way interaction between intervention (capsaicin or control), time (pre, post or $-5,0,5,10,15,20,25,30,35 \mathrm{~min}$ ) and test day (1 and 2) with all lower terms were included in the model to check whether the intervention effect over time depends on test day. In case the interaction was not significant, this interaction term was removed from the model and the intervention effect at each time-point was reported for both test days combined. For baseline impedance, solely the time points pre (between -10 and 0 min) and post infusion (between +32 and +35 min) were included in the model in order to ignore the effect of the fluid perfusion and bolus clearance on baseline impedance. A random intercept and/or slope (time) were included and different covariance structures (unstructured and variance components) were considered for these random effects, where the final model was chosen based on Akaike's information criterion (AIC).

For both locations separately, TRPV1 expression, transcription, and intercellular space area were analyzed with a linear mixed model which included a two way interaction between treatment and test day. In case the two way interaction was non significant, the intervention effect was reported for the two test days combined. 
Data are presented as means \pm (SEM) unless specified otherwise. P-value $\leq 0.05$ was considered as statistically significant.

\subsection{Sample size calculation}

Data for executing this sample size calculation were retrieved from Farre et al. with the following parameters for mucosal integrity: alpha ()$=0.05$, power $=0.80$, mean difference=716 Ohm (control vs. esophageal acid perfusion=2960 Ohm vs. 2244 Ohm), standard deviation ()=690..$^{5}$ According to this sample size calculation, we needed to include 14 healthy volunteers to be able to reject the null hypothesis that the capsaicin infusion has a similar effect as control solution on baseline impedance with a probability (power) of 0.80 . With regards to dropouts, we were able to include up to 15 healthy volunteers.

\section{Results}

Fifteen volunteers were included in this study. Two participants dropped out after screening and randomization; 1 volunteer was not able to schedule the test days and 1 volunteer became ill due to reasons unrelated to the study and discontinued study participation. 13 volunteers were included in the study analysis ( 4 males; mean $\pm \mathrm{SD}$ age: $27.6 \pm 14.3$ years, BMI $22.5 \pm 1.3 \mathrm{~kg} / \mathrm{m}^{2}$ ) for analysis of baseline impedance. This included one study participant who only completed one test day (saline condition) and dropped out prior to the second test day. As for the analysis of TRPV1 immunohistochemistry and mRNA expression, only samples from participants who completed both test days were included ( $n=12$ ). Similarly, for DIS analysis, each group contained 12 samples, except for the proximal biopsies in the saline group, which included 11 samples due to fixation artefacts.

\subsection{Effects in the distal esophagus}

Perfusion of capsaicin into the distal esophagus resulted in significantly higher scores for heartburn (overall $p$-value 0.004) and retrosternal pain (overall $p$-value 0.047) over time (Figure 7.3). Notably, both pain and retrosternal pain persisted after cessation of capsaicin during the timeframe of the experiment. 


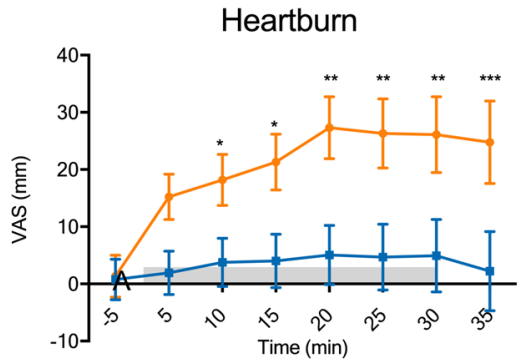

A

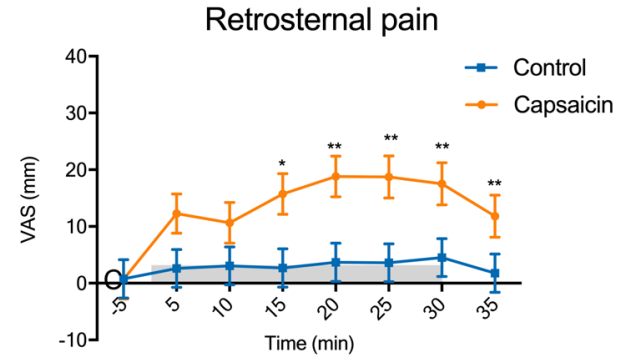

B

Figure 7.3 VAS scores for Heartburn (A) and Retrosternal Pain (B) (estimated means \pm SEM). Grey box 0-30 min: perfusion period. Overall p-value heartburn: 0.004 . Overall $p$-value retrosternal pain: 0.047 . ${ }^{\star} p$-value<0.05, ${ }^{* *} p$-value<0.01, ${ }^{* \star *} p$-value<0.001. VAS: visual analog scale.

These effects were accompanied with changes in baseline impedance in the distal esophagus (Figure 7.4A). Both capsaicin and saline perfusion resulted in decreased baseline impedance. However, this decrease was of greater magnitude after capsaicin perfusion compared to saline, albeit this difference was not significant. After discontinuation of capsaicin perfusion, baseline impedance remained lower compared with the value before perfusion. Following the perfusion of saline, baseline impedance increased above pre-perfusion levels. We therefore observed a significant difference in recovery of $966 \mathrm{ohm}$ (estimated mean (SEM) for capsaicin pre and post: 3468 (257) $\Omega$ and 3313 (277) $\Omega$ vs. saline pre and post: 2918 (261) $\Omega$ and 3728 (266) $\Omega$, p-value for difference in change scores 0.027).
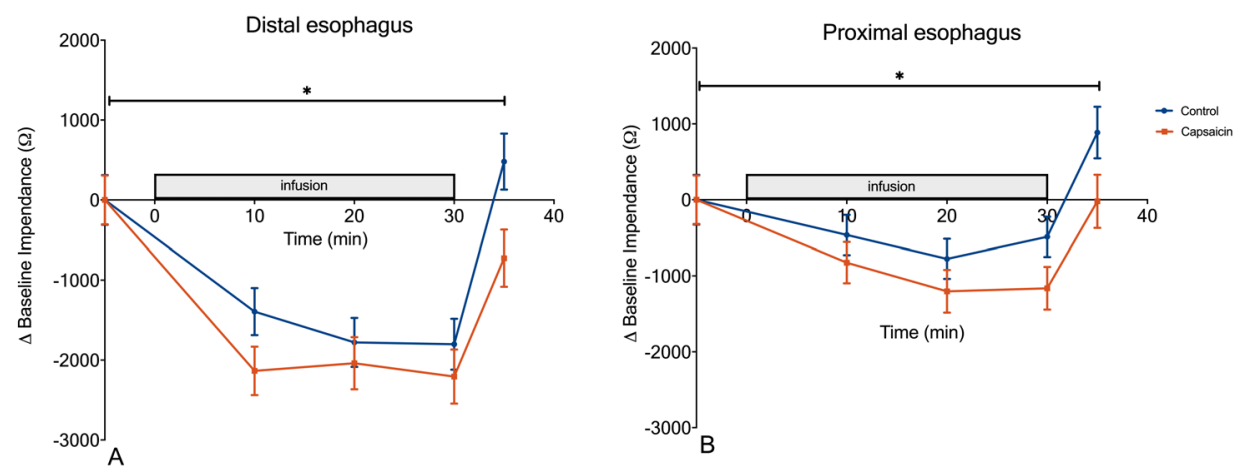

Figure 7.4 $\Delta$ Baseline impedance over time in the distal (A) and proximal (B) esophagus. Grey box: infusion period. * significant difference between capsaicin and control perfusion, pre vs. post. Proximal: significant difference pre and post perfusion between the two treatments, p-value: 0.007. Distal: significant difference pre and post perfusion between the two treatments, p-value: 0.027. 
There was a significant inverse association between VAS scores for retrosternal pain and mucosal integrity for capsaicin and saline conditions combined (slope -0.006, pvalue: $0.031,95 \% \mathrm{Cl}[-0,011 ;-0.001]$ ). For heartburn, there was a non-significant relation between baseline impedance and heartburn in the distal esophagus (slope -0.007. p-value: 0.080, 95\% Cl [-0,015; 0,001]).

Baseline impedance before the start of the perfusion on both test days was not significantly different ( $p$-value 0.369). The fluctuation of the baseline impedance in an empty esophagus ranges between 2000 and $4000 \Omega$ in normal adults. ${ }^{23}$

\subsection{Effects in the proximal esophagus}

Distal perfusion of both solutions resulted in a decrease in baseline impedance in the proximal esophagus over time (Figure 7.4B). Comparable to the distal esophagus, this decrease was also of greater magnitude after capsaicin perfusion compared to saline in the proximal esophagus. However, the decrease was less pronounced compared to the distal esophagus for both conditions. After cessation of the perfusions, baseline impedance recovered above pre-perfusion levels for saline. For capsaicin, baseline impedance fully recovers to the value before perfusion, contrary to what was observed in the distal esophagus. This difference in recovery was $1139 \mathrm{ohm}$ (estimated mean (SEM) for capsaicin pre and post: 3017 (294) $\Omega$ and 3047 (310) $\Omega$ vs. saline pre and post: 2329 (294) $\Omega$ and 3497 (301) $\Omega$, p-value for difference in change scores 0.007).

\subsection{Intercellular space area}

The intercellular space width was not significant different between the type of solution in the proximal ( $p$-value 0.330 ) and distal esophagus ( $p$-value 0.171) (Figure 7.5).

However, there was a significant negative association between the intercellular space area and baseline impedance just prior to obtaining the biopsy in the distal esophagus (slope -0.001, p-value 0.002, 95\% Cl [-0.0001; -0.00003]). 


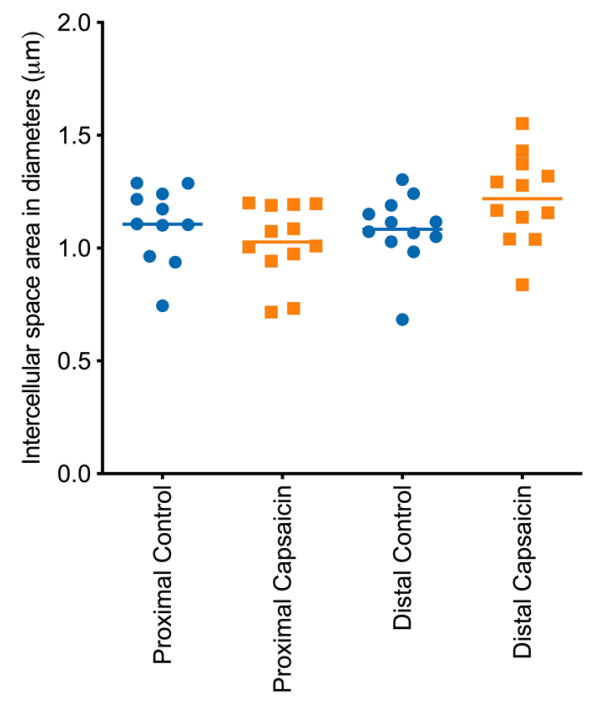

Figure 7.5 Mucosal intercellular space diameter in biopsies from the proximal and distal esophagus in healthy volunteers after exposure to capsaicin and control. There was no significant significant difference for the treatment in both locations ( $p$-value proximal esophagus 0.330, p-value distal esophagus 0.171). $n=12$, proximal control $n=11$.

\subsection{TRPV1 immunohistochemistry and mRNA expression}

There was no significant difference in $\mathrm{H}$-scores for Trpv1 between the type of solution after correction for location (distal $p$-value 0.970 and proximal p-value 0.761) (Figure 7.6A). There was no significant difference in TRPV1 mRNA levels between between the type of solution after correction for location (distal $p$-value 0.829 and proximal $p$ value 0.186) (Figure 7.6B). 
TRPV1

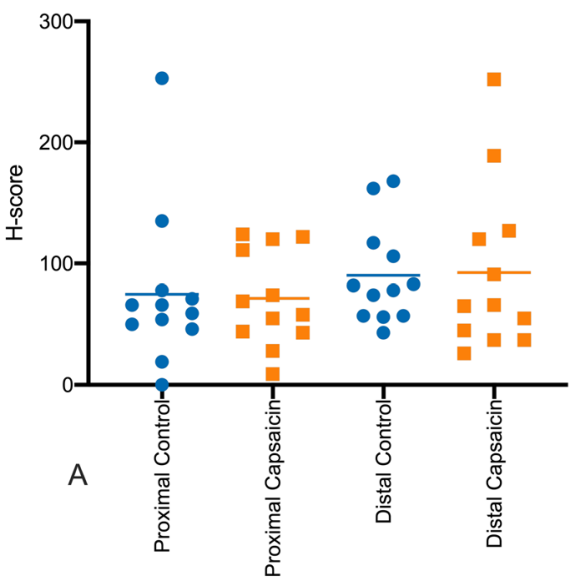

TRPV1

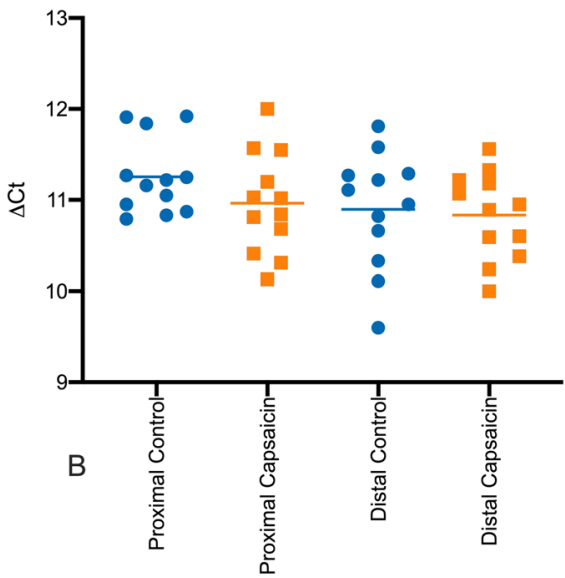

Figure $7.6 \quad$ A) TRPV1 immunohistochemistry: $\mathrm{H}$-score for Trpv1. There was no significant difference between the treatments after correction for location (distal $p$-value 0.970 and proximal $p$-value 0.761 ). B) TRPV1 mRNA expression: delta Ct value for TRPV1. There was no significant difference between the treatments after correction for location (distal $p$-value 0.829 and proximal $p$-value 0.186). $\mathrm{n}=12$. TRPV1: transient receptor potential vanilloid 1

\section{Discussion}

The present results suggest a role for impaired mucosal integrity in the generation of esophageal pain induced by TRPV1 receptor activation. Perfusion with the TRPV1 agonist mucosal stressor capsaicin in the distal esophagus resulted in decreased baseline impedance, and in particular an impaired capacity to restore impedance following perfusion, indicating impaired mucosal integrity for a prolonged time period. This was accompanied by larger intercellular space widths leading to more exposure of the sensory nerve endings of the esophageal mucosa to capsaicin and other noxious stimuli. In addition, pain scores during the perfusion showed a significant association with the decreased baseline impedance of the distal esophagus.

Besides the impaired mucosal integrity, pain generation can also be related to primary dysfunction of the afferent nerve endings (i.e. through sensitization). It has been hypothesized that increased transcription of the TRPV1 receptor may contribute to the perception of hearburn in NERD patients. ${ }^{8,9,24}$ Furthermore, the release of neuropeptides, such as substance $P$ and calcitonin-gene related peptide, from 
TRPV1-expressing nerves, may result in neurogenic inflammation and consequent activation of the inflammatory cascade in the esophageal mucosa leading to mucosal afferent hypersensitivity. In addition, this inflammatory cascade can also contribute to the impairment of the mucosal barrier. ${ }^{25}$ We did not observe significant alterations of TRPV1 expression either at mRNA or protein levels, albeit prompt changes within this relatively short timeframe are unlikely to occur. In the esophageal mucosa, the TRPV1 receptor is expressed both on the sensory nerves and epithelial cells ${ }^{26}$, but its mRNA is more likely to be derived only from the epithelial cells. The role of epithelial TPRV1 in relation to pain signaling remains to be established. On the other hand, it has been reported that peripheral inflammation induces axonal transport of TRPV1 mRNA from dorsal root ganglia to central and peripheral axon terminals ${ }^{27}$, and such phenomena may also occur as a result of esophageal acid exposure. ${ }^{28}$

Regardless of the localization within the esophageal mucosa, it appears that pain intensity is not related to the amount of the TRPV1 receptor. Indeed, pain sensation is a complex process, which is not only determined by mucosal mechanisms, but also by central sensory and autonomic processing at the spinal cord and brain levels. Nevertheless, this study provides substantiation for the postulate that esophageal pain generation depend on the mucosal barrier resistance and consequently the exposure of TRPV1-expressing sensory terminals to different stimuli, rather than TRPV1 upregulation. We provide an overview of the postulated mechanisms in Figure 7.7 .

The impedance value as an indicator of the mucosal barrier function, remained permanently reduced in the distal, capsaicin-perfused esophagus even after completing the stimulation. In the proximal esophagus, impedance fully recovered to the pre-perfusion control values after a moderate, transient decrease during the intervention, and the intercellular space width was not altered. However, it should be noted that baseline impedance and the intercellular space width do not necessarly reflect the exact same pathophysiological mechanisms. 


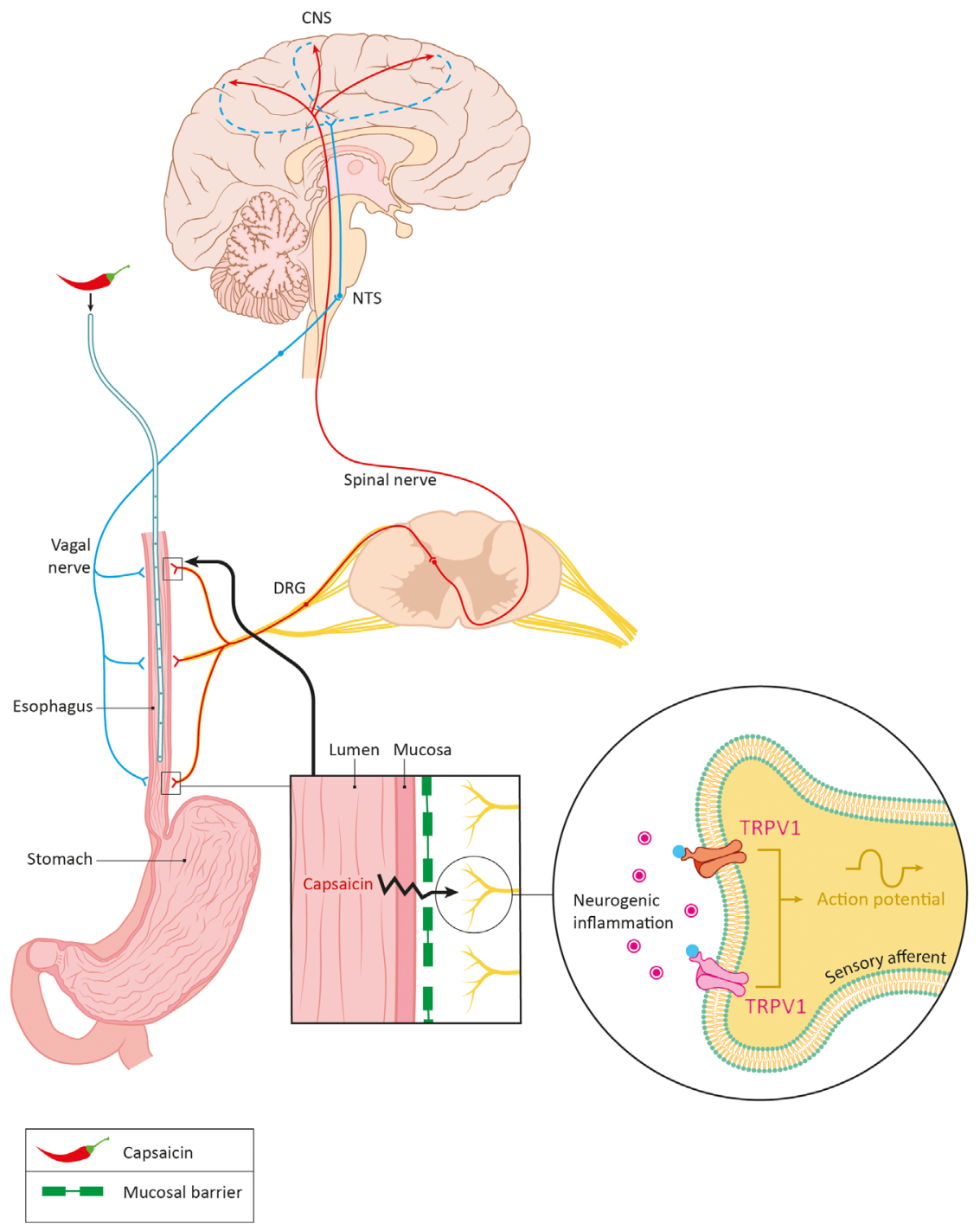

Figure 7.7 Schematic depiction of the hypothesized effects of esophageal perfusion with capsaicin. NTS: nucleus tractus solitarius. DRG: dorsal root ganglion. TRPV1: transient receptor vanilloid 1.

Interestingly, pain sensation persisted even after cessation of the capsaicin infusion. We speculate that the recovery of the baseline impedance in both locations after the stimulation reflect to the mucosal barrier restoring mechanisms to protect the mucosa from potentially noxious substances. This reinforcement of the mucosal 
barrier leads to a less permeable epithelium and reduces interactions between noxious substances and the nociceptive afferents. The differences between the distal and proximal esophagus can be explained by the higher sensitivity of the proximal part to noxious stimuli as a defence mechanism to protect the airways ${ }^{29}$ from the influx of potentially noxious substances. This is supported by results demonstrating that nerve endings in the proximal esophagus are closer to the lumen compared to the distal part. ${ }^{16}$

In contrast to the present results demonstrating no intercellular space changes in the proximal biopsies after distal capsaicin perfusion, earlier studies with acid (both $\mathrm{pH} 2.0$ and 5.5) perfusion in a similar way in 14 healthy volunteers induced significantly enlarged intercellular space area in both esophageal parts. ${ }^{17}$ Although protons also mainly activate the TRPV1 ion channel similarly to the selective agonist capsaicin, the bindig sites and the activation mechanisms are different. ${ }^{30}$ Furthermore, acid perfusion elicited almost no symptoms ${ }^{17}$ in agreement with the observation that esophageal submucosal injection of capsaicin but not acid was able to induce pain. ${ }^{31}$ Therefore, we hypothesize that the reflectory reinforcement of the mucosal barrier, in particular in the proximal esophagus, is specifically induced when pain signals are generated.

An intriguing observation was that after 30 min saline perfusion the baseline impedance increased above the pre-perfusion values after the cessation of the stimulus in both the proximal and distal esophagus. This phenomenon was also observed in a previous study. ${ }^{5}$ The saline infused in our study had a $\mathrm{pH}$ of 6.2 , whereas the solution in the Farré study had a $\mathrm{pH}$ of $7.2 .^{5}$ The $\mathrm{pH}$ of physiological saline can vary between 6.15-8.15. ${ }^{32}$ In this sense, our control condition rather resembles the effect of a weak acid than neutral solution and may therefore have resulted in the observed decrease of baseline impedance. It appears that the same underlying mechanisms might be at operation during both conditions. Nevertheless, even when the direction of changes are comparable between capsaicin and saline, the effects of capsaicin infusion are significantly larger in magnitude and this difference might be related to the degree of the mucosal barrier impairment and the pain response elicited.

Besides the important outcomes and novelties, there are some limitations of this study, such as the relatively small sample size that might have resulted in a type II statistical error. This means that some results cannot be treated as firmly conclusive, in particular with regards to the secondary endpoints, such as the effect on 
intercellular cell width. In addition, the timing of the endoscopy and biopsy retrieval might have influenced the accuracy by which we were able to detect any findings on intercellular space level. It may be possible that any alterations occurred were (partially) reversed at the moment of the biopsy retrieval. Regarding baseline impedance measurements, technical factors, such as attachment of the catheter to the esophageal mucosa or fluid on the catheter, might have influenced measurements which can render values less accurate as surrogate markers for epithelial integrity. In addition, we cannot rule out that the proximal part of the esophagus was also exposed to capsaicin through regurgitation. As this was a study performed in healthy voluneers, it remains to be established what the exact role of the described phenomena is in patients with reflux/heartburn symptoms.

In summary, the most important novel findings of this study are that i) TRPV1 activation by capsaicin infusion in the distal esophagus resulted in an impaired mucosal barrier and ii) pain intensity (sensory response) was related to the magnitude of this impairment but not to TRPV1 expression. Therefore, pain is likely to be the result of increased exposure of the sensory nerve terminals to stimulants through barrier impairement. Our results provide important novel insight into esophageal pain generation which has clinical relevance for treating heartburn and related symptoms, as well as for providing rationale for esophageal barrier protection as a therapeutic modality. ${ }^{33}$ 


\section{References}

1. Tack J, Becher A, Mulligan C, Johnson DA. Systematic review: the burden of disruptive gastrooesophageal reflux disease on health-related quality of life. Aliment Pharmacol Ther. 2012;35(11): 1257-66.

2. El-Serag HB. Epidemiology of non-erosive reflux disease. Digestion. 2008:78 Suppl 1:6-10.

3. Caviglia R, Ribolsi M, Maggiano N, Gabbrielli AM, Emerenziani S, Guarino MP, et al. Dilated intercellular spaces of esophageal epithelium in nonerosive reflux disease patients with physiological esophageal acid exposure. Am J Gastroenterol. 2005;100(3):543-8.

4. Tobey NA, Hosseini SS, Argote CM, Dobrucali AM, Awayda MS, Orlando RC. Dilated intercellular spaces and shunt permeability in nonerosive acid-damaged esophageal epithelium. Am J Gastroenterol. 2004; 99(1):13-22.

5. Farre R, Blondeau K, Clement D, Vicario M, Cardozo L, Vieth M, et al. Evaluation of oesophageal mucosa integrity by the intraluminal impedance technique. Gut. 2011;60(7):885-92.

6. Tobey NA, Carson JL, Alkiek RA, Orlando RC. Dilated intercellular spaces: a morphological feature of acid reflux--damaged human esophageal epithelium. Gastroenterology. 1996;111(5):1200-5.

7. Kindt S, Vos R, Blondeau K, Tack J. Influence of intra-oesophageal capsaicin instillation on heartburn induction and oesophageal sensitivity in man. Neurogastroenterol Motil. 2009;21(10):1032-e82.

8. Guarino MP, Cheng L, Ma J, Harnett K, Biancani P. Altomare A, et al. Increased TRPV1 gene expression in esophageal mucosa of patients with non-erosive and erosive reflux disease. Neurogastroenterol Motil. 2010:22(7):746-51, e219.

9. Yoshida N, Kuroda M, Suzuki T, Kamada K, Uchiyama K, Handa O, et al. Role of nociceptors/ neuropeptides in the pathogenesis of visceral hypersensitivity of nonerosive reflux disease. Dig Dis Sci. 2013:58(8): 2237-43.

10. Silva RO, Bingana RD, Sales TMAL, Moreira RLR, Costa DVS, Sales KMO, et al. Role of TRPV1 receptor in inflammation and impairment of esophageal mucosal integrity in a murine model of nonerosive reflux disease. Neurogastroent Motil. 2018:30(8).

11. Woodland P, Shen Ooi JL, Grassi F, Nikaki K, Lee C, Evans JA, et al. Superficial Esophageal Mucosal Afferent Nerves May Contribute to Reflux Hypersensitivity in Nonerosive Reflux Disease. Gastroenterology. 2017:153(5):1230-9.

12. Cicala M, Emerenziani S, Caviglia R, Guarino MP, Vavassori P, Ribolsi M, et al. Intra-oesophageal distribution and perception of acid reflux in patients with non-erosive gastro-oesophageal reflux disease. Aliment Pharmacol Ther. 2003;18(6):605-13.

13. Emerenziani S, Ribolsi M, Sifrim D, Blondeau K, Cicala M. Regional oesophageal sensitivity to acid and weakly acidic reflux in patients with non-erosive reflux disease. Neurogastroenterol Motil. 2009; 21(3): 253-8.

14. Fass R, Naliboff B, Higa L, Johnson C, Kodner A, Munakata J, et al. Differential effect of long-term esophageal acid exposure on mechanosensitivity and chemosensitivity in humans. Gastroenterology. 1998;115(6):1363-73.

15. van Hoeij FB, Weijenborg PW, van den Bergh Weerman MA, van den Wijngaard RM, Verheij J, Smout AJ, et al. Mucosal integrity and sensitivity to acid in the proximal esophagus in patients with gastroesophageal reflux disease. Am J Physiol Gastrointest Liver Physiol. 2016;311(1):G117-22.

16. Woodland P, Aktar R, Mthunzi E, Lee C, Peiris M, Preston SL, et al. Distinct afferent innervation patterns within the human proximal and distal esophageal mucosa. Am J Physiol Gastrointest Liver Physiol. 2015:308(6):G525-31.

17. Farre R, Fornari F, Blondeau K, Vieth M, De Vos R, Bisschops R, et al. Acid and weakly acidic solutions impair mucosal integrity of distal exposed and proximal non-exposed human oesophagus. Gut. 2010; 59(2):164-9

18. Commission E. Opinion of the Scientific Committee on Food on Capsaicin [Internet]. Brussels, Belgium: European Commission; 2002 Feb 26 [Available from: https://ec.europa.eu/food/sites/food/ files/safety/docs/fs_food-improvement-agents_flavourings-out120.pdf. 
19. van Avesaat M, Troost FJ, Westerterp-Plantenga MS, Helyes Z, Le Roux CW. Dekker J, et al. Capsaicininduced satiety is associated with gastrointestinal distress but not with the release of satiety hormones. Am J Clin Nutr. 2016;103(2):305-13.

20. Parker BA, Sturm K, Maclntosh CG, Feinle C, Horowitz M, Chapman IM. Relation between food intake and visual analogue scale ratings of appetite and other sensations in healthy older and young subjects. Eur $\mathrm{J}$ Clin Nutr. 2004:58(2):212-8.

21. Bohonyi N, Pohoczky K, Szalontai B, Perkecz A, Kovacs K, Kajtar B, et al. Local upregulation of transient receptor potential ankyrin 1 and transient receptor potential vanilloid 1 ion channels in rectosigmoid deep infiltrating endometriosis. Mol Pain. 2017:13:1744806917705564.

22. Kun J, Szitter I, Kemeny A, Perkecz A, Kereskai L, Pohoczky K, et al. Upregulation of the transient receptor potential ankyrin 1 ion channel in the inflamed human and mouse colon and its protective roles. PLoS One. 2014:9(9):e108164.

23. Tutuian R, Castell DO. Review article: complete gastro-oesophageal reflux monitoring - combined pH and impedance. Aliment Pharmacol Ther. 2006:24 Suppl 2:27-37.

24. Kim JJ, Kim N, Choi YJ, Kim JS, Jung HC. Increased TRPV1 and PAR2 mRNA expression levels are associated only with the esophageal reflux symptoms, but not with the extraesophageal reflux symptoms. Medicine (Baltimore). 2016;95(32):e4387.

25. Blevins CH, Iyer PG, Vela MF, Katzka DA. The Esophageal Epithelial Barrier in Health and Disease. Clin Gastroenterol Hepatol. 2018;16(5):608-17.

26. Knowles $\mathrm{CH}$, Aziz Q. Visceral hypersensitivity in non-erosive reflux disease. Gut. 2008:57(5):674-83

27. Tohda C, Sasaki M, Konemura T, Sasamura T, Itoh M, Kuraishi Y. Axonal transport of VR1 capsaicin receptor mRNA in primary afferents and its participation in inflammation-induced increase in capsaicin sensitivity. J Neurochem. 2001;76(6):1628-35.

27. Suzuki T, Yoshida N, Mizushima K, Kamada K, Handa O, Takagi T, et al. T1967 TRPV1 Expression Associated with Nerve Growth Factor Mediates the Esophageal Visceral Hypersensitivity. Gastroenterology. 2008;134(4):A-589-A-90.

28. Suzuki T, Yoshida N, Mizushima K, Kamada K, Handa O, Takagi T, et al. T1967 TRPV1 Expression Associated with Nerve Growth Factor Mediates the Esophageal Visceral Hypersensitivity. Gastroenterology. 2008:134(4):A-589-A-90.

29. Shaker R, Lang IM. Reflex mediated airway protective mechanisms against retrograde aspiration. Am J Med. 1997:103(5A):64S-73S.

30. Hazan A, Kumar R, Matzner H, Priel A. The pain receptor TRPV1 displays agonist-dependent activation stoichiometry. Sci Rep. 2015:5:12278.

31. Lee RH, Korsapati H, Bhalla V, Varki N, Mittal RK. Esophageal Submucosal Injection of Capsaicin but Not Acid Induces Symptoms in Normal Subjects. J Neurogastroenterol Motil. 2016;22(3):436-43.

32. Abrahamsen J, Norrie B, Andersen PK, Stokke DB, Nedergaard OA. pH in physiological salt solutions: direct measurements. Acta Anaesthesiol Scand. 1990;34(8):616-8.

33. Savarino E, Zentilin P, Marabotto E, Pellegatta G, Coppo C, Brunacci M, et al. Drugs for improving esophageal mucosa defense: where are we now and where are we going? Ann Gastroenterol. 2017; 30(6):585-91. 



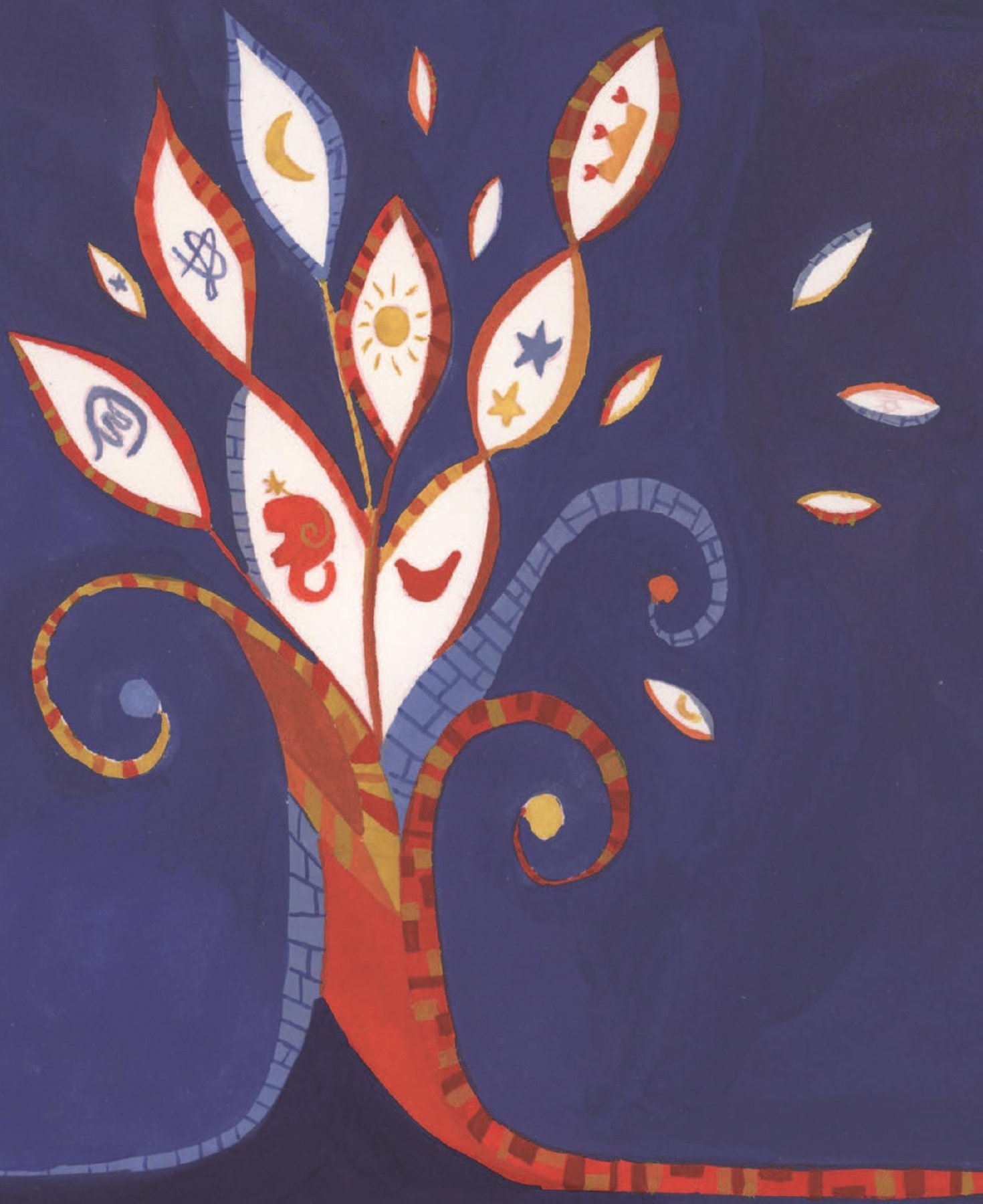




\title{
CHAPTER 8
}

\author{
Relative intercellular space area in \\ gastroesophageal reflux disease: a new \\ standardized method for the evaluation of the \\ intercellular space diameter
}

N.F. Rinsma*, L. van de Laarschot*, J.M. Conchillo, A.M.E. Alleleyn,

D. Keszthelyi,P. Vanden Berghe, A.A.M. Masclee, R. Farré

"Both authors contributed equally to the study work 


\section{Abstract}

\section{Background}

Dilation of intercellular spaces is considered as an early marker for gastroesophageal reflux disease (GERD). Traditionally, evaluation of intercellular space diameter (ISD) is performed by placement of random transects in 10 transmission electron microscopy (TEM) photographs per subject. This method may not take the irregularity of the intercellular space fully into account and is time consuming. We present the relative intercellular space area (ISA) as an alternative method for a more representative evaluation of ISD.

\section{Methods}

21 GERD patients with and without endoscopic esophagitis (EE) and 12 healthy volunteers were enrolled and biopsies were obtained for TEM. ISD was assessed using the classic method (ISDC) and ISA by two investigators that worked independently. ISA was assessed in 3 TEM photographs by measuring the area of the intercellular space divided by its corresponding length.

\section{Results}

ISA-values showed a high correlation with corresponding ISDc-values ( $r$ : 0.84 , $\mathrm{p}<0.001)$. However, ISDc-values were larger when compared to ISA-values $(1.32 \mu \mathrm{m} \pm$ 0.05 vs. $0.90 \mu \mathrm{m} \pm 0.04, \mathrm{p}<0.001$ ). Both methods showed an excellent intraobserver

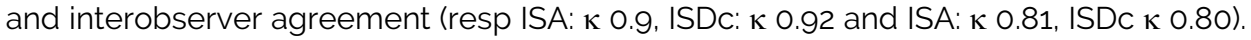
Comparison between subgroups showed an increased ISD only in patients with EE by both methods but not in EE-negative patients.

\section{Conclusion}

Evaluation of the ISD using ISA showed a high intra- and interobserver agreement, a strong correlation with values obtained with ISDc and the ability to discriminate the presence of DIS in patients with EE. This more representative and less timeconsuming approach can be used to reliably assess the ISD in GERD patients in future studies. 


\section{Introduction}

Gastroesophageal reflux disease (GERD) affects 10-20\% of the adult population worldwide and has a great impact on quality of life of individuals affected and health care costs. ${ }^{1}$ The cardinal symptom in GERD is heartburn, which is thought to originate from direct exposure of acid reflux to sensory nerve endings in the deeper layers of the esophageal mucosa., Exposure of acid reflux to sensory nerve endings is obvious when patients present with large mucosal breaks (i.e. erosive esophagitis) in the distal esophagus. The majority of GERD patients present with an intact esophageal mucosa on endoscopy and are classified as non-erosive reflux disease (NERD) in case of abnormal acid exposure; as reflux hypersensitivity $(\mathrm{RH})$ in case of normal acid exposure but positive symptom correlation and as functional heartburn in case of normal acid exposure and negative symptom association. ${ }^{4}$ In the EE-negative patients, the sensory nerve endings are not directly exposed and the route of activation by acid is less clear. In order to understand the origin of heartburn in absence of erosions, research has focussed on histological changes of the esophageal mucosa that may facilitate the passage of acid to the sensory nerve endings. Dilation of intercellular spaces (DIS), first described in 1979 in patients with erosive esophagitis (EE) and more recently also in EE-negative patients, was presented as the missing link in the pathogenesis of heartburn in NERD and $\mathrm{RH}^{3.5-7}$

Since the introduction of the concept of DIS, different methods have been used to evaluate the intercellular spaces from esophageal biopsies. Some studies have used light microscopy, although transmission electron microscopy (TEM) is now recognized as the superior technique to determine DIS. ${ }^{8}$ The classic evaluation of the intercellular space (ISDC) was first described by Tobey et al and consists of the measurement of the intercellular space diameter (ISD), based on 10 randomly drawn perpendicular transects from the cell membrane of a central cell to the opposing cell membranes per microphotograph in a total of 10 TEM photographs of a single subject. ${ }^{6}$ Although this method has been used in several studies, it is also frequently disputed..$^{9-11}$ One of the concerns is that ISDc may not fully take the irregularity of intercellular space delineation enough into account, especially if dilatation of the intercellular space is absent. The intercellular space between esophageal epithelial cells is highly irregular and even completely absent when neighbouring cells are connected by multiple interdigitations. Furthermore, it has been argued that the placement of 10 transects in a TEM photograph is not completely at random and evaluation of 10 TEM photographs per subject is time consuming.

Farré et al described an alternative method to assess ISD in rabbits: the relative intercellular space area (ISA). In 3 TEM photographs the intercellular space area is 
divided by the corresponding length, resulting in a mean intercellular space diameter over the covered area, including both retracted and dilated segments. ${ }^{12,13}$ As ISA covers large areas of the intercellular space, it only requires the analysis of 3 nonoverlapping TEM photographs of the basal and suprabasal layers for a representative ISD value. ISA may therefore be a more representative approach that is less prone to bias and less time consuming.

In this study, we present ISA as an alternative method for the evaluation of ISD in human biopsy samples. We aim to evaluate the inter- and intra-observer variability as well as the time consumption of this alternative method in comparison with ISDc. A second aim is to evaluate the ability of ISA to identify differences in ISD between patients with erosive esophagitis (EE) and EE-negative patients and healthy volunteers (HVs).

\section{Methods}

\subsection{Study protocol}

The current study is part of a study protocol investigating the mucosal barrier function in GERD patient with both with and without EE, and healthy volunteers (HVs). ${ }^{14}$ Written informed consent was obtained from all subjects before enrolment. The study was approved by the Medical Ethics Committee of the Maastricht University Medical Center and registered in a clinical trial register (NCT01867931).

\subsection{Study population}

From the outpatient clinic of the Gastroenterology and Hepatology division of the Maastricht University Medical Centre+, patients with chronic (>6 months) heartburn and/or regurgitation that had previously been diagnosed with GERD were included. GERD patients were categorized into two endoscopic phenotypes: with EE and EEnegative. Patients with esophageal erosions on previous or current endoscopy were categorized as EE. Patients without erosions on previous and current study endoscopy underwent 24-h MII-pH monitoring to establish either abnormal or normal acid exposure (abnormal: $>4 \%$ of time $\mathrm{pH}<4$ ) and positive or negative association between symptoms and reflux episodes (SAP $\geq 95 \%$ ). Furthermore, we included healthy volunteers, without any gastrointestinal symptom, especially heartburn or regurgitation that underwent a standardized screening including assessment of Rome III criteria. 


\subsection{Endoscopy}

Before the endoscopy all patients were required to stop PPI-therapy for 7 days. Erosive esophagitis, when present, was graded according to the L.A. classification. Biopsies were obtained $5 \mathrm{~cm}$ above the gastro-esophageal junction using standard disposable biopsy forceps (Radial Jaw 4 forceps, Boston Scientific, Natick, MA) by an experienced endoscopist (JMC) using the same biopsy taking technique. In patients with erosive esophagitis, biopsies were taken from non-eroded mucosa.

\subsection{Transmission electron microscopy}

A single esophageal biopsy was directly immersed in 3\% glutaraldehyde fixative buffered in $0.09 \mathrm{M} \mathrm{KH}_{2} \mathrm{PO}_{4}$ at $\mathrm{pH} 7.4$ at room temperature. After a minimum of 24 hours of immersion, samples were then washed in $0.09 \mathrm{M} \mathrm{KH}_{2} \mathrm{PO}_{4}$ buffer with $7.5 \%$ sucrose and transferred to a $1 \% \mathrm{OsO}_{4}+1.5 \%$ ferrocyanide solution and buffered to $\mathrm{pH}$ 7.4 with $0.1 \mathrm{M}$ veronalacetate for subsequent post-fixation for $1 \mathrm{~h}$ at $4^{\circ} \mathrm{C}$. After washing in phosphate veronalacetate buffer containing $7 \%$ sucrose at $\mathrm{pH} 7.4$, dehydration was carried out rapidly in graded ethanol series followed by embedding in Epon. Ultrathin tissue sections were cut and examined with a Philips CM 100 electron microscope. Of each biopsy specimen 10 TEM photographs were taken. TEM photographs were obtained from the basal and suprabasal layers of the epithelium at $\times 4000$ magnification by an independent researcher, who was experienced in the recognition of the different layers of the epithelium and blinded for the status of the subject.

\subsection{Assessment of intercellular space diameter}

Intercellular space diameter was assessed using both methods by two blinded investigators that worked independent of each other.

\subsubsection{Relative intercellular space area (ISA)}

ISA was evaluated in 3 representative TEM photographs per subject. For the assessment, based on the division of the area by the corresponding length (an estimation of the perimeter of the cell), first a single line was drawn through the intercellular space around 2-3 cells in the microphotograph (Figure 8.1A). Multiple lines were drawn which were optically the most suitable for calculation of cellular space. A region of interest (ROI) around this line was defined to include the intercellular space between the two cells, without inclusion of intracellular content. The software allowed us to customize a ROI of different $\mu \mathrm{m}$ (Figure 8.3B blue circles). Then, the pixel threshold was chosen to include only pixels from the intercellular 
space. Pixels considered for the analysis were visualized in yellow (Figure 8.3C). Based on this threshold, the area around the line included in the ROI was automatically calculated and divided by the length of this line using custom - written (by PVB) image analysis software in IGOR Pro (WaveMetrics Inc., Oregon, USA). Per subject, the average of the area of different regions of interest from the 3 TEM photographs was used for the analysis.

\subsubsection{Classical ISD assessment (ISDC)}

ISD was calculated in 10 TEM photographs per subject by drawing 10 random transects perpendicular to the opposing cell membranes across the intercellular spaces from a single cell using the computer software Image J (National Institute of Health, USA), as previously described (Figure 8.1D). ${ }^{7.15}$ This resulted in 100 ISD values per subject. The mean of these values was calculated per subject.

A

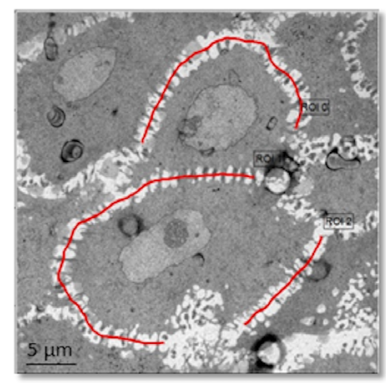

D

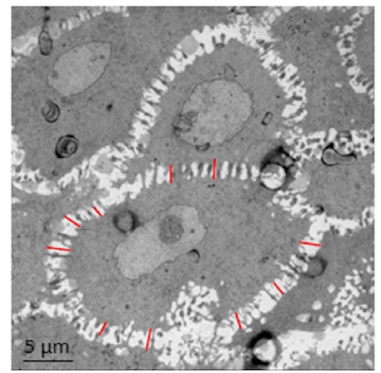

B

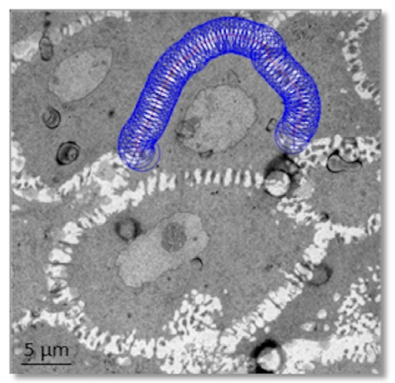

E

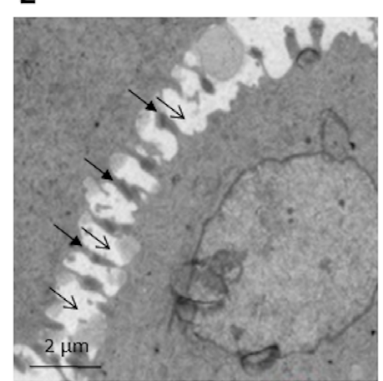

C

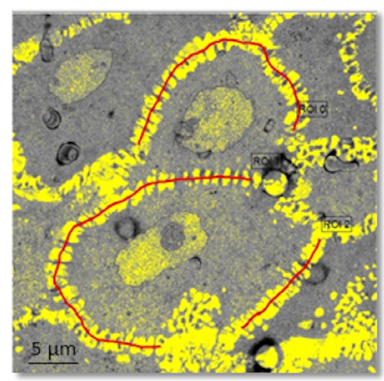

Figure 8.1 Alternative assessment of ISD (ISA). A) Multiple lines (red) are drawn through the intercellular space. Crossings where intercellular spaces merge are not included. B) a region of interest is marked around the lines to cover the selected intercellular space. C) Based on the pixel threshold, the intercellular space area is then calculated and divided by its corresponding length. D) Classic assessment of ISD (ISDc) using 10 transects to the opposing cell membrane. E) Detail of a microphotograph showing the interdigitations of the esophageal epithelial cells (black arrow) and the intercellular space (open arrow). 


\subsection{Intra- and interobserver variability and time consumption}

The calculation of the ISD of all TEM photographs using both methods was performed twice by a single investigator. After the initial assessment of ISD using both methods, the investigator (FR) was blinded for the previous results and the analyses were repeated one week later. Interobserver agreement for both methods was also assessed in all microphotographs by a second investigator (LL) that worked independently and was blinded for the results of the other investigator. The time consumed by evaluation of ISD in 5 subjects by both methods was recorded and compared.

\subsection{Statistical analysis}

Data are expressed as mean \pm standard error of the mean (SEM). Simple comparisons between the two different methods were performed using the independent samples t-test. Correlations between outcomes of ISA and ISDc were calculated using the Pearson correlation coefficient. Cohen's Kappa coefficient was used to analyse interand intraobserver variability. Comparison of ISD between groups was performed using the one-way ANOVA to determine whether significant differences exist between groups, then the Tukey's post-hoc test was applied. A p-value below 0.05 was considered statistically significant. All statistical analyses were performed using commercially available computer software (IBM SPSS Statistics for Windows, Version 22. Armonk, NY: IBM Corp.).

\section{Results}

\subsection{Subject characteristics}

Twenty-two GERD patients and $12 \mathrm{HVs}$ were included in the study. All patients were on proton-pump inhibitory (PPI) therapy before inclusion of the study. One patient was not able to stop PPI therapy and was excluded before the endoscopy. In another patient, measurement of ISD failed as the biopsy did not contain sufficient basal cell layers. Furthermore, two healthy volunteers showed esophagitis despite not having any symptoms and were excluded from the study.

In the final analysis 10 EE patients (6 men, mean age 62 years (range 45-77)), 10 EEnegative reflux patients ( 6 men, mean age 48 years (range $28-70$ )) and $10 \mathrm{HVs}$ ( 5 men, mean age 35 (range 21-65)) were included. All EE patients showed active esophagitis 
during the study endoscopy. Grade A esophagitis according to the L.A. classification was present in 6 patients; grade $B$ in 3 patients and grade $C$ in 1 patient. Of the EEnegative patients, 6 had abnormal acid exposure: non-erosive reflux disease (NERD). The other 4 had normal acid exposure but had a positive symptom association and were classified as reflux hypersensitivity $(\mathrm{RH})$.

\subsection{Relative intercellular space area (ISA)}

ISA showed a high correlation with corresponding ISDc-values ( $r$ : $0.84, p<0.001$ ) (Figure 8.2). A comparable correlation was observed in EE-negative reflux patients ( $r$ : $0.92, p<0.001)$ and healthy volunteers $(r: 0.73, p=0.02$ ). In EE patients, the correlation was moderate but still significant ( $r$ : 0.63, $p<0.05)$.

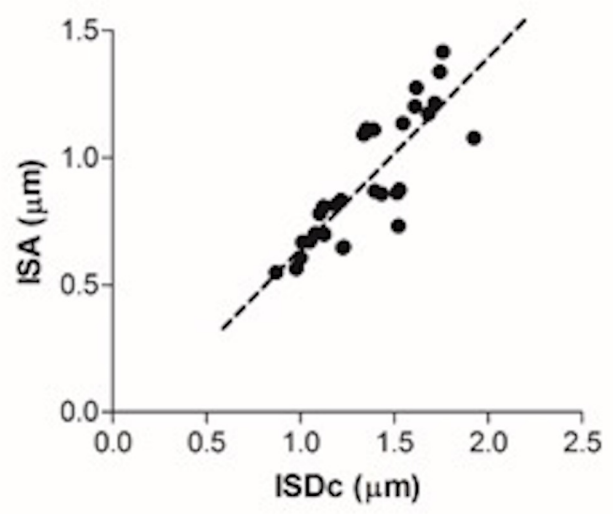

Figure 8.2 Correlation between intercellular space diameter (in $\mu \mathrm{m}$ ) as assessed with ISA and ISDc. A positive correlation ( $r=0.084$ ) was found comparing both methods of measuring intercellular spaces $(p<0.001)$

\subsection{Intra- and interobserver variability}

Both methods showed an excellent intraobsever agreement, with comparable $\mathrm{k}$ values (ISA: 0.91 and ISDc: 0.92). Interobserver agreement of both methods was good, with again comparable $\mathrm{k}$-values (ISA: 0.81 and ISDc 0.80).

\subsection{Time analysis}

The analysis using the ISA method proved to be more time consuming per TEM photograph when compared to ISDC (ISA: $119 \mathrm{~s} \pm 8$ vs. ISDC: $63 \mathrm{~s} \pm 2, p<0.001$ ). However, when comparing the time consumption of the analysis of the mandatory 10 
TEM photographs per subject with ISDc versus 3 microphotographs with ISA, the latter is less time consuming (ISA: $350 \pm 13$ S vs ISDc: $628 \pm 15$ s, $p<0.001$ ).

\subsection{Direct comparison ISA vs ISDc}

Although ISA and ISDc values showed a strong correlation, a large difference in the mean ISD-value per subject was found between the two methods. Mean difference between the methods was $0.44 \mu \mathrm{m}(\mathrm{p}<0.001)$. Therefore, it was not able to perform a Bland Altman plot (difference plot). As ISDc values were derived from 10 TEM photographs and ISA-values from 3 microphotographs, we performed another comparison of both methods using the same 3 microphotographs. Also in this 3 by 3analysis, ISDc-values were significantly larger when compared to the mean diameter as assessed with ISA (Table 8.1). This finding was consistent in EE, EE-negative patients and HVs (Table 8.1) and was found in the analysis of the second observer (data not shown).

Table 8.1 Comparison of outcomes of ISA and ISDc in EE, NERD and HVs in the same 3 TEM photographs.

\begin{tabular}{lllc}
\hline ISD & ISA $(\boldsymbol{\mu m})$ & ISDc $(\boldsymbol{\mu m})$ & p-value \\
\hline All subjects & $0.90 \pm 0.04$ & $1.32 \pm 0.05$ & $<0.001$ \\
EE & $1.08 \pm 0.07$ & $1.61 \pm 0.07$ & $<0.001$ \\
EE-negative & $0.83 \pm 0.07$ & $1.20 \pm 0.07$ & $<0.001$ \\
HV & $0.79 \pm 0.06$ & $1.14 \pm 0.06$ & $<0.001$ \\
\hline
\end{tabular}

EE, erosive esophagitis; HV, healthy volunteers. The ISD was expressed as mean \pm SEM.

\subsection{Differences in ISD between subsets of GERD and healthy volunteers}

Both methods showed a clear difference in ISD of patients with erosive esophagitis vs. non-erosive reflux disease patients and healthy volunteers (Figure 8.3). However, no difference in ISD was found between EE-negative patients and HVs, regardless of the method used to evaluate the ISD. 
a

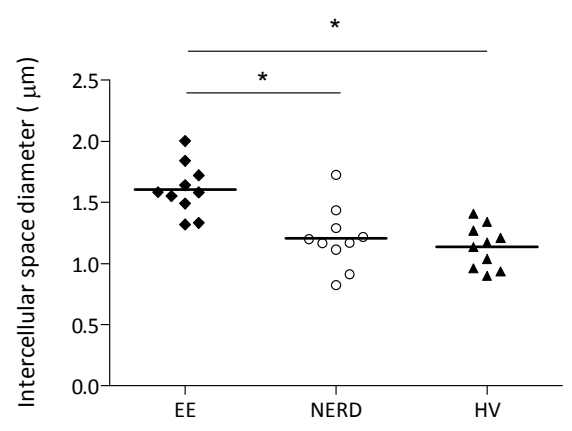

b

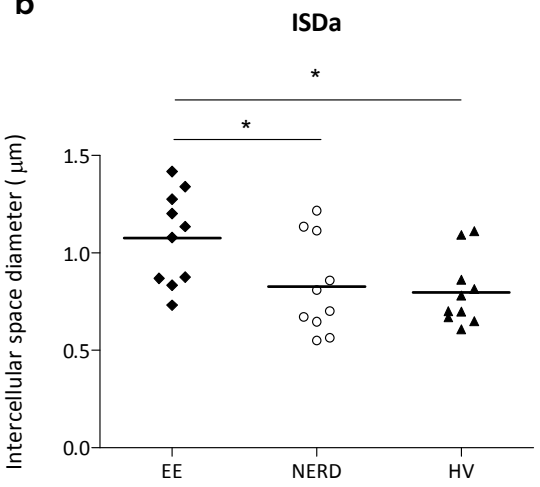

Figure 8.3 Comparison of ISD in different phenotypes of GERD (EE and EE-negative) and healthy volunteers $(\mathrm{HV})$, using the ISDc (a) and the ISA (b) method. ${ }^{*} \mathrm{p}<0.05$.

\section{Discussion}

In the present study, we aimed to evaluate the relative intercellular space area (ISA) as an alternative, more representative and efficient approach to calculate the intercellular space diameter (ISD) in TEM microphotographs.

Our main findings were: 1) ISA showed an excellent intra- and interobserver agreement and a strong correlation with ISD-values obtained with the classic method; 2) as ISA requires only 3 TEM photographs, the analysis is less time consuming; 3) direct comparison of both methods showed that the average ISD obtained with ISA was significantly smaller, but the ability to differentiate EE, EE-negative and HVs was comparable for both methods.

The need for an alternative method to calculate ISD from TEM photographs has been previously acknowledged; the placement of transects during the ISDC assessment in a highly irregular intercellular space with dilated and retracted segments may not lead to a representative mean intercellular space diameter. In addition, the placement of the transects is not fully at random and therefore susceptible to bias. Furthermore, the classical method requires 10 TEM photographs per subject to obtain 100 ISD values for a single subject. To obtain 10 non-overlapping TEM photographs of the basal and suprabasal layers from a single biopsy is laborious and the subsequent analysis is time consuming.

Other research groups recognized these shortcomings of ISDC and described alternative methods to assess ISD over the past years. Vaezi et al. tried to overcome the possibility of a selection bias by superimposing computer generated lines over 10 
TEM photographs, that subsequently randomly allocated the placement of transects between two cell membranes. ${ }^{10}$ However, by using this method the authors were not able to identify differences in ISD between GERD patients and controls. As the authors did not re-analyse the TEM photographs using ISDc, it is unknown whether this negative result was related to the samples or to the method used in that study. ${ }^{10}$ Neumann et al. used Delesse's principle as previously described by Weibel to calculate the intercellular space volume from 2-D TEM photographs. ${ }^{16,17}$ Delesse's principle states that the planimetric fraction of a section occupied by sections of a given component corresponds to the fraction of the tissue volume occupied by this component. A point grid was superimposed on each of 10 microphotographs per subject and based on the fraction of points within the intercellular space in relation to points of the total mucosa, a relative volume fraction of the intercellular space was calculated. The volumetric assessment was not compared to ISDc. The concept of the intercellular ratio, introduced by Johanessen et al, resembles parts of the volumetric assessment described by Neumann et al: a grid containing 150 linecrossing points is imposed over 10 microphotographs per biopsy, and the number of crossing points within the intercellular space are divided by the total number of grid points. ${ }^{18}$ The intercellular space ratio showed high intra- and interobserver agreement, but a poor correlation with ISDc. Although the above-mentioned methods clearly overcome the possible bias of subjective transect placement, the analysis of 150 crossing points in each of 10 TEM photographs of a single subject is still time consuming. Weijenborg et al. also reported an intercellular space ratio, however, based the ratio on the difference in contrast between inter- and intracellular space..$^{11,19}$ Although the investigators used 10 TEM photographs per subject, the computergenerated ratio is possibly time saving and likely more representative compared to a 150-point superimposed grid. Nevertheless, there may be another weakness when using the intercellular space ratio either by superimposing a grid or using contrast to differentiate inter- and intracellular space. To calculate the ratio between inter- and intracellular space, an entire TEM photograph with perfectly preserved tissue is demanded, without artefacts or tissue disruption by the handling of the biopsy. In our experience, it can be laborious to obtain 10 non-overlapping. TEM photographs from a single biopsy without inclusion of the metal grid or broken areas, frequently observed in most of the ultrathin sections.

In the present study we evaluated an alternative method that was previously used to assess the intercellular space in rabbits ${ }^{12,13}$, but was never before validated or compared to the classic method. We show in the present study that the assessment of ISA has good intra- and interobserver agreement. Strength of ISA is the requirement of only 3 TEM photographs to reproduce similar results when compared 
to ISDc. It is not only less time consuming to analyse, but also the process of obtaining non-overlapping, intact TEM photographs in the basal and suprabasal layers of the epithelium is much easier when only 3 TEM photographs are required. The analysis by ISA also includes the interdigitations (retracted segments) present in the intercellular spaces (Figure 8.1E) with limited space between two opposing cell membranes. Although a strong correlation between outcomes of ISA and ISDc were found, direct comparison of ISD-values show that ISA-values were consistently smaller compared to ISDc-values. This is most likely due to the inclusion of these interdigitations, areas in which ISD is small or even absent. These irregularities of the intercellular space may not be taken into account when using the ISDc. We therefore believe that ISA gives a more balanced representation of the intercellular space diameter and argue that ISA can provide a representative ISD-value in only 3 TEM photographs. In contrast to the methods that are based on the ratio between interand intracellular space, ISA can still be used in TEM photographs with small areas that are slightly damaged or with a preservation artefact, as they can be excluded from the analysis by selecting well preserved regions of the TEM photograph.

A second aim of our study was to evaluate the ability of ISA to identify differences in ISD between subsets of the study population. ISA identified a clear difference between EE vs. EE-negative reflux patients and controls, similar to the results of the classic method. In the present study, the presence of DIS in EE-negative reflux patients could not be identified, irrespective of the method used. The presence of DIS in the mucosa of EE-negative reflux patients is widely accepted, however studies supporting this finding all used ISDc. ${ }^{715,20,21}$ Alternative methods are less conclusive about DIS in EE-negative reflux patients. The volumetric assessment of the intercellular space by Neumann et al. revealed an increased intercellular space volume in patient with $\mathrm{EE}$, however the intracellular space volume of EE-negative reflux patients was not different from controls. ${ }^{16}$ The computer calculated intercellular space ratio of Weijenborg et al. showed no difference between EE, EEnegative reflux patients and healthy volunteers, although group numbers were relatively small. ${ }^{19}$ Thus, so far no alternative method could identify DIS in EE-negative reflux patients, however a future study using a larger number of patients should be performed to provide a more conclusive answer. In addition, the fact that no difference was found in DIS between EE-negative reflux patients and healthy control could also be related to the fact that some EE-negative patients had pathological acid exposure (NERD) and some had normal acid exposure with positive symptom correlation: reflux hypersensitivity $(\mathrm{RH})$.

In summary, evaluation of the intercellular space diameter using the relative intercellular space area showed a high intra- and interobserver agreement and a 
strong correlation with ISD values obtained with the classical assessment. Furthermore, ISA was able to discriminate DIS in EE patients, similar to the classic assessment. Therefore, we conclude that this more representative and less time consuming approach can be used to reliably assess the intercellular space diameter in GERD patients in future studies. Nevertheless, future efforts should me aimed at applying analytical techniques to assess intercellular spaces in light microscopy as this is less laborious compared to TEM. 


\section{References} Barlow WJ, Orlando RC. The pathogenesis of heartburn in nonerosive reflux disease: a unifying hypothesis. Gastroenterology. 2005:128(3):771-8.

3. Vakil N, van Zanten SV, Kahrilas P, Dent J, Jones R, Global Consensus G. The Montreal definition and classification of gastroesophageal reflux disease: a global evidence-based consensus. Am J Gastroenterol. 2006:101(8):1900-20; quiz 43.

4. Aziz Q, Fass R, Gyawali CP, Miwa H, Pandolfino JE, Zerbib F. Functional Esophageal Disorders. Gastroenterology. 2016.

5. Hopwood D, Milne G, Logan KR. Electron microscopic changes in human oesophageal epithelium in oesophagitis. J Pathol. 1979:129(4):161-7.

6. Tobey NA, Carson JL, Alkiek RA, Orlando RC. Dilated intercellular spaces: a morphological feature of acid reflux--damaged human esophageal epithelium. Gastroenterology. 1996;111(5):1200-5.

7. Tobey NA, Hosseini SS, Argote CM, Dobrucali AM, Awayda MS, Orlando RC. Dilated intercellular spaces and shunt permeability in nonerosive acid-damaged esophageal epithelium. Am J Gastroenterol. 2004:99(1):13-22.

8. Ribolsi M, Perrone G, Caviglia R, Gentile M, Emerenziani S, Luca Guarino MP, et al. Intercellular space diameters of the oesophageal epithelium in NERD patients: head to head comparison between light and electron microscopy analysis. Dig Liver Dis. 2009;41(1):9-14.

9. Park S, Chun HJ, Jang JS, Keum B, Seo YS, Kim YS, et al. Is intercellular space different among layers in normal esophageal mucosa? An electron microscopic study. Dig Dis Sci. 2011:56(12):3492-7.

10. Vaezi MF, Slaughter JC, Smith BS, Washington MK, Jerome WG, Garrett CG, et al. Dilated intercellular space in chronic laryngitis and gastro-oesophageal reflux disease: at baseline and post-lansoprazole therapy. Aliment Pharmacol Ther. 2010;32(7):916-24.

11. Weijenborg PW, Rohof WO, Akkermans LM, Verheij J, Smout AJ, Bredenoord AJ. Electrical tissue impedance spectroscopy: a novel device to measure esophageal mucosal integrity changes during endoscopy. Neurogastroenterol Motil. 2013:25(7):574-8, e457-8.

12. Farre R, De Vos R, Geboes K, Verbecke K, Vanden Berghe P. Depoortere I, et al. Critical role of stress in increased oesophageal mucosa permeability and dilated intercellular spaces. Gut. 2007:56(9):1191-7.

13. Farre R, van Malenstein H, De Vos R, Geboes K, Depoortere I, Vanden Berghe P, et al. Short exposure of oesophageal mucosa to bile acids, both in acidic and weakly acidic conditions, can impair mucosal integrity and provoke dilated intercellular spaces. Gut. 2008:57(10):1366-74.

14. Rinsma NF, Farre R, Troost FJ, Elizalde M, Keszthelyi D, Helyes Z, et al. Exploration of the Esophageal Mucosal Barrier in Non-Erosive Reflux Disease. Int J Mol Sci. 2017:18(5).

15. Caviglia R, Ribolsi M, Maggiano N, Gabbrielli AM, Emerenziani S, Guarino MP, et al. Dilated intercellular spaces of esophageal epithelium in nonerosive reflux disease patients with physiological esophageal acid exposure. Am J Gastroenterol. 2005:100(3):543-8.

16. Neumann H, Monkemuller K, Fry LC, Dombrowski F, Kuester D, Beyer M, et al. Intercellular space volume is mainly increased in the basal layer of esophageal squamous epithelium in patients with GERD. Dig Dis Sci. 2011:56(5):1404-11.

17. Weibel ER, Kistler GS, Scherle WF. Practical stereological methods for morphometric cytology. J Cell Biol. 1966:30(1):23-38.

18. Johannessen R, Skogaker N, Halgunset J, Petersen H, Kleveland PM. A standardized method for measuring intercellular spaces in esophageal biopsies in patients with suspected gastroesophageal reflux disease (the intercellular space ratio). Scand J Gastroenterol. 2013:48(11):1235-41.

19. Weijenborg PW, Smout AJ, Verseijden C, van Veen HA, Verheij J, de Jonge WJ, et al. Hypersensitivity to acid is associated with impaired esophageal mucosal integrity in patients with gastroesophageal reflux disease with and without esophagitis. Am J Physiol Gastrointest Liver Physiol. 2014:307(3):G323-9. 
20. Calabrese C, Bortolotti M, Fabbri A, Areni A, Cenacchi G, Scialpi C, et al. Reversibility of GERD ultrastructural alterations and relief of symptoms after omeprazole treatment. Am J Gastroenterol. 2005;100(3):537-42.

21. Caviglia R, Ribolsi M, Gentile M, Rabitti C, Emerenziani S, Guarino MP, et al. Dilated intercellular spaces and acid reflux at the distal and proximal oesophagus in patients with non-erosive gastro-oesophageal reflux disease. Aliment Pharmacol Ther. 2007;25(5):629-36. 


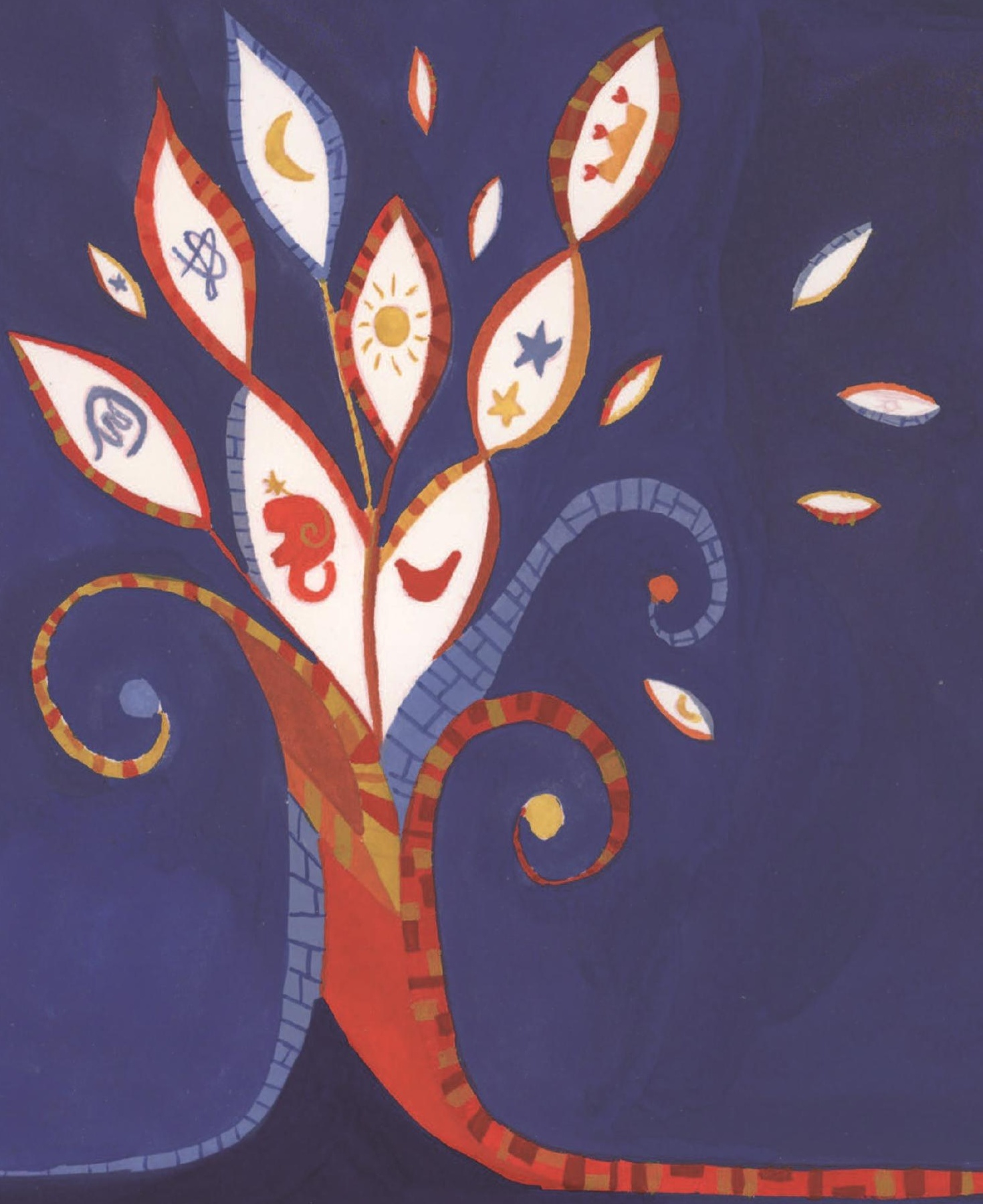




\section{CHAPTER 9}

General discussion 
Chapter 9 


\section{General discussion}

The research findings presented in this thesis add to our knowledge on the role of the proximal part of the gastrointestinal (GI) tract in the maintenance of 'gut health'. The term 'gut health' is becoming increasingly popular, reflected by its frequent use in scientific literature. ${ }^{1}$ The Gl tract is able to contribute to health in many ways. This is not solely dependent on the food processing of nutrients and fluid secretion and absorption. The Gl tract is a large sensory organ, which responds to a variety of signals which arise and are perceived in the lumen. It has a protective role against intraluminal noxious or toxic substances and is equipped to sense, digest and absorb nutrients. In this respect, sensing and signalling in the upper Gl tract has a major role in gut and systemic homeostasis and consequently in preserving gut health and systemic health as it is able to discriminate between beneficial and potentially harmful stimuli and signals. The primary focus of this thesis was the role of the proximal Gl tract and its ability to sense the chemical content in the lumen in order to orchestrate important responses to preserve Gl homeostasis. We specifically focused on two areas: 1) mechanisms of the proximal Gl tract to control satiety and food intake (nutrients, food components and mechanical sensing) and 2) the role of TRP channels and the mucosal barrier and their involvement in chemo-nociception and pain generation in the proximal Gl tract. This final chapter summarizes the main findings presented in this thesis. These findings are discussed in the light of findings from previous publications and the current knowledge and understanding of its background and clinical relevance. Finally, suggestions and implications for future research are presented.

\section{Main findings}

In the first part of this thesis we focused on the gut as a potential target in the regulation of food intake and satiety. Previous work showed that all three macronutrients (lipids, proteins and carbohydrates) are able to activate the intestinal brake; a negative feedback mechanism to the motor, secretory and sensory functions of the more proximal parts of the Gl tract, including food intake and satiety. In chapter 2. we provided a detailed overview of the literature on published studies in which macronutrients have been infused in the different parts of the small intestine. We concluded that a proximal to distal gradient exists with respect to the magnitude of intestinal brake activation: the more distal the delivery of intact nutrients or degradation products in the small intestine takes place, the more pronounced the effect on food intake and satiety. The 'proof on concept' study described in chapter 3 
showed that an encapsulated protein and carbohydrate mixture with "ileal release formula" resulted in a significant reduction in food intake and stronger feelings of satiety compared to a control product with proximal Gl release. Ileal delivery of lipids, which were incorporated in emulsified alginate beads in order to delay the release and digestive breakdown of dietary lipids, was able to reduce food intake (chapter 4) to a similar extent compared to the protein and carbohydrate mixture in chapter 3 . In chapter 5, we investigated mechanical sensing of the stomach and whether influencing this mechanical sensing was able to affect food intake and satiety. Lidocaine, known for its anesthetic effects, was infused into the stomach of healthy volunteers, to test the hypothesis that lidocaine via inhibition of mechanical distension might impair feelings of satiety/satiation and increase food intake. Lidocaine, however, did not result in an increase in food intake nor in a decrease in satiety.

With regard to the satiating effect of tastants, a recent study from our group revealed that intraduodenal infusion of the combination of the tastants sweet, bitter and umami resulted in a significant decrease in food intake and a reduction of hunger scores. Based on the findings in chapter $\mathbf{2}$, where a proximal to distal gradient in ileal brake activation was observed, we investigated the effect on food intake of an identical combination of tastants when infused into the ileum and/or duodenum compared to a placebo infusion. For both locations, ileum and duodenum, and also for simultaneous infusion at both sites, no significant effects on food intake or satiety were observed after infusion with a combination of tastants compared to placebo infusion (chapter 6).

In the second part of this thesis, we investigate the sensory function of the Gl tract with respect to the detection of potentially noxious stimuli. Such stimuli generally elicit aversive responses such as pain, nausea and abdominal discomfort. To better understand pain generation in the esophagus, we conducted a study in which capsaicin was infused into the esophagus (chapter 7). Capsaicin is the pungent ingredient in chili peppers and a well-known TRPV1 receptor agonist. The TRPV1 receptor plays a major role in nociception and pain signalling. We observed that an impaired (more leaky) mucosal barrier and consequently increased exposure of mucosal and submucosal sensory afferents to this noxious substance play a key role in the generation of pain symptoms. A protective reflex mechanism occurs in the nonexposed more proximal part of the esophagus that results in an enforcement of the mucosal barrier. The measurement of intercellular spaces in the esophageal mucosa allows quantification of the barrier dysfunction. Finally, in chapter 8, we compared two methods to measure intercellular space area: the classic measurement of the intercellular space diameter (ISD) and the relative intercellular space area (ISA). A 
strong correlation between the two methods was observed with the advantage that ISA is significantly less time consuming.

\section{Nutrient sensing in food intake regulation}

Intestinal sensing of nutrients in the lumen of the Gl tract plays a major role in the regulation of food intake and energy balance. The rapidly increasing prevalence of obesity and its associated comorbidities results in expanding impact on health care utilization and costs. Bariatric surgery is known to be highly effective in achieving sustained weight loss. On the other hand, this is a drastic measure with profound effects on gut function and is only available for a small subgroup of patients. The mechanism of weight loss after Roux-en-Y gastric bypass is based on both a restrictive and a malabsorptive component, in which nutrients are less rapidly digested and absorbed or even malabsorbed. The response to this increased amount of nutrients and their degradation products entering the more distal parts of the gut appears to play a key role in the sustained weight loss seen after bariatric surgery in a mechanism referred to as the intestinal brake. This implicates that the effect of these nutrients in the lumen of the more distal small intestine could be an interesting target for less invasive strategies for weight loss. Data about this distal to proximal feedback mechanism were first studied with ileal lipid infusion. ${ }^{2,3}$ The concept of this feedback mechanism was based on the weight loss observed in studies with morbidly obese patients after jejunoileal bypass $(\mathrm{JIB})^{4}{ }^{4}$ The results observed after JIB or ileal transposition in rats led to experiments in humans with intestinal catheter intubation and perfusion studies. Welch et al. were the first to observe a delay in gastric emptying and food intake reduction after ileal fat perfusion. ${ }^{5,6}$ In one of these studies, not only ileal but also jejunal fat infusion was performed and both infusions, ileal and jejunal, were able to significantly reduce food intake. ${ }^{6}$ Based on these landmark studies, this feedback mechanism became an interesting target for food-based strategies in the battle against overweight and obesity. Several groups of researchers have investigated whether this effect also occurs in other parts of the small intestine and they compared the magnitude of this feedback mechanism on food intake. ${ }^{7.8}$ Even though proteins are regarded as the most satiating macronutrient, all three macronutrients were able to activate this intestinal brake to the same extent. ${ }^{9}$ In our literature review in chapter 2 we observed a proximal to distal gradient with regard to the magnitude of this feedback mechanism. We observed that the higher the caloric infusion rates, the stronger the inhibitory effect on food intake and that this effect is site-dependent. Increasing the small intestinal surface area exposed to nutrients reduces gastric emptying rate and food intake. ${ }^{10,11}$ Protein infusion into the duodenum 
at a rate of $>3 \mathrm{kcal} / \mathrm{min}$ was needed in order to induce a reduction in food intake. ${ }^{12}$ In the study performed by van Avesaat et al., lower protein infusion rates were chosen. Ileal infusion of protein at a rate of $0.9 \mathrm{kcal} / \mathrm{min}$ resulted in a significantly lower food intake compared to intraduodenal infusion of the same amount of protein. ${ }^{13}$ Potential mechanisms that can be held responsible for the difference in food intake after distal compared to proximal small intestinal administration of nutrients are related to the process of a delay in digestion and the presence of degradation products in the more distal small intestine, distribution and types of nutrient sensing receptors and the subsequent entero-endocrine responses.

\section{Digestion and absorption of nutrients}

Nutrient digestion starts immediately after ingestion, in the oral cavity. In the small intestine protein, carbohydrates and fat have already largely been broken down into respectively amino acids, monosaccharides and monoglycerides and fatty acids for detection and subsequent absorption. A possible explanation for the results observed in this thesis, relates to the magnitude of the intestinal brake effect on food intake. The sensing of degradation products of macronutrients appears to be more relevant and stronger compared to sensing of intact macronutrients for activation of small intestinal signals in satiety and food intake regulation. For example, duodenal infusion of a very small amount of the amino acid L-tryptophan (caloric load $0.15 \mathrm{kcal} / \mathrm{min}$ ) was already able to induce a significant effect on food intake and satiety. ${ }^{14}$ Likewise, duodenal infusion of the fatty acid $\mathrm{C} 12$ at a caloric load of $0.4 \mathrm{kcal} / \mathrm{min}$, was able to induce a significant reduction in food intake. ${ }^{15}$ It should be taken into account that these degradation products are rapidly absorbed from the duodenum and jejunum and do not progress to more distal parts of the small intestine under normal circumstances. Studies that have investigated the direct effects of ileal infusion of nutrient degradation products on ileal brake activation are lacking up to now. The obtained results thus far suggest that exposure of the more distal small intestine to nutrients or their degradation products could be an interesting and promising target for weight management strategies.

\section{Encapsulation of nutrients}

The majority of the studies investigating the acute effects of macronutrient infusion in the small intestine have been performed with naso-intestinal catheters. In case we intend to investigate the effects of repetitive administration of nutrients into the distal small intestine, this intubation method is not feasible: it is too invasive and associated with significant discomfort for the volunteer or patient. Therefore, it is necessary to 
develop new methods in order to deliver the nutrients at a desired (distal) intestinal location. Currently, methodology is available with "slow intestinal release" of nutrients and of pharmaceutical products. An elegant example is that of ileocolonic release of peppermint oil capsules, which have been used in a study on the efficacy and tolerability of small intestinal versus colonic release of peppermint oil using the ColoPulse technology. ${ }^{16,17}$ Another example is the Fabuless emulsion. This emulsion consists of very fine vegetable oil droplets made of naturally occurring palm oil coated with galactolipids as emulsifiers. Initially, a significant effect on food intake 4-8 hours after intake of yoghurt with Fabuless was observed when compared with normal fat. ${ }^{18,19}$ It was hypothesized that this effect is related to the fact that the presence of the Fabuless emulsion in the small intestinal lumen allows the formation of fatty acid crystals that then act as slow-release capsules. ${ }^{20}$ The distal small intestine is, as a result, exposed to a higher intraluminal fatty acid content and consequently activates the ileal brake. Subsequent results revealed, however, that repetitive ingestion of Fabuless was not able to decrease energy intake and body weight. $^{21}$

Another interesting encapsulation technique is micro-encapsulation. Microencapsulation technique creates the possibility to encapsulate large amounts of macronutrients for delivery in the distal small intestine. In this thesis, we investigated ileal delivery of a mixture of carbohydrate and protein (chapter 3). This study describes the acute effects of these micro-encapsulates on food intake and satiety. We observed a significant food intake reduction and increase in satiety after ingestion of the micro-encapsulates compared to the placebo mixture (with more proximal release). Evidence that is in line with a more distal release of the micro-encapsulates compared to placebo is the observation of a plasma glucose peak 30 min after ingestion of the placebo mixture, that was not observed after ingestion of the microencapsulate mixture. This peak suggests that the placebo mixture is directly absorbed in the proximal small intestine resulting in an increase in plasma glucose concentration. A similar result was observed by Poppitt et al. where the ileal infusion of glucose prevented an increase in plasma glucose concentration to occur. These investigators observed an increase in Glucagon-like peptide 1 (GLP-1) release, which may explain the absence of the glucose peak after ileal glucose infusion. ${ }^{22}$ The study presented in this thesis was designed and carried out as a proof-of-principle test. We did not investigate the exact timing and location of release of the micro-encapsulates. More studies are needed to investigate the exact location of disintegration of microencapsulates and whether repetitive ingestion is able to induce weight loss on the longer term. In chapter 4, lipids were encapsulated in calcium-alginate beads to delay lipolysis with the purpose to prevent absorption in the proximal small intestine and as 
a result increase the exposure of the distal small intestine to lipid. It was shown that ingestion of this yoghurt containing emulsion-alginate beads resulted in a small but significant effect on food intake. This result on food intake was comparable to the effects on food intake observed in chapter 3. In that study, the digestion dynamics of the encapsulated lipids were anticipated via extensive in vitro experiments. For both studies, more detailed knowledge on the exact behavior (disintegration time) of the encapsulated lipids and carbohydrate and protein mixture in vivo in the small intestinal lumen is needed.

The effects on food intake observed in chapter 3 and 4 are less pronounced compared to several intubation studies. A possible factor negatively interfering with intake of food is the use intestinal tubes for nutrient delivery. These tubes give rise to discomfort and thereby affecting eating behavior. Another important notification is that, as observed in Fabuless, the functionality of the micro-encapsulates and emulsion-alginate bead can be influenced by the thermal processing of food. ${ }^{23}$ This needs to be studied in more detail before these delayed delivery techniques can be effectively applied in daily life.

\section{Gastric sensing}

The stomach plays a major role in controlling satiety and food intake. The mechanisms of action of food intake regulation in the stomach differ from the mechanisms in the small intestine. The signals arising from the small intestine in response to the presence of nutrients in the lumen are mainly activated by chemo sensation of the intraluminal content. The satiating effect from the stomach is mainly caused by mechanical stimulation, from volume and pressure changes of the stomach wall, that lead to meal termination. Distension of the stomach wall activates mechanosensitive vagal afferents, sending signals to specific areas the brain that influence food intake and satiety. Human studies have shown that distension of the stomach wall via inflation of a balloon results in a reduction in hunger scores. ${ }^{24-26}$ In contrast to chapter 3 and 4 , where nutrient sensing of the small intestine was investigated to help to reduce food intake, in chapter 5 we investigated a strategy to increase food intake via a gastric intervention. Despite the worldwide major health problems caused by overweight and obesity, there are still a lot of patients suffering from malnutrition. Especially elderly and patients with malignancies suffer from anorexia and malnutrition. ${ }^{27,28}$ In elderly, postprandial fullness and satiation are increased compared to younger subjects. This is associated with delayed gastric emptying, larger antral area and overactive sensing profile of the gastrointestinal mechanoreceptors. ${ }^{29}$ In chapter 5 , we hypothesized that inhibition of the signals 
arising from the mechanoreceptors in the stomach wall causes a greater distension during a meal. In rats, it was shown that gastric infusion of lidocaine, a local anesthetic, resulted in an increase in food intake. ${ }^{30}$ We were not able to fully replicate the impressive results from the animal studies in humans; we observed a modest, non-significant increase in food intake after infusion of $200 \mathrm{mg}$ lidocaine directly into the stomach compared to placebo. Lidocaine was well tolerated by all the participants and did not cause more Gl symptoms compared to placebo infusion. A possible explanation for the non-significant differences in our study is related to the fact that we included healthy male volunteers with normal eating behavior and intact gastric capacity. In the placebo experiment the volunteers already had near maximum intake of an ad libitum meal, a condition that could not be further improved via lidocaine infusion. Future experiments should focus on subjects with impaired gastric capacity such as dyspeptic patients, cancer patients or elderly.

Another factor is related to the gastric area that was inhibited by lidocaine. It is known that the both the proximal and distal stomach have a key role in the perception of fullness and meal termination. After oral ingestion a meal is initially stored in the proximal part of the stomach. When gastric emptying starts, the meal is gradually transported to the antrum. In our study, infusion of lidocaine may have blunted signals arising from mechanosensitive afferents in the distal instead of the proximal stomach, because of the more distal infusion catheter position. Impaired signalling from the distal stomach may have resulted in more rapid gastric emptying and activation of the duodenal brake, thereby inhibiting additional food intake of the meal.

\section{Sensing of non-caloric tastants in the proximal Gl tract}

Gastric satiation is known to be volume, stretch and distension dependent, while intestinal satiation is primarily dependent on sensing of intraluminal nutrients and influenced by the caloric load of these nutrients. Non-caloric tastants (combination of bitter, sweet and umami) are able to exert food intake reduction when infused into the duodenum. ${ }^{31}$ Herewith, it was shown that satiety signals from the intestine are not solely related to the number of calories ingested, but also from other characteristics of food ('taste molecules'). Taste receptors are expressed in the entire small intestinal tract, however it was unknown whether a proximal to distal gradient in food reduction is also present for this receptor activation. ${ }^{32}$ In chapter 6 , it was shown that the effect of infusion of tastants solely into the duodenum or ileum, or infused simultaneously in both locations, were not able to decrease food intake. An explanation for the inability to replicate the results in the study of van Avesaat et al., may be related to the study protocol involving the catheter placement. In our study, participants were intubated 
with a naso-duodenal-ileal catheter for four consecutive days and they consumed the ad libitum meal with catheter. In study protocol of Avesaat et al., the catheter was removed before the ad libitum meal and the meal consumption was not influenced by the presence of an intestinal catheter. From an evolutionary perspective it is apparent that taste receptors are more widely distributed and activated in the more proximal parts of the gastrointestinal tract. For example, bitter substances are linked to a potentially toxic effect, therefore sensing of these bitter compounds results in food aversion. ${ }^{33}$ Little is known about taste receptor expression and distribution throughout the Gl tract. This information is relevant and may help to develop strategies for weight management.

\section{Nociceptive function of the gut: understanding pain mechanisms in the esophagus using capsaicin}

Pain mechanisms in the Gl tract contribute to preserve gut health. Capsaicin, the pungent substance in chili peppers, is known to elicit a pain response via activation of TRPV1 receptors. In patients with complaints of heartburn or retrosternal pain but without esophageal erosions upon endoscopic examination, also referred to as nonerosive reflux disease, the exact mechanism of generation of pain symptoms is not completely understood. An increased transcription and expression of the TRPV1 receptor in these group of patients has been described in literature. ${ }^{34,35}$ In order to better understand the role of the esophageal mucosa in this complex process, we infused capsaicin into the distal esophagus. We observed in that experiment, that an impaired mucosal barrier plays a key role in the generation of symptoms. A reflex mechanism was activated in the proximal part of the esophagus in order to protect the afferent nerve endings from excitation resulting in pain. This effect is comparable to the effects observed in the small intestine: sensing a stressor (capsaicin), tastant or macronutrient results in an effect of the more proximally located parts of the Gl tract (feedback inhibition or activation). We provided evidence that the mucosal barrier plays a key role in esophageal pain sensation. This pain response was not related to the amount TRPV1 mRNA or protein in the esophageal mucosa. These results provide additional insight into esophageal pain symptom generation that has clinical relevance for treatment of this symptom, providing rationale for "esophageal barrier protection" as a therapeutic modality.

\section{Implication and suggestions for future directions}

Sensing and signalling in the Gl tract in order to maintain gut health is becoming an interesting research topic. An important aim is to better understand the physiology of 
nutrients, gastric and food component sensing because this may provide leads to therapeutic interventions in pathological conditions such as obesity and malnutrition. In this thesis, several strategies have been presented. Here we provide suggestions for future research focusing on nutrient, food components and mechanical sensing. The research in strategies to increase satiety signals has focused on the negative feedback in the Gl tract in order to explore whether this intestinal brake can be used as anti-obesity measure. In chapter 2, it was concluded that a proximal to distal gradient exists in relationship to intestinal brake activation and that the ileum has the most pronounced effect on satiety and food intake. This was studied for macronutrients and non-caloric tastants with naso-intestinal catheters. Distal intestinal delivery of a micro-encapsulate mixture of protein and carbohydrate (chapter 3) and lipids from emulsion alginate beads (chapter 4) was investigated and resulted in a decrease in food intake and increase in satiety. The exact intestinal behavior of these products and underlying mechanisms need to be investigated in more detail. In vivo studies, with biological markers (blood concentrations, intestinal aspiration at multiple sites, or on radiography), may help to provide more information of the exact site of release of the nutrients and in this way, help to design interventions aimed at maximizing biological effects. For clinical use, these products need to be studied over a longer period of time with multiple ingestions spread over the day. Moreover, long-term studies (weeks, months) are needed to demonstrate whether these products, after showing acute effects, are also able to exert long-term effects on food intake and on body weight. Human studies with these types of products focusing on the prevention of weight gain in pre-obese subjects would be of interest but are very demanding and costly. Up to now, little is known on ileal brake activation with slow release or encapsulated products in obese subjects. The majority of the human studies that investigated the mechanisms related to the intestinal brake have been performed in healthy volunteers. Some studies have suggested that intestinal brake activation is less pronounced in overweight and obese subjects compared to lean subjects. ${ }^{36,37}$ Moreover, it would be interesting to investigate the efficacy of encapsulation of macronutrients versus non-caloric tastants; it is hypothesized that non-caloric tastants exert their negative feedback on satiety in the more proximal parts of the small intestine, especially the bitter substance. We recommended to investigate encapsulation of the bitter substance and not of a mixture as desired effects on food intake might be blunted this way. From an evolutionary point of view, bitter substances are linked to food aversion. The strong bitter substance denatonium benzoate is added to household products to prevent ingestion of potential harmful noxious products through taste aversion. ${ }^{38,39}$ This bitter substance is known to suppress food intake and gastric motility in mice ${ }^{40}$ and 
stimulate the in vitro release of GLP-1 and cholecystokinin (CCK), which increase satiety and satiation. It is crucial to investigate whether infusion of such a strong bitter substance in the proximal parts of the Gl tract in humans will eventually result in a reduction in food intake. In addition, distribution of the tastants receptors in the small intestinal tract needs to be explored in more detail. This knowledge will also aid the development of more effective anti-obesity strategies based on the stimulation of intestinal test receptors. Taken together, more detailed understanding is crucial in the advancement of the intestinal brake research field as many experimental results have not been reproducible in the clinical setting. We need to return to basic science approaches to unravel the molecular background of intestinal sensing and investigate the physico-chemical properties, intestinal behavior and biological effects of novel encapsulated products aimed at effective stimulation of abovementioned sensing mechanisms. A promising strategy with the potential to decrease satiety signals was investigated for the first time in humans (chapter 5).

Lidocaine infusion into the stomach did not result in significant effects on food intake or satiety. Several lessons were learned from that study. First, since lidocaine was well tolerated, in future studies, the dose of lidocaine should be further increased. Second, lidocaine can be dissolved in a larger volume in order to reach a larger surface area with more pronounced blunting of signals arising from the mechanoreceptors in the stomach wall. Third, the tip of the gastric catheter should be placed at the esophago-gastric junction in order to maximize exposure of the fundic region to lidocaine. Fourth, we also observed an order effect; participants ate significantly more on the second test day compared to first test day. We hypothesized that participants were more familiar with the study procedures (catheter placement and removal), which caused this significant test day effect. For future studies, it is recommended to choose a parallel study design instead of a crossover study. Fifth, the effect of lidocaine on food intake deserves further evaluation in conditions with impaired food intake, for example in patients with disturbed gastrointestinal sensory perceptions.

Chapter 7 provided more insight in esophageal pain symptom generation and it was observed that the mucosal barrier plays a key role in this mechanism as part of the nociceptive sensing function of the upper Gl tract. It would be of clinical relevance to investigate whether there are therapeutic modalities to enforce the mucosal barrier in order to prevent symptoms to arise, for example in patients with NERD. Several products aimed at esophageal mucosal protection are now available on the market, however, their exact efficacy and role in a therapeutic algorithm needs further clarification. These products could have an important therapeutic potential, since not all patients with GERD have a therapeutic response during acid suppressive therapy. 
In Table 9.1 we summarized the existing compounds which are able to produce a therapeutic effect on the mucosal barrier. Many of these products are derived from natural compounds. One recent study of Leite Sales et al. studied the native sulfated polysaccharide Gracilaria Caudata and it was shown that this substance had a protective role in the esophageal mucosal barrier in NERD patients. ${ }^{41}$ There is in fact quite a long history of these products but there has not yet been a breakthrough in terms of their application in clinical practice. Perhaps this is related to our incomplete understanding of esophageal sensory physiology. The current findings can open the scientific discussion anew in order to establish the position of these products in the management of reflux symptoms. In this respect, it is interesting to further investigate which structural aspects of these mucoprotective compounds are responsible their beneficial effect. Studies investigating the esophageal barrier function in vivo (using for instance baseline impedance measurements) allow further insight into these mechanisms.

Table 9.1 Mucosal protective compounds.

\begin{tabular}{|c|c|c|c|c|c|}
\hline Compound & Composition & Mechanism of action & $\begin{array}{l}\text { Clinical } \\
\text { effectiveness }\end{array}$ & Side effects & Reference \\
\hline Sucralfate & $\begin{array}{l}\text { Aluminum salt } \\
\text { of sucrose } \\
\text { sulfate }\end{array}$ & $\begin{array}{l}\text { Adsorb bile salts and } \\
\text { forming stable } \\
\text { complexes with } \\
\text { protein molecules } \\
\text { which are resistant to } \\
\text { pepsin }\end{array}$ & $\begin{array}{l}\text { 1. Improving } \\
\text { symptoms } \\
\text { 2. Healing erosive } \\
\text { esophagitis } \\
\text { 3. Maintenance } \\
\text { therapy for GERD }\end{array}$ & $\begin{array}{l}\text { 1. Constipation } \\
\text { 2. Benzoar } \\
\text { formation and } \\
\text { encephalopathy }\end{array}$ & $42-45$ \\
\hline Alginate & Seaweed & $\begin{array}{l}\text { Forms a raft floating } \\
\text { over gastric contents }\end{array}$ & $\begin{array}{l}\text { 1. Reduces the } \\
\text { number of acid reflux } \\
\text { 2. Displace the } \\
\text { postprandial acid } \\
\text { pocket in patients } \\
\text { with reflux } \\
\text { 3. Covers the } \\
\text { esophageal luminal } \\
\text { mucosa }\end{array}$ & $\begin{array}{l}\text { No significant side } \\
\text { effects }\end{array}$ & $46-48$ \\
\hline $\begin{array}{l}\text { Hyaluronic } \\
\text { acid } \\
\text { chondroitin } \\
\text { sulfate }\end{array}$ & $\begin{array}{l}\text { Both } \\
+ \text { compounds } \\
\text { are } \\
\text { glycosamino- } \\
\text { glycans }\end{array}$ & $\begin{array}{l}\text { Dispersed in a bio } \\
\text { adhesive carrier these } \\
\text { compounds form } \\
\text { macromolecular } \\
\text { complex which coats } \\
\text { the esophageal } \\
\text { mucosa }\end{array}$ & $\begin{array}{l}\text { 1. Short term } \\
\text { symptom relief in } \\
\text { patients with NERD } \\
\text { and GERD. } \\
\text { 2. In combination with } \\
\text { PPI, there was more } \\
\text { symptom relief than } \\
\text { PPI alone. }\end{array}$ & Allergy & 49 \\
\hline
\end{tabular}




\section{References}

1. Cummings JH, Antoine JM, Azpiroz F, Bourdet-Sicard R, Brandtzaeg P, Calder PC, et al. PASSCLAIM--gut health and immunity. Eur J Nutr. 2004;43 Suppl 2:I118-II73.

2. Read NW, McFarlane A, Kinsman RI, Bates TE, Blackhall NW, Farrar GB, et al. Effect of infusion of nutrient solutions into the ileum on gastrointestinal transit and plasma levels of neurotensin and enteroglucagon. Gastroenterology. 1984;86(2):274-80.

3. Spiller RC, Trotman IF, Higgins BE, Ghatei MA, Grimble GK, Lee YC, et al. The ileal brake--inhibition of jejunal motility after ileal fat perfusion in man. Gut. 1984:25(4):365-74.

4. $\quad$ Payne JH, DeWind LT. Surgical treatment of obesity. Am J Surg. 1969:118(2):141-7.

5. Welch I, Saunders K, Read NW. Effect of ileal and intravenous infusions of fat emulsions on feeding and satiety in human volunteers. Gastroenterology. 1985;89(6):1293-7.

6. Welch IM, Sepple CP, Read NW. Comparisons of the effects on satiety and eating behaviour of infusion of lipid into the different regions of the small intestine. Gut. 1988;29(3):306-11.

7. Lin HC, Zhao XT, Wang L. Intestinal transit is more potently inhibited by fat in the distal (ileal brake) than in the proximal (jejunal brake) gut. Dig Dis Sci. 1997:42(1):19-25.

8. Chaikomin R, Wu KL, Doran S, Meyer JH, Jones KL, Feinle-Bisset C, et al. Effects of mid-jejunal compared to duodenal glucose infusion on peptide hormone release and appetite in healthy men. Regul Pept. 2008;150(1-3):38-42.

9. van Avesaat M, Troost FJ, Ripken D, Hendriks HF, Masclee AA. Ileal brake activation: macronutrientspecific effects on eating behavior? Int J Obes (Lond). 2015:39(2):235-43

10. Lin HC, Doty JE, Reedy TJ, Meyer JH. Inhibition of gastric emptying by acids depends on $\mathrm{pH}$, titratable acidity, and length of intestine exposed to acid. Am J Physiol. 1990;259(6 Pt 1):G1025-30.

11. Meyer JH, Tabrizi Y, DiMaso N. Hlinka M, Raybould HE. Length of intestinal contact on nutrient-driven satiety. Am J Physiol. 1998;275(4):R1308-19

12. Ryan AT, Feinle-Bisset C, Kallas A, Wishart JM, Clifton PM, Horowitz M, et al. Intraduodenal protein modulates antropyloroduodenal motility, hormone release, glycemia, appetite, and energy intake in lean men. Am J Clin Nutr. 2012;96(3):474-82.

13. van Avesaat M, Ripken D. Hendriks HF, Masclee AA, Troost FJ. Small intestinal protein infusion in humans: evidence for a location-specific gradient in intestinal feedback on food intake and Gl peptide release. Int J Obes (Lond). 2017:41(2):217-24.

14. Steinert RE, Luscombe-Marsh ND, Little TJ, Standfield S, Otto B, Horowitz M, et al. Effects of intraduodenal infusion of L-tryptophan on ad libitum eating, antropyloroduodenal motility, glycemia, insulinemia, and gut peptide secretion in healthy men. J Clin Endocrinol Metab. 2014;99(9):3275-84.

15. Feltrin KL, Little TJ, Meyer JH, Horowitz M, Rades T, Wishart J, et al. Effects of lauric acid on upper gut motility, plasma cholecystokinin and peptide $Y Y$, and energy intake are load, but not concentration, dependent in humans. J Physiol. 2007:581(Pt 2):767-77.

16. Weerts Z, Keszthelyi D, Vork L, Aendekerk NCP, Frijlink HW, Brouwers J, et al. A Novel Ileocolonic Release Peppermint Oil Capsule for Treatment of Irritable Bowel Syndrome: A Phase I Study in Healthy Volunteers. Adv Ther. 2018:35(11):1965-78.

17. Weerts Z, Masclee AAM, Witteman BJM, Clemens CHM, Winkens B, Brouwers J, et al. Efficacy and Safety of Peppermint Oil in a Randomized, Double-Blind Trial of Patients With Irritable Bowel Syndrome. Gastroenterology. 2020;158(1):123-36.

18. Burns AA, Livingstone MB, Welch RW, Dunne A, Reid CA, Rowland IR. The effects of yoghurt containing a novel fat emulsion on energy and macronutrient intakes in non-overweight, overweight and obese subjects. Int J Obes Relat Metab Disord. 2001;25(10):1487-96.

19. Burns AA, Livingstone MB, Welch RW, Dunne A, Robson PJ, Lindmark L, et al. Short-term effects of yoghurt containing a novel fat emulsion on energy and macronutrient intakes in non-obese subjects. Int $J$ Obes Relat Metab Disord. 2000;24(11):1419-25

20. Knutson L, Koenders DJ, Fridblom H, Viberg A, Sein A, Lennernas H. Gastrointestinal metabolism of a vegetable-oil emulsion in healthy subjects. Am J Clin Nutr. 2010:92(3):515-24. 
21. Chan YK, Strik CM, Budgett SC, McGill AT, Proctor J, Poppitt SD. The emulsified lipid Fabuless (Olibra) does not decrease food intake but suppresses appetite when consumed with yoghurt but not alone or with solid foods: a food effect study. Physiol Behav. 2012;105(3):742-8.

22. Poppitt SD, Shin HS, McGill AT, Budgett SC, Lo K, Pahl M, et al. Duodenal and ileal glucose infusions differentially alter gastrointestinal peptides, appetite response, and food intake: a tube feeding study. Am J Clin Nutr. 2017:106(3):725-35.

23. Smit HJ, Keenan E, Kovacs EM, Wiseman SA, Peters HP, Mela DJ, et al. No efficacy of processed Fabuless (Olibra) in suppressing appetite or food intake. Eur J Clin Nutr. 2011;65(1):81-6.

24. Nieben OG, Harboe $H$. Intragastric balloon as an artificial bezoar for treatment of obesity. Lancet. 1982;1(8265):198-9.

25. Powley TL, Phillips RJ. Gastric satiation is volumetric, intestinal satiation is nutritive. Physiol Behav. 2004:82(1):69-74.

26. Rigaud D, Trostler N, Rozen R, Vallot T, Apfelbaum M. Gastric distension, hunger and energy intake after balloon implantation in severe obesity. Int J Obes Relat Metab Disord. 1995:19(7):489-95.

27. Morley JE. Anorexia of aging: physiologic and pathologic. Am J Clin Nutr. 1997:66(4):760-73.

28. Ryan AM, Power DG, Daly L, Cushen SJ, Ni Bhuachalla E, Prado CM. Cancer-associated malnutrition, cachexia and sarcopenia: the skeleton in the hospital closet 40 years later. Proc Nutr Soc. 2016;75(2): 199-211.

29. Sturm K, Parker B, Wishart J, Feinle-Bisset C, Jones KL, Chapman I, et al. Energy intake and appetite are related to antral area in healthy young and older subjects. Am J Clin Nutr. 2004:80(3):656-67.

30. http://patentscope.wipo.int/search/en/detail.jsf?docld=WO2013171252\&recNum=36\&maxRec=105995 \&office=\&prevFilter=\&sortOption=\&queryString=\&tab=PCTDescription. BCPMtFFlaFRIAf, inventor.

31. van Avesaat M, Troost FJ, Ripken D, Peters J. Hendriks HF, Masclee AA. Intraduodenal infusion of a combination of tastants decreases food intake in humans. Am J Clin Nutr. 2015;102(4):729-35.

32. Bezencon C, le Coutre J. Damak S. Taste-signaling proteins are coexpressed in solitary intestinal epithelial cells. Chem Senses. 2007:32(1):41-9.

33. Steiner JE, Glaser D. Hawilo ME, Berridge KC. Comparative expression of hedonic impact: affective reactions to taste by human infants and other primates. Neurosci Biobehav Rev. 2001;25(1):53-74.

34. Knowles CH, Aziz Q. Visceral hypersensitivity in non-erosive reflux disease. Gut. 2008:57(5):674-83.

35. Guarino MP, Cheng L, Ma J. Harnett K, Biancani P. Altomare A, et al. Increased TRPV1 gene expression in esophageal mucosa of patients with non-erosive and erosive reflux disease. Neurogastroenterol Motil. 2010;22(7):746-51, e219.

36. Duca FA, Swartz TD, Sakar Y, Covasa M. Decreased intestinal nutrient response in diet-induced obese rats: role of gut peptides and nutrient receptors. Int J Obes (Lond). 2013:37(3):375-81.

37. Stewart JE, Seimon RV, Otto B, Keast RS, Clifton PM, Feinle-Bisset C. Marked differences in gustatory and gastrointestinal sensitivity to oleic acid between lean and obese men. Am J Clin Nutr. 2011;93(4):703-11.

38. Berning CK, Griffith JF, Wild JE. Research on the effectiveness of denatonium benzoate as a deterrent to liquid detergent ingestion by children. Fundam Appl Toxicol. 1982;2(1):44-8.

39. Sibert JR, Frude N. Bittering agents in the prevention of accidental poisoning: children's reactions to denatonium benzoate (Bitrex). Arch Emerg Med. 1991:8(1):1-7.

40. Janssen S, Laermans J, Verhulst PJ, Thijs T, Tack J. Depoortere I. Bitter taste receptors and alphagustducin regulate the secretion of ghrelin with functional effects on food intake and gastric emptying. Proc Natl Acad Sci U S A. 2011;108(5):2094-9.

41. Sales T, Nicolau LAD, Rodrigues RLM, Nascimento RR, Paula SM, da Costa-Filho HB, et al. Polysaccharide from Gracilaria caudata protects the human esophageal mucosal barrier: A differential topical effect and structural dependence. Int J Biol Macromol. 2020;150:354-61.

42. Williams RM, Orlando RC, Bozymski EM, Readling RD, Castell DO, Roufail WM, et al. Multicenter trial of sucralfate suspension for the treatment of reflux esophagitis. Am J Med. 1987:83(3B):61-6.

43. Surdea-Blaga T, Bancila I, Dobru D, Drug V. Fratila O, Goldis A, et al. Mucosal Protective Compounds in the Treatment of Gastroesophageal Reflux Disease. A Position Paper Based on Evidence of the Romanian Society of Neurogastroenterology. J Gastrointestin Liver Dis. 2016;25(4):537-46.

44. Orlando RC, Turjman NA, Tobey NA, Schreiner VJ, Powell DW. Mucosal protection by sucralfate and its components in acid-exposed rabbit esophagus. Gastroenterology. 1987:93(2):352-61. 
45. Donnellan C, Sharma N. Preston C. Moayyedi P. Medical treatments for the maintenance therapy of reflux oesophagitis and endoscopic negative reflux disease. Cochrane Database Syst Rev. 2005(2): CD003245.

46. Kwiatek MA, Roman S, Fareeduddin A, Pandolfino JE, Kahrilas PJ. An alginate-antacid formulation (Gaviscon Double Action Liquid) can eliminate or displace the postprandial 'acid pocket' in symptomatic GERD patients. Aliment Pharmacol Ther. 2011;34(1):59-66.

47. Savarino E, de Bortoli N, Zentilin P, Martinucci I, Bruzzone L, Furnari M, et al. Alginate controls heartburn in patients with erosive and nonerosive reflux disease. World J Gastroenterol. 2012;18(32):4371-8.

48. Zentilin P, Dulbecco P. Savarino E, Parodi A, liritano E, Bilardi C, et al. An evaluation of the antireflux properties of sodium alginate by means of combined multichannel intraluminal impedance and $\mathrm{pH}$ metry. Aliment Pharmacol Ther. 2005:21(1):29-34.

49. Savarino V. Pace F. Scarpignato C, Esoxx Study G. Randomised clinical trial: mucosal protection combined with acid suppression in the treatment of non-erosive reflux disease - efficacy of Esoxx, a hyaluronic acid-chondroitin sulphate based bioadhesive formulation. Aliment Pharmacol Ther. 2017: 45(5):631-42. 



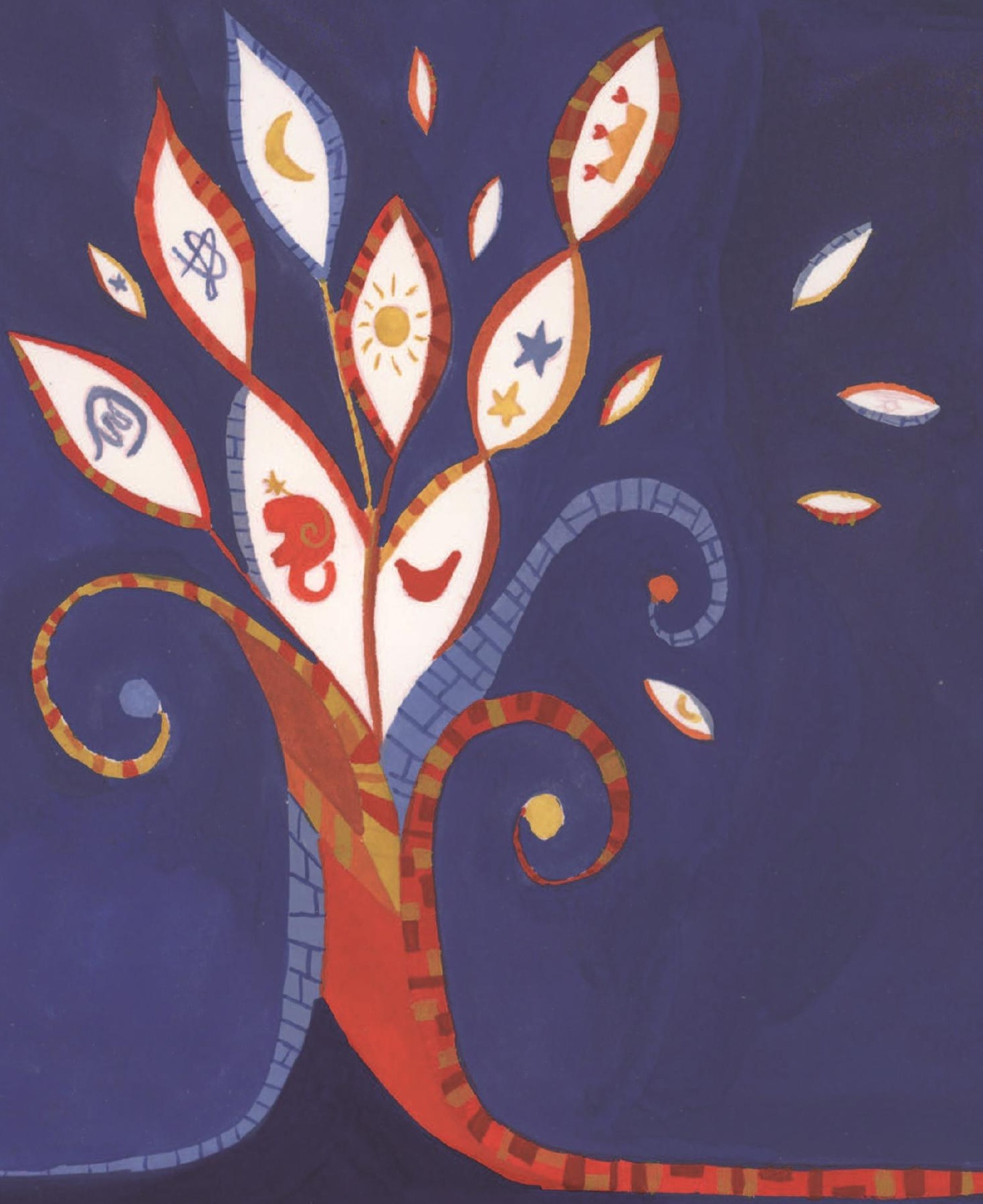




\title{
ADDENDUM
}

\author{
Summary \\ Samenvatting \\ Impact \\ Dankwoord \\ List of publications \\ Curriculum vitae
}


Addendum 


\section{Summary}

The gastrointestinal (Gl) tract is a large sensory organ that responds to a wide variety of signals originating from the Gl lumen, for example, nutrients and endogenous or exogenous substances that can have beneficial effects but also potentially noxious. Sensing of these substances via the mucosal receptors and the signals arising from these responses are crucial for maintaining physiological homeostatic processes. We focused on the ability of the Gl lumen to sense nutrients or food components and consequently activating signals to influence food intake and satiety. Furthermore, we investigated the effect of a potentially noxious substance on pain regulation in the esophagus.

In Chapter 2, we reviewed studies in which gastrointestinal nutrient (protein, fat and carbohydrates) infusion was performed. There was substantial evidence that all parts of the Gl tract are able to activate the so-called 'intestinal brake', a negative feedback mechanism on food intake and satiety. We observed a difference between the site and the length of infusion in the small intestine and the magnitude of this effect on food intake and satiety. In several studies it was observed that the ileum had the most potent effect on food intake and satiety. A proximal to distal gradient with regards to gastrointestinal nutrient infusion seems to exist.

In Chapter 2, we concluded that activation of the 'ileal brake' reduces food intake and alters satiety to the greatest extent. Other studies also showed the potential of repetitive ileal brake activation and its possible effect on long term weight management. These studies were performed with naso-intestinal catheters. To investigate the possible clinical application of ileal brake activation, less invasive strategies are needed. In Chapter 3. we performed a 'proof of concept' study in which we investigated the effect of encapsulated macronutrients (protein, fat and carbohydrates) targeting the distal small intestine. The effect on food intake and satiety was compared to a control product that integrated in the proximal Gl tract (stomach). Fifty-nine healthy volunteers with overweight were included in this double-blind randomized, controlled, cross-over study. The study was performed within two test days in which the volunteers received in random order the encapsulated nutrient mixture or the control product. Visual analogue scale (VAS) scores for satiety and blood samples for glucose analysis were collected during the test day and food intake was measured with an ad libitum meal at the end of the test day. Ingestion of the encapsulated nutrient mixture decreased food intake compared to the control product. Moreover, VAS scores for hunger and satiety were significant 
different from the control product. Plasma glucose concentrations immediately increased after ingestion of the control product, while the encapsulated nutrient mixture did not show an increase. This observation suggests more distal release of the encapsulated nutrient mixture and a proximal release of the control product. Future studies are needed to investigate whether this effect is sustained after repetitive ingestion of the encapsulated nutrient mixture. Future studies should also focus on long-term results after orally ingested macronutrients with distal release and whether this strategy can be used in weight management.

In Chapter 4, we investigated whether lipids, encapsulated in calcium alginate beads, delay lipolysis with the purpose to prevent absorption in the proximal small intestine and as a result increase the exposure in the distal small intestine. These emulsionalginate beads were added to yoghurt and ingested by healthy overweight subjects in a cross-over design. The control product contained an equicaloric mixture of nonencapsulated nutrients with similar sensory properties. Food intake was measured with an ad libitum meal and satiety scores were measured during the test day. We observed that food intake significantly reduced compared to the control product.

In contrast to chapter 3 and 4 , where nutrient sensing of the small intestine was investigated to reduce food intake and increase satiety, in Chapter 5 we investigated an intervention to increase food intake and alter satiety via a gastric intervention. Increasing food intake could be beneficial in the elderly population who suffer from 'anorexia of aging' or patients with chronic diseases in which anorexia or cachexia (for example cancer cachexia) occur. We hypothesized that inhibition of signals arising from the mechanoreceptors in the stomach wall by lidocaine, a local anesthetic, caused a greater distension during a meal, and consequently have a negative feedback on satiety and food intake. In rats, it was already observed that this intervention increased food intake. In this human trial, we were not able to replicate the results observed in rats. We observed a modest, non-significant, increase in food intake after infusion of $200 \mathrm{mg}$ lidocaine with a catheter in the stomach compared to placebo infusion. The small, non-significant increase can be explained by the fact that in this study we only include healthy participants and not patients with disturbed gastrointestinal sensory perception. Previous studies have shown that sensory pathways in the Gl tract are affected by age. The results in Chapter 3, 4 and $\mathbf{5}$ show that the $\mathrm{Gl}$ tract is an attractive target in altering food intake and satiety and this paves the way for future studies to further elucidate the concept of modifying responses arising from the $\mathrm{Gl}$ tract to the content of the intestinal lumen and consequently influence food intake and satiety. 
Another important function of the gastrointestinal tract is sensing different taste signals. There are five basics tastes: bitter, sour, sweet, salty and umami. The function of taste receptors in the Gl tract is to sense food components. Several studies have shown that these taste receptors are expressed throughout the entire Gl tract. It was already observed that duodenal infusion of a combination of sweet, bitter and umami significantly decreased food intake and increased satiety scores. In Chapter 6, we investigated whether the aforementioned proximal-to-distal gradient found for the intestinal brake (Chapter 2) is also operative for taste receptor activation. We conducted a single-blind randomized cross-over trial in which 14 participants where intubated with a nasoduodenalileal catheter. They all received four infusion regimens: duodenal and ileal placebo, duodenal tastants and ileal placebo, duodenal placebo ileal tastants, duodenal tastants and ileal tastants. We observed no differences in food intake or satiety between the various interventions. A possible explanation for not being able to replicate the results from a previous study is that all participants were intubated with a catheter for four consecutive days, which may have influenced small effects on eating behavior.

The physiological role of the Gl tract is to sense nutrients and activate appropriate effector mechanisms. Another important role of the intestinal lumen is to detect and eliminate potentially harmful substances and consequently initiate several protective responses. We investigated in Chapter 7 whether a possible protective response occurs after perfusion of a potentially harmful substance in the esophagus. Capsaicin, the pungent substance is known for its ability to induce pain via the Transient Receptor Potential Vanilloid 1 (TRPV-1) channel. This receptor plays an important role in nociceptive signalling of somatic and visceral pain. In this study, we investigated whether esophageal TRPV1 activation by capsaicin perfusion induces pain and affects the mucosal barrier integrity. The mucosal barrier integrity was evaluated by intraluminal impedance measurements and evaluation of intercellular space width by transmission electron microscopy (TEM). We observed that capsaicin perfusion resulted in TRPV1 activation and consequently induced more pain compared to the saline-treated participants. This is likely to be explained by an impaired mucosal barrier and defective restoration capacity in the esophagus. A disrupted mucosal barrier in the esophagus results in more TRPV1 activation by the phenomenon that the sensory nerve afferents which express the TRPV1 receptor are more exposed to capsaicin. The sensing mechanism of capsaicin in the esophageal lumen and the signals arising from this pain sensation could provide rationale for esophageal barrier protection as a therapeutic modality. 
In Chapter 8, we compared two different methods to evaluate intercellular space in esophageal biopsies. In this study we compared the classic evaluation of the intercellular space (ISDC) with an alternative method; the relative intercellular space area (ISA). The most important difference between these two methods is the number of transmission electron microscopy photos needed for analysis (10 vs. 3). Another importation concern is that ISDc may not fully take the irregularity of intercellular space delineation into account. The results showed that evaluation of the intercellular space using the alternative ISA method showed a strong correlation with the values obtained with ISDc. The alternative method (ISDC) is more representative and less time-consuming. ISA also showed a high intra and interobserver agreement. This more representative and less timeconsuming approach can be used to reliably assess the intercellular space in patients with gastroesophageal reflux disease (GERD) or nonerosive gastroesophageal reflux disease (NERD) in future studies.

In Chapter 9, we summarized and integrated the key findings of the studies presented in this thesis. New findings in relation to previous described studies with regards to the sensing and signaling function of the upper Gl tract are also discussed. 


\section{Samenvatting}

Het maag-darmstelsel is een orgaan dat reageert op een breed scala aan signalen afkomstig vanuit het lumen van het maag-darmstelsel. Voorbeelden hiervan zijn voedingsstoffen, endogene of exogene stoffen met potentieel gunstige of potentieel schadelijke effecten. Het detecteren ('sensing') van deze stoffen via de mucosale receptoren en de signalen die hierna ontstaan zijn cruciaal voor het in standhouden van verschillende fysiologische homeostatische processen in het lichaam. We hebben ons in dit proefschrift gefocust op de eigenschappen van het lumen van het maag-darmstelsel om voedingsstoffen of voedselcomponenten te detecteren en als gevolg hiervan signalen te activeren om de voedselinname en verzadiging te beïnvloeden. Daarnaast onderzochten we het beschermende effect van een potentieel schadelijke stof en de relatie met pijnregulatie in de slokdarm.

In Hoofdstuk 2 evalueren we studies waarin macronutriënten (eiwitten, vetten en koolhydraten) in verschillende delen van het maag-darmstelsel werden geïnfundeerd. Er is substantieel bewijs dat alle delen van het maag-darmstelsel de zogenoemde 'intestinal brake' kunnen activeren. Dit beschrijft een negatief feedbackmechanisme op voedselinname en verzadiging. We observeerden een verschil tussen de plaats en de lengte van de infusie in de dunne darm en de mate van dit effect op de voedselinname en verzadiging. Verschillende studies toonden dat het ileum het grootste negatieve effect had op voedselinname en verzadiging. Er lijkt een proximale naar distale gradiënt te bestaan met betrekking tot infusie van macronutriënten in de dunne darm en het effect op voedselinname en verzadiging.

In Hoofdstuk 2 concludeerden we dat activering van de 'ileal brake' het grootste effect heeft op voedselinname en verzadiging. Andere studies toonden ook dat herhaaldelijke activering van de 'ileal brake' een mogelijk effect heeft op lichaamsreductie voor de langere termijn. Deze studies zijn uitgevoerd met neusdarm katheters. Minder invasieve strategieën zijn nodig om de klinische toepassing van 'ileal brake' activering te onderzoeken.

In Hoofdstuk 3 hebben we een proof of concept studie uitgevoerd waarin we het effect van ge-encapsuleerde macronutriënten (eiwitten, vetten en koolhydraten) die opgenomen werden in de distale dunne darm onderzocht. Het effect van deze geencapsuleerde macronutriënten op voedselinname en verzadiging werd vergeleken met een controle product dat in het proximale deel van het maag-darmstelsel werd opgenomen. 59 gezonde vrijwilligers met overgewicht werden geïncludeerd in deze dubbelblinde, gerandomiseerde, placebo-gecontroleerde, cross-over studie. De 
studie werd uitgevoerd op twee testdagen waarin de vrijwilligers in willekeurige volgorde of het actieve ge-encapsuleerde product of het controle product innamen. Gedurende de testdag werden VAS-scores voor verzadiging en bloedmonsters voor glucose verzameld en de voedselinname werd gemeten middels een ad libitum maaltijd aan het einde van de testdag. Inname van het actieve ge-encapsuleerde product resulteerde in een significante afname van de voedselinname in vergelijking met het controle product. Daarnaast zagen wij een significante afname van VASscores voor honger en een significante toename van VAS-scores voor verzadiging na inname van het actieve ge-encapsuleerde product vergeleken met het controle product. Plasma glucose levels namen onmiddellijk toe na inname van het controle product, terwijl het actieve ge-encapsuleerde product geen toename liet zien. Deze resultaten suggereren dat het controle product direct in het proximale gedeelte van het maag-darmstelsel werd opgenomen en dat het actieve ge-encapsuleerde product mogelijk in het laatste stuk van het maag-darmstelsel werd opgenomen. Toekomstige studies zijn nodig om te onderzoeken of dit effect aanhoudt na herhaaldelijke inname van het ge-encapsuleerde product en zo te onderzoeken of deze strategie toepasbaar is voor gewichtsreductie op de lange termijn.

In Hoofdstuk 4 hebben we onderzocht of vetten, ingekapseld in calcium alginaat korrels, lipolyse vertragen met als doel absorptie in de proximale dunne darm te voorkomen en als resultaat de blootstelling in de distale dunne darm te vergroten. Deze emulsie alginaat korrels werden toegevoegd aan yoghurt en ingenomen door gezonde proefpersonen met overgewicht in een cross-over design. Het controle product bevatte een equicalorisch mengsel van niet-ingekapselde voedingsstoffen met vergelijkbare sensorische eigenschappen. Voedselinname werd gemeten met een ad libitum maaltijd en verzadigingsscores werden gemeten gedurende de testdag. We observeerden dat de voedselinname significant verminderde na inname van het yoghurt product met de ingekapselde vetten in vergelijking met het controle product.

In tegenstelling tot hoofdstuk 3 en 4 , waar het detecteren van voedingsstoffen in de dunne darm werd onderzocht om voedselinname te verminderen en verzadiging te verhogen, onderzochten we in Hoofdstuk $\mathbf{5}$ een interventie om de voedselinname te verhogen en de verzadiging te beïnvloeden met een interventie via de maag. Het verhogen van de voedselinname kan gunstig zijn voor ouderen die lijden aan 'anorexia of aging' of patiënten met chronische ziekten waarbij anorexia of cachexie (bijvoorbeeld kankercachexie) voorkomt. Onze hypothese was dat remming van signalen afkomstig van de mechanoreceptoren in de maagwand door infusie van 
lidocaïne, een lokaal anestheticum, een negatieve feedback heeft op verzadiging en voedselinname. Bij ratten werd dit fenomeen al geobserveerd en toediening van lidocaïne zorgde voor een toename van de voedselinname. In deze humane studie waren we niet in staat om de resultaten die bij ratten werden waargenomen te repliceren. We zagen een kleine, niet-significante, toename van de voedselinname na infusie van 200 mg lidocaïne via een maagkatheter in vergelijking met infusie van de placebo. Deze, niet-significante toename kan worden verklaard door het feit dat we in deze studie alleen gezonde deelnemers hebben geïncludeerd en geen personen met een gestoorde gastro-intestinale sensorische functie. Eerdere studies hebben aangetoond dat de sensorische pathway in het maag-darmstelsel wordt beïnvloed door leeftijd. De resultaten van Hoofdstuk 3, 4 en 5 laten zien dat het maagdarmstelsel een interessant target is om voedselinname en verzadiging te beïnvloeden. Dit maakt de weg vrij voor toekomstige studies om het concept van het modificeren van reacties die voortkomen uit het maag-darmstelsel als reactie op de inhoud van de intestinale lumen en als gevolg daarvan voedselinname en verzadiging te beïnvloeden verder te onderzoeken.

Een andere belangrijke functie van het maag-darmstelsel is het waarnemen van verschillende smaaksignalen. Er zijn vijf basissmaken: bitter, zuur, zoet, zout en umami. De functie van smaakreceptoren in het maag-darmstelsel is het waarnemen van voedselcomponenten. Verschillende onderzoeken hebben aangetoond dat deze smaakreceptoren door het hele maag-darmstelsel tot expressie worden gebracht. Er werd al eerder waargenomen dat duodenale infusie van een combinatie van zoet, bitter en umami de voedselinname significant verminderde en de verzadiging deed toenemen. In Hoofdstuk 6 hebben we onderzocht of de eerdergenoemde proximalenaar-distale gradiënt gevonden voor de 'intestinal brake' activering (Hoofdstuk 2) ook toepasbaar is voor activatie van smaakreceptoren. We hebben een single-blind, gerandomiseerde, cross-over studie uitgevoerd waarbij bij 14 deelnemers een nasoduodenale-ileale katheter werd ingebracht. Ze kregen allemaal vier infusie regimes: duodenum en ileum placebo, duodenum smaakstoffen en ileum placebo, duodenum placebo ileum smaakstoffen, duodenum smaakstoffen en ileum smaakstoffen. We zagen geen verschil in voedselinname of verzadiging tussen de verschillende infusie regimes. Een mogelijke verklaring voor het niet kunnen repliceren van de resultaten van de eerder genoemde studie is dat alle deelnemers vier opeenvolgende dagen een katheter hadden, wat mogelijk een invloed had op het eetgedrag.

De fysiologische rol van het maag-darmstelsel is het detecteren van voedingsstoffen en het activeren en toepassen van effectormechanismen. Een andere belangrijke rol 
van het lumen van de darm is het detecteren en elimineren van potentieel schadelijke stoffen en het initiëren van verschillende beschermende reacties. In Hoofdstuk 7 hebben we onderzocht of er een mogelijke beschermende reactie optreedt na perfusie van een potentieel schadelijke stof in de slokdarm. Capsaïcine staat bekend om zijn vermogen om pijn te veroorzaken via het Transient Receptor Potential Vanilloid 1 (TRPV-1) kanaal. Deze receptor speelt een belangrijke rol bij de nociceptieve signalering van somatische en viscerale pijn. In deze studie hebben we onderzocht of oesofagiale TRPV1-activering door perfusie van capsaïcine in de slokdarm pijn veroorzaakt en de integriteit van de mucosale barrière beïnvloedt. De integriteit van de mucosale barrière werd geëvalueerd door middel van intraluminale impedantiemetingen en evaluatie van de intercellulaire afstand door transmissieelektronenmicroscopie (TEM). We hebben geobserveerd dat capsaïcine perfusie resulteerde in TRPV1-activering en meer pijn veroorzaakte in vergelijking met perfusie van de zout oplossing. Dit wordt waarschijnlijk verklaard door een verminderde mucosale barrière en een onvermogen tot herstel hiervan in de slokdarm. Een verstoorde mucosale barrière in de slokdarm resulteert in meer TRPV1-activering door het fenomeen dat de sensorische zenuwafferenten, die de TRPV1-receptor tot expressie brengen, meer worden blootgesteld aan capsaïcine. Het detectiemechanisme van capsaïcine in het lumen van de slokdarm en de signalen die voortkomen uit deze pijnsensatie geven onderbouwing voor bescherming van de slokdarmbarrière als een therapeutische modaliteit.

In Hoofdstuk 8 hebben we twee verschillende methoden vergeleken om de intercellulaire afstand in slokdarmbiopten te evalueren. In deze studie vergeleken we de klassieke evaluatie van de intercellulaire afstand (ISDC) met een alternatieve methode; relatieve intercellulaire afstand (ISA). Het belangrijkste verschil tussen deze twee methoden is het aantal transmissie-elektronen microscopiefoto's dat nodig is voor analyse (10 versus 3). Een ander belangrijk gegeven is dat ISDc niet volledig rekening houdt met de onregelmatigheid van de afbakening van de intercellulaire ruimte. De resultaten toonden aan dat evaluatie van de intercellulaire ruimte met behulp van de alternatieve ISA-methode een sterke correlatie vertoonde met de waarden verkregen met ISDc. De alternatieve methode (ISA) is representatiever en minder tijdrovend. ISA liet ook een hoge intra- en interobserver overeenkomst zien. Deze meer representatieve en minder tijdrovende benadering kan in toekomstige studies worden gebruikt om de intercellulaure afstand bij patiënten met gastrooesofageale refluxziekte (GERD) of niet-erosieve gastro-oesofageale refluxziekte (NERD) betrouwbaar te beoordelen. 
In Hoofdstuk 9 vatten we de belangrijkste bevindingen van de onderzoeken in dit proefschrift samen. Nieuwe bevindingen en de relatie tot de resultaten in eerder beschreven studies met betrekking tot de detectie- en signaleringsfunctie van het maag-darmstelsel worden besproken. 
Addendum 


\section{Impact}

With the studies presented in this thesis, we aimed to understand the role of the gastrointestinal (Gl) tract in preserving Gl physiology by sensing the content of the gut lumen. The $\mathrm{Gl}$ tract is a sensory organ that responds to a wide variety of signals from the Gl lumen. At first, the Gl tracts detects, senses and absorbs nutrients from the lumen. Second, the Gl tracts senses potential noxious or toxic materials which can enter the systemic compartment via the epithelial barrier. This 'sensing and signalling' mechanism via the mucosal receptors and the intestinal network is crucial for maintaining Gl homeostasis.

In the first part of this thesis we focus on the function of the Gl tract and its ability to influence food intake and satiety by the detection, digestion and absorption of nutrients. The Gl tract is seen as an interesting target to influence food intake and satiety. The worldwide prevalence of overweight and obesity has nearly tripled the last 40 years, which comes with increased comorbidities, such as cardiovascular diseases. Moreover, this increasing prevalence also has significant economic and social impact. Bariatric procedures are successful in inducing weight loss on the long term in morbidly obese patients. However, patients with overweight are not eligible for these procedures. Therefore, non-invasive novel strategies are needed in the battle against the obesity epidemic. This thesis provides two studies in which macronutrients (lipid, carbohydrates and protein) were encapsulated and ingestion of these products resulted in a decrease in food intake. Future studies should focus on whether this effect is also observed after repetitive or chronic ingestion of these products. However, these studies provide a first step towards the development of novel functional foods. Encapsulated nutrients targeting the distal small intestine can be added in a dairy product in order to increase satiety and reduce food intake. This strategy could be of benefit in overweight patients or to prevent overweight to occur in normal weight patients.

Both the stomach and the small intestine have an important role in controlling food intake and satiety, but underlying mechanisms differ from each other. The satiating effect from the stomach mainly occurs via stretching and tension mechanoreceptors after ingestion of a meal. In this thesis, we investigated whether this effect could be influenced by the infusion of lidocaine, a local anaesthic, in the stomach via a nasogastric catheter. We observed that infusion of lidocaine resulted in a small, but non-significant increase in food intake. However, we cannot exclude that the intubation may have influenced the results observed in our study. Future studies 
need to consider other methods of administration of the lidocaine into the stomach, for example encapsulation, in order to further investigate the effect of lidocaine on the mechanoreceptors in the stomach wall. Moreover, strategies to target the entire stomach wall should also be considered.

Besides nutrients, other food components are sensed by the Gl lumen. This thesis investigated the potential role of the non-caloric bitter substance in decreasing food intake and increasing satiety. Tastants can serve as an important nutritional target in the treatment of overweight and obesity. However, the decrease in food intake observed was rather small. The impact of this study is in line with the studies in which macronutrients were encapsulated; a rather modest effect on food intake. However, ingestion of a certain amount of capsules with the bitter substance could lead to a reduction in food intake and subsequently in a reduction in body weight. Future, longterm studies are needed to investigate whether this strategy can be preventive in the battle against overweight and obesity.

In the second part of this thesis focused on the responses of the upper Gl tract and the role of TRPV1 against potential noxious substances. We observed that infusion of capsaicin, the pungent substance of chilli peppers, into the distal esophagus resulted in pain and a decrease in impedance of the esophagus wall. This was also related to the intercellular space area in the distal esophagus. This suggests that an impaired mucosal barrier plays a major role in pain symptom generation in patients with nonerosive reflux disease (NERD). This study provides additional insight into esophageal pain symptom generation which has clinical relevance for treatment of heartburn and related symptoms, providing additional rationale for esophageal barrier protection as a therapeutic modality. The findings in this study can open the scientific discussion in order to establish the position of mucoprotective agents in the management of reflux symptoms. Future studies should focus on which structural aspects of these mucoprotective compounds are responsible for the beneficial effect.

In summary, the research presented in this thesis shows that the upper Gl tract has an important role in maintaining gut-health and that it can be considered as an interesting target to influence Gl psychology in a beneficial way. Sensing of nutrients and food components in the upper Gl tract can be seen as an interesting target to influence food intake and satiety. Moreover, the epithelial barrier in the upper Gl tract is considered to play a major role in the protection against potential noxious substances. Taken together, this thesis provides relevant information regarding the 
sensing and signalling function of the upper Gl tract in order to activate several pathways that are involved in maintaining $\mathrm{Gl}$ and systemic homeostasis. 
Addendum 


\section{Dankwoord}

leder proefschrift bevat een dankwoord, het meest gelezen hoofdstuk van het boekje. Het schrijven van dit dankwoord voelt dan ook als een trotse afsluiting van mijn PhD. Allereerst wil ik beginnen om alle proefpersonen te bedanken die hebben deelgenomen aan de wetenschappelijke onderzoeken die in dit proefschrift beschreven staan. Zonder de hulp en bereidwilligheid van de proefpersonen konden de resultaten niet tot stand komen. Daarnaast wil ik een aantal personen in het bijzonder bedanken die hebben bijgedragen aan de totstandkoming van dit proefschrift.

Prof. dr. Masclee, beste Ad, ik weet nog goed dat ik net mijn opleiding geneeskunde in Rotterdam had afgerond en graag terug wilde naar mijn 'roots'. Ik kwam met $u$ in contact en onze band voelde direct warm en vertrouwd. $U$ adviseerde mij om mijn 'oudste' coschap in deze regio te doen en daarna bood u mij een PhD plek aan in Maastricht. Alternatief: $U$ heeft gedurende onze samenwerking, naast de interesse in mijn werk, ook altijd interesse getoond in mij als persoon. Ik heb veel bewondering voor uw passie voor het wetenschappelijk onderzoek en dit heeft mij gestimuleerd als onderzoeker. Ondanks uw drukke agenda kon ik altijd bij u binnenlopen voor overleg of een babbel. $U$ heeft regelmatig uw vertrouwen in mij uitgesproken en daarvoor wil ik u bedanken. Ik zal u gaan missen als u met uw welverdiende pensioen gaat.

Dr. Keszthelyi, beste Daniel, dank voor je hulp bij de verschillende studies beschreven in dit proefschrift. Ik bewonder je passie en drive voor wetenschappelijk onderzoek. Ik heb veel van je geleerd. Je bent een voorbeeld als arts en onderzoeker voor mij. Het oneindig herschrijven van onze artikelen dreef mij af en toe tot wanhoop. echter heeft het wel dit proefschrift naar een hoger niveau getild. Ook met privézaken kon ik bij je terecht, waarvoor heel veel dank.

Dr. Troost, beste Freddy, in het begin van mijn promotietraject hebben we samengewerkt. Je maakte mij wegwijs binnen de onderzoekswereld. Samen met Tim hebben we de stoma studie succesvol volbracht. Onze tripjes naar Parijs waren ook altijd genieten. Dank voor de prettige samenwerking.

Dr. Bakker, beste Minke, toen ik in Rotterdam mijn interesse voor de MDL kenbaar maakte, werd ik door de opleider aldaar naar jou verwezen. Mijn oudste coschap heb ik onder jouw supervisie met veel plezier in Heerlen gedaan. Ondanks dat een 
volledig coschap bij de MDL in het toenmalige Atrium MC nog nooit in die vorm had plaatsgevonden, had je een mooi programma voor mij samengesteld. Je was mijn referentie voor de sollicitatie naar een opleidingsplek, waarvoor ik je wil bedanken. Toen ik hoorde dat je in het MUMC+ ging werken was ik heel enthousiast. Als mijn mentor, opleider en collega hoop ik dat deze samenwerking nog lang mag bestaan!

Prof. dr. Bouvy, beste Nicole, wat was ik blij verrast toen ik hoorde dat jij tot voorzitter van mijn beoordelingscommissie werd benoemd. We hebben samen een aantal studies uitgevoerd en ik vond het altijd heel prettig samenwerken met jou. Het cadeau dat ik van u kreeg voor de geboorte van mijn eerste zoon is nog altijd een groot succes!

Prof. dr. Tack, prof. dr. Witteman, dr. Lenaerts en dr. Adam, bedankt voor het kritisch evalueren van mijn proefschrift en het deel uitmaken van mijn beoordelingscommissie.

Als vreemdeling uit Rotterdam kwam ik snel in een warm bad terecht. Mede dankzij het mooie MDL-onderzoeksteam heb ik mijn promotietijd als geweldig ervaren. Ik kon bij jullie terecht voor alle vragen met betrekking tot onderzoek en privékwesties. Onze lunchmomenten, congresbezoeken, borrels en feestjes waren fantastisch en onvergetelijk. Daisy, Martine, Ankie, Fedde, Bouke, Chantal, Steven, Kirsten, Montserrat, Elhaseen, Roel, Pauline, Corinne, Roel, Zsa Zsa, Lisa, Roy, Yala, Selwyn, Hao Ran, Fabienne, Dion, Tim H., Pan, Lonne, Gonny, Bram, Heike, Toon, Wenke, Anke, Quirine, Laura en Merlijne, allemaal heel veel dank voor de mooie momenten, samenwerking, adviezen, roddels, grappen, warmte en gezelligheid.

Een paar collega's wil ik apart benoemen. Mark, bedankt voor je hulp bij de introductie binnen de groep en de start van mijn PhD traject. Jouw hulp maakte dit alles een stuk gemakkelijker. Ik kon een gedeelte van jouw onderzoeken voortzetten. Je hebt me veel geleerd over het opzetten van een onderzoek en het schrijven van artikelen. Je maakte altijd tijd voor het beantwoorden van mijn vragen. Tim, wat hebben wij veel uren samen doorgebracht in ons mooie lab. De stoma studie die we in de avonduren en weekenden samen hebben uitgevoerd heeft ons veel tijd en moeite gekost, maar samen hebben we er ons met veel lol, grappen en af en toe een beklag doorheen geslagen. Ik had dit met niemand anders willen doen. Onze tripjes naar Parijs samen waren ook onvergetelijk. Dank voor het overnemen van mijn onderzoeken tijdens mijn zwangerschapsverlof. Je bent een fijne collega en ik hoop dat we elkaar snel in de kliniek weer tegenkomen! 
Bas, Dion en Eveline, bedankt voor de fijne tijd als kamergenoten. Marin, Ellen en Wiesje, wat was het een onvergetelijke trip naar de DDW in Chicago!

Ik wil graag de MDL-collega's in de kliniek van het MUMC+ bedanken voor de fijne samenwerking gedurende mijn PhD tijd. Ton, de endoscopie dames en in het bijzonder de dames van de functiekamer Anja, Nicole en Rachelle, dank voor jullie hulp bij de praktische zaken in mijn studies. Daarnaast wil ik de dames van het secretariaat bedanken. Elly, Mietsie, Nienke en Tiny, jullie waren altijd zeer vriendelijk en behulpzaam.

Ik wil ook mijn collega's bedanken tijdens mijn vooropleiding Interne Geneeskunde in het MUMC+. In het bijzonder, Prof. Koopmans, Richard dank voor je ondersteuning, begeleiding en luisterend oor tijdens de vooropleiding. Dr. Magdelijns, Fabienne, als mentor en supervisor heb je veel voor mij betekend. Dank dat je altijd bereid was om naar mijn verhalen te luisteren.

Lieve Gaby, sinds de middelbareschooltijd zijn we onafscheidelijk. Wat hebben wij mooie momenten gehad samen! Ondanks dat onze wegen een andere kant op zijn gegaan, is onze vriendschap altijd blijven bestaan. De positieve instelling en gedrevenheid is iets wat ik in jou bewonder. Ik vind het bijzonder om te zien hoe jouw politieke carrière je past. Ook in moeilijke tijden was je er altijd daar voor mij. Ik weet zeker dat al je dromen werkelijkheid worden. Ik ben trots op zo'n vriendin aan mijn zijde!

Lieve Roos, Odette en Sophie, 'bende van ellende'. We leerden elkaar kennen in onze studententijd bij de RVSV in Rotterdam. In de loop van de jaren groeiden we naar elkaar toe en werden we steeds hechter. Dit resulteerde erin dat we na onze tijd in onze RVSV-huizen samen op de Burgemeester Meineszlaan gingen wonen. Wat hebben wij hier een geweldige tijd gehad en mooie herinneringen gemaakt. Onze gezamenlijke reisjes hebben ook de nodige hilariteit opgeleverd; ik zal de momenten tijdens onze reis in Marokko nooit vergeten. Wat zijn wij een heerlijke chaos samen. Dank voor jullie steun, adviezen en interesse. Ik hoop dat we elkaar in de toekomst vaker kunnen zien!

Lieve Diede, Diederik, oud-huisgenoot, jaarclubgenoot en lieve vriendin. Letterlijk sinds onze aankomst in Rotterdam zijn wij onafscheidelijk. Ik heb nog nooit meegemaakt je zo snel een klik voelt met een persoon. We hebben in de loop van de jaren een hele bijzondere band ontwikkeld. Dankzij het lobbyen van jou ben ik in 
Jaarclub Leeuw terecht gekomen. Onze tijd in Villa Ravage was fantastisch; ik herinner onze tv-momenten (Lingo) op de bank, onze tripjes naar 'Eetgoed', onze dansjes op de sociëteit en een geweldig huwelijk in Toscane. Ik vind jou een prachtig persoon en je bent een hele bijzondere vriendin voor mij. Ik zal er altijd voor je zijn. Heel veel knuffels!

Lieve Anne, wij zijn elkaar als vriendinnen gelukkig nooit uit het oog verloren en daar ben ik heel blij mee. Je bent altijd heel geïnteresseerd geweest in mijn promotietraject en opleiding. Ik wil je bedanken voor de hardloopmomenten, bootcamp, lunches, wandelingen en je onvoorwaardelijke steun. Je bent een schatje!

Ik wil de rest van Jaarclub Leeuw, huisgenoten van Villa Ravage en de Eurekaweek commissie bedanken voor alle momenten van plezier en ontspanning.

En dan mijn paranimfen Luc en Annique.

Luc, lieve grote broer. Ik keek als kind al erg tegen je op. Je kon af en toe erg wild met mij stoeien, maar je ging altijd voor mij door het vuur. Ik hoefde niet lang na te denken wie ik voor de rol als paranimf moest vragen. De afgelopen tijd ben je een enorme steun voor mij geweest en was je er daar voor mij als broer. Ik kan altijd op je terugvallen en je bekommert je oprecht om mij. Ik vind het mooi om te zien hoe je geniet van je gezin en hoeveel liefde je voor je kinderen hebt. Je bent een bijzondere broer en papa.

Daarnaast wil ik je vriendin, Kimberley, ook bedanken. Ik kan altijd fijn met je praten als collega dokter over het werk. Je hebt een verfrissende en nuchtere kijk op zaken, wat voor mij goed werkt. Ik wil je bedanken voor je steun. Ik vind het heel mooi om te zien dat jullie samen als gezin gelukkig zijn.

Annique, je bent de vriendin die het langst in mijn leven is. We leerden elkaar kennen in de buurt op straat waar wij veel samen speelden. Daarna gingen we naar dezelfde middelbare school en samen op hockey. Wat hebben wij veel bijzondere momenten samen meegemaakt. Onze band is in de loop van de jaren steeds hechter geworden. Jouw positieve instelling weet mij altijd te raken en werkt gewoon aanstekelijk. Ik weet nog dat jij mij elke ochtend een 'positieve spreuk' stuurde. Ik kan altijd terecht in jouw warme nestje op de Caumerbeeklaan bij jouw fijne familie en dat voelt zo goed aan. Je was er daar voor me toen ik je nodig had en dat waardeer ik ontzettend. Ik ben benieuwd wat de toekomst voor jou in petto heeft. Ik weet zeker heel veel goeds. Ik 
ben heel blij om te zien dat je gelukkig bent met Pepijn en Alba. Je verdient alle het geluk van de wereld! Je bent voor mij een bijzondere, unieke en lieve vriendin en een prachtig mooi persoon. Onze vriendschap is mij zoveel waard!

Lieve Toine, lief broertje. Mensen zeggen vaak dat wij veel op elkaar lijken en volgens mij klopt dat ook. Ondanks je lengte blijf je altijd mijn kleine broertje en zal ik er altijd daar voor je zijn. Ik vind het mooi om te zien hoe je nu je vaderlijke rol vervult. Ik wil je bedanken voor je onvoorwaardelijke steun.

Lieve Mama, altijd ben je trots geweest op mij als dochter. Door jouw kwaliteit om alles tot in de puntjes voor ons te regelen heb ik een zorgeloze jeugd gehad en alle kansen die op mijn pad kwamen kunnen benutten. Jij bent de drijvende kracht achter de keuze voor de studie Geneeskunde. Tijdens mijn promotietraject en de opleiding daarna zijn wij dichter tot elkaar gegroeid. Je hebt altijd veel interesse in mijn onderzoek en opleiding getoond. Dank voor je luisterend oor en je adviezen. Ik hou van je!

Lieve Papa, wat ben jij toch een belangrijk persoon in mijn leven. Ik begreep dat toen ik nog een baby was, ik constant op jouw schoot zat. Dit is nooit meer veranderd. De band die wij hebben is bijzonder en uniek. Je vertelde mij ooit; als twee bijzondere personen elkaar ontmoeten dan kan er iets heel moois ontstaan. Dat is wat onze band typeert. Bedankt voor je luisterend oor, adviezen en er gewoon daar als vader voor mij te zijn. In mindere tijden was je daar voor mij als vader, zonder oordeel of kritiek. Jouw knuffels geven mij zoveel warmte en liefde. Zonder jou had ik dit proefschrift nooit kunnen afronden. Ik hou ontzettend veel van jou, lieve papa.

Lieve Fedde en Sef, mijn jongens, mijn boeven, mijn zoontjes, mijn alles. Dat jullie gelukkig zijn, is het allerbelangrijkste in mijn leven. Jullie verrijken mijn leven. Ik hou zo ontzettend veel van jullie en jullie maken mij zo ontzettend trots en gelukkig. Heel veel kusjes en knuffels! 
Addendum 


\section{List of publications}

Alleleyn AM*, van Avesaat $\mathbf{M}^{*}$, Troost FJ, Masclee AA. Gastrointestinal Nutrient Infusion Site and Eating Behavior: Evidence for A Proximal to Distal Gradient within the Small Intestine? Nutrients. 2016 Feb 26;8(3):117.

* Both authors contributed equally to the manuscript.

Alleleyn AME, van Avesaat M, Ripken D, Bleiel SB, Keszthelyi D, Wilms E, Troost FJ, Hendriks HFJ, Masclee AAM. The Effect of an Encapsulated Nutrient Mixture on Food Intake and Satiety: A Double-Blind Randomized Cross-Over Proof of Concept Study. Nutrients. 2018 Nov 17;10(11):1787.

Bröker MEE, Klompenhouwer AJ, Gaspersz MP, Alleleyn AME, Dwarkasing RS, Pieters IC, de Man RA, IJzermans JNM. Growth of Focal Nodular Hyperplasia is Not a Reason for Surgical Intervention, but Patients Should be Referred to a Tertiary Referral Centre. World J Surg. 2018 May;42(5):1506-1513.

Klaassen T, Alleleyn AME, van Avesaat M, Troost FJ, Keszthelyi D, Masclee AAM. Intraintestinal Delivery of Tastants Using a Naso-Duodenal-Ileal Catheter Does Not Influence Food Intake or Satiety. Nutrients. 2019 Feb 23;11(2):472.

Corstens MN, Troost FJ, Alleleyn AME, Klaassen T, Berton-Carabin CC, Schroën K, Masclee AAM. Encapsulation of lipids as emulsion-alginate beads reduces food intake: a randomized placebo-controlled cross-over human trial in overweight adults. Nutr Res. 2019 Mar;63:86-94.

Paulus GF, van Avesaat M, van Rijn S, Alleleyn AME, Swain JM, Abell TL, Williams DB, Bouvy ND, Masclee AAM. Multicenter, Phase 1, Open Prospective Trial of Gastric Electrical Stimulation for the Treatment of Obesity: First-in-Human Results with a Novel Implantable System. Obes Surg. 2020 May;30(5):1952-1960.

Klaassen T, Keszthelyi D, Alleleyn AME, Wilms E, Bast A, Masclee AAM, Troost FJ. Effect of oral or intragastric delivery of the bitter tastant quinine on food intake and appetite sensations: a randomised crossover trial. Br J Nutr. 2021 Jan 14:125(1):92-100. 


\section{Submitted for publication}

Alleleyn AME, Keszthelyi D, Rinsma NF, Csekő K, Kajtár B, Helyes Z, Winkens B, Masclee AAM, Conchillo JM. Evidence for the role of impaired mucosal integrity in the generation of esophageal pain using capsaicin in humans. 


\section{Curriculum vitae}

Annick Maria Elisabeth Alleleyn was born on the 22th of March 1990 in Heerlen, the Netherlands. She attended primary school in Gulpen and Heerlen and finished her secondary education (Gymnasium) at the Bernardinuscollege in Heerlen in 2008. In that same year, she started medical school at the Erasmus University in Rotterdam. After obtaining her medical degree in 2015, she started as PhD-fellow at the division of Gastroenterology and Hepatology of Maastricht University Medical Center+

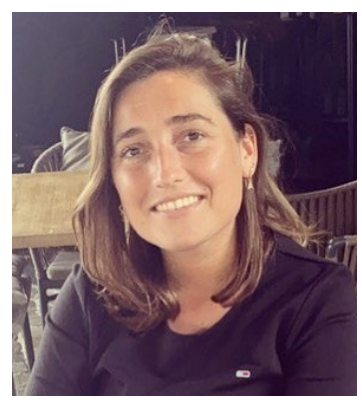
(MUMC+), under the supervision of prof. dr. Masclee and dr. Keszthelyi. The research was performed within the NUTRIM school of Nutrition and Translational Research in Metabolism (Maastricht University). In November 2018, she started her residency Gastroenterology-Hepatology. The first two years of her residency she worked at the department of Internal Medicine at the MUMC+, under supervision of prof. dr. Koopmans. In February 2021, she continued her residency GastroenterologyHepatology at MUMC+, under supervision of prof. dr. Masclee and dr. Kruimel. 
